\title{
Electrochemical Anion Sensing: Supramolecular Approaches
}

\author{
Robert Hein, Paul D. Beer*, Jason J. Davis* \\ Department of Chemistry, University of Oxford, South Parks Road, Oxford OX1 3QZ, U.K. \\ *jason.davis@chem.ox.ac.uk; paul.beer@chem.ox.ac.uk
}

\begin{abstract}
Anions play a vital role in a broad range of environmental, technological and physiological processes, making their detection/quantification valuable. Electroanalytical sensors offer much to the selective, sensitive, cheap, portable and real time analysis of anion presence where suitable combinations of selective (non covalent) recognition and transduction can be integrated. Spurred on by significant developments in anion supramolecular chemistry, electrochemical anion sensing has received considerable attention in the past two decades. In this review we provide a detailed overview of all electroanalytical techniques that have been used for this purpose, including voltammetric, impedimetric, capacititive and potentiometric methods. We will confine our discussion to sensors that are based on synthetic anion receptors with a specific focus on reversible, non-covalent interactions, in particular hydrogen- and halogen-bonding. Apart from their sensory properties we will also discuss how electrochemical techniques can be used to study anion recognition processes (e.g. binding constant determination) and will furthermore provide a detailed outlook over future efforts and promising new avenues in this field.
\end{abstract}

\section{Contents}

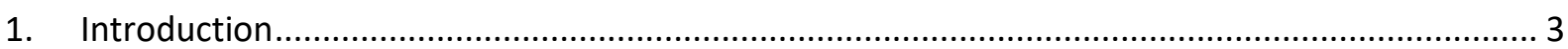

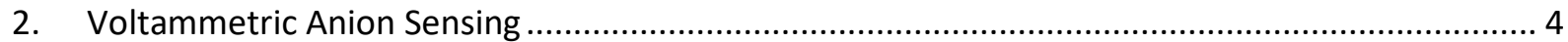


2.1 General Experimental and Theoretical Considerations......................................................... 4

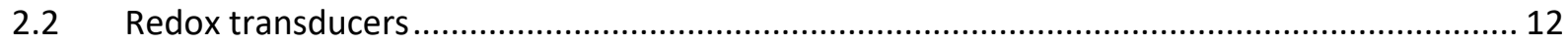

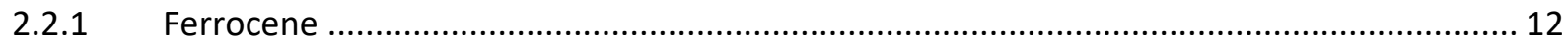

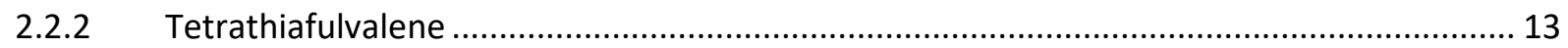

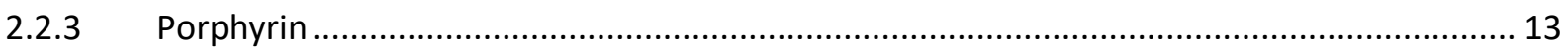

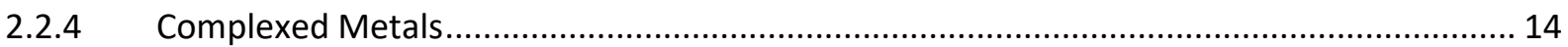

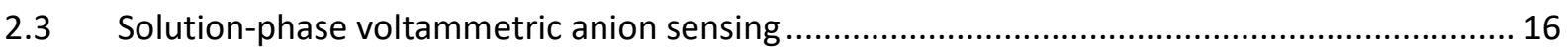

2.3.1 Redox-active receptors based on $\mathrm{N}-\mathrm{H}$ hydrogen bond donors ........................................... 16

2.3.2 Redox-active receptors based on C-H hydrogen bond donors ......................................... 27

2.3.3 Redox-active receptors based on C-I halogen-bond donors ............................................. 34

2.3.4 Redox-active receptors based on boranes and boronic acids........................................... 37

2.3.5 Redox-active receptors based on other anion binding motifs ........................................... 45

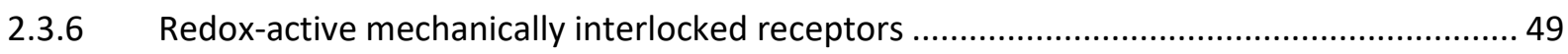

2.3.7 Redox-active dendritic and nanoparticle based sensing configurations............................... 55

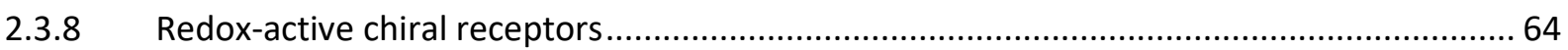

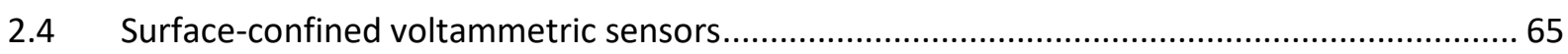

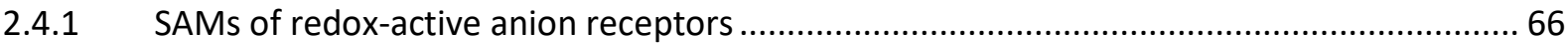

2.4.2 Polymeric anion receptive interfaces................................................................................ 76

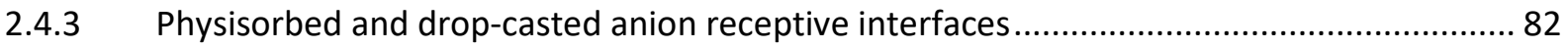

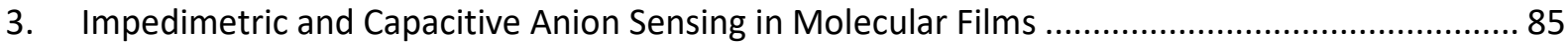

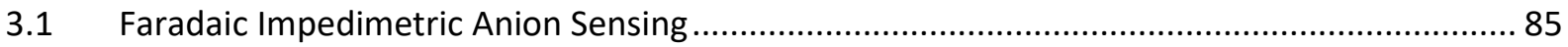

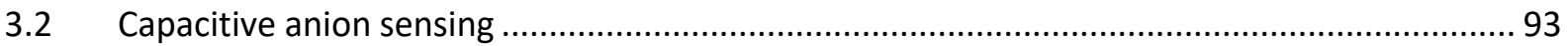

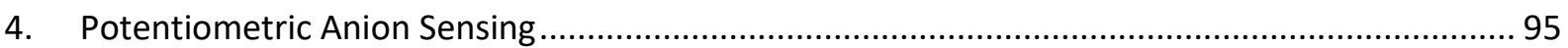

4.1 General Experimental and Theoretical Considerations.......................................................... 95

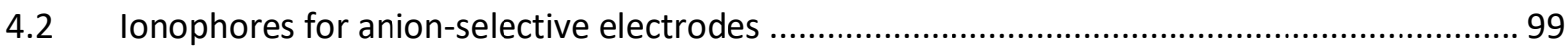

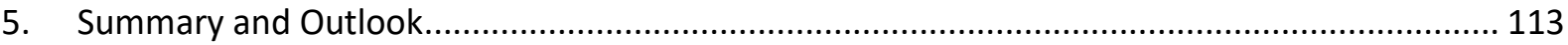

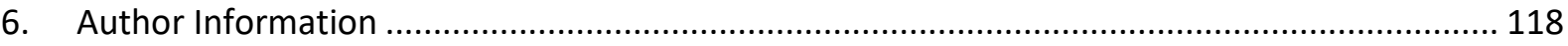

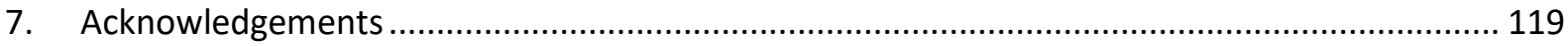

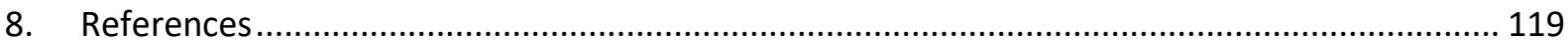




\section{Introduction}

Due to their biological, technological, and environmental relevance, an ability to selectively detect anions is of paramount interest for many applications. While cation recognition and sensing has been relatively well established for some decades ${ }^{1-2}$ anion binding and sensing remains notably more challenging, mainly due to the more complex geometries of anions, $\mathrm{pH}$ dependence and their inherently strong hydration. ${ }^{3-5}$ Traditionally, supramolecular anion receptors rely on hydrogen-bonding $(\mathrm{HB})$ and electrostatic interactions to drive anion recognition, while more recently other non-covalent interactions, such as halogen-bonding (XB), have been increasingly exploited, showing enhanced or complementary performance to more traditional approaches. ${ }^{6-7}$ An increased understanding of directional bonding approaches and the importance of solvent dynamics at binding sites has, in recent years, facilitated the preparation of synthetic receptors with a fine-tuned anion recognition site that can enable selective binding of specific anionic species. ${ }^{8}$ The incorporation of a transducer (e.g. electrochemical/optical) responsive to the presence of the target analyte can then enable not only recognition but also sensing. Electrochemical sensing strategies have received increasing attention due to their real-life potential applicability. Specifically, electrochemical sensory devices are inherently cheap, sensitive and scalable with a number now being commercially available. ${ }^{9}$

In this review we highlight significant advances in the field of electrochemical anion sensing that have been made over the past two decades with some reference to earlier important works where necessary. This includes a brief introduction to all electroanalytical techniques that are relevant to (an)ion sensing applications including voltammetric, impedimetric/capacitive and potentiometric approaches. Electrochemical anion sensors categorized by the specific nature of the supramolecular non-covalent interaction primarily 
used to reversibly bind small, inorganic anions are then explicitly discussed. Particular highlights include complex receptor designs (e.g. chiral and mechanically interlocked receptors), novel anion-receptive motifs (e.g. C-H hydrogen-bond donors and C-I halogenbond donors) and other approaches that have not been reviewed in detail elsewhere. Importantly, both theoretical and experimental considerations that are pertinent to the sensory systems are examined with reference to analytical performance, as well as their use as more fundamental tools to elucidate host-guest interactions.

\section{Voltammetric Anion Sensing}

\subsection{General Experimental and Theoretical Considerations}

Voltammetric techniques such as cyclic voltammetry (CV), differential pulse voltammetry (DPV) or square wave voltammetry (SWV) are some of the most commonly used electrochemical techniques to study anion binding in solution or at interfaces. Transduction of an anion binding event at a (synthetic) receptor is achieved with the help of a redox transducer, whose electrochemical potential is modulated by the presence of the anion (see Figure 1). Almost invariably this modulation is a cathodic shift of the transducers' half-wave potential which can be rationalized by a stabilization of the higher oxidation state. Various mechanisms for this stabilization have been proposed, with through-bond and throughspace communication between the anion binding site and the redox transducer being the most important ones. ${ }^{1,10}$ In both cases an effective transduction of the binding event is only possible if the two sites are spatially and/or electronically coupled. 

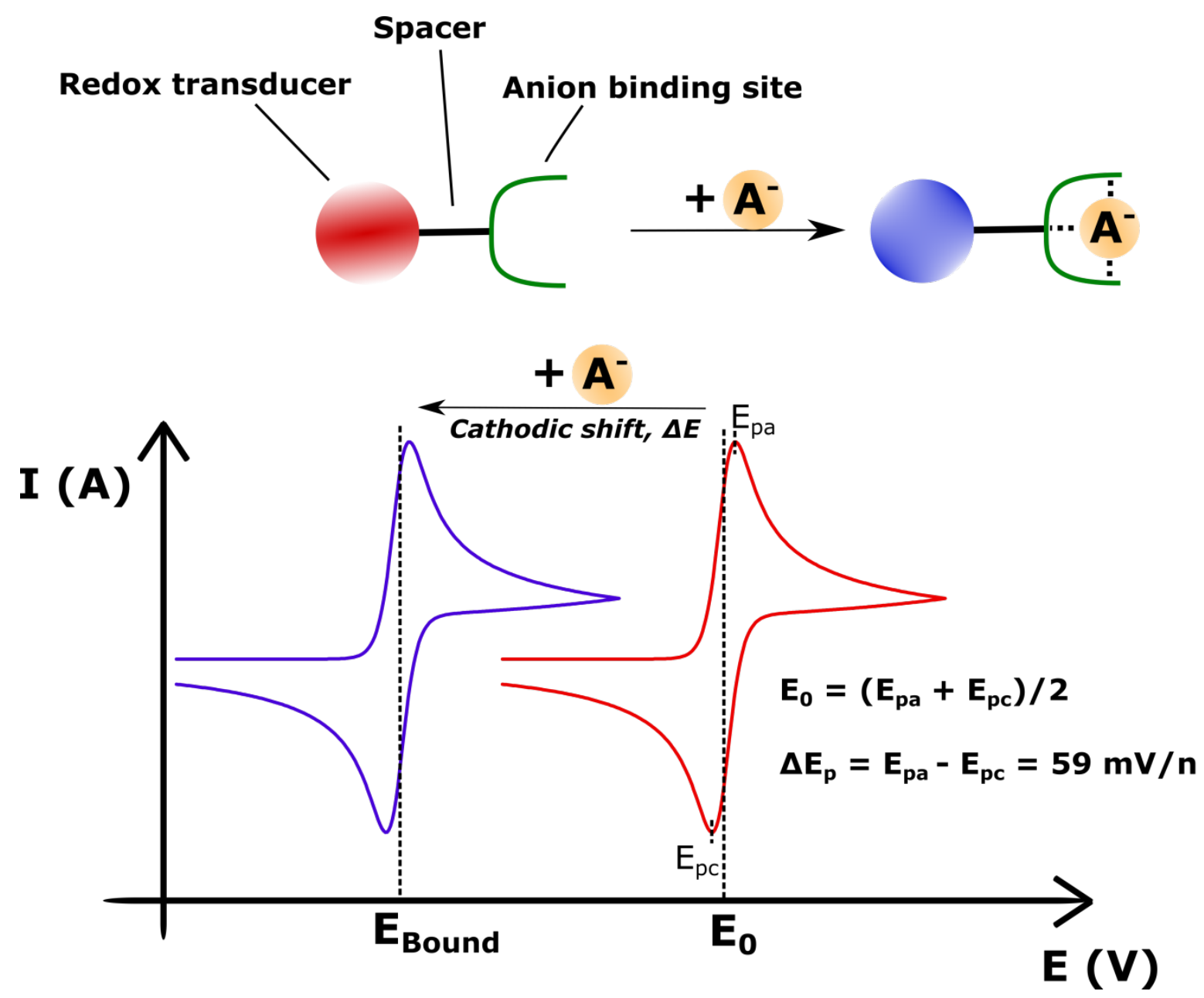

Figure 1. Schematic depiction of the general sensing principle of voltammetric anion sensors. Anion binding induces a cathodic perturbation of the redox transducer that is measureable via voltammetric techniques such as CV. The depicted voltammograms represent an ideal, reversible case in which the initial half-wave potential of the transducer $\mathrm{E}_{0}$ as well as the peak separation $\Delta \mathrm{E}_{\mathrm{p}}$ can be described by the depicted equations.

While the binding equilibrium in simple host-guest systems can be described by $K=\frac{[H G]}{[H][G]}$ (for a 1:1 stoichiometric host-guest complex system) it should be noted that this is not an accurate description for redox active receptors because the receptor site binding affinity is dependent on the redox state; specifically anion binding is enhanced upon a local oxidation, resulting in the square scheme shown in Figure 2 . In fact, it is precisely this change in binding strength that causes the observed voltammetric response, which can, in its most general form, be described by eqn. 1 as derived previously. ${ }^{1,11}$ The ratio of $K_{0 x} / K_{\text {Red }}$, where $K_{0 x}$ and 
$\mathrm{K}_{\text {Red }}$ are the (an)ion binding constants of the oxidized and reduced receptor respectively, can be obtained directly from the maximum shift of the transducer in the presence of the target guest and is often called binding enhancement factor (BEF) or reaction coupling efficiency. For $[\mathrm{G}]>>[\mathrm{H}]$ a special case has been described (eqn. 2) which can be utilised for extraction of both $\mathrm{K}_{\mathrm{ox}}$ and $\mathrm{K}_{\mathrm{Red}}$ from binding isotherms via non-linear least square fitting. ${ }^{12}$

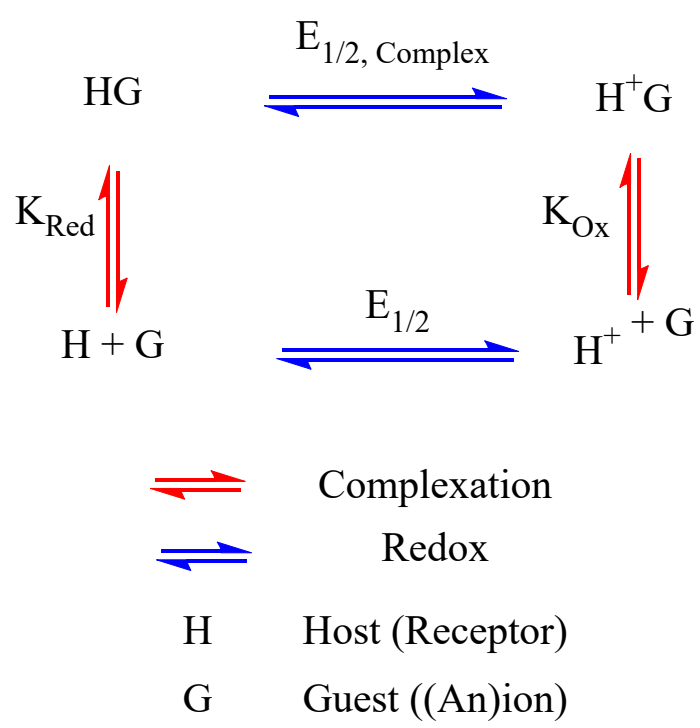

Figure 2. Square scheme for the host-guest equilibria involved in voltammetric (an)ion sensing.

$$
\begin{aligned}
& \Delta E=-\frac{R T}{n F} * \ln \left(\frac{K_{O x}}{K_{\text {Red }}}\right) \\
& \Delta E=-\frac{R T}{n F} * \ln \left(\frac{1+K_{O x} *[G]}{1+K_{\text {Red }} *[G]}\right)
\end{aligned}
$$

In both cases it should be noted that the response (shift of the receptor's formal potential) is dependent on the relative change in anion binding constants between the different oxidation states $\left(\mathrm{K}_{\mathrm{Ox}} / \mathrm{K}_{\text {Red, }}\right.$ Figure 3$)$. Therefore, a large response is expected in systems where the redox event generates a species in which anion binding is strongly affected. This 
simple observation again demonstrates why efficient spatial and/or electronic coupling between the anion binding site and the redox transducer are required to induce a measurable perturbation of the formal potential.

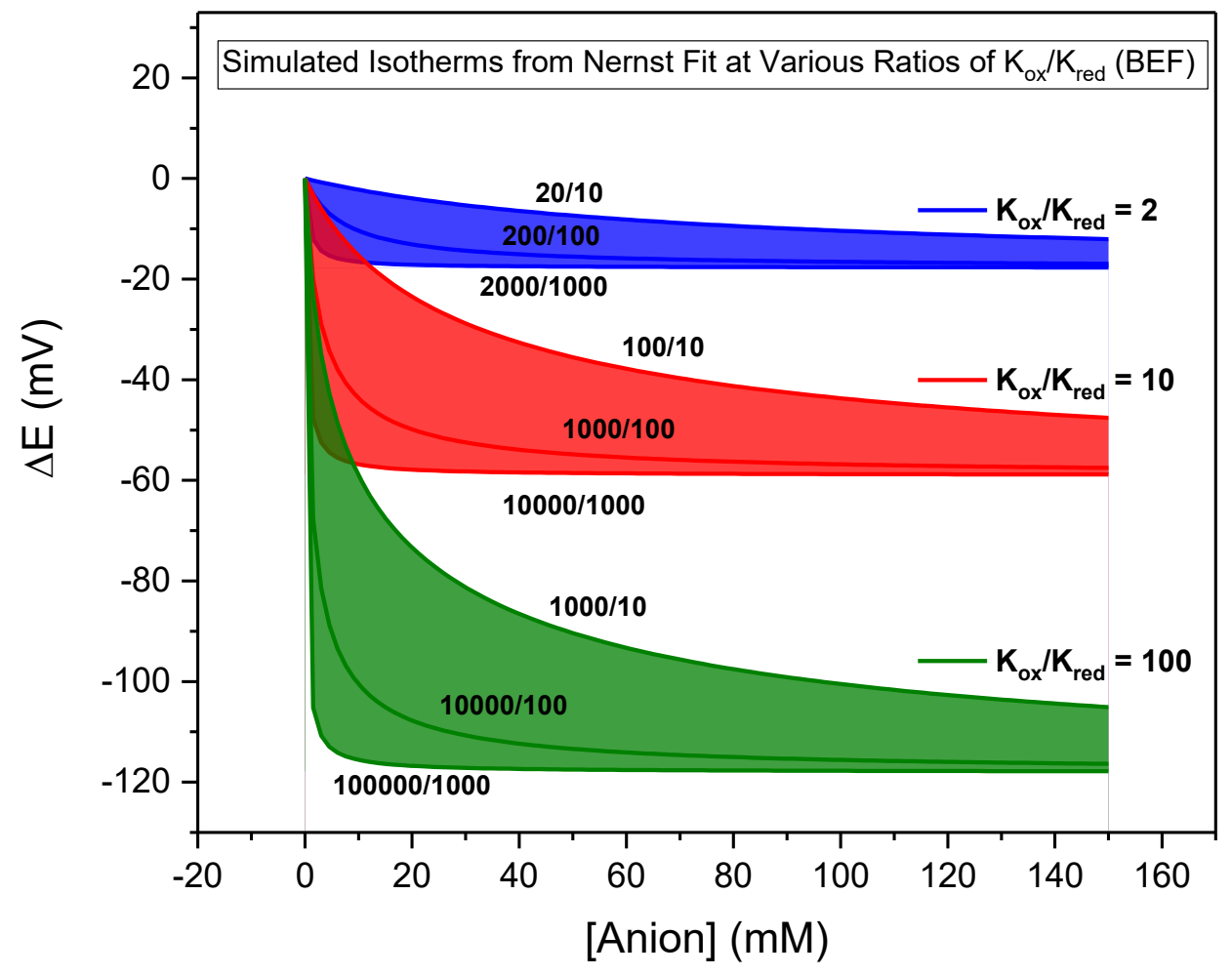

Figure 3. Simulated binding isotherms according to eqn. 2 at various ratios of $K_{0 x} / K_{\operatorname{Red}}(B E F$, binding enhancement factor). The magnitude of the cathodic shift upon anion binding to a redox-active host, according to this model with $[\mathrm{G}]>>\mathrm{H}]$ (and fast exchange), is thus mainly determined by the ratio of the binding constants rather than their magnitude.

Advantageously, the (transient) electrochemical generation of an anion receptor with a higher oxidation state allows anion sensing in competitive solvent systems where anion binding in the neutral (reduced) state is not significant. According to the principles discussed above it is precisely in this case, where $\mathrm{K}_{\mathrm{Ox}}$ is large and $\mathrm{K}_{\mathrm{Red}}$ is very low (or tends to zero), 
where we would expect a significant response. Such a "switch-on" transducer (a voltammetry generated higher oxidation state and more potent anion receptor) facilitates anion sensing in competitive media that would not be possible based on other sensory mechanisms (e.g. optical sensors) where typically no additional modulation of the anion binding is possible. However, it should also be noted that, under these circumstances, the use of complementary techniques, such as NMR spectroscopy, is particularly difficult exactly because the binding in the reduced state is difficult to measure (too low) while the oxidised state is often difficult to isolate and/or is paramagnetic. Herein we will not report on any binding constants that were obtained by such complementary techniques as they offer little insight into the electrochemical performance of the sensors and are often conducted in different solvents and in the absence of electrolyte. We will, in select cases, report on the electrochemically determined $\mathrm{K}_{\mathrm{ox}}$ and/or $\mathrm{K}_{\text {Red }}$ binding constants, usually in the form of the $\operatorname{BEF}\left(\mathrm{K}_{\mathrm{Ox}} / \mathrm{K}_{\mathrm{Red}}\right)$. The interested reader can also calculate this ratio from the provided magnitude of the voltammetric perturbation via eqn. 1.

In an idealised voltammetric analysis, the reporting signal transduces the specific anion binding event only; in reality a number of dielectric and ion pairing effects can contribute in a manner that is highly dependent on the electrolyte(s) that are used. In order to minimise errors associated with solution phase resistance (i.e. ohmic drop) to voltammetric peak positions a large excess ( $\geq 100 \mathrm{mM}$ ) of a supporting electrolyte is usually employed. It is imperative that this electrolyte does not interfere with the anion binding event. Thus, large non-coordinating anions (like perchlorate $\left(\mathrm{ClO}_{4}^{-}\right)$or hexafluorophosphate $\left(\mathrm{PF}_{6}^{-}\right)$) are most commonly used (usually as tetrabutylammonium (TBA) salts). Another important consideration, often overlooked, is the inherent electrostatic (de)stabilisation ${ }^{13}$ of the (charged) redox states in the presence of the supporting electrolyte and solvent. For 
example, the half-wave potential of the simple ferrocene/ferrocenium ( $\left.\mathrm{Fc} / \mathrm{Fc}^{+}\right)$couple is strongly dependent on the concentration (and nature) of the supporting electrolyte as well as the solvent. ${ }^{14}$ At higher salt concentrations and/or in more polar solvents the charged ferrocenium is more strongly stabilized through charge screening. This effect is particularly dramatic in non-polar solvents such as $\mathrm{DCM}$, where the half-wave potential of $\mathrm{Fc} / \mathrm{Fc}^{+}$is more than $500 \mathrm{mV}$ more cathodic in the presence of $100 \mathrm{mM}$ electrolyte (TBA-tetrafluoroborate) in comparison to the solvent/electrolyte system containing only $1 \mathrm{mM} \mathrm{TBABF} 4$. While this stabilization ceases (plateaus) above approximately $100 \mathrm{mM}$ electrolyte in more polar solvents (acetonitrile (ACN) or dimethylformamide (DMF)), these solvent induced cathodic perturbations can be observed in DCM up to $500 \mathrm{mM}$ supporting electrolyte. While this effect has not been investigated in depth for different solvents, electrolytes and redox transducers ${ }^{15}$ it is expected that this is a general observation that should be taken into account, especially in non-polar solvents. Thus, to avoid false-positive results, where observed shifts do not arise from a specific binding event but non-specific (electrostatic) stabilization upon addition of target anion, voltammetric anion sensing should ideally be carried out at constant ionic strength and with carefully integrated control experiments with a non-receptive control (the latter revealing any non-specific interactions that might cause voltammetric perturbations).

In the following sections we highlight relevant examples of a variety of redox centreappended anion sensors and their performance towards the voltammetric sensing of various anions in different solvents. It should be noted that when discussing selectivities, unless otherwise specified, we refer to the selectivities that are observed in the electrochemical experiments, which can differ from those observed by other techniques such as NMR. Furthermore, the absence of a significant electrochemical signal is not always indicative of 
no binding (i.e. when $\mathrm{K}_{\mathrm{ox}} / \mathrm{K}_{\text {Red }} \approx 1$ ). Please also note that throughout this review article cathodic responses are represented with a negative sign to indicate a shift to less positive potentials, i.e. $\Delta E=E_{\text {Bound }}-E_{0}$, and that all reported shift values are rounded to two significant figures. This notation is inconsistent across the literature and while the binding of anions almost always induces a cathodic response the opposite effect (anodic response) has also been reported (see below).

Most of the parent redox transducers described in the following sections display fully or quasi-reversible electrochemical behaviour, however this is often not the case for the modified (receptive) transducers and in particular in the presence of anions, especially in non-competitive solvents. For example, while the ferrocene/ferrocenium $\left(\mathrm{Fc} / \mathrm{Fc}^{+}\right)$couple is fully reversible in organic solvents, the presence of certain anions (e.g. phosphates) almost always induces a certain degree of irreversibility. The reversibility of a diffusive electrochemical system can most easily be assessed by cyclic voltammetry where in an ideal (fully reversible) system the peak separation between anodic and cathodic peaks is $59 \mathrm{mV} / \mathrm{n}$, where $\mathrm{n}$ is the number of electrons transferred. Furthermore, the ratio of anodic and cathodic peak current $\mathrm{i}_{\mathrm{pa}} / \mathrm{i}_{\mathrm{pc}}$ should be close to unity (all electrochemically generated species being fully transformed back during the reverse scan) and the peak current should be linearly dependent on the square-root of the scan rate (see Randles-Sevcik equation). Under real measuring conditions, almost all systems display quasi-reversible behaviour (with small deviations from these idealities). For solution-phase voltammetric anion sensing (quasiJreversibility is not an absolute requirement and irreversible transducers can theoretically be used, which however significantly complicates data analysis and their applicability as useful sensors. 
In some cases the voltammetric response of the sensors is not a progressive shift of the transducer's redox couple but rather a so-called "two-wave" behaviour i.e. the progressive disappearance of the initial wave with a concomitant emergence of a new wave at lower potential. This is attributed to strong binding and a slow (anion-receptor)-exchange (slow ligation on/off rates) which is most commonly observed in non-competitive solvents such as DCM. In this case the BEF ( $\left.\mathrm{K}_{\mathrm{Ox}} / \mathrm{K}_{\mathrm{Red}}\right)$ can be obtained directly from the difference in $\mathrm{E}_{1 / 2}$ of these waves, while under the more frequently encountered fast exchange conditions (progressive shift of the wave) the BEF can only be obtained at a plateauing response or from explicit fitting of the binding isotherms. In the slow exchange regime the magnitude of the cathodic perturbation is independent of anion concentration, only the (ratio of) peak currents of the initial and new wave can be utilised to infer the analyte concentration. However, this is usually only possible at substoichiometric quantities of anion (with respect to the number of binding sites), because at 1 equivalent of analyte the receptor is saturated (quantitative binding) and further addition of anions does not perturb the system further (i.e. only the new wave is observed with no additional changes in currents or potentials). In these cases we do not specifically mention the concentration of anions at which the voltammograms were measured.

A final additional consideration is the inherent ability of basic anions to deprotonate receptors in non-polar solvents; this can induce a voltammetric perturbation that does not arise from a non-covalent (e.g. H-bonding) anion binding interaction. Unless pertinent to the discussion this behaviour will not be explicitly highlighted. 


\subsection{Redox transducers}

A number of redox transducers have found application in voltammetric anion sensors, the most common of which are introduced in the following sections. A brief summary of their advantages and disadvantages (for applications as anion sensors) can be found in Table 1.

\subsubsection{Ferrocene}

Since its discovery in the early 1950s ferrocene (Fc) has been used in a broad range of electrochemical systems and derived sensors, ${ }^{16-17}$ due largely to its availability, ease of synthetic modification and favourable electrochemical properties. Most importantly the $\mathrm{Fc} / \mathrm{Fc}^{+}$couple displays a well-defined, reversible one electron redox couple at moderate potentials and is compatible with a wide range of solvents, electrolytes and analytes. Furthermore it is particularly favourable as a transducer in anion receptors due to the 'switch-on' of binding upon oxidation, and together with the related isoelectronic metallocene, cobaltocenium, were the very first redox transducers employed in anion receptors, as reported by Beer. ${ }^{18}$ In fact, the first synthetic redox-active anion sensor, reported in 1989, was based on a cobaltocenium macrocyclic receptor. ${ }^{19}$ The cobaltocene/cobaltocenium $\left(\mathrm{Cp}_{2} \mathrm{Co} / \mathrm{Cp}_{2} \mathrm{Co}^{+}\right)$couple displays very similar redox-properties as the $\mathrm{Fc} / \mathrm{Fc}^{+}$couple, with the most marked difference being a significantly lower $\mathrm{E}_{1 / 2}$ (approx. $1.3 \mathrm{~V}$ vs $\left.\mathrm{Fc} / \mathrm{Fc}^{+}\right)$. Notably, this can facilitate the sensing of anions whose oxidation potential is incompatible with the $\mathrm{Fc} / \mathrm{Fc}^{+}$couple (such as iodide), however, this low potential can be incompatible with a variety of solvents. In addition to this, the challenging synthetic manipulation of charged cobaltocenium (derivatives) renders Fc a much more commonly employed transducer. 


\subsubsection{Tetrathiafulvalene}

Tetrathiafulvalene (TTF) is another redox-active molecule that has received considerable attention as a transducer in synthetic anion receptors. In contrast to Fc, TTF exhibits three stable, reversible redox states ( $\mathrm{TTF}$, the radical cation $\mathrm{TTF}^{+\bullet}$ and the dication $\mathrm{TTF}^{2+}$ ) allowing for additional tuning of the anion-receptor interaction. ${ }^{20}$ However, while the first redox couple $\left(\mathrm{TTF} / \mathrm{TTF}^{+\bullet}\right)$ is accessible at potentials similar to those of $\mathrm{Fc} / \mathrm{Fc}^{+}$, the second couple $\left(\mathrm{TTF}^{+\bullet} / \mathrm{TTF}^{2+}\right)$ has a half-wave potential that is more anodic by $\approx 350 \mathrm{mV}$. Depending on the electron-density at the TTF derivative and the solution-phase conditions, this second couple often overlaps with anions possessing a low oxidation potential (e.g. $\mathrm{Br}^{-}, \mathrm{I}^{-}$or $\mathrm{N}_{3}{ }^{-}$). As a consequence only the first couple is usually exploited to transduce an anion binding event. Additionally, TTF possesses rich spectroelectrochemical properties and has found many applications in molecular electronics and in switches. ${ }^{21}$ In comparison to Fc however, TTF is much less synthetically accessible and has only rarely been applied within more complex receptive architectures such as those based on macrocyclic, interlocked or dendrimeric systems.

\subsubsection{Porphyrin}

Porphyrins (free base and metallo-porphyrins) represent an interesting motif for sensing applications due to their rich photophysical and electrochemical properties; the latter is manifested by two quasi-reversible oxidative couples $\left(\mathrm{P} / \mathrm{P}^{+\bullet}\right.$ and $\left.\mathrm{P}^{+\bullet} / \mathrm{P}^{2+}\right)$ at potentials more anodic than that of $\mathrm{Fc} / \mathrm{Fc}^{+}$both of which are strongly dependent on the specific substitution/metalation of the porphyrin. ${ }^{22}$ Whilst synthetically non-trivial to manipulate, porphyrins possess rich chemistry with respect to substitution patterns and the nature of the coordinated metal. Advantageously, the metal-centre of the metallo-porphyrin can act as an 
anion binding site which is strongly coupled to the porphyrin resulting in efficient signal transduction. Similarly, anions can directly engage in $\mathrm{H}$-bonding to the central $\mathrm{N}-\mathrm{H}$ donors of the free base porphyrin. In spite of this only very few porphyrin-based voltammetric anion sensors have been developed.

\subsubsection{Complexed Metals}

Different metal complexes, in particular those of the first and second row transition metals have been utilised as transducers in electrochemical sensors. Most commonly nitrogenous ligands such as bipyridine (bpy) or terpyridine (tpy) are used to form stable and electrochemically well-behaved transducer complexes. The derivatization of these ligands facilitates the introduction of binding sites into the organic scaffold and further allows tuning of the redox properties of the complex by variation of the electron density. Most commonly the redox couples are reversible one-electron metal-centred oxidative couples at moderate to high potentials. It is worth noting that at, very low potentials, additional ligand-centred reductive couples are often observed, albeit rarely used to transduce anion binding. If the metal is coordinatively unsaturated, an anionic analyte may directly bind to the metal, which, according to the principles established in Section 2.1, should result in an increased voltammetric response. Additionally, different types of ligands can be incorporated via sequential complexation, enabling, for example, a tuning of the number of receptive sites or incorporation of additional functionalities. Examples of voltammetric receptors containing different metal complex transducers and their redox characteristics are reviewed in Sections 2.3.1, 2.3.2 and 2.3.4.

\subsubsection{Organic transducers}


A diverse class of redox-transducers are those based on organic redox-active functionalities.

While these are arguably the most synthetically adaptable and tuneable transducers they have received considerably less attention. This may be attributed to their complex electrochemical behaviour, which is often solvent and/or $\mathrm{pH}$ dependent. One such transducer are the tri(alkyl/aryl)amines which can be (reversibly) oxidized at moderate to high potentials and have found some application in anion sensors as discussed in Sections 2.3.1 and 2.3.4. Similarly, (hydro)quinones have received considerable attention in various electrochemical studies, but their use in anion sensors has been limited by their relatively complex solvent and pH dependent electrochemistry which arises from two proton coupled one-electron reductions. Indeed, early studies of quinone-based anion sensors produced responses that were difficult to rationalise ${ }^{23-24}$ impeding their further use. ${ }^{25}$ Another solely organic electrochemically active motif that has been extensively studied in switches and interlocked structures, but has found little use in anion sensors, is the bipyridinium motif found in diquat(DQ)/paraquat(PQ). ${ }^{26}$ This dicationic transducer can be reversibly reduced at low potentials in two one-electron steps $\left(\mathrm{DQ}^{2+} / \mathrm{DQ}^{+\bullet}\right.$ and $\left.\mathrm{DQ}^{+\bullet} / \mathrm{DQ}\right)$ thus deactivating anion binding. While this facilitates sensing of anions with low half-wave potentials, such as iodide, it has found limited use in voltammetric sensors most likely because of the demanding synthetic pathways required.

Table 1. Comparison of different redox transducers for application in derived voltammetric (anion) sensors.

\begin{tabular}{lll}
\hline Transducer & Advantages & Disadvantages \\
\hline Ferrocene & -Well-defined, reversible redox couple & \\
& -Synthetically very adaptable & \\
TTF & - Two-stage oxidation & -Synthetically challenging \\
& -Rich spectro(electro)chemistry & -Moderate/high oxidation potential \\
& -Conducting & \\
Porphyrin & -Highly tuneable by metal substitution & -Reversibility often compromised \\
& -Rich photophysical properties & -High oxidation potential(s) \\
& -Biomimetic & -Reversibility often compromised \\
\end{tabular}




\begin{tabular}{lll}
\hline $\begin{array}{l}\text { Metal } \\
\text { complexes }\end{array}$ & $\begin{array}{l}\text {-Highly adaptable through metal or ligand } \\
\text { substitution }\end{array}$ & - Synthetically often challenging \\
& -Often luminescent (double readout) & \\
Organic & -Tuneable redox potentials & $\begin{array}{l}\text {-Solvent or } \mathrm{pH} \text {-dependent redox properties } \\
\end{array}$ \\
\hline
\end{tabular}

$a$ - relevant for molecular electronics. $b$ - in particular for the second oxidation process; reversibility often solvent dependent.

\subsection{Solution-phase voltammetric anion sensing}

\subsubsection{Redox-active receptors based on $\mathrm{N}-\mathrm{H}$ hydrogen bond donors}

$\mathrm{N}-\mathrm{H}$ hydrogen bond $(\mathrm{HB})$ donor groups are not only ubiquitous in nature but have found wide-spread use in all areas of chemistry, including anion-supramolecular chemistry in which they are arguably the most commonly used anion receptive motif. Almost invariably early voltammetric anion sensors, but also recent examples, are based on $\mathrm{N}-\mathrm{H}$ hydrogen bond donors. A large variety of such systems, mainly containing amide and urea binding sites, were reported in the 1990 s and have been reviewed extensively. ${ }^{27-28}$ Many of these early systems and the majority of more recent examples in the last two decades, utilise an integrated Fc redox transducer with amine $e^{29-32}$, amide ${ }^{33-37}$, imidazole ${ }^{38-42}$, amide/urea macrocycle ${ }^{43-44}, \quad$ thiourea ${ }^{45}$, amidine $^{46}, \quad$ guanidine $e^{47-48}, \quad$ cyclotriveratrylene-amide ${ }^{36}$, calix[4]pyrrole $49, \quad$ calix[4]arene-amide ${ }^{50-51}, \quad$ calix[4]arene-urea ${ }^{52-53}$ or calix[4]areneamine/imine ${ }^{54}$ conjugates (see Figure 4 for examples). Their sensory performance does not significantly deviate from those of earlier systems; most display a progressive cathodic shift of the respective $\mathrm{Fc} / \mathrm{Fc}^{+}$redox couple upon anion addition with some displaying a "twowave" behaviour, of which a representative example, as assessed by SWV, is shown in Figure 5. Furthermore the majority of these sensors are electrochemically reversible and their anion selectivity largely dictated by the nature of the $\mathrm{N}-\mathrm{H}$ hydrogen bonding binding site as well as anion basicity. In the following we will briefly highlight some representative examples 
of such receptors, before discussing $\mathrm{N}-\mathrm{H}$ HB sensors based on non-Fc transducers in more detail.

In 2001 Reynes et al. reported a detailed comparison of acyclic and cyclic ferrocenylamide based sensors including the cyclotriveratrylene receptor 1 (Figure 4). ${ }^{36}$ As in almost all of the sensors discussed in this review, 1 displayed only one redox couple indicating that all three ferrocene transducer groups were simultaneously, independently oxidized. This system displayed a particularly interesting response to 1 equiv. of anions. $\mathrm{F}^{-}$and $\mathrm{HSO}_{4}^{-}$induced only small perturbations with a one-wave (progressive shift) behaviour. This was also highly solvent dependent where $\mathrm{F}^{-}$only perturbed the $\mathrm{Fc} / \mathrm{Fc}^{+}$couple in $\mathrm{ACN}(-60 \mathrm{mV})$ with no perturbation in the less competitive solvent $\mathrm{DCM}$. Conversely, $\mathrm{HSO}_{4}^{-}$induced a small response in $\mathrm{DCM}(-20 \mathrm{mV})$ while no shifts were measured in $\mathrm{ACN}$. 1 responded to the biologically relevant oxoanions $\mathrm{H}_{2} \mathrm{PO}_{4}^{-}$and $\mathrm{ATP}^{2-}$ in both $\mathrm{ACN}(-140 \mathrm{mV}$ and $-160 \mathrm{mV}$, respectively) and DCM (-230 $\mathrm{mV}$ for both anions) displaying a "two-wave" behaviour. A similar system based on bis-Fc-containing calix[4]arene-urea receptors $\mathbf{2}$ was later studied where the cathodic perturbations (of approximately $-100 \mathrm{mV}$ ) induced in the presence of 2 equiv. of $\mathrm{H}_{2} \mathrm{PO}_{4}^{-}$in $\mathrm{DCM}$ were independent of linker length $(n=1,3) .52$ Additionally, the replacement of the urea motif in $\mathbf{2}$ with an amide, a poorer HB donor, elicited a similar electrochemical response, indicating that binding in this non-competitive solvent was driven almost entirely by electrostatic interactions between the anion and the $\mathrm{Fc}^{+}$moieties, a behaviour that has been exploited in numerous systems containing no specific anion binding sites (see Sections 2.3.5 and 2.3.7).

Apart from the ubiquitously used amide and urea binding sites, thioureas have been incorporated into various Fc-based voltammetric sensors, such as $\mathbf{3 a}$ and $\mathbf{3 b} .^{45}$ Both displayed significant responses to the basic $\mathrm{F}^{-}, \mathrm{OAc}^{-}, \mathrm{H}_{2} \mathrm{PO}_{4}^{-}$and $\mathrm{HP}_{2} \mathrm{O}_{7}^{3-}$ (1 equiv. in DMSO) of 
between -90 to $-150 \mathrm{mV}$ for $\mathbf{3 a}$ and -120 to $-200 \mathrm{mV}$ for $\mathbf{3 b}$. The response of the less electron-rich $\mathbf{3 b}$ was larger by at least $-20 \mathrm{mV}$ in all cases. Neither receptor showed any response to 10 equiv. of $\mathrm{Cl}^{-}, \mathrm{Br}^{-}, \mathrm{HSO}_{4}{ }^{-}$and $\mathrm{NO}_{3}{ }^{-}$.

In a more recent study Nieto et al. assembled a bis(ferrocenyl-amidine) receptor 4 via Pt(II)mediated nucleophilic addition. ${ }^{46}$ The $\mathrm{Fc} / \mathrm{Fc}^{+}$couple of this sensor displayed a "two-wave" behaviour upon addition of $\mathrm{H}_{2} \mathrm{PO}_{4}^{-}$in ACN/DCM 5:1, as shown in Figure 5. In this slowexchange, strong binding regime these voltammograms can often be used to infer the stochiometry of the receptor-anion complex. In this case the new wave at lower potential ($90 \mathrm{mV}$ more cathodic) is only fully developed at 2 equiv. of $\mathrm{H}_{2} \mathrm{PO}_{4}^{-}$suggesting formation of a 1:2 stochiometric host-guest complex. 


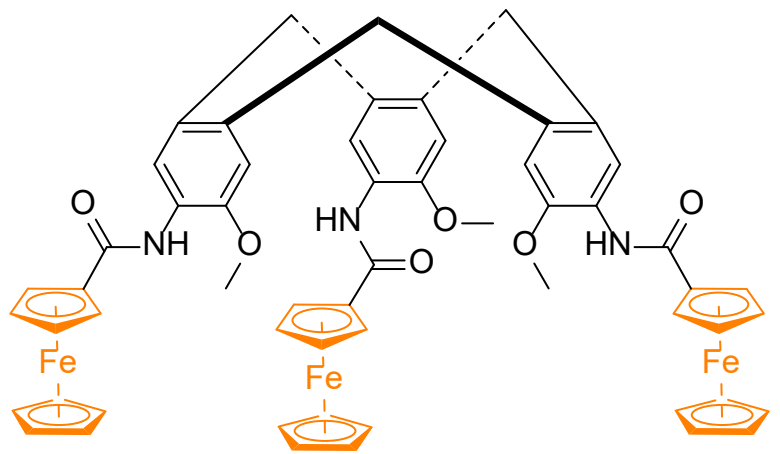

1

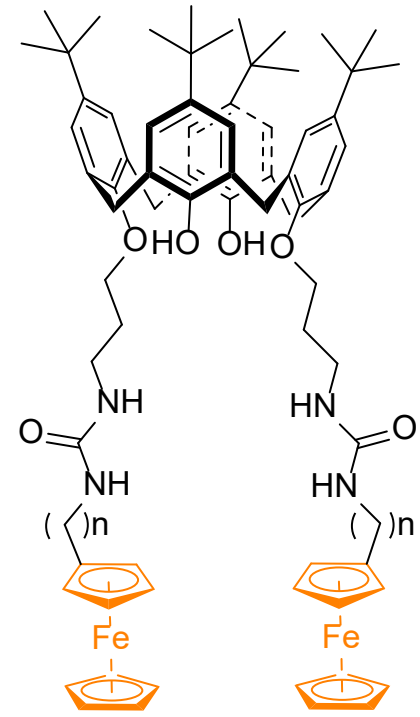

2: $n=1,3$

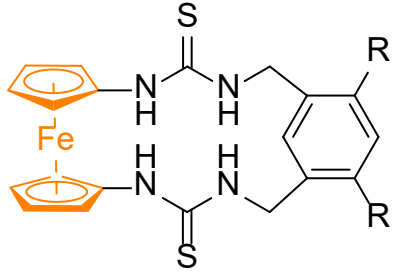

3a: $\mathrm{R}=\mathrm{CH}\left(\mathrm{CH}_{3}\right) 2$

3b: $R=H$

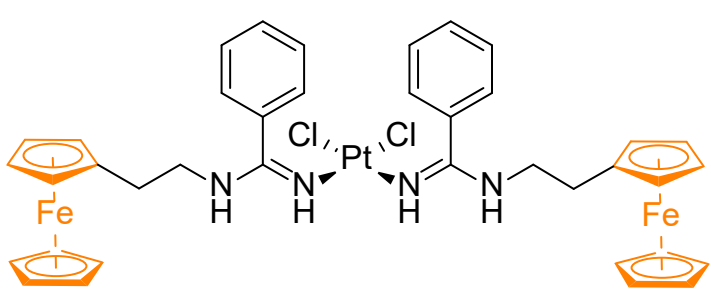

4

Figure 4. Representative voltammetric anion sensors based on Fc and typical N-H anion binding sites.

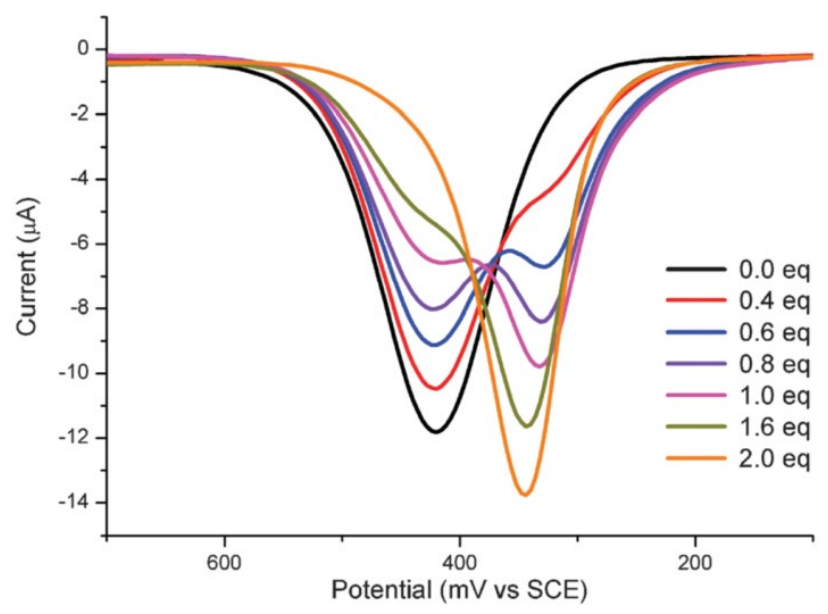

Figure 5. Representative evolution of a SWV upon addition of anions (two wave behaviour). In this specific case receptor 4 was titrated with $\mathrm{H}_{2} \mathrm{PO}_{4}^{-}$in $\mathrm{ACN} / \mathrm{DCM}$ 5:1. Reproduced from Ref. ${ }^{46}$ Copyright 2011 The Royal Society of Chemistry. 
While in a preliminary report an amide-functionalised TTF had been demonstrated to voltammetrically respond to chloride ${ }^{55}$, the first in depth investigation of a TTF-containing anion receptor was reported by Becher and coworkers in $2003 .{ }^{56} \mathrm{~A}$ calix[4]pyrrole receptor was employed which was directly linked to TTF at one of the pyrrole units (5, Figure 6). Voltammetric anion sensing was then carried out in ACN by monitoring the perturbations of the first redox couple $\left(\mathrm{TTF} / \mathrm{TTF}^{+\bullet}\right)$. Both $\mathrm{Br}^{-}(-34 \mathrm{mV})$ and $\mathrm{Cl}^{-}(-43 \mathrm{mV})$ induced significant cathodic shifts at low concentrations ( $0.5 \mathrm{mM}, 1$ equiv.).

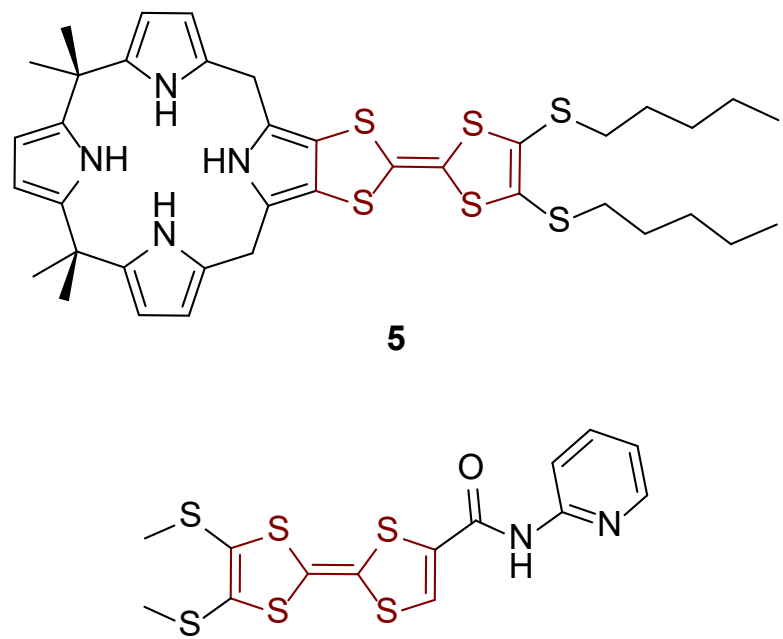

6

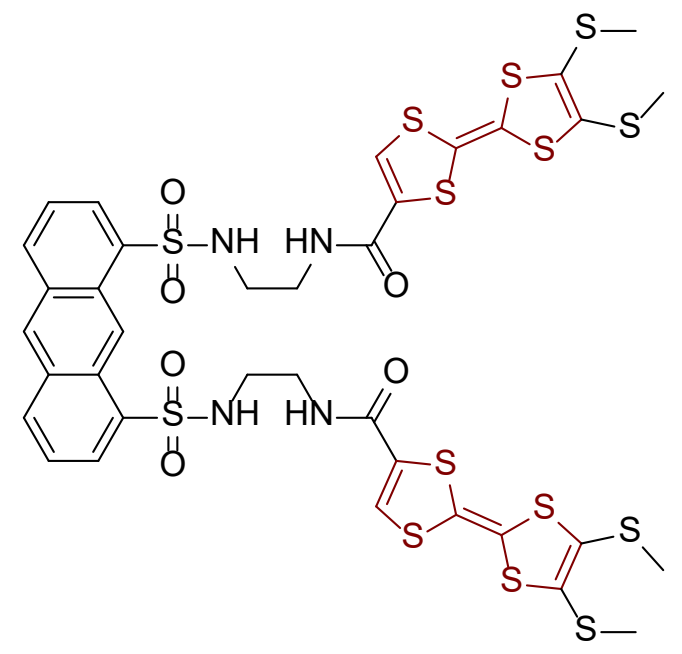

7

Figure 6. Early examples of TTF voltammetric anion sensors based on calix[4]pyrrole and amide binding sites.

Other early examples were published by Zhu's group who directly conjugated amide-binding sites to the TTF core to afford the simple mono-amide TTF receptor $6^{57}$ as well as the more complex amide-sulfonamide receptor 7 (Figure 6). ${ }^{58}$ The former was utilised for the selective sensing of $\mathrm{H}_{2} \mathrm{PO}_{4}^{-}$in DCM whereby both TTF couples underwent significant perturbations; the first couple shifted cathodically by $-100 \mathrm{mV}$ in the presence of 2 equiv. $\mathrm{H}_{2} \mathrm{PO}_{4}^{-}$, while, 
interestingly, the second couple shifted anodically by $160 \mathrm{mV} .{ }^{57}$ This unexpected behaviour was rationalised by destabilisation of the $\mathrm{TTF}^{2+}$ by formation of a 2:1 TTF-anion complex. The addition of other anions such as $\mathrm{F}^{-}, \mathrm{Br}^{-}, \mathrm{Cl}^{-}$or $\mathrm{OAc}^{-}$did not induce any significant perturbations while the voltammetric behaviour in the presence of $\mathrm{HSO}_{4}^{-}$was more complex, most likely due to protonation of the pyridine moiety. A similar complex behaviour was also observed for 7 , whereby addition of 2 equiv. of $\mathrm{F}^{-}, \mathrm{Cl}^{-}$or $\mathrm{OAc}^{-}$induced cathodic perturbations of both TTF couples with splitting of the first couple. ${ }^{58}$ The addition of $\mathrm{H}_{2} \mathrm{PO}_{4}{ }^{-}$ induced the appearance of a new wave $-170 \mathrm{mV}$ more cathodic than the first couple while the second wave was only perturbed minimally. Interestingly, the addition of $\mathrm{HSO}_{4}^{-}$led to significant cathodic perturbations only for the second couple. The presence of the anthracene backbone of the receptor furthermore enabled fluorescent anion sensing whereby only $\mathrm{F}^{-}$led to a significant luminescence switch-on. A similar TTF-monoamideBODIPY system was also employed for the voltammetric and fluorimetric sensing of fluoride in DCM. ${ }^{59}$

It should be noted that the "selective" sensing of fluoride, or other basic anions, in many of the systems discussed arises from receptor deprotonation rather than a specific hydrogenbonding interaction. Precisely this behaviour was exploited by Xiong et al. who reported a 2,4-dinitrophenylhydrazone-TTF sensor (8, Figure 7). Upon addition of $\mathrm{F}^{-}$to 8 in DCM large anodic shifts of up to $400 \mathrm{mV}$ (both couples) were observed. This interesting behaviour arises because deprotonation of the hydrazone leads to conjugation and subsequent intramolecular electron transfer from the electron rich TTF to the electron deficient dinitrophenyl group. This latter moiety furthermore allows optical fluoride detection whereby both electrochemical and optical sensing of $\mathrm{F}^{-}$was achieved with good selectivity over $\mathrm{OAC}^{-}, \mathrm{H}_{2} \mathrm{PO}_{4}^{-}, \mathrm{Br}^{-}, \mathrm{Cl}^{-}$and $\mathrm{NO}_{3}^{-}$. 


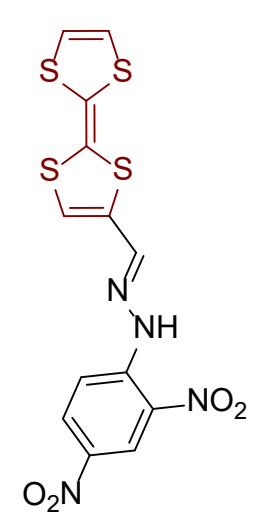

8

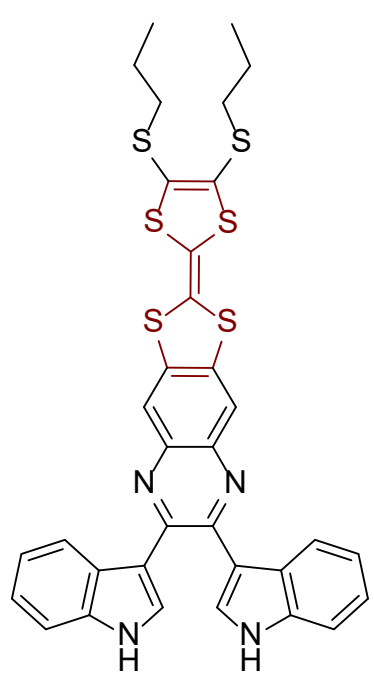

9

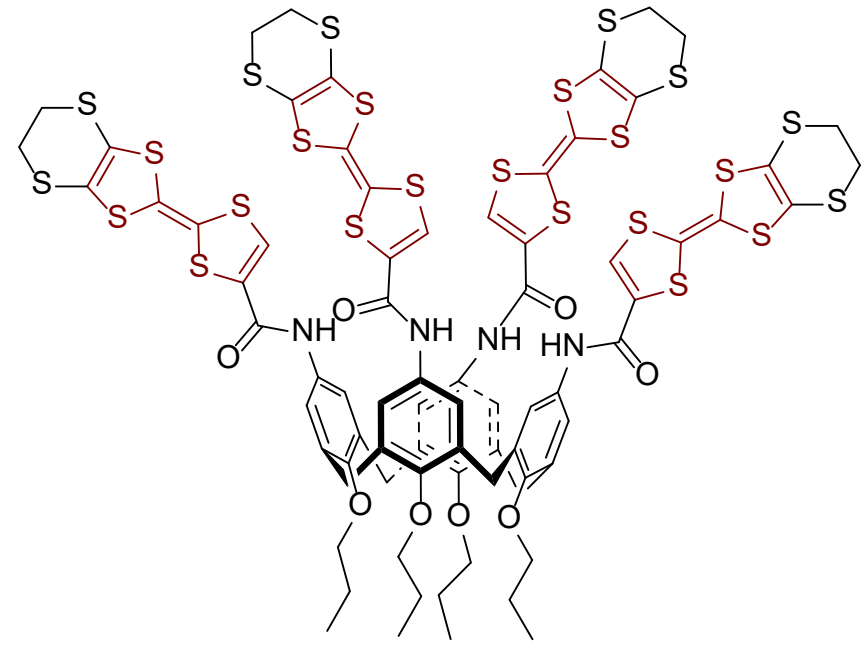

10.cone

Figure 7. TTF-containing sensors based on different receptive motifs including 2,4-dinitrophenylhydrazone, diindolylquinoxaline and calix[4]arene (only cone conformation shown).

A similar dual signalling approach was also reported by Sessler, whereby a diindolylquinoxaline-TTF 9 was used as a sensor for $\mathrm{F}^{-}$and $\mathrm{H}_{2} \mathrm{PO}_{4}^{-} \cdot{ }^{60}$ Large cathodic shifts of the TTF/TTF ${ }^{\bullet}$ redox couple of $-280 \mathrm{mV}$ and $-110 \mathrm{mV}$ in the presence of $\mathrm{F}^{-}$and $\mathrm{H}_{2} \mathrm{PO}_{4}^{-}$were observed, respectively ( 2 equiv. in DCM). Sessler and Kim also investigated a calix[4]arene based receptor 10 modified with four TTF units. Two different conformations of the receptor (cone and 1,3-alternate) were isolated and studied with both displaying four redox couples in DCM. The presence of multiple of redox waves, in the apparently degenerate TTF units, was attributed to intramolecular interactions between the redox sites. ${ }^{61}$ Interestingly, the addition of anions induced anodic perturbations of all couples, attributed to inhibition of electron transfer between the calix[4]arene core and the TTF units. Impressively, 10.cone demonstrated anodic perturbations of $450 \mathrm{mV}$ in the presence of 1 equiv. of $\mathrm{HP}_{2} \mathrm{O}_{7}^{3-}$ with smaller shifts seen for $\mathrm{H}_{2} \mathrm{PO}_{4}^{-}(220 \mathrm{mV}), \mathrm{F}^{-}(240 \mathrm{mV}), \mathrm{OAc}^{-}(210 \mathrm{mV})$ and $\mathrm{Cl}^{-}(33 \mathrm{mV})$. The performance of 10.alt in the presence of these anions was markedly different with shifts of 
$160,170,270,40$ and $26 \mathrm{mV}$, respectively. Dai's group later reported diamino-diamido TTF anion receptors capable of voltammetric sensing of other oxanions (sulfate and oxalate) in more competitive solvent systems such as ACN/MeOH (9:1) or ACN/DMF (9:1). ${ }^{62-63}$

While an early study ${ }^{64}$ demonstrated the potential of porphyrin as a transducer for anion sensing, its use has been, as noted above, limited. One rare example was reported in the "picket fence" tetra-amide-imidazolium Zn-porphyrin 11 (Figure 8). ${ }^{65}$ Addition of 5 equiv. of $\mathrm{Cl}^{-}(-180 \mathrm{mV}), \mathrm{HSO}_{4}^{-}(-140 \mathrm{mV})$ and $\mathrm{NO}_{3}{ }^{-}(-95 \mathrm{mV})$ led to the expected cathodic perturbation of the $\mathrm{P} / \mathrm{P}^{+\bullet}$ couple in $\mathrm{ACN}$ while $\mathrm{ClO}_{4}^{-}$induced no shifts and $\mathrm{H}_{2} \mathrm{PO}_{4}^{-}$led to precipitation. In a later study similar systems based on the tetra-amide-porphyrin scaffold were studied whereby the specific influence of the nature of the metal-centres $\left(\mathrm{Fe}(\mathrm{Cl}), \mathrm{Co}\left(\mathrm{PF}_{6}\right), \mathrm{Ni}, \mathrm{Cu}, \mathrm{Zn}\right.$, $\mathrm{Cd}$ or $\mathrm{Hg}$ ) on the sensory performance was systematically investigated. ${ }^{66}$ The photophysical and electrochemical properties of $\mathbf{1 2}$ are strongly dependent on the nature of the metal centre. For example, the half-wave potential for the first couple differed by $360 \mathrm{mV}$ between the 12.Cd (lowest $E_{1 / 2}$ ) and 12.Fe(Cl) (highest) in 1:1 DCM/ACN. While addition of 5 equiv. of $\mathrm{ClO}_{4}^{-}$resulted in no perturbations, addition of $\mathrm{Cl}^{-}, \mathrm{H}_{2} \mathrm{PO}_{4}^{-}$or $\mathrm{NO}_{3}{ }^{-}$induced significant cathodic shifts in almost all systems. The largest shifts for all anions were observed for $\mathbf{1 2 . H g}$ with some significant variance between receptors for different anions. Interestingly, the addition of these anions to the unmodified tetraphenylporphyrin (TPP) compounds TPP.Cu, TPP.Zn and TPP.Cd led to significantly larger cathodic perturbation for all anions with all tested compounds. While the anion binding constants (and selectivity) to the amide-containing receptors $\mathbf{1 2}$ is certainly larger than those of the TPPs this again importantly demonstrates that the response of these systems is not driven by the magnitude of the binding strength but the relative difference in binding between the differently charged states, which, apparently, in the case of the metallated TPPs, is larger. 
The sensory properties of the free-base porphyrinogen derivative $\mathbf{1 3}$ have also been investigated. ${ }^{67}$ In ortho-dichlorobenzene both porphyrin couples were cathodically perturbed upon addition of anions (up to 3 equiv.) with maximum shifts of $-600 \mathrm{mV}\left(\mathrm{F}^{-}\right),-580$ $\mathrm{mV}\left(\mathrm{OAc}^{-}\right),-570 \mathrm{mV}\left(\mathrm{H}_{2} \mathrm{PO}_{4}^{-}\right),-70 \mathrm{mV}\left(\mathrm{NO}_{3}{ }^{-}\right)$and $-60 \mathrm{mV}\left(\mathrm{ClO}_{4}^{-}\right)$. These substantial responses can most likely be attributed to the choice of the extremely apolar solvent, the good electronic communication (coupling) between the binding site and the transducer and potentially deprotonation of the receptor.

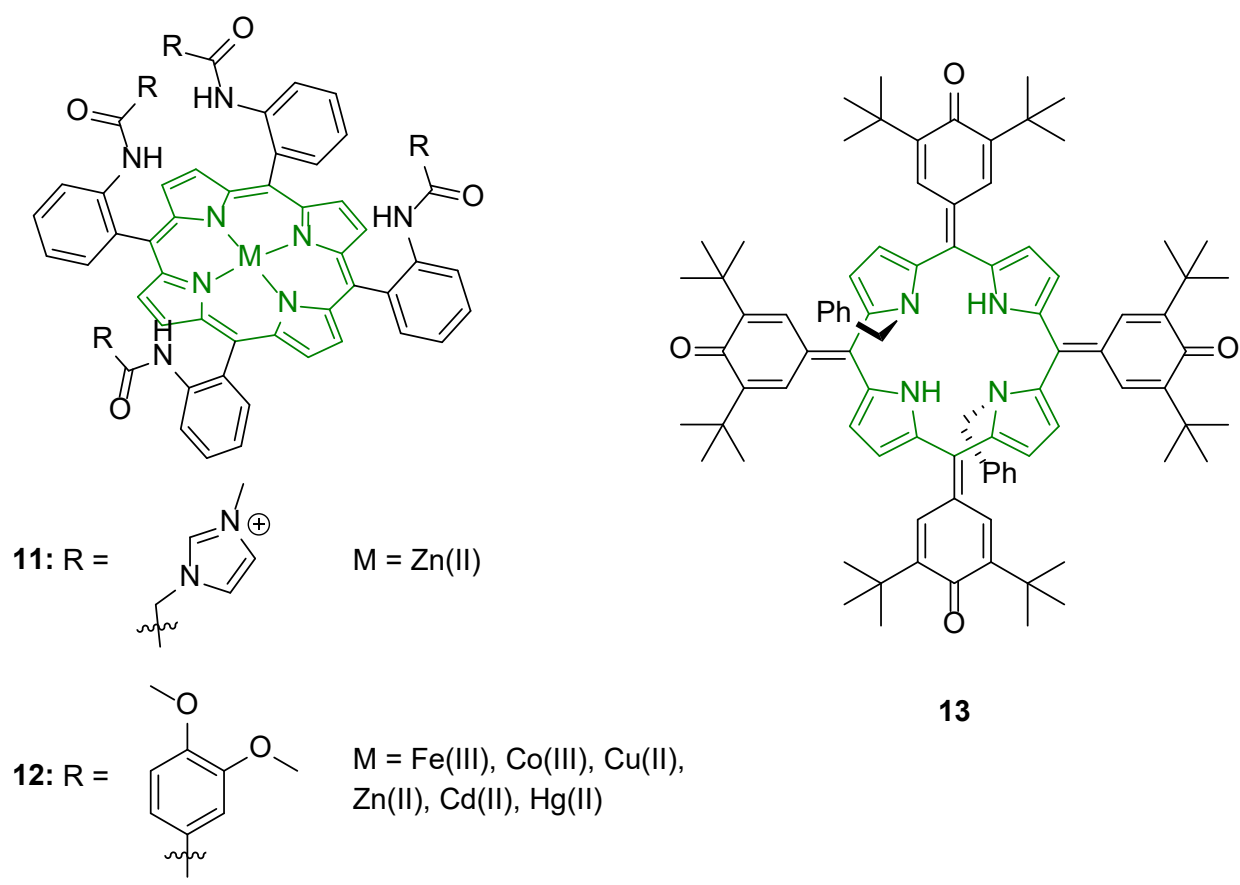

Figure 8. Porphyrin-based receptors for voltammetric anion sensing.

A variety of other redox-receptors based on metals have also been reported, whereby an advantageous double readout (electrochemical, luminescent) is often feasible. Most of these receptors are based on transition metal complexes of ruthenium or osmium with receptor modified nitrogenous ligands, such as bipy, terpy, imidazole or pyrazole (for example receptors 14 and 15, Figure 9, in which anion sensing was reported via the $\mathrm{M}^{2+} / \mathrm{M}^{3+}$ 
couple) ${ }^{68-72}$ In a rare example of a receptor containing two redox transducers Beer and coworkers reported tetraamide macrocycles $16 \mathbf{a}-\mathbf{b}$ containing both a $\mathrm{Ru}(\mathrm{bpy}) 3^{2+}$ as well as either a $\mathrm{Fc}$ or a $\mathrm{Cp}_{2} \mathrm{Co}^{+}$transducer. ${ }^{73} \mathrm{Cl}^{-}$sensing in $\mathrm{ACN}$ was achieved both via the metallocene as well as bpy redox couples, with cathodic perturbation of $16 a$ of $-40 \mathrm{mV}$ and $60 \mathrm{mV}$ for the couples, respectively (anion in excess). Interestingly, the cobaltocenium analogue $16 b$ exhibited an even larger perturbation of both couples of $-90 \mathrm{mV}$ and $-110 \mathrm{mV}$, respectively.

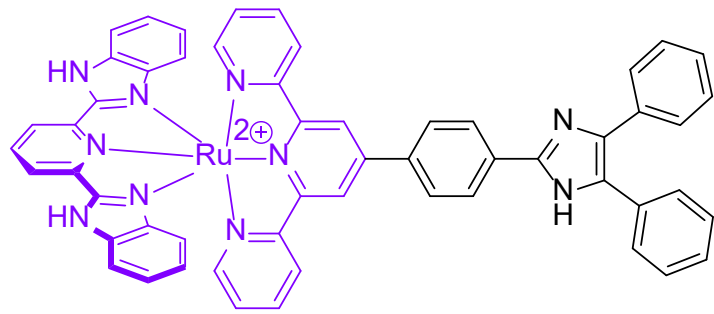

14

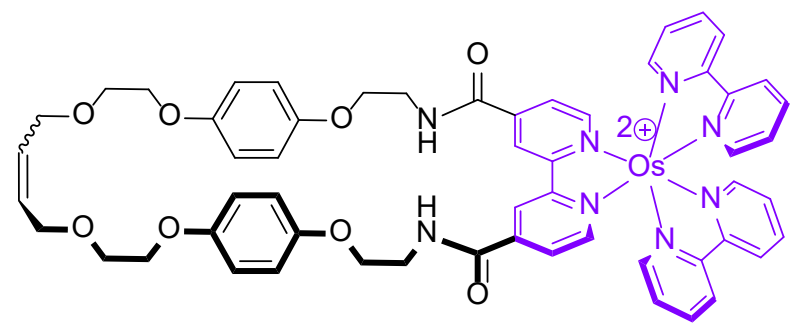

15

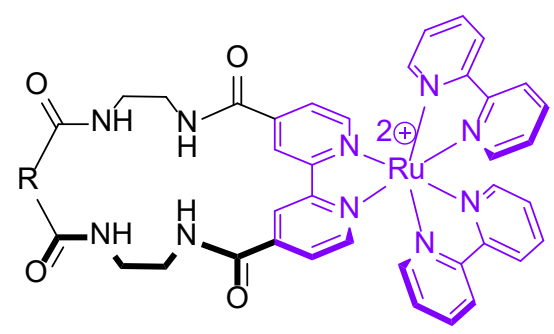

$16 a: R=$

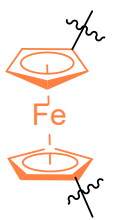

16b: $R=$

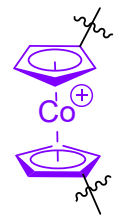

Figure 9. Ruthenium- and osmium-containing voltammetric anion sensors.

The scarcely utilised redox-active dithiocarbamate-metal motif has been investigated by Beer and co-workers in a variety of acyclic and macrocyclic receptors (Figure 10). ${ }^{74-76}$ For example simple macrocycles 17 containing two dithiocarbamate (DTC) copper(II) moieties have been shown to sense anions through electrostatic interactions only. ${ }^{76}$ 17a and $17 \mathrm{c}$ display two quasi-reversible overlapping $\mathrm{Cu}^{2+/ 3+}$ oxidation waves at moderate potentials 
while 17b shows only one, albeit broad, wave. Significant cathodic shifts are only observed for $17 \mathrm{~b}$ in the presence of the large, tetrahedral anions $\mathrm{ReO}_{4}^{-}$and $\mathrm{H}_{2} \mathrm{PO}_{4}^{-}$(-85 $\mathrm{mV}^{-}$each) with a negligible response towards $\mathrm{Cl}^{-}, \mathrm{Br}^{-}$and $\mathrm{NO}_{3}^{-}$in all cases (5 equiv. in DCM/ACN 4:1). This indicates that both electrostatic interactions and size-complementarity govern anion binding in these bimetallic macrocycles.

The DTC motif has also been extended to other metals, such as Co(III), in generating a reporting signal. The amide Co-DTC cryptands 18 were reported to respond to $\mathrm{Cl}^{-}, \mathrm{BzO}^{-}$, $\mathrm{HSO}_{4}^{-}$and $\mathrm{H}_{2} \mathrm{PO}_{4}^{-}$through perturbations of the $\mathrm{Co}^{3+/ 4+}$ couple. ${ }^{74}$ Both receptors showed the largest response to $\mathrm{H}_{2} \mathrm{PO}_{4}^{-}$, which was greatest for $18 \mathrm{a}(-130 \mathrm{mV})$, while in all other cases $\mathbf{1 8 b}$ was more responsive $(-50 / 60 \mathrm{mV}$; all at 10 equiv. in $\mathrm{DCM})$.

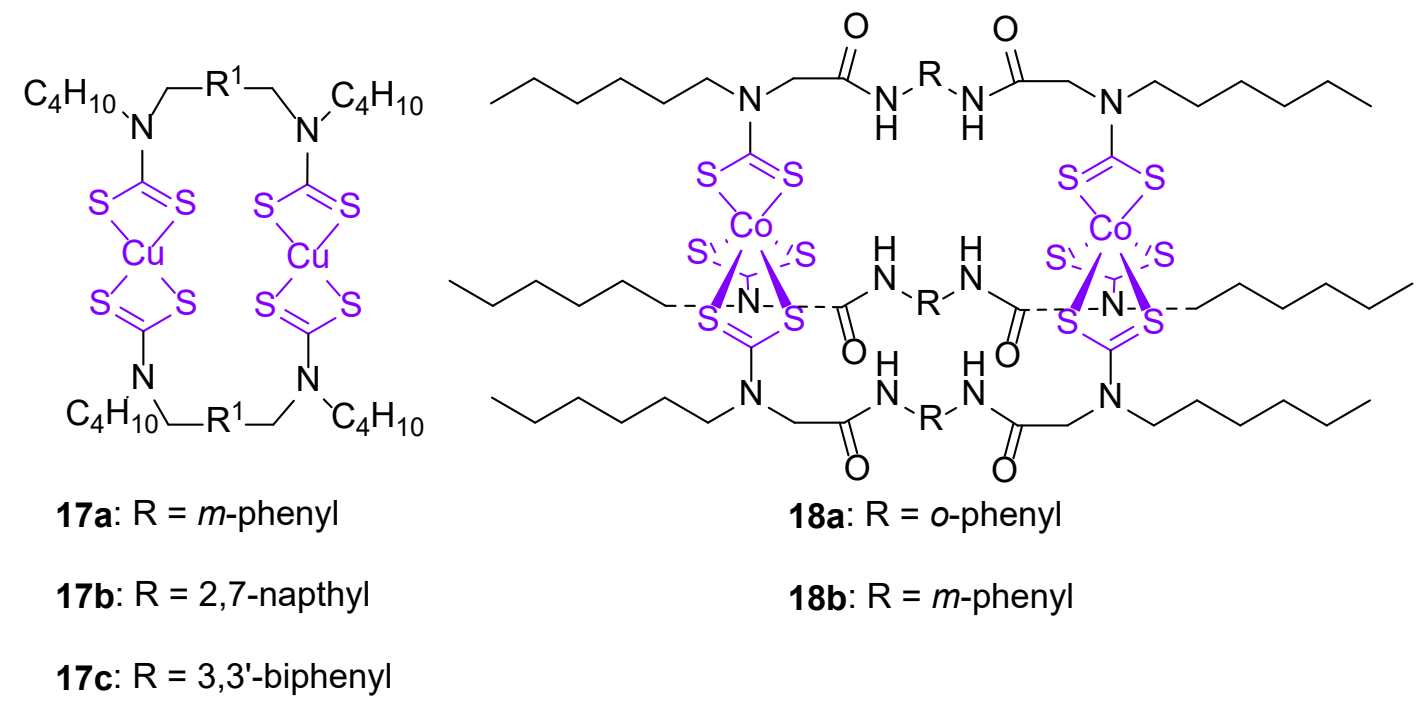

Figure 10. DTC-containing macrocyclic and cryptand anion sensors.

Other purely organic redox-active anion receptors containing a p-phenylenediamine transducer have been reported (19-20, Figure 11). ${ }^{77}$ Both of these urea-based hosts displayed a one-electron oxidation at potentials approximately 100-200 mV higher than $\mathrm{Fc} / \mathrm{Fc}^{+}$with an additional, more anodic, oxidation being observed for the symmetric receptor 
19. Binding studies with $\mathrm{OAC}^{-}, \mathrm{BzO}^{-}, \mathrm{NO}_{2}^{-}$and $\mathrm{Cl}^{-}$in $\mathrm{ACN}$ revealed the appearance of a new couple at lower potentials, whose potential was significantly more cathodic (by -140 to -250 $\mathrm{mV}$ ) for the three former anions, while $\mathrm{Cl}^{-}$elicited much smaller responses for both receptors $(-16 \mathrm{mV}$ and $-34 \mathrm{mV})$. The largest response of the unsymmetric receptor 20 in the presence of $\mathrm{OAc}^{-}(-250 \mathrm{mV})$ corresponds to a large BEF $\left(\mathrm{K}_{\mathrm{Ox}} / \mathrm{K}_{\mathrm{Red}}\right)$ of 14500.

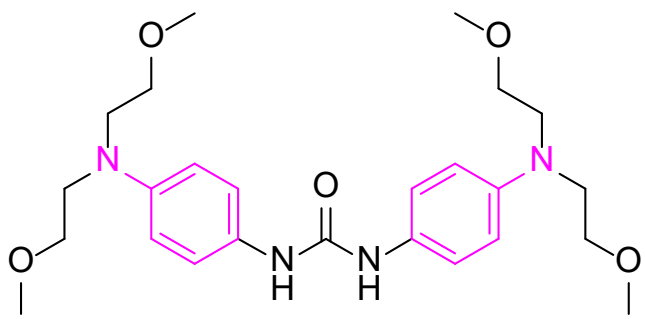

19<smiles>COCCN(CCOC)c1ccc(NC(=O)Nc2ccc([N+](=O)[O-])cc2)cc1</smiles>

20

Figure 11. Redox-active urea anion receptors.

\subsubsection{Redox-active receptors based on $\mathrm{C}-\mathrm{H}$ hydrogen bond donors}

$\mathrm{C}-\mathrm{H}$ hydrogen bonding has recently gained significant attention as a potent interaction to drive anion recognition. ${ }^{78}$ While often weaker than $\mathrm{N}-\mathrm{H}$ bond donors, $\mathrm{C}-\mathrm{H}$ bonds are much less prone to deprotonation, a problem, as highlighted in examples above, that is often observed for $\mathrm{N}-\mathrm{H}$ bond donors in less-competitive media when binding more basic anions such as $\mathrm{F}^{-}$or $\mathrm{OAc}^{-}$. A prominent $\mathrm{C}-\mathrm{H} \mathrm{H}$-bond motif is provided by imidazolium. The first example of an imidazolium-based $\mathrm{C}-\mathrm{H} \mathrm{H}$-bonding voltammetric sensor was published as early as 2000 in which simple Fc-imidazolium receptors were shown to respond to anions. ${ }^{79}$ More systematic studies on acyclic ${ }^{80-84}$ and cyclic $^{85}$ imidazolium-based sensors have only been conducted more recently. For example Jin and coworkers reported in-depth studies of a series of mono-and bis(imidazolium)-substituted ferrocenes 21a-f with varying ferrocenemethylene- imidazolium group linker length (Figure 12). $\cdot{ }^{80,84}$ Unsurprisingly, the magnitude of 
the cathodic shifts of 21a-d were strongly dependent on the methylene linker length whereby the magnitude of the $\mathrm{Fc} / \mathrm{Fc}^{+}$cathodic shift response upon $\mathrm{F}^{-}, \mathrm{Cl}^{-}$and $\mathrm{HSO}_{4}{ }^{-}$addition (10 equiv. in ACN) diminished significantly with increasing distance between the ferrocene and imidazolium binding sites. Interestingly, this attenuation was observed to be dependent upon the nature of the anion; for example, the response of 21a-d towards $\mathrm{F}^{-}$decreased from $-230 \mathrm{mV}$, to $-160 \mathrm{mV},-28 \mathrm{mV}$ to $-12 \mathrm{mV}$ while the $\mathrm{Cl}^{-}$response magnitude was significantly lowered from $-65 \mathrm{mV}$, to $-21 \mathrm{mV},-13 \mathrm{mV}$, to $-10 \mathrm{mV}$.

The incorporation of imidazolium into a bipy-ligand allowed the facile assembly of the highly-preorganized cage-like-receptor 22 after complexation with Co(II) (Figure 12) ${ }^{86}$ Initial experiments in ACN revealed significant cathodic perturbation of the $\mathrm{Co}^{2+} / \mathrm{Co}^{3+}$ couple upon addition of up to 1.5 equiv. $\mathrm{Cl}^{-}(-140 \mathrm{mV})$ or $\mathrm{Br}^{-}(-120 \mathrm{mV})$. Due to the relatively high halfwave potential of the receptor $\left(+100 \mathrm{mV}\right.$ vs. $\left.\mathrm{Fc} / \mathrm{Fc}^{+}\right)$the analysis of other anions with moderate oxidation potentials was not possible in $\mathrm{ACN}$ prompting the use of $A C N / \mathrm{H}_{2} \mathrm{O} 4: 1$ for further studies. In this solvent system a significant and well-defined response was observed for a wider range of anions in the order $\mathrm{Cl}^{-}>\mathrm{Br}^{-} \approx \mathrm{OCN}^{-}>\mathrm{SCN}^{-} \approx \mathrm{I}^{-}$with shifts of up to $-120 \mathrm{mV}$, as can be seen in Figure 13. 


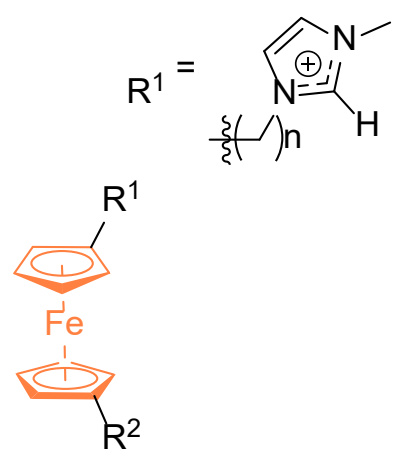

21a-d: $n=0,1,3,4, R^{2}=H$

21e-f: $n=0$ or $4, R^{2}=R^{1}$

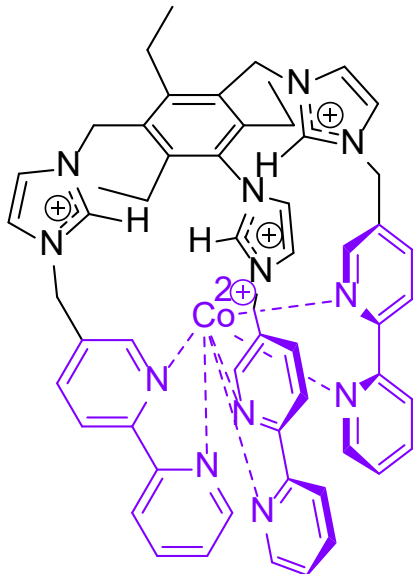

22

Figure 12. Imidazolium C-H bond donors in Fc- and Co(bpy) ${ }_{3}$-containing sensors.

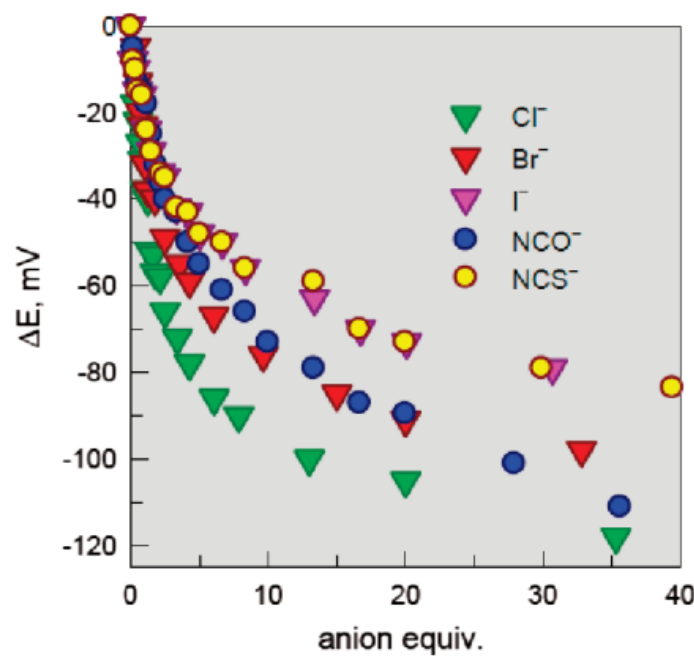

Figure 13. Electrochemical binding isotherms of cage 22 upon addition of various anions in $A C N / H_{2} \mathrm{O} 4: 1$.

Reproduced with permission from Ref. ${ }^{86}$ Copyright 2008 American Chemical Society.

Another potent $\mathrm{C}-\mathrm{H}$ bond donor motif recently investigated is 1,2,3-triazole. ${ }^{87}$ The heterocycle's widespread use can largely be attributed to the ease of preparation (via click chemistry from an azide and alkyne) and the potent polarised $\mathrm{C}-\mathrm{H}$ bond in the 5-position. Furthermore the $\mathrm{C}-\mathrm{H}$ hydrogen bond donor potency can be easily enhanced via methylation at the 3-position, yielding the cationic triazolium. 
Early examples of triazole-containing voltammetric anion sensors were reported by Astruc (Fc-triazole dendrimers discussed separately, vide infra), and Tárraga and Molina. The simple Fc-triazole-pyrene receptor 23 (Figure 14) exhibited a cathodic shift of -100 mV in DCM only for $\mathrm{HP}_{2} \mathrm{O}_{7}^{3-}$, while $\mathrm{H}_{2} \mathrm{PO}_{4}^{-}, \mathrm{HSO}_{4}^{-}, \mathrm{OAc}^{-}, \mathrm{NO}_{3}{ }^{-}, \mathrm{F}^{-}, \mathrm{Cl}^{-}$and $\mathrm{Br}^{-}$elicited no response. ${ }^{88} \mathrm{Kim}^{\prime}$ group utilised the bis(Fc-triazole) receptor 24 to also selectively sense $\mathrm{H}_{2} \mathrm{PO}_{4}^{-}$and $\mathrm{HP}_{2} \mathrm{O}_{7}{ }^{3-}$ with selectivity over all halides, $\mathrm{PF}_{6}{ }^{-}, \mathrm{ClO}_{4}{ }^{-}, \mathrm{HSO}_{4}{ }^{-}$and $\mathrm{OAc}^{-}$(2 equiv. in $\left.\mathrm{DCM}\right) .{ }^{89}$ The phosphorus oxoanions induced cathodic shifts of the $\mathrm{Fc} / \mathrm{Fc}^{+}$transducer of $\approx-200$ and $\approx-180 \mathrm{mV}$, respectively. DFT calculations show that $\mathrm{Cl}^{-}$is bound by a total of three $\mathrm{HB}^{\prime} \mathrm{s}$; two from the triazole moieties $\left(H_{a}\right)$ as well as one from the internal aryl proton $\left(H_{b}\right)$ (Figure 15).

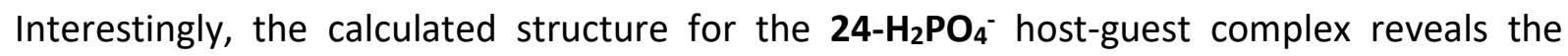
formation of two further HB's from the $\alpha$-protons of the Fc's cyclopentadienyl ( $H_{c}$, Figure 15) a rarely considered, yet potentially important contribution to anion binding. The design of the receptor was later elaborated on by the introduction of additional amide binding sites between the triazole and Fc moieties. ${ }^{90}$ Under equivalent conditions as for the aforementioned system this sensor responded to $\mathrm{H}_{2} \mathrm{PO}_{4}^{-}$more weakly with a cathodic shift of $-130 \mathrm{mV}$.

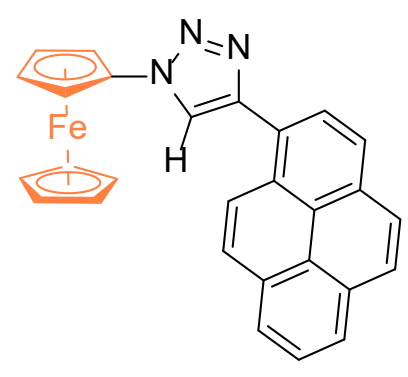

23

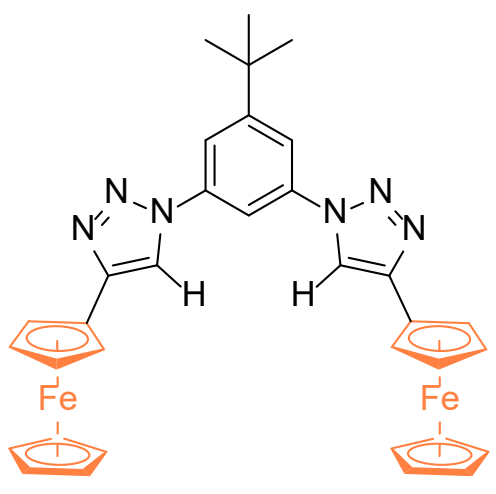

24

Figure 14. Early examples of simpe Fc-triazole based voltammetric anion sensors. 

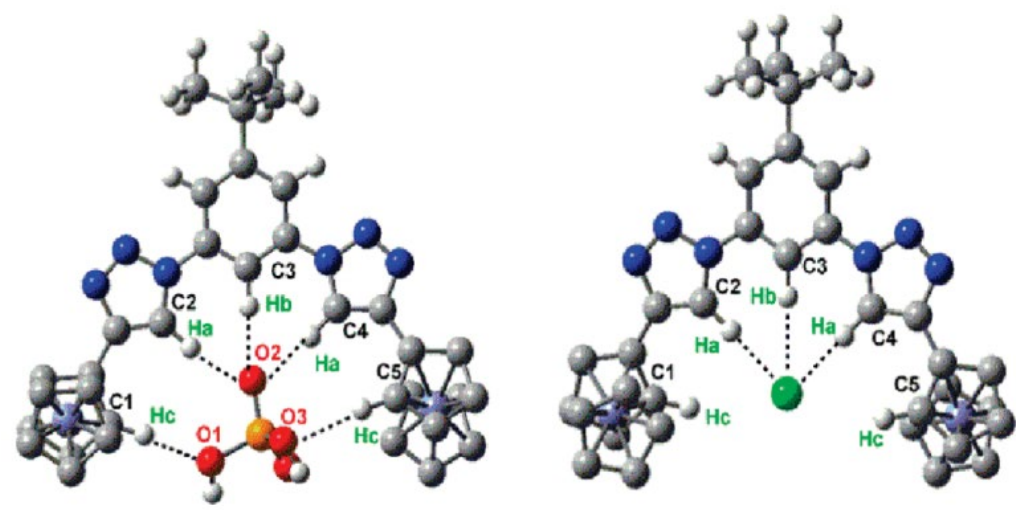

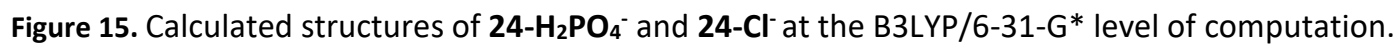
Reproduced with permission from Ref. ${ }^{89}$ Copyright 2011 American Chemical Society.

Tárraga and Molina also conducted an in depth study on a range of related ferrocene triazole receptors 25-32 (Figure 16). ${ }^{91}$ All receptors displayed $\mathrm{Fc} / \mathrm{Fc}^{+}$cathodic shifts in the presence of $\mathrm{HP}_{2} \mathrm{O}_{7}{ }^{3-}, \mathrm{H}_{2} \mathrm{PO}_{4}^{-}, \mathrm{F}^{-}$and $\mathrm{OAC}^{-}$in $\mathrm{ACN}$ (27 and 30 in ACN/DCM 1:1 due to solubility issues) with no response to $\mathrm{HSO}_{4}^{-}, \mathrm{NO}_{3}{ }^{-}, \mathrm{Cl}^{-}$and $\mathrm{Br}^{-}$in almost all cases (a response was observed for $\mathrm{Cl}^{-}$and $\mathrm{Br}^{-}$for receptor 26). The receptors 25, 26 and 29 exhibited two redox waves where the more anodic one was assigned to the $\mathrm{N}$-substituted $\mathrm{Fc}(\mathrm{N}-\mathrm{Fc})$ and the other the C-substituted Fc (C-Fc) (Figure 17). Interestingly, the anion-receptor complexes of $\mathbf{2 5}$ and 26 displayed only one wave at a significantly more cathodic potential (with the exception of the 25-F- adduct) (Figure 17). The overall magnitude of anion binding induced cathodic perturbation of $\mathrm{N}-\mathrm{Fc}$ in $\mathbf{2 5}, \mathbf{2 6}$ and $\mathbf{2 9}$ was comparatively much larger than that of the C-Fc (by up to one order of magnitude in some cases). For example the C-Fc of $\mathbf{2 9}$ was not responsive to $\mathrm{OAc}^{-}$, while the $\mathrm{N}-\mathrm{Fc}$ exhibited a $-100 \mathrm{mV}$ response in the presence of the same anion. It should be noted that this contrasting responsive behaviour most likely does not arise from a better "communication" between the binding site and the N-Fc but from a pronounced "anion binding switch-on from $29^{2+}$ to $29^{3+"}$ when all three Fc moieties are 
oxidized. The authors furthermore showed that the response of $\mathbf{2 8}$ to the basic anions $\mathrm{HP}_{2} \mathrm{O}_{7}^{3-}, \mathrm{H}_{2} \mathrm{PO}_{4}^{-}, \mathrm{F}^{-}$and $\mathrm{OAc}^{-}$arises from deprotonation. The positively charged triazolium receptors $\mathbf{2 6}$ and $\mathbf{3 2}$ exhibited larger cathodic shift magnitudes towards all tested anions in comparison to their neutral analogues $\mathbf{2 5}$ and $\mathbf{3 1 .}$

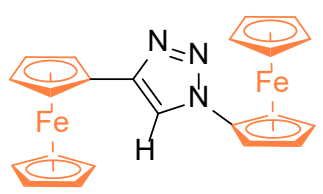

25

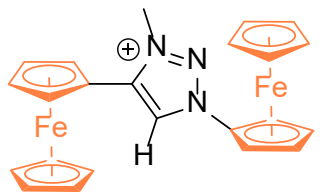

26

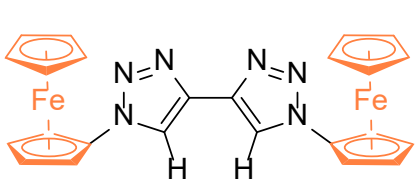

27

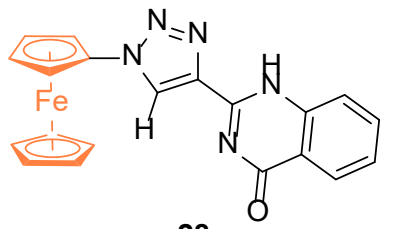

28

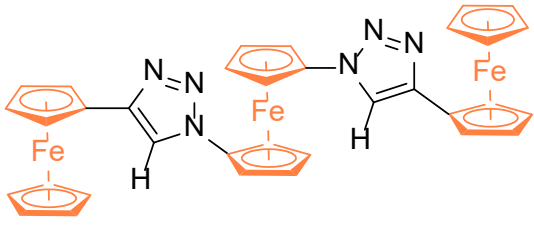

29<smiles></smiles>

30<smiles>c1ccc(-n2cc(-c3cc4ccccc4c4ccccc34)nn2)cc1</smiles>

31

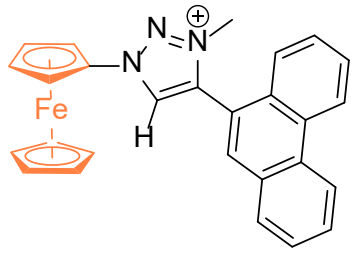

32

Figure 16. Structures of various Fc-triazole receptors.

a)

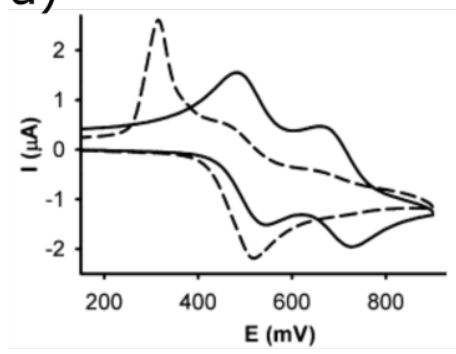

b)

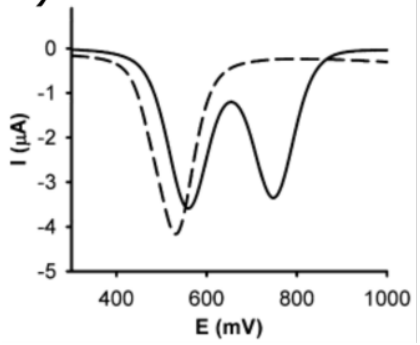

c)

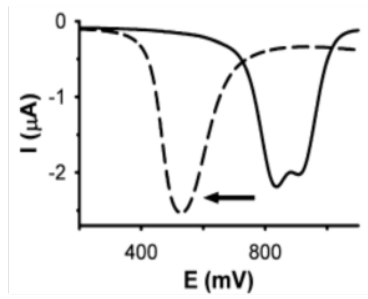

Figure 17. a) $S W V s$ and b) $C V s$ of 25 in $A C N, 0.1 \mathrm{M} \mathrm{TBAPF}_{6}$ (solid lines) and in the presence of $\mathrm{H}_{2} \mathrm{PO}_{4}^{-}$(dashed lines). C) SWVs of 26 in ACN, 0.1 M TBAPF 6 (solid lines) in the presence of a) $\mathrm{H}_{2} \mathrm{PO}_{4}^{-}$(dashed lines). Reproduced with permission from Ref. ${ }^{91}$ Copyright 2013 American Chemical Society. 
The incorporation of Fc and triazoles into macrocyclic structures has also been investigated by White et al. ${ }^{92}$ and Li et al..$^{93}$ who prepared two different macrocyclic receptors and acyclic analogues 33-36 (Figure 18). Large cathodic shifts of up to $-240 \mathrm{mV}$ (for 34) were observed for all receptors in the presence of 2 equiv. $\mathrm{H}_{2} \mathrm{PO}_{4}^{-}$in $\mathrm{DCM}$ with much smaller shifts measured for $\mathrm{Cl}^{-}, \mathrm{F}^{-}$and $\mathrm{OAc}^{-}$(max. $-32 \mathrm{mV}$ for $\mathrm{F}^{-}$with 33).

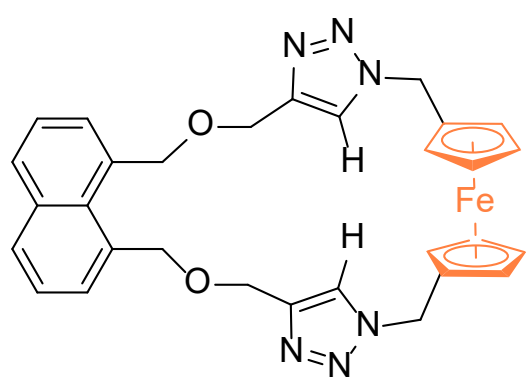

33

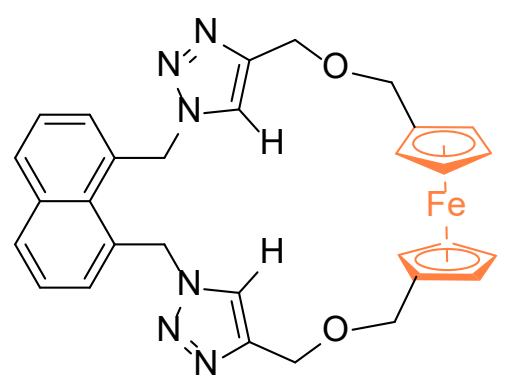

35

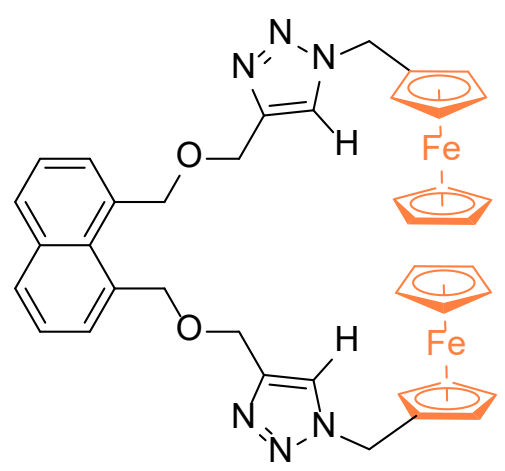

34

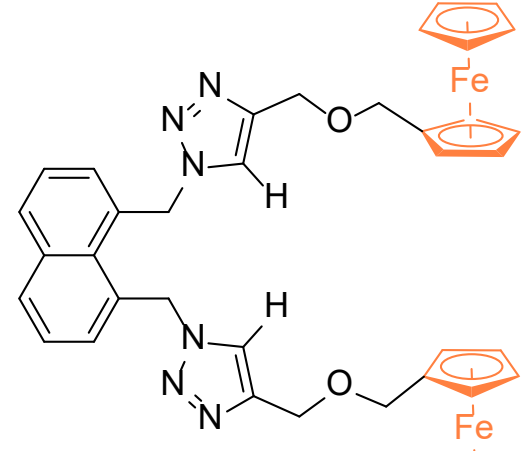

36

Figure 18. Macrocyclic and acyclic Fc-triazole receptors.

Sensing of $\mathrm{H}_{2} \mathrm{PO}_{4}^{-}$and $\mathrm{HP}_{2} \mathrm{O}_{7}{ }^{3-}$ in $\mathrm{DCM}$ was also achieved with a Fc-triazole-modified styrene polymer which, interestingly, showed an enhanced response in comparison to a model monomer and moderate selectivity over $\mathrm{Cl}^{-}$and $\mathrm{Br}^{-} .{ }^{94}$ Another example of a receptor 
exploiting triazole HB donors is a recent report on a Fc-based calix[4]arene 37 (Figure 19). ${ }^{95}$ A selective anodic voltammetric response of the $\mathrm{Fc} / \mathrm{Fc}^{+}$couple was observed for $\mathrm{F}^{-}$in DCM/ACN 1:1, albeit with significant loss of reversibility. This behaviour is analogous to that observed for the similar TTF-appended calix[4]arene receptor $\mathbf{1 0} .^{61}$

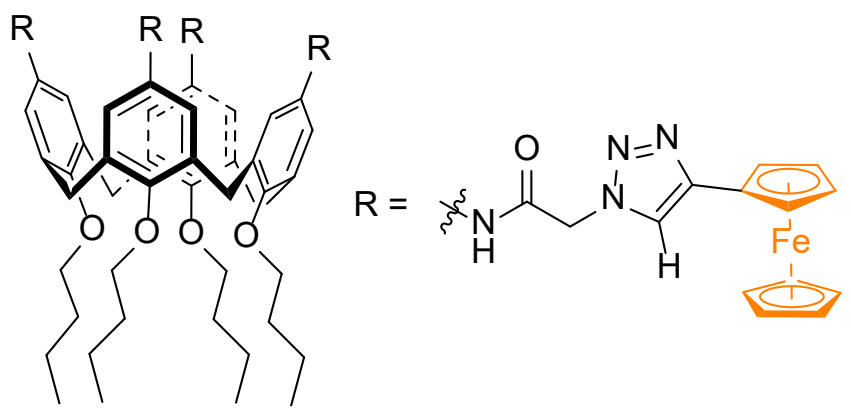

37

Figure 19. Fc-triazole-appended calix[4]arene.

\subsubsection{Redox-active receptors based on C-I halogen-bond donors}

The proto-triazole/triazolium motifs can be modified to the halogen-bonding (XB) 5-iodo1,2,3-triazole and corresponding charge assisted XB triazolium donor analogues which have recently been utilised in anion receptors. ${ }^{96}$ Based on this motif, Beer and coworkers reported the first example of a XB-receptive voltammetric anion sensor in $2015^{97}$ wherein a range of neutral and cationic $\mathrm{XB}$ and $\mathrm{HB}$ receptors were prepared (Figure 20) and studied in $\mathrm{ACN}$. Both receptors 38a and 39a displayed moderate cathodic perturbations in the presence of 10 equiv. $\mathrm{Cl}^{-}\left(-32\right.$ and $-30 \mathrm{mV}$, respectively) and $\mathrm{Br}^{-}(-19$ and $-18 \mathrm{mV}$, respectively) the magnitudes of which were notably much larger for these XB receptors in comparison to the halide cathodic responses of the $H B$ analogues $\mathbf{3 8 b}$ and $\mathbf{3 9 b}$. The $X B$ 1,3-bis-triazoleferrocene receptor $40 \mathrm{a}$, an analogue of receptor 39a, demonstrated selectivity for $\mathrm{N}_{3}{ }^{-}(-40$ $\mathrm{mV}$ ) over $\mathrm{Cl}^{-}, \mathrm{Br}^{-}$and $\mathrm{OAc}^{-}$(max -22 $\mathrm{mV}$ for $\mathrm{Br}^{-}$) in $\mathrm{ACN} / \mathrm{H}_{2} \mathrm{O} 99: 1$ at 10 equiv. ${ }^{98}$ Importantly, the enhanced cathodic responses for all the XB ferrocene receptors mentioned above (in 
comparison to their $\mathrm{HB}$ analogues), was attributed to better electronic communication of anion binding through the XB interaction and/or stronger binding, Molina and coworkers also studied the XB analogue of their previously discussed HB receptor 29 (Figure 16) in ACN/DCM 1:1 where the cathodic response of the XB-sensor in the presence of anions (vide supra) was comparatively smaller in all cases, which is not necessarily a reflection of weaker binding. ${ }^{99}$

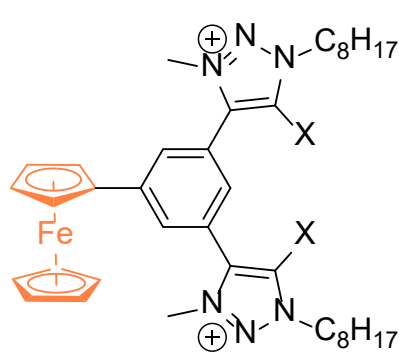

38a: $X=1$

38b: $X=\mathrm{H}$

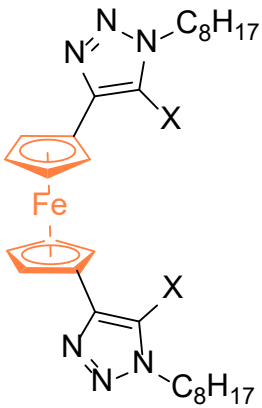

39a: $X=1$

39b: $X=H$
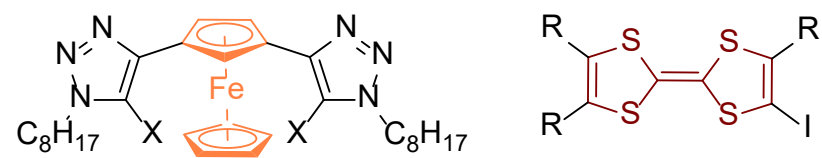

40a: $X=1$

41a: $\mathrm{R}=\mathrm{H}$

40b: $\mathrm{X}=\mathrm{H}$

41b: $R=M e$

Figure 20. Halogen-bonding voltammetric anion sensors based on Fc or TTF.

Recently, Schöllhorn and Fave used halogen-bonding to drive anion recognition at iodomodified TTFs $41 .{ }^{12,100}$ The simple substitution of a $\mathrm{C}-\mathrm{H}$ bond by $\mathrm{C}-\mathrm{I}$ in the TTF core enabled voltammetric sensing of $\mathrm{Cl}^{-}$and $\mathrm{Br}^{-}$in $\mathrm{DMF}$ via cathodic perturbations of both TTF couples. ${ }^{12}$ Importantly, this work is one of the rare examples of a rigorous analysis of electrochemical binding isotherms and binding constants as described above (eqn. 2) with determination of both $\mathrm{K}_{\mathrm{Ox}}$ and $\mathrm{K}_{\mathrm{Red}}$ (rather than just their ratio). Data fitting revealed binding constants of 20

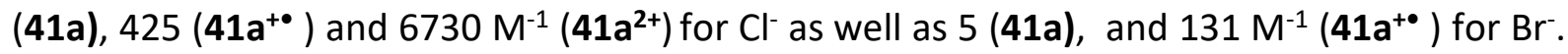
No perturbations of the TTF redox couples were observed in the presence of $\mathrm{NO}_{3}{ }^{-}, \mathrm{OTf}^{-}, \mathrm{ClO}_{4}{ }^{-}$ or for the parent TTF with any of the studied anions. Later in depth studies of the 
methylated iodo-TTF 41b conclusively proved that the observed behaviour can be attributed to the specific halogen-bonding interaction between the receptors and anions. ${ }^{100}$ Furthermore the authors assessed the influence of various other parameters, such as solvent and electrolyte influences and electrode nature and size (all of which are rarely studied) on

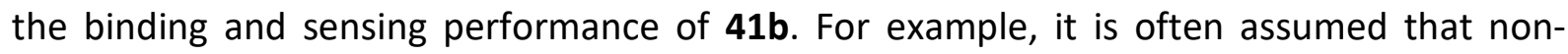
coordinating electrolyte anions do not interfere with anion sensing/binding. However, the authors demonstrated that the electrochemical voltammetric anion sensing performance of the system using different "non-coordinating" electrolyte anions such as $\mathrm{BF}_{4}{ }^{-}, \mathrm{MsO}^{\prime}, \mathrm{TfO}^{-}$, $\mathrm{NO}_{3}^{-}, \mathrm{ClO}_{4}^{-}, \mathrm{PF}_{6}^{-}$or $\mathrm{BARF}^{-}$([tetrakis[3,5-bis(trifluoromethyl)phenyl]borate) can vary significantly. For example, the magnitude of the cathodic shift for $\mathrm{Cl}^{-}$(100 equiv.) in the presence of different electrolytes ranged between -36 and $-49 \mathrm{mV}$ while $\mathrm{K}_{\mathrm{Ox}}\left(\mathrm{K}_{\mathrm{TTF}+\bullet}\right)$ ranged between 180 and $470 \mathrm{M}^{-1}$ and $\mathrm{K}_{\text {Red }}$ was negligible $(<20 \mathrm{mV})$ in all cases. The best performance was observed for BARF- indicating that smaller, commonly used "noncoordinating" anions such as $\mathrm{BF}_{4}^{-}$or $\mathrm{PF}_{6}^{-}$can indeed compete with binding/signal transduction under these conditions. ${ }^{100}$

XB-donors have also been investigated in viologen-based sensors (Figure 18). For example Beer and coworkers incorporated halogen- and hydrogen-bonding triazoles into the diquat motif to afford $\mathbf{4 2}$ which allowed facile sensing of halides in $\mathrm{ACN} .{ }^{101}$ Unsurprisingly, in light of the $X B$ ferrocene receptors, the $X B$ receptor generally outperformed the HB receptor, with cathodic shifts of the $\mathrm{DQ}^{2+} / \mathrm{DQ}^{+\bullet}$ couple of $-80,-30$ and $-10 \mathrm{mV}$ as well as $-40,-15$ and $-20 \mathrm{mV}$ for $\mathrm{Cl}^{-}, \mathrm{Br}^{-}$and $\mathrm{I}^{-}$for $\mathbf{4 2 a}$ and $\mathbf{4 2 b}$, respectively (at 10 equiv.). Recently Schöllhorn and coworkers reported the examination of a similar paraquat-based system $\mathbf{4 3}^{100}$ which exhibited $\mathrm{Cl}^{-}$and $\mathrm{Br}^{-}$induced cathodic shifts of the $\mathrm{PQ}^{2+} / \mathrm{PQ}^{+\bullet}$ of -31 and $-20 \mathrm{mV}$ for $43 \mathrm{a}$ in DMF (100 equiv.), respectively. The HB analogue 43b showed smaller responses of -19 and - 
$10 \mathrm{mV}$, while interestingly the perfluorinated $43 \mathrm{c}$ outperformed $43 \mathrm{~b}$ with shifts of -25 and $12 \mathrm{mV}$. Even phenylsubstituted $43 \mathrm{~d}$ responded to $\mathrm{Cl}^{-}(-19 \mathrm{mV})$, but not to $\mathrm{Br}^{-}$. These observations suggest that $\mathrm{HB}$ interactions are minimal and that the response is mainly driven by electrostatic, anion- $\pi$ and, in the case of $43 a, X B$ interactions.

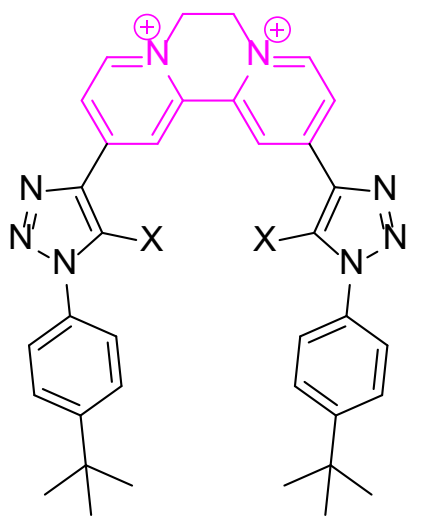

42a: $X=1$

42b: $X=H$

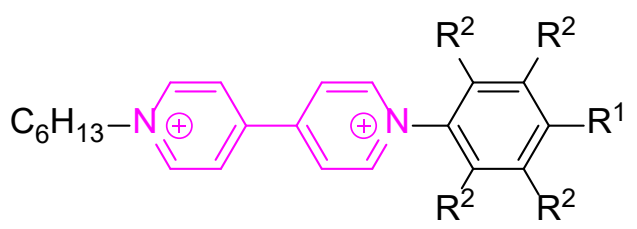

43a: $R^{1}=I, R_{2}=F$

43b: $\mathrm{R}^{1}=\mathrm{H}, \mathrm{R}_{2}=\mathrm{F}$

43c: $R^{1}=R_{2}=F$

43d: $R^{1}=R_{2}=H$

Figure 21. Redox-active halogen- and hydrogen-bonding bipyridinium anion receptors.

\subsubsection{Redox-active receptors based on boranes and boronic acids}

Boronic acids and other boron derivatives have long been employed as potent receptors for diols (e.g. sugars) or hard inorganic anions (e.g. fluoride or cyanide). The latter react with a Lewis-acidic boron centre via formation of a negatively charged, (pseudo)tetrahedral boronate, for example: $\operatorname{ArB}(\mathrm{OH})_{2}+\mathrm{F}^{-} \rightleftharpoons \mathrm{ArB}(\mathrm{OH})_{2} \mathrm{~F}^{-}$. This equilibrium usually lies far to the right and there is a high selectivity for $\mathrm{F}^{-}$over the other halides and other anions. However, depending on reaction conditions and $\mathrm{pH}$, a variety of other equilibria have to be considered, whereby further substitution can occur to yield $\mathrm{ArB}(\mathrm{OH}) \mathrm{F}_{2}{ }^{-}$or $\mathrm{ArBF}_{3}{ }^{-102}$

The first example of a voltammetric fluoride receptor based on a boronic acid was reported in 1995 by Shinkai and coworkers who used ferroceneboronic acid (44, Figure 22) as a simple 
yet effective sensor. ${ }^{103}$ The authors demonstrated that $\mathbf{4 4}$ displayed a cathodic perturbation upon exposure to fluoride in neutral water (up to $-150 \mathrm{mV}$ at $1 \mathrm{M}$ ). Importantly, no significant shifts were observed in the presence of $1 \mathrm{M} \mathrm{Cl}^{-}, \mathrm{Br}^{-}, \mathrm{SCN}^{-}, \mathrm{SO}_{4}^{-}$or $\mathrm{H}_{2} \mathrm{PO}_{4}^{-}$. Similarly, the voltammetric response of cyclic boronic esters 45 and 46 towards $\mathrm{F}^{-}$were studied. ${ }^{104}$ The former showed a large cathodic shift of $\approx-530 \mathrm{mV}$ in the presence of excess $\mathrm{F}^{-}$ in $\mathrm{DCM}$ while the latter underwent hydrolysis to afford the parent calixarene and $\mathrm{FCB}(\mathrm{OH}) \mathrm{F}_{2}$. In order to achieve electrochemical $\mathrm{CN}^{-}$detection the groups of Aldridge and Fallis later also developed the electron-rich borane sensors $47 a$ and $47 b .{ }^{105}$ Sensor $47 a$ responded to $\mathrm{CN}^{-}$in ACN (-560 mV), while also giving a response to $\mathrm{F}^{-}$. Interestingly, additional functionalisation of the lower $\mathrm{Cp}$ ring by permethylation lowered the half wave-potential of $\left[\mathbf{4 7} \mathbf{b} \cdot \mathbf{C N}^{-}\right]$to such a degree that it was oxidised by air, allowing not only electrochemical, but also colorimetric detection of $\mathrm{F}^{-}$and $\mathrm{CN}^{-}$. Other dual-signalling sensors based on Fc-containing boron receptors have also been reported more recently. ${ }^{106-107}$

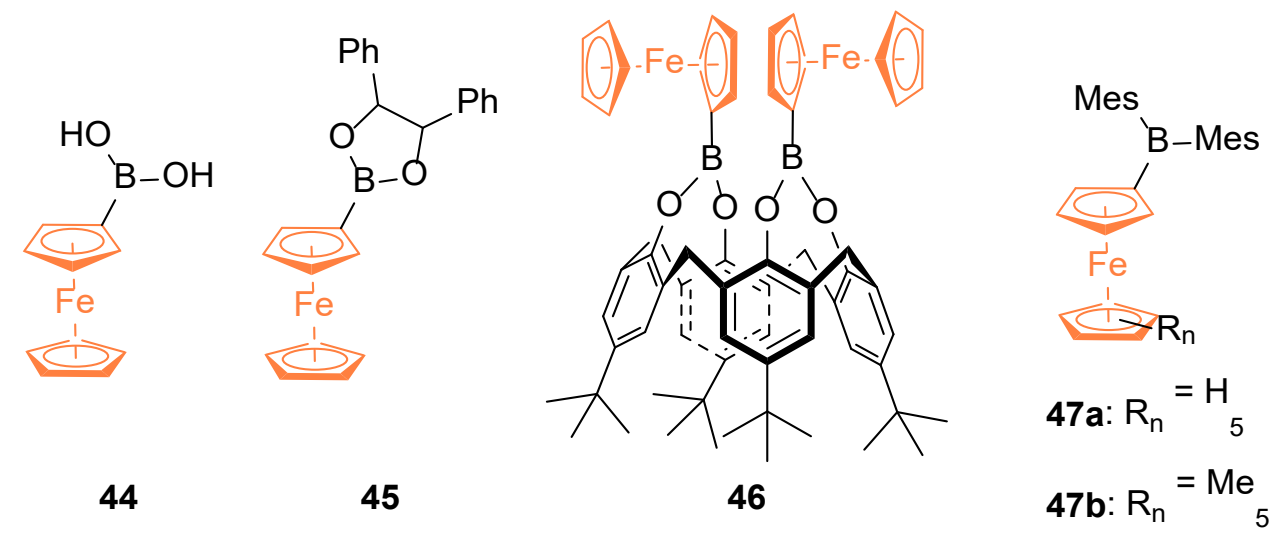

Figure 22. Ferroceneboronic acid and borane based voltammetric anion sensors.

In addition to ferrocene, a variety of other redox-transducers have been incorporated into boron-based receptors. For example, electrochemical and optical detection of $\mathrm{F}^{-}$was achieved with the TTF-appended trimesitylborane 48 (Figure 23). ${ }^{108}$ Addition of 1 equiv. of $\mathrm{F}^{-}$ 
induced a $-60 \mathrm{mV}$ cathodic shift of the first oxidation peak of 48 in THF, with no further changes at higher fluoride concentrations. The second oxidative couple $\left(\mathrm{TTF}^{+\bullet} / \mathrm{TTF}^{2+}\right)$ experienced some cathodic perturbation also, albeit smaller. Interestingly, a monosubstituted derivative of $\mathbf{4 8}$ with only one appended pyrrolo-TTF group displayed significantly different behaviour under the same conditions with the appearance of a new wave, cathodically shifted by $-140 \mathrm{mV}$, for only the oxidation of the first couple. More recently a voltammetric fluoride sensor based on the TTF-vinylogue molecular tweezer 49 was reported. ${ }^{109} \mathrm{CV}$ studies in DCM revealed one quasi-reversible couple which up upon addition of up to 1 equiv. of $\mathrm{F}^{-}$shifted cathodically, by up to $-140 \mathrm{mV}$. Further addition of an additional equivalent of $\mathrm{F}^{-}$induced irreversible oxidation with the appearance of two new waves, one at higher and lower potentials, and a concomitant disappearance of the initial (shifted) anodic wave. This behaviour was rationalised by a conformational change induced by electrostatic repulsion between the boronate moieties resulting in a step-wise oxidation of the receptor. 

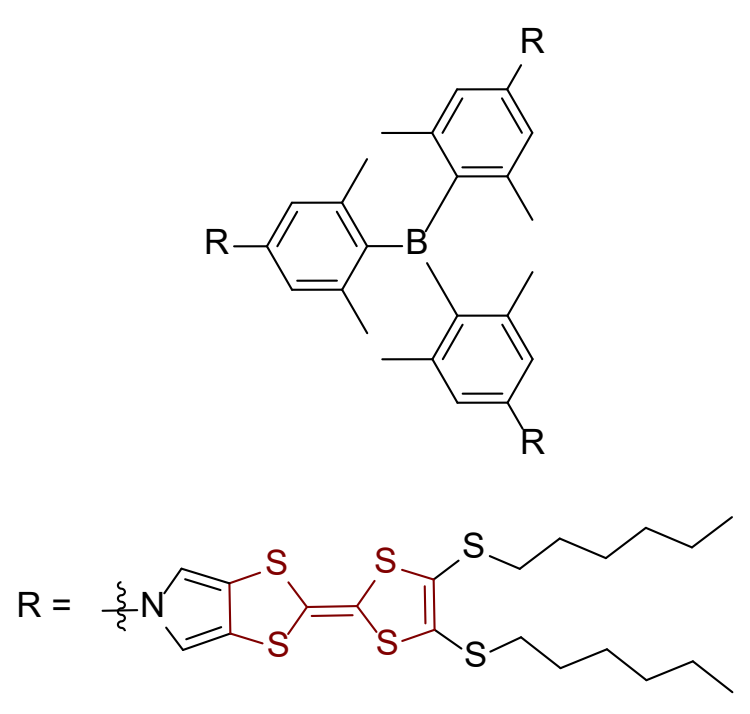

48

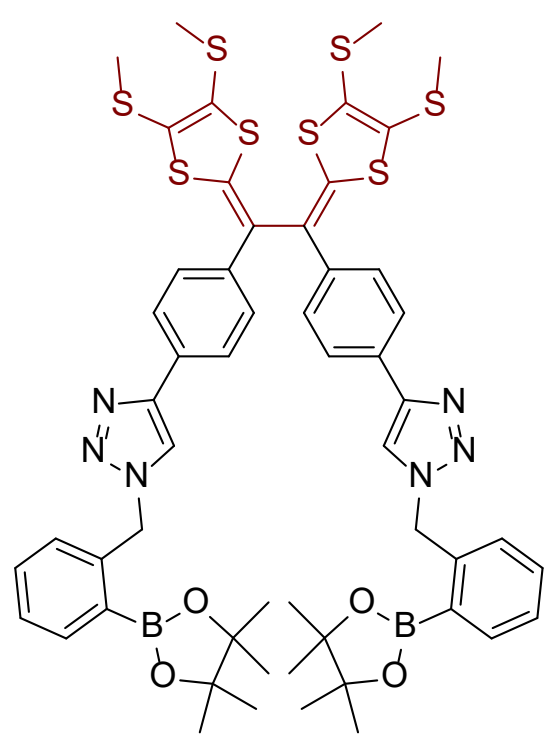

49

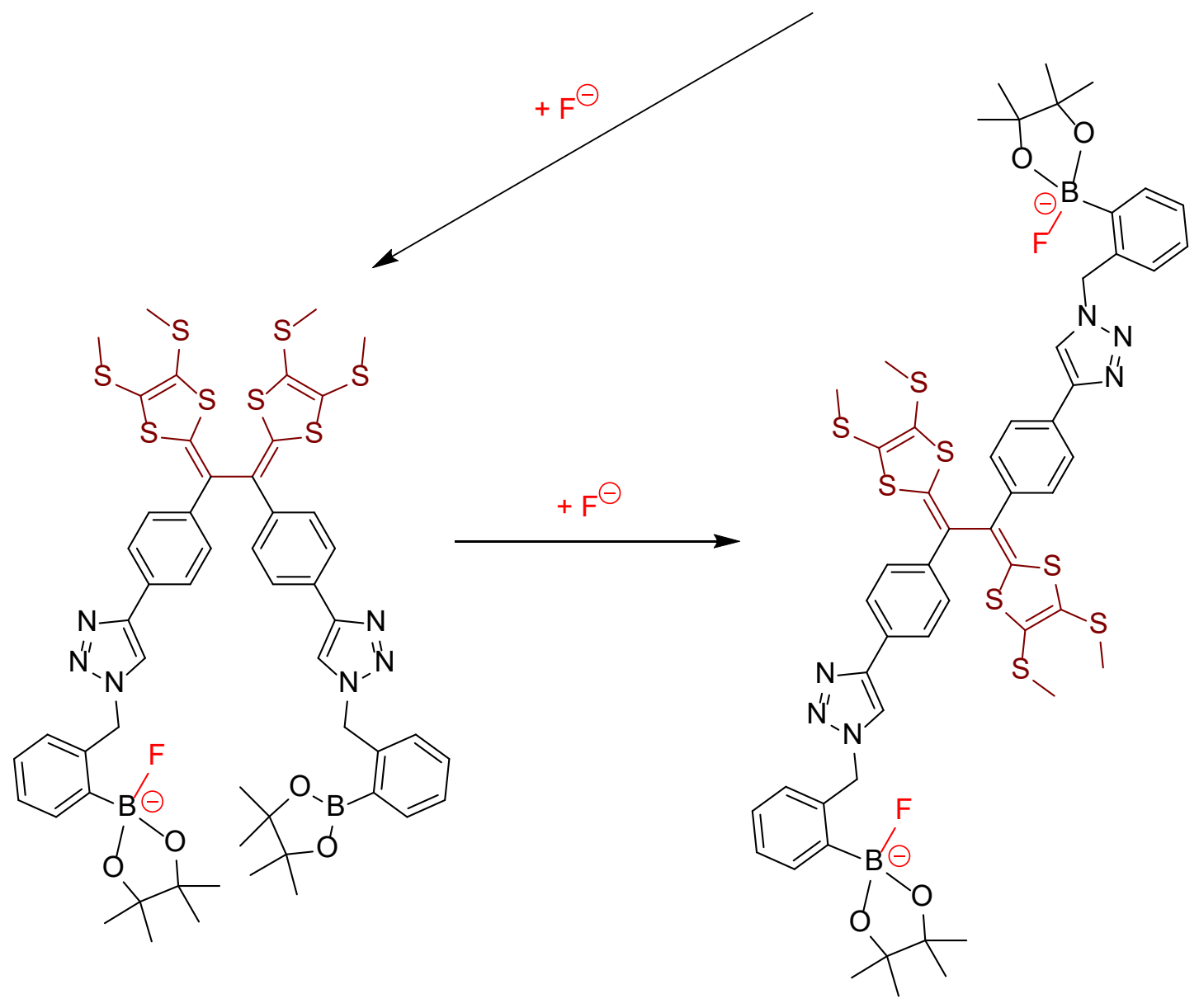

Figure 23. TTF and boron-containing voltammetric receptors for fluoride sensing including the proposed conformational change of molecular tweezer $\mathbf{4 9}$ upon sequential binding of $\mathrm{F}^{-}$. 
In the early 2000s Fabre et al. reported a Fe(tpy) $2^{2+}$ based sensor 50 (Figure 24) for the detection of $\mathrm{F}^{-}$in $\mathrm{MeOH} / \mathrm{H}_{2} \mathrm{O}$ 1:1. ${ }^{110}$ The $\mathrm{Fe}^{2+/ 3+}$ couple shifted cathodically by up to $-160 \mathrm{mV}$ in the presence of $10 \mathrm{mM} \mathrm{F}^{-}$, corresponding to $\mathrm{K}_{\mathrm{Ox}} / \mathrm{K}_{\mathrm{Red}}=560 . \mathrm{Cl}^{-}$elicited a much smaller response of $-20 \mathrm{mV}$ and $\mathrm{Br}^{-}, \mathrm{NO}_{3}{ }^{-}$and $\mathrm{SO}_{4}{ }^{2-}$ induced even smaller perturbations. It should be noted that the binding stoichiometry could not be conclusively determined, but, based on UV-Vis studies the authors suggested $1: 1$ and 1:2 host-guest complex formation. Fabre's group also investigated the sensory properties of the related bipyridyl analogue $\mathbf{5 1}$ in pure aqueous buffer. ${ }^{111}$ Electrochemical fluoride binding studies were then carried out at three different $\mathrm{pH}$ values of $0.5,2.1$ and 3 , whereby the cathodic perturbation in the presence of $20 \mathrm{mM} \mathrm{F}^{-}$was significantly smaller at the lowest $\mathrm{pH}(-100 \mathrm{mV})$ in comparison to $\mathrm{pH} 2.1(-150$ $\mathrm{mV})$ and $\mathrm{pH} 3(-140 \mathrm{mV})$. This is most likely a reflection of the moderate $\mathrm{pK}_{\mathrm{a}}$ of $\mathrm{HF}(\approx 3.0)$ resulting in a significantly lower concentration of free $\mathrm{F}^{-}$at lower $\mathrm{pH}$. This study is an important illustration of the influence of solution phase conditions, such as $\mathrm{pH}$, on the sensing performance of such systems, in particular when employing receptors whose properties are $\mathrm{pH}$ dependent and/or anions that possess moderate $\mathrm{pK}_{\mathrm{a}}$ 's. Further complications for the real-life application of boronic acid based receptors for the sensing of $\mathrm{F}^{-}$is the strong interference from sugars, which have also been shown to elicit a response in many of the discussed boronic-acid based sensors. The immobilization of a derivative of $\mathbf{5 1}$ onto an electrode has also been investigated as discussed in Section 2.4.2.

More recently Gabbaï's group reported another redox-active metal complex $\mathbf{5 2}$ based on a dimesityl boron binding site. ${ }^{112}$ The $\mathrm{Ru}^{2+/ 3+}$ couple possesses a moderate half-wave potential of $+51 \mathrm{mV}$ (vs $\mathrm{Fc} / \mathrm{Fc}^{+}$, in $\mathrm{DMF}$ ) which was observed to shift $-200 \mathrm{mV}$ cathodically in the presence of 1 equiv. of $\mathrm{CN}^{-}$while addition of 1 equiv. of $\mathrm{F}^{-}$induced a more complex behaviour with the appearance of an additional new wave $-240 \mathrm{mV}$ more cathodically 
perturbed (Figure 25). Both waves displayed significantly reduced peak currents, which was further exacerbated by the addition of another 5 equiv. of $\mathrm{F}^{-}$. The authors suggested that this was caused by precipitation of $\mathbf{5 2 \cdot} \cdot \mathbf{F}$ at the electrode. Addition of the $\mathrm{F}^{-}$scavenger $\mathrm{Al}\left(\mathrm{NO}_{3}\right)_{3}$ led to the almost complete recovery of the initial voltammetric behaviour of free $\mathbf{5 2}$ showing that such systems can generally be regenerated, albeit only when stoichiometric quantities of scavengers are used.

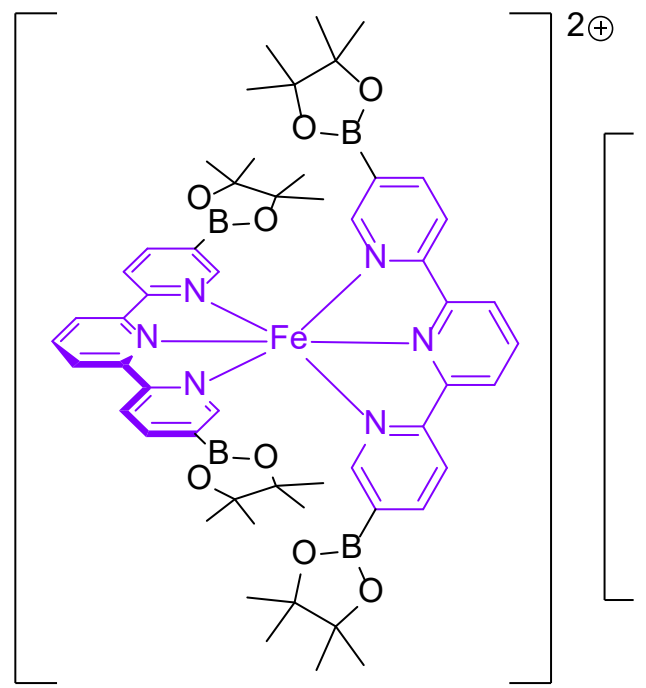

50

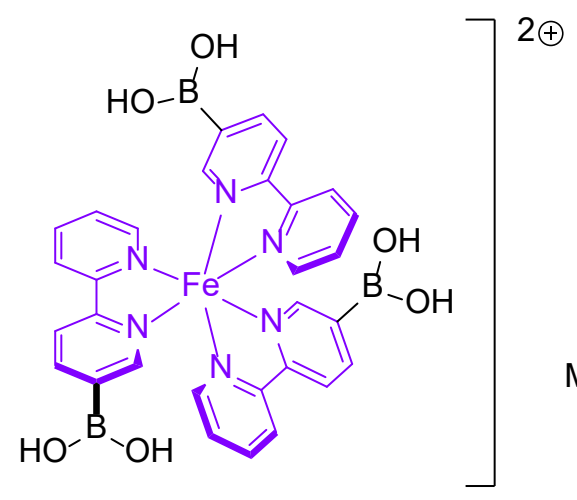

51

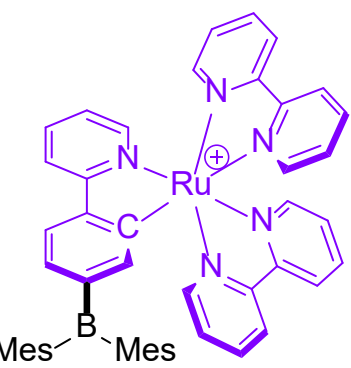

52

Figure 24. Redox-active metal complexes based on boron-containing ligands. 


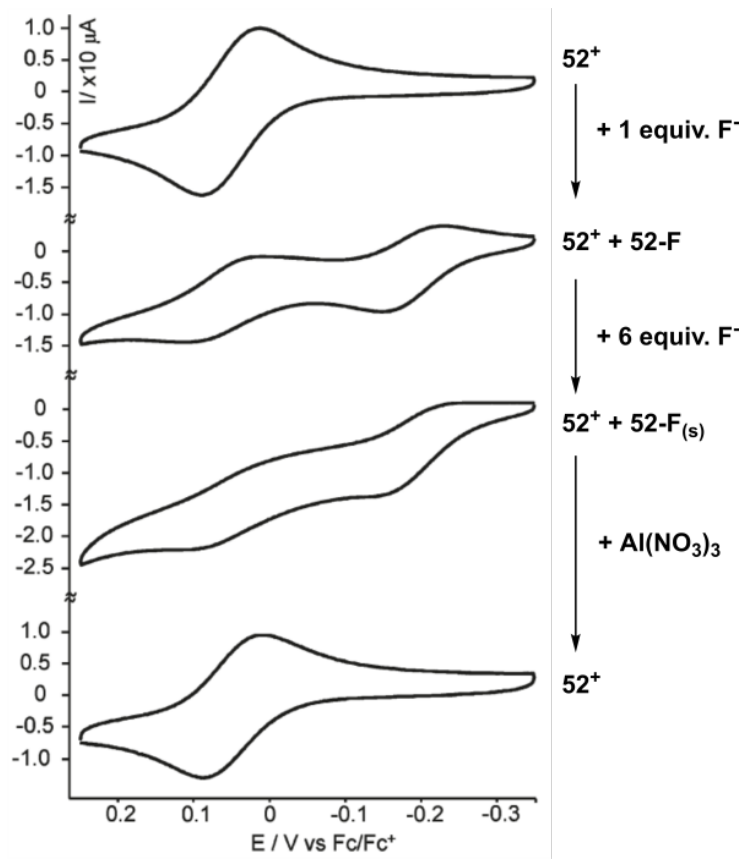

Figure 25. CVs of 52 in DMF, $0.1 \mathrm{M} \mathrm{TBAPF}_{6}$ upon sequential addition of 1 and 6 equiv. of $\mathrm{F}^{-}$and subsequent recovery after addition of $\mathrm{Al}\left(\mathrm{NO}_{3}\right)_{3}$. Reproduced with permission from Ref. ${ }^{112}$ Copyright 2010 American Chemical Society.

Both aforementioned groups have reported the voltammetric behaviour of other organic boron-containing fluoride receptors. For example, the redox response of mono-, di- and triboronic ester substituted triphenylamines 53a-c (Figure 26) were investigated. ${ }^{113}$ All receptors responded to increasing concentrations of fluoride in DCM by a decrease in the peak currents of the original couple and the emergence of a new couple at lower potential. In the case of the di- and trisubstituted $\mathbf{5 3} \mathbf{b}$ and $\mathbf{5 3} \mathbf{c}$ the simultaneous emergence of two and three new waves were observed, respectively, indicating fluoride binding at all boronic ester groups. The third new couple of $53 \mathrm{c}$ was shifted cathodically by $-670 \mathrm{mV}$. The binding enhancement upon one-electron oxidation was large in all cases, in particular for the binding of the first fluoride ion with $\mathrm{K}_{\mathrm{Ox}} / \mathrm{K}_{\mathrm{Red}} \geq 44200$ for all receptors. Vinyl derivatives of these receptors were later also studied for the voltammetric fluoride sensing in solution and at functionalised electrodes. ${ }^{114}$ 
Gabbaï later studied dimesytilboryl naphtalenes 54-56 as voltammetric sensors relying directly on redox processes at the boron centre. ${ }^{115-116}$ For example 54a and 54b displayed two reversible reductive waves at approx. -2.2 and $-2.6 \mathrm{~V}\left(\mathrm{vs} . \mathrm{Fc} / \mathrm{Fc}^{+}\right)$in THF which were attributed to stepwise, one-electron reduction of the two borane moieties, reflective of the coordinative unsaturation. ${ }^{115}$ Incremental addition of up to 1 equiv. of $F^{-}$led to the concomitant, progressive loss of redox reversibility of both waves indicating that $\mathrm{F}^{-}$acts as a bridging ligand and coordinates to both boron centres simultaneously rendering both saturated and redox inactive (a representative crystal structure of the related $\mathbf{5 6}-\boldsymbol{\mu}_{\mathbf{2}}-\mathbf{F}^{-}$can be seen in Figure 27). None of the other halides nor $\mathrm{OAc}^{-}, \mathrm{NO}_{3}^{-}$or $\mathrm{NO}_{2}^{-}$invoked any voltammetric response under the same conditions. A similar voltammetric behaviour was also reported for $\mathbf{5 5}$ whose single reductive couple disappeared after addition of 1 equiv. of $\mathrm{F}^{-}$in THF. ${ }^{116}$ The symmetric diborane $\mathbf{5 6}$ however showed two separate reduction waves indicating strong intramolecular electronic coupling between both boron centres. The addition of 1 equiv. of $\mathrm{F}^{-}$induced the same behaviour as noted above, but only for the more anodic wave, while the other wave shifted cathodically by -50 to $-60 \mathrm{mV}$. Further addition of $\mathrm{F}^{-}$up to 2.25 equiv. induced only modest perturbations, with a small reduction in peak currents, but no full loss of redox activity. This indicates that binding of a second $\mathrm{F}^{-}$bridging ligand is much less favourable than binding of the first $\mathrm{F}^{-}$, in good agreement with the strong electronic coupling between both sites. 


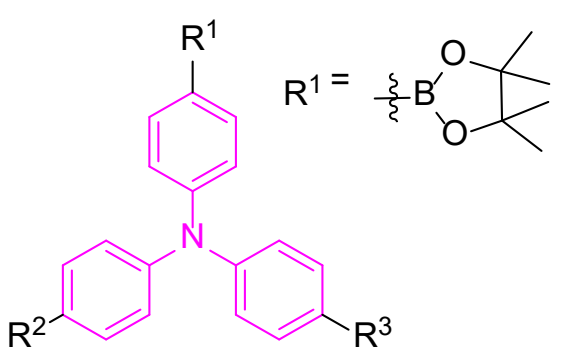

53a: $R^{2}=R_{3}=H$

53b: $R^{2}=R_{1}, R^{3}=H$

53c: $R^{2}=R_{3}=R^{1}$

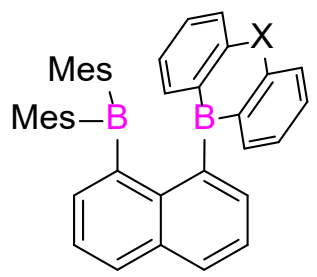

54a: $X=0$

54b: $X=S$<smiles>CB(C)c1cccc2cccc(O)c12</smiles>

55<smiles>C[As](C)c1cccc2cccc(O)c12</smiles>

56

Figure 26. Boron-containing, organic voltammetric anion sensors.

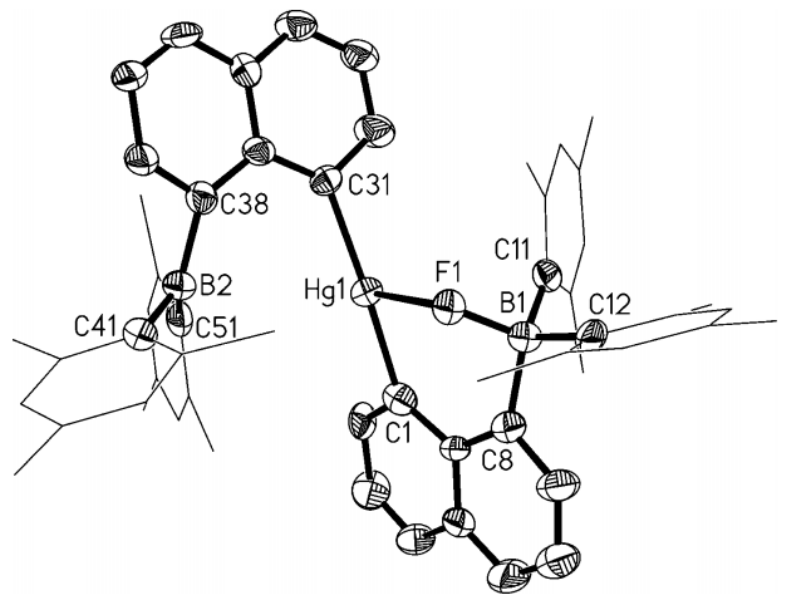

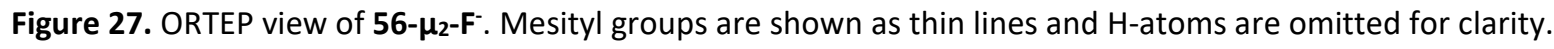
Reproduced with permission from Ref. ${ }^{116}$ Copyright 2008 The Royal Society of Chemistry.

\subsubsection{Redox-active receptors based on other anion binding motifs}

The voltammetric sensing of ATP2- in water has been reported by Reynes et al. employing viologen-functionalised Fc receptors $57-59$ (Figure 28). ${ }^{117}$ Anion recognition was largely driven by electrostatics and charge transfer interactions of the electron rich guest with the 
electron deficient viologens. While the viologen motif itself is also electroactive and could be used as a transducer (see Section 2.3.3) the $\mathrm{Fc} / \mathrm{Fc}^{+}$redox couple was monitored instead (transduction via the viologen was inhibited due to redox associated electrode adsorption). Small cathodic shifts were observed for 57 in the presence of 2 equiv. $\mathrm{HSO}_{4}{ }^{-}, \mathrm{S}_{2} \mathrm{O}_{4}^{-}$and $\mathrm{ATP}^{2-}$ (all -10 mV) and for 58 with $\mathrm{S}_{2} \mathrm{O}_{4}^{-}(-10 \mathrm{mV}), \mathrm{PhPO}_{4}{ }^{2-}(-10 \mathrm{mV})$ and $\mathrm{ATP}^{2-}(-25 \mathrm{mV}$; all in pure water). No response was observed for either receptor in the presence of $\mathrm{H}_{2} \mathrm{PO}_{4}{ }^{-}, \mathrm{HPO}_{4}{ }^{2-}$, $\mathrm{SO}_{4}{ }^{2-}, \mathrm{CF}_{3} \mathrm{COO}^{-}, \mathrm{F}^{-}$or $\mathrm{Cl}^{-}$. The incorporation of pyrrole furnished $\mathbf{5 9}$ which was electropolymerised onto a carbon electrode to give polymeric films. This interface showed an enhanced voltammetric response to the target anions (-35 $\mathrm{mV}$ for $\mathrm{ATP}^{2-},-20 \mathrm{mV}$ for $\mathrm{HSO}_{4}{ }^{-}$ and $-10 \mathrm{mV}$ for $\mathrm{S}_{2} \mathrm{O}_{4}^{-}$at $1 \mathrm{mM}$ ). The voltammetric response of this interface towards ATP $^{2-}$ is illustrated in Figure 29. Further examples and discussions about surface-confined voltammetric receptors can be found in Section 2.4 .

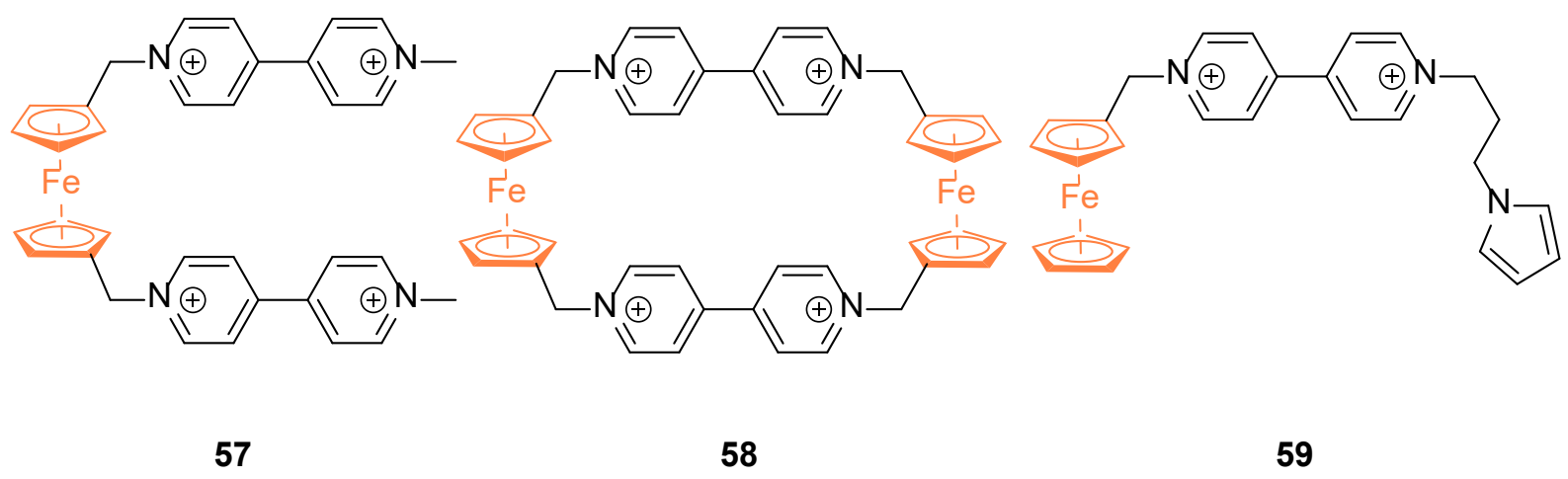

Figure 28. Viologen-Fc conjugates for voltammetric sensing of ATP2- in water. 
a)

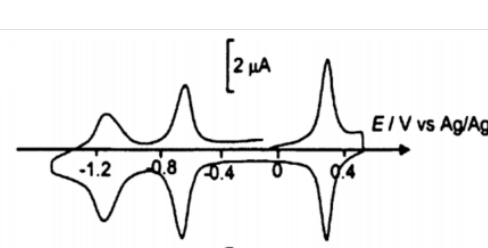

b)

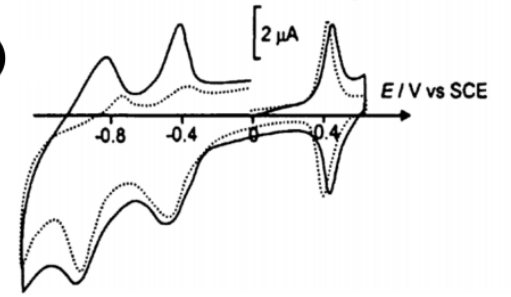

c)

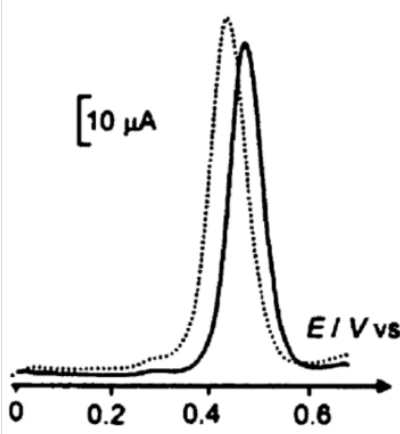

d)

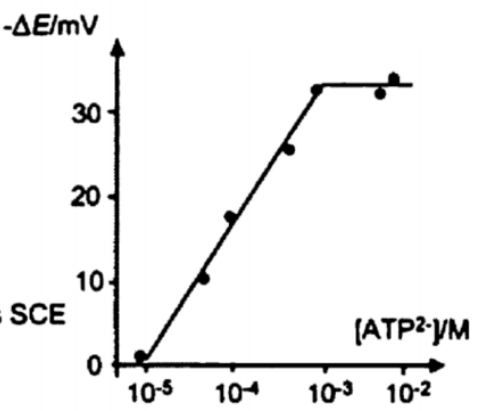

Figure 29. 59 Film $_{\text {on }} \mathrm{GC}$ electrode. a) CV in ACN, $0.1 \mathrm{M} \mathrm{TBAPF}_{6}$. b) and c) CV and SWV in $\mathrm{H}_{2} \mathrm{O}, 50 \mathrm{mM} \mathrm{KNO}_{3}$ without ATP2- (full line) and with 1 mM ATP ${ }^{2-}$ (dotted line). d) The corresponding binding isotherm of ATP2Reproduced with permission from Ref. ${ }^{117}$ Copyright 2004 The Royal Society of Chemistry.

Electrostatically driven anion recognition was also explored by the same group using the ferrocenylmethyl trimethylammonium cation. ${ }^{118}$ This very simple sensor responded not only to $\mathrm{H}_{2} \mathrm{PO}_{4}^{-}$and $\mathrm{ATP}^{2-}$ in DCM with large perturbation of $-470 \mathrm{mV}$ and $-280 \mathrm{mV}$, respectively, but even in the more competitive ACN large shifts of $-300 \mathrm{mV}$ and $-240 \mathrm{mV}$ were observed (all at 1 equiv.). In pure $\mathrm{MeOH}$ only ATP2- induced a modest response of $-30 \mathrm{mV}$. The authors later improved on this design through the incorporation of an additional Zn-porphyrin site to produce 60 (Figure 30). ${ }^{119}$ The additional axial coordination of anions to the $\mathrm{Zn}$-center not only alters the selectivity of this sensor, but also allows additional binding modulation via the redox-active properties of the metallo-porphyrin. The addition of $\mathrm{H}_{2} \mathrm{PO}_{4}^{-}$in $\mathrm{DCM}$ induced significant shifts of the $\mathrm{Fc} / \mathrm{Fc}^{+}$couple $(-240 \mathrm{mV})$, but also led to significant loss of electroactivity of both transducers. In contrast the Fc transducer remained quasi-reversible in the presence of $\mathrm{Cl}^{-}(-130 \mathrm{mV}$ shift). A more interesting behaviour was observed in the presence of $\mathrm{NO}_{3}^{-}$and $\mathrm{HSO}_{4}^{-}$however; both anions induced cathodic perturbation for the $\mathrm{Fc} / \mathrm{Fc}^{+}$as well as the $\mathrm{P} / \mathrm{P}^{+\bullet}$ couple. The former was equally perturbed by both anions $(\approx-80$ $\mathrm{mV}$ at 20 equiv.) while only the $\mathrm{P} / \mathrm{P}^{+\bullet}$ couple showed a larger but different response of -90 
$\mathrm{mV}$ and $-140 \mathrm{mV}$ for $\mathrm{NO}_{3}{ }^{-}$and $\mathrm{HSO}_{4}{ }^{-}$, respectively. The authors reported another interesting observation: the $\mathrm{P}^{+\bullet} / \mathrm{P}^{2+}$ couple, which was initially observed to disappear during the titration, actually coalesces with the $\mathrm{P} / \mathrm{P}^{+\bullet}$ couple to from a new two-electron wave $\left(\mathrm{P} / \mathrm{P}^{2+}\right) .{ }^{119}$ Therefore, in such porphyrin systems consideration should be given that the response of the "first" wave might actually correspond to a two-electron oxidation.

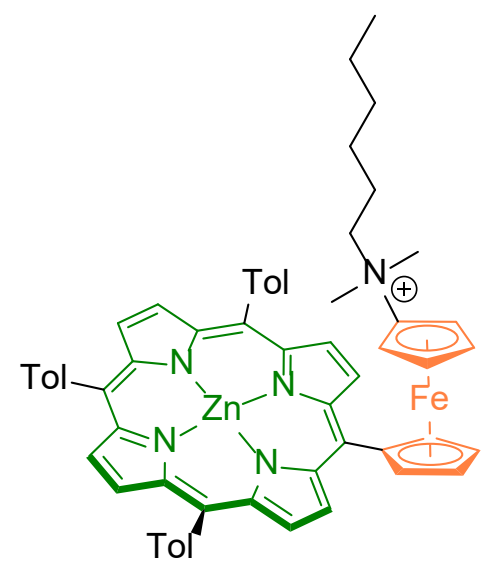

60

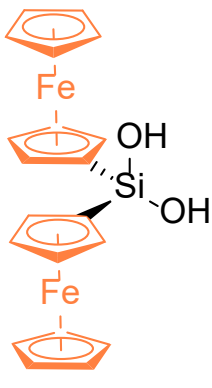

61

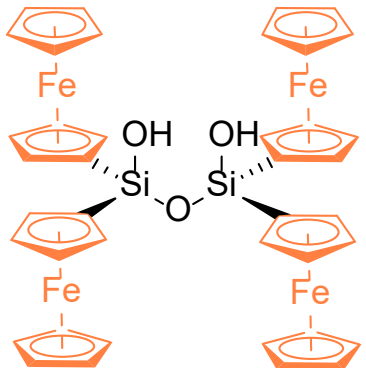

62

Figure 30. Fc-porphyrin-alkylammonium receptor and silanol-functionalised ferrocenes.

Cuadrado and coworkers recently introduced Fc-containing silanols 61 and 62 as an interesting class of novel redox-active anion sensors (Figure 30). ${ }^{120}$ Investigations of 61 in DCM/ACN 1:1 revealed two separate Fc couples that shifted cathodically by -90 and $-100 \mathrm{mV}$ in the presence of 1 equiv. $\mathrm{OAc}^{-}$as shown in Figure 31a-b. Sensor 62 was investigated in DCM/ACN 1:2 showing more complex behaviour with three waves, where upon addition of 1 equiv. OAc the first and second couple merge at a potential that is almost equivalent to the original potential of the first wave $(-60 \mathrm{mV}$ shift for second couple; Figure $31 \mathrm{c}-\mathrm{d})$. The most anodic third wave also shifts cathodically by $-60 \mathrm{mV}$. Addition of $\mathrm{Cl}^{-}$induces cathodic perturbation of both receptors albeit with smaller magnitude $(-40 \mathrm{mV}$ for $\mathbf{6 1}$ and $-\mathbf{2 0} \mathrm{mV}$ for 62 (for the most anodic wave in both cases)). 


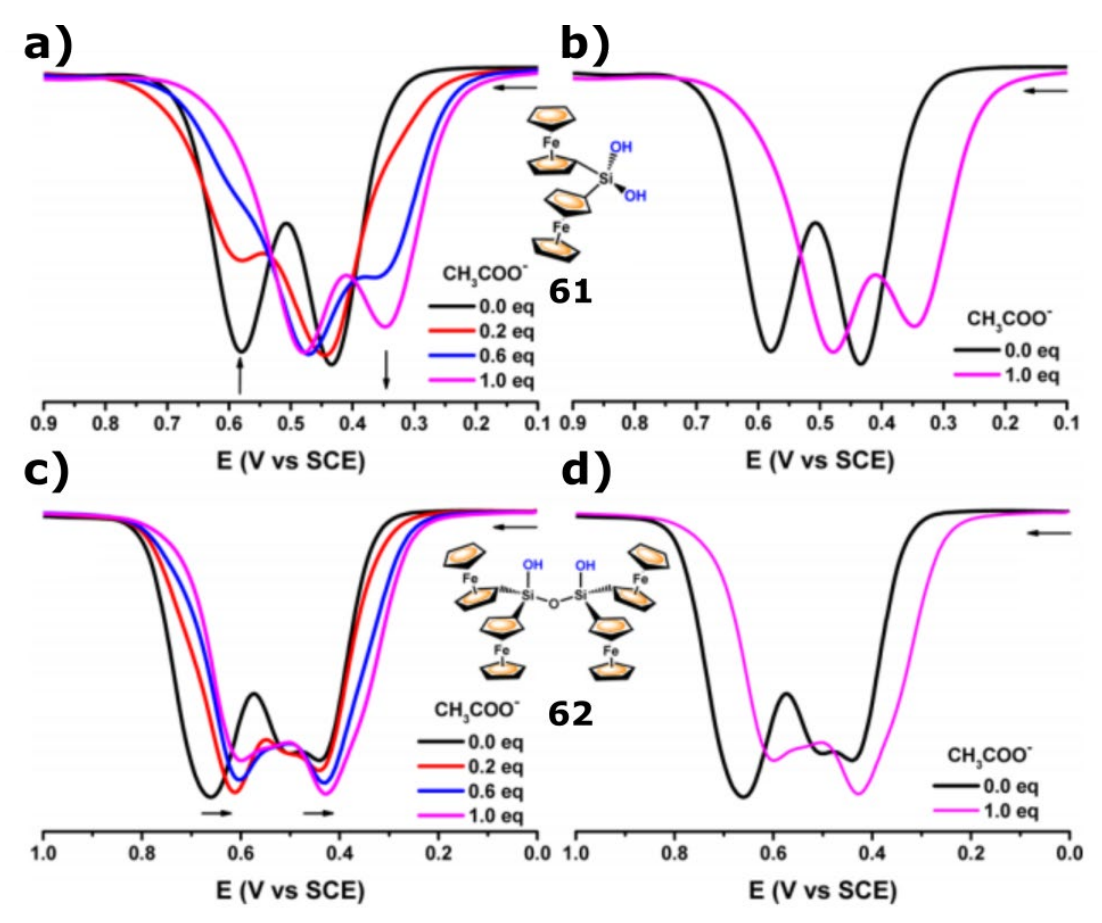

Figure 31. SWVs of a) and b) 61 in DCM/ACN 1:1 and c) and d) 62 in DCM/ACN 1:2 upon addition of OAC:. Reproduced with permission from Ref. ${ }^{120}$ Copyright 2016 American Chemical Society.

\subsubsection{Redox-active mechanically interlocked receptors}

In recent years mechanically interlocked receptors such as rotaxanes or catenanes, have been increasingly studied in the field of anion recognition. ${ }^{8,121-122}$ This can mainly be attributed to their unique 3-dimensional binding cavities, which often not only leads to enhanced anion binding strength, but, importantly, imbues much enhanced selectivities over simpler acyclic or macrocyclic systems. The more intimate three-dimensional control over local dielectric/hydration is also of increasing importance when seeking to conduct anion sensing in competitive (aqueous) media. The first example of a solution-phase redox-tagged interlocked structure for anion sensing was reported by Evans and Beer in 2011, whereby a rotaxane 63 was employed, comprising a pyridinum-bisamide axle and a 5ferrocenylisophtalamide-based macrocycle (Figure 32). ${ }^{123}$ Voltammetric studies in ACN 
revealed significant cathodic perturbations for $\mathrm{Cl}^{-}, \mathrm{H}_{2} \mathrm{PO}_{4}^{-}, \mathrm{BzO}^{-}$and $\mathrm{HSO}_{4}^{-}$of up to $-100 \mathrm{mV}$ (for $\mathrm{H}_{2} \mathrm{PO}_{4}^{-}$at 10 equiv.) while the maximum shift for $\mathrm{Cl}^{-}(-20 \mathrm{mV}$ ) was already observed at 1 equiv. indicative of strong binding. The Fc-transducer has not only been incorporated into the macrocyclic component but has also been used as a stopper in the axle component of a [2]rotaxane $64 .{ }^{124}$ This system displayed a similar behaviour to the previous example, whereby addition of 1 equiv. $\mathrm{Cl}^{-}$in ACN/DCM 1:1 was sufficient to induce plateauing of the response $(-20 \mathrm{mV}$ shift), which was not observed for the axle alone. The relatively small shifts that are observed in these systems are most likely a reflection of the strong binding in the neutral state ( $K_{\text {Red }}$ large) which is not significantly modified through the introduction of an additional charge upon oxidation of Fc moiety. This is not necessarily detrimental in sensing applications, where the overall magnitude of the output is not always important (as long as the output is reproducible and signal-to-noise is low) and is often offset by the largely enhanced selectivities of these interlocked systems.

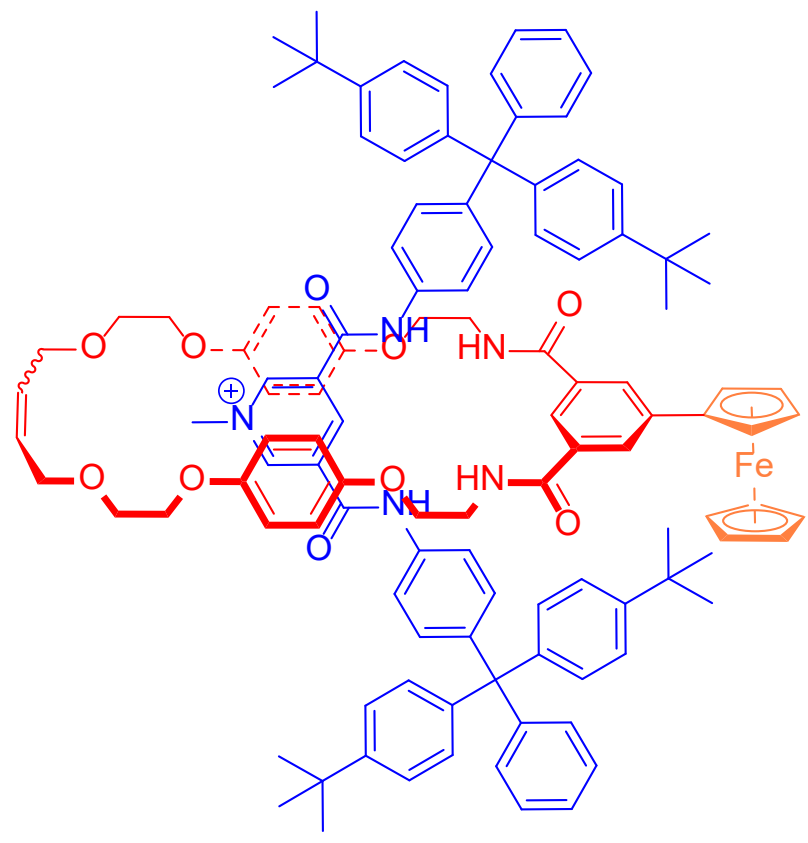

63

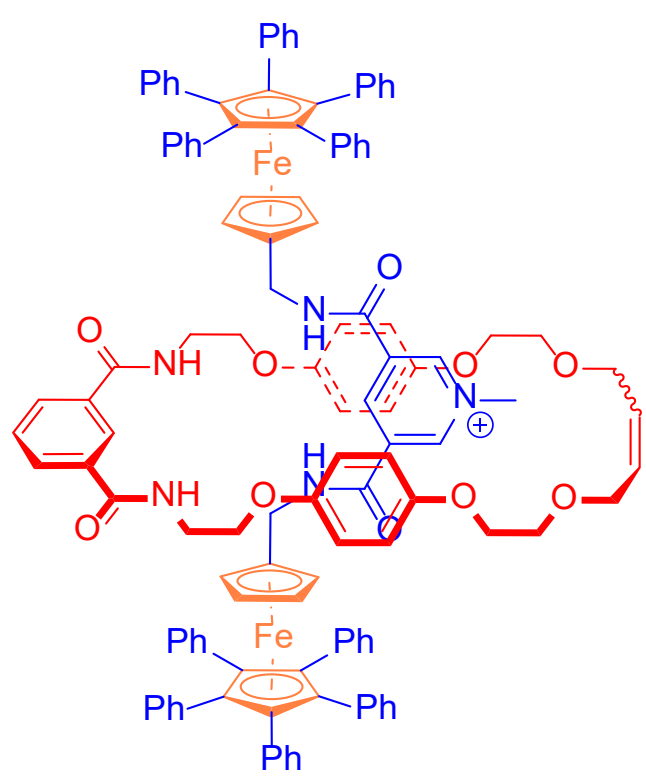

64

Figure 32. Fc-containing [2]rotaxanes. 
The incorporation of a Fc-transducer into the axle of a [3]rotaxane has also been achieved, yielding 65 (Figure 33). ${ }^{125}$ This system displays much larger cathodic perturbation in the presence of $\mathrm{Cl}^{-}(-55 \mathrm{mV}$ at 2 equiv. with negligible further shifts at higher equiv.) indicating that a 1:2 stoichiometric host-guest complex is formed whereby two anions bind in each of the cavities (quantitative binding). A much more complex behaviour was observed in the presence of $\mathrm{SO}_{4}{ }^{2-}$ where, depending on the anion concentration, "two-wave" behaviour (slow exchange) was observed, with shifts of up to $-270 \mathrm{mV}$ (5 equiv.). A similar sensory behaviour towards $\mathrm{Cl}^{-}$as in the previous examples, was also observed for the Fc-containing [2]catenane $66 . .^{126}$ 

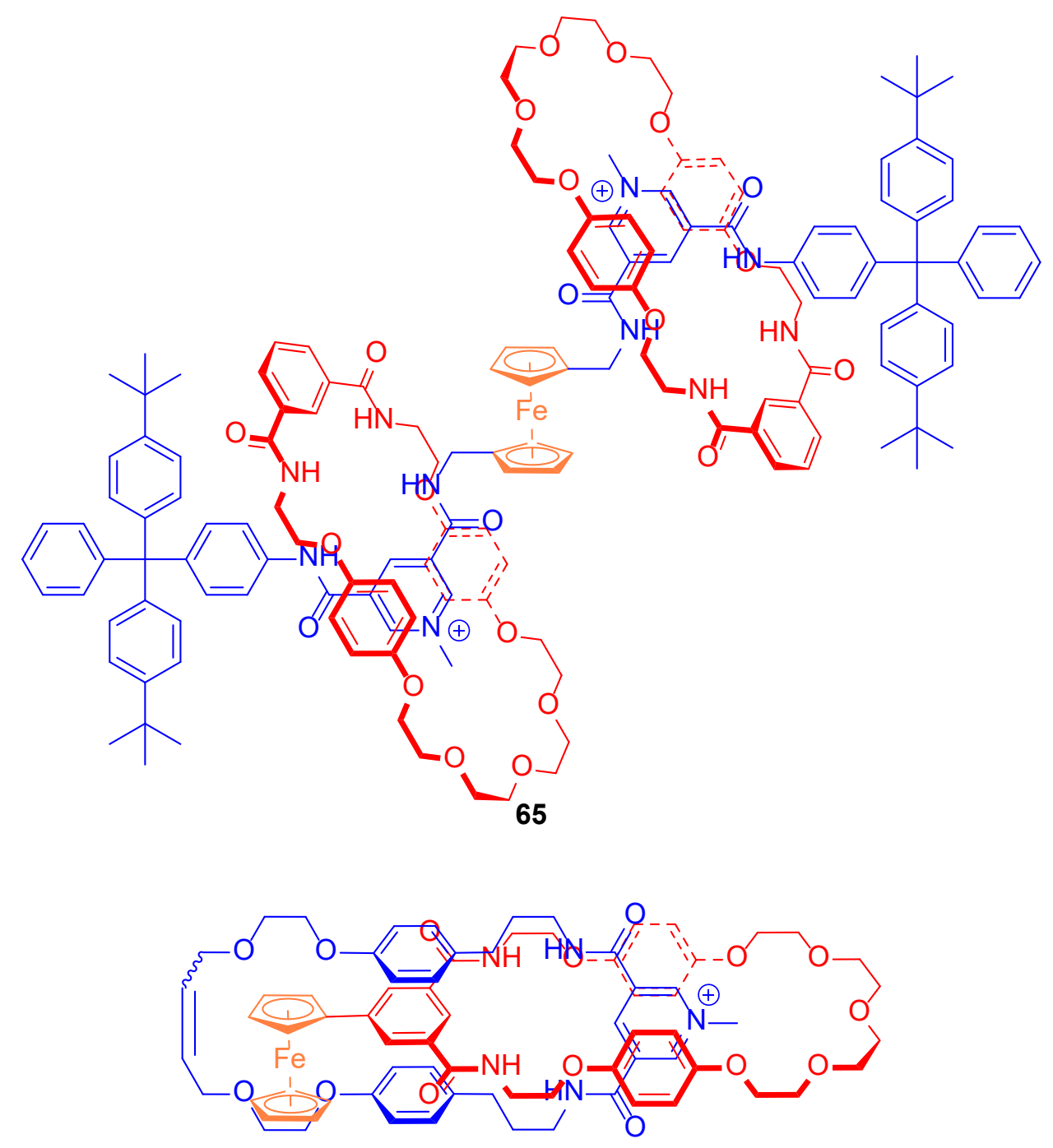

66

Figure 33. Fc-containing [3] rotaxane and [2]catenane.

Lim et al. later also reported a range of neutral redox-active [2] rotaxanes based on a pyridine-N-oxide axle. ${ }^{127}$ Rotaxane 67 (Figure 34) displayed cathodic shifts in ACN/DCM 1:1 that were larger for all tested anions $\left(\mathrm{Cl}^{-}, \mathrm{Br}^{-}, \mathrm{OAc}^{-}\right.$and $\left.\mathrm{H}_{2} \mathrm{PO}_{4}{ }^{-}\right)$than those observed for the macrocycle alone. Recently, a redox-active all-halogen bonding rotaxane 68 was utilised for the selective sensing of $\mathrm{Br}^{-}$over $\mathrm{Cl}^{-}$and $\mathrm{SCN}^{-}$in $\mathrm{ACN} /$ acetone/ $\mathrm{H}_{2} \mathrm{O}$ 45:45:10. ${ }^{128}$ The only non- 
Fc transducer that has been used in voltammetric, interlocked anion sensors is porphyrin which Brown et al. introduced into the axle or macrocyclic component of [2] rotaxanes (as free-base porphyrin). ${ }^{129}$ These sensors are structurally very similar to the Fc-containing [2]rotaxanes 63 and 64, whereby the Fc transducer was replaced with the free-base porphyrin. Preliminary electrochemical studies in DCM/ACN 1:1 revealed cathodic perturbations of the $\mathrm{P} / \mathrm{P}^{+\bullet}$ couple in the presence of 2 equiv. $\mathrm{Cl}^{-}$of -50 and $-25 \mathrm{mV}$ for the porphyrin-stoppered and porphyrin-macrocycle rotaxanes, respectively. 


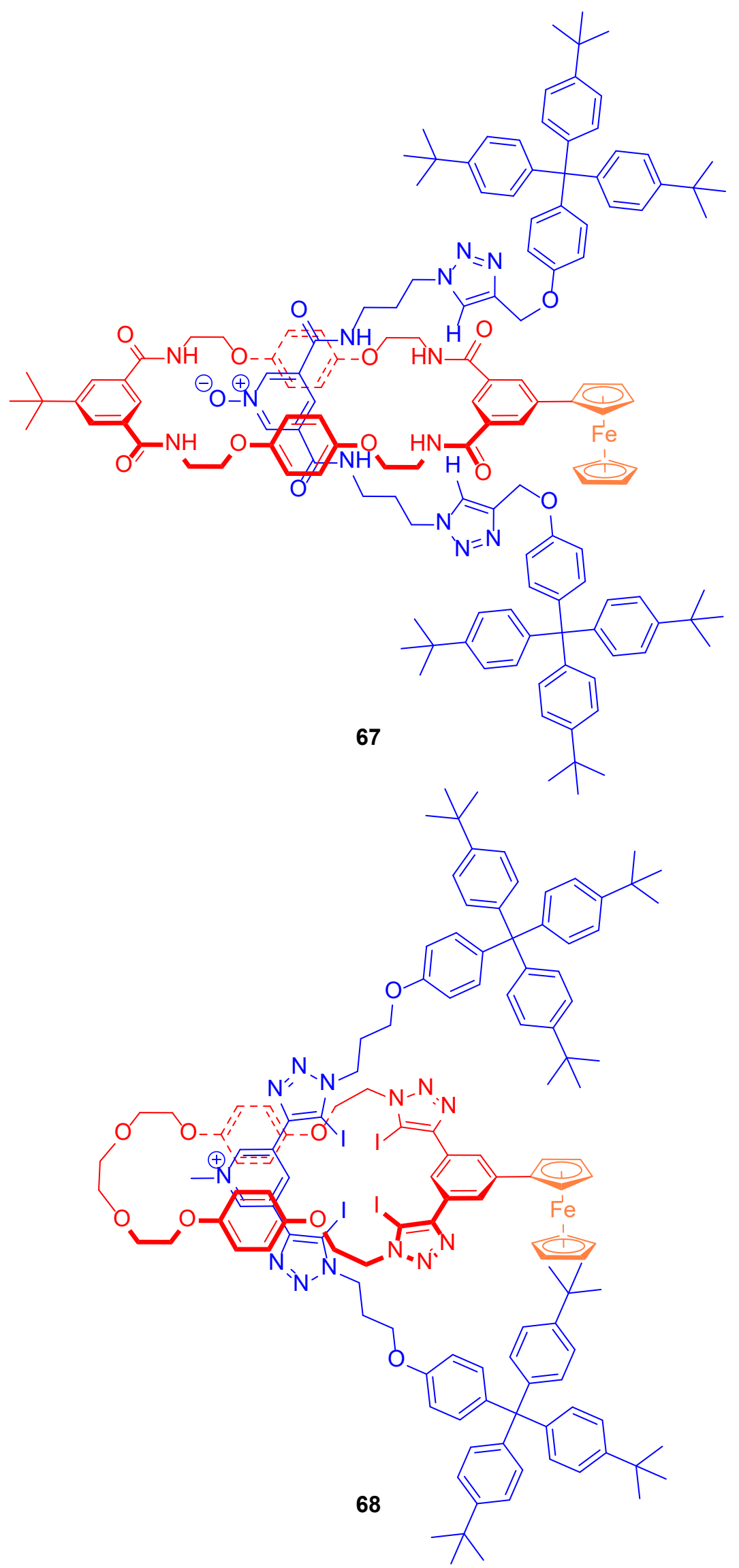

Figure 34. Neutral and all halogen-bonding redox-active [2]rotaxanes. 


\subsubsection{Redox-active dendritic and nanoparticle based sensing configurations}

Dendrimers have found numerous applications in a myriad of fields including catalysis, medicine, imaging and sensing. ${ }^{130-132}$ In 1997 Astruc and coworkers reported the first use of Fc-amide functionalised dendrimers $69-\boldsymbol{n}$ for voltammetric anion sensing (Figure 35 ). ${ }^{133}$ The authors demonstrated that the cathodic shift of these dendrimers in the presence of $\mathrm{H}_{2} \mathrm{PO}_{4}^{-}$, $\mathrm{HSO}_{4}{ }^{-}, \mathrm{Cl}^{-}$and $\mathrm{NO}_{3}{ }^{-}$was strongly dependent on the number of dendrimer branches, with a significantly increased response observed on increasing the number of branches from 1 to 3 , 9 and 18, attributed to cooperative effects. While the non-dendrimeric control compound comprising of one Fc-amide branch only responded to $\mathrm{H}_{2} \mathrm{PO}_{4}^{-}(-45 \mathrm{mV}$ at 1 equiv. per branch in DCM) 69-3 also responded to $\mathrm{HSO}_{4}^{-}(-30 \mathrm{mV})$ and with a much larger response for $\mathrm{H}_{2} \mathrm{PO}_{4}^{-}{ }^{-}$ $110 \mathrm{mV})$. Increasing the number of dendrimer branches allowed for a broader range of anions to be sensed including $\mathrm{Cl}^{-}(69-9)$ and additionally $\mathrm{NO}_{3}^{-}(69-18)$. The cathodic response of 69-18 to $\mathrm{H}_{2} \mathrm{PO}_{4}^{-}$of $-315 \mathrm{mV}$ was seven times larger than that of $69-1$ corresponding to an extremely large binding switch-on of $\mathrm{K}_{\mathrm{ox}} / \mathrm{K}_{\mathrm{Red}}$ of 219000 . These observations show that in addition to electrostatic and other non-covalent interactions (i.e. hydrogen-bonding) local topological effects play a significant role in these systems, which is often rationalised by formation of suitable binding pockets in the higher-generation dendrimers.

Importantly, these and all subsequently discussed redox-active dendrimers display a single redox wave, irrespective of their size (and number of terminal redox groups) and even in very large dendrimers almost all branches are redox active. This indicates that, on the time scale of voltammetric experiments, electron transfer to the whole dendrimer is facile which can be attributed to fast tumbling in addition to electron-transfer between discrete Fcunits. ${ }^{134-135}$ 
Based on their initial work Astruc's group also investigated the analogous cobaltocenium terminated dendrimers $\mathbf{7 0 - 9}$ and $\mathbf{7 0 - 1 8 .} .^{136}$ The former showed, in comparison to $\mathbf{6 9 - 9}$ slightly enhanced cathodic shifts of the $\mathrm{Cp}_{2} \mathrm{Co}^{+} / \mathrm{Cp}_{2} \mathrm{Co}$ couple in the presence of $\mathrm{H}_{2} \mathrm{PO}_{4}{ }^{-}, \mathrm{HSO}_{4}{ }^{-}$and $\mathrm{Cl}^{-}$ . These studies were, due to solubility constraints, conducted in the more polar solvent system ACN/DMF (2:15). Interestingly, the higher generation 70-18 elicited much smaller responses to the same anions (i.e. a negative dendrimeric effect), whereby quantitative analysis was hampered by adsorption and precipitation. The former is a frequently observed problem; especially the larger dendrimers often significantly adsorbed onto the electrode surface. While this can lead to more complex voltammetric behaviour, it can be utilised to form interfacial voltammetric sensors, as discussed in Section 2.4.3. 

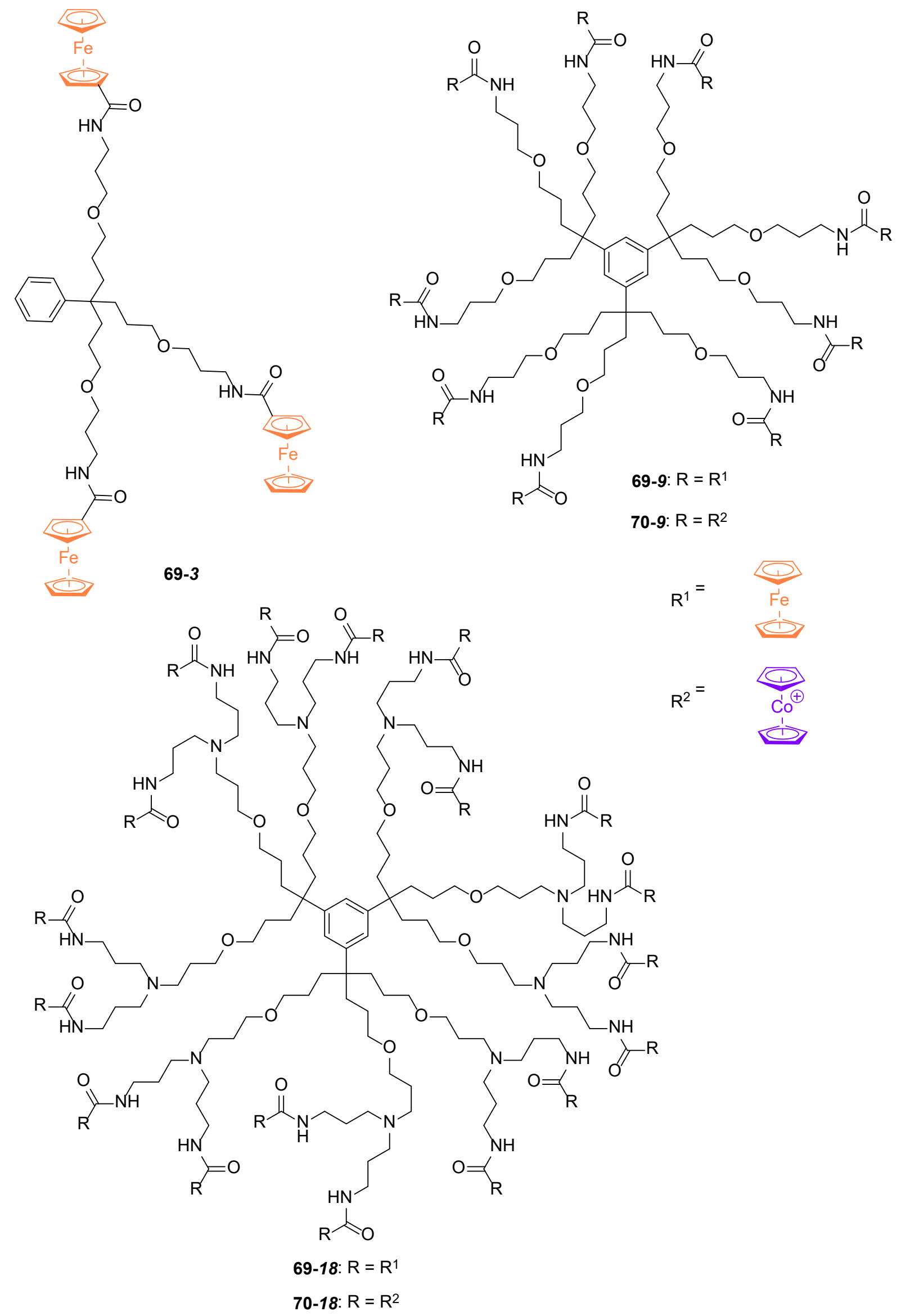

Figure 35. First dendrimeric voltammetric anion sensors based on Fc and cobaltocenium. 
The sensory behaviour of five generations of pentamethylamidoferrocenyl dendrimers 71-n (Figure 36) derived from a polyamine core have been investigated in detail by Daniel et al..$^{137}$ In this work pentamethylation of the Fc transducer was sufficient to significantly reduce decomposition as well as adsorption problems that are observed in the corresponding unmethylated receptor, enabling quantitative binding studies with $\mathrm{H}_{2} \mathrm{PO}_{4}^{-}$in both $\mathrm{DMF}$ and DCM even for the large $G_{4}$ and $G_{5}$ dendrimers 71-32 and 71-64. However, only very small dendrimeric effects were observed; in all cases the cathodic shifts observed were around $150 \mathrm{mV}$, irrespective of solvent or dendrimer generation. Additionally these shifts were significantly smaller than those observed with the parent, unmethylated receptors, which is most easily rationalised by decreased $\mathrm{H}$-bond donor strength due to higher electron-density of 71-n. The response of $\mathbf{7 1 - 4 , 8 , 1 6 , 3 2}$ towards ATP2- in DCM was slightly smaller ( $\approx-130 \mathrm{mV})$, with no significant dendrimeric effect. In comparison to $\mathrm{H}_{2} \mathrm{PO}_{4}^{-}$however, the equivalence point in this case was already reached at 0.5 equiv. of ATP2- per branch, indicating 2:1 complexation between the $\mathrm{Fc}^{*}$-amide and $\mathrm{ATP}^{2-}$. Such a 2:1 binding stoichiometry has also been observed for the monovalent $\mathrm{H}_{2} \mathrm{PO}_{4}^{-}$with the urea-dendrimers $72-4,8,16,32$ in DMSO. ${ }^{138}$ This series of receptors showed complex dendrimeric effects with larger response of 72-8 and 72-16 in comparison to either 72-4 or 72-32. In analogy to the previous examples these sensors also showed good selectivity towards $\mathrm{H}_{2} \mathrm{PO}_{4}^{-}$over $\mathrm{Cl}^{-}$and $\mathrm{HSO}_{4}^{-}$. The sensing of $\mathrm{H}_{2} \mathrm{PO}_{4}^{-}$and $\mathrm{ATP}^{2-}$ has also been carried out with amidoferrocene-terminated dendrimers that have not been assembled covalently, but rather via $\mathrm{H}$-bonding between primary amines and phenols. ${ }^{139-140}$ Another voltammetric $\mathrm{H}_{2} \mathrm{PO}_{4}^{-}$sensor was produced by immobilisation of simple amidoferrocene receptors onto single wall carbon nanotubes (SWNTs) displaying 
large cathodic shifts of $-230 \mathrm{mV}$ in DCM (diffusive conditions), indicating similar cooperative, "dendritic" effects. ${ }^{141}$

An interesting redox-transducer, the tetra nuclear iron cluster $\left[\mathrm{CpFe}\left(\mu_{3}-\mathrm{CO}\right)\right]_{4}$, was incorporated into dendrimers $\mathbf{7 3 - 9 , 1 6 , 2 7}$ which were shown to be competent ATP2sensors. ${ }^{142}$ The reversible one-electron oxidation of $\mathrm{Fe}_{4} / \mathrm{Fe}_{4}{ }^{+}$at potentials close to $\mathrm{Fc} / \mathrm{Fc}^{+}$was used in transduction, where 73-16 showed the largest response to ATP2- in DCM (-170 mV) while the shifts for 73-9 and 73-27 were smaller with $-40 \mathrm{mV}$ and $-110 \mathrm{mV}$, respectively. The smaller response for the larger dendrimer was rationalised by the larger distance between

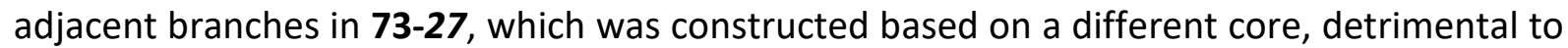
2:1 complexation. However the large 73-27 was better suited for the formation of redoxactive films on Pt electrodes which were used as a reusable ATP2- sensor (see also Section 2.4.3). Interestingly these receptors are the first dendrimer-based voltammetric sensors that display selectivity for ATP2- over $\mathrm{H}_{2} \mathrm{PO}_{4}^{-}$.

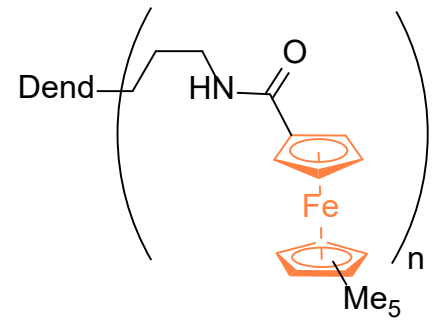

71-n

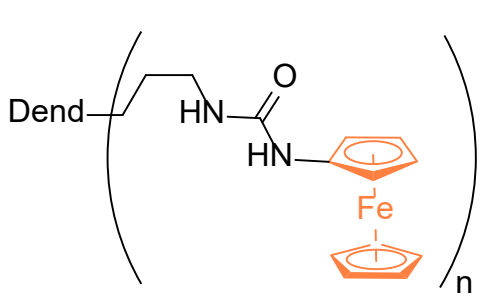

72-n

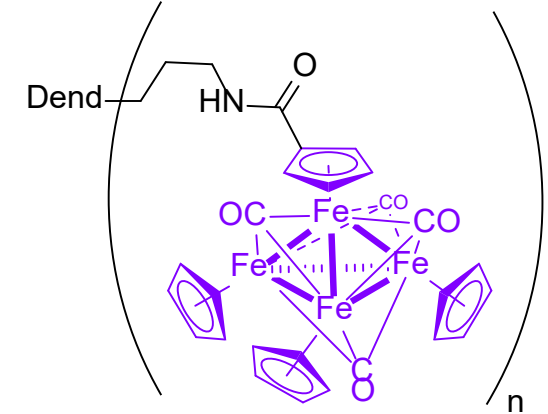

73-n

Figure 36. Amide and urea dendrimers based on different iron-containing transducers.

More recently dendrimers have been assembled via "click" chemistry, significantly expanding their structural diversity. ${ }^{143}$ The 1,2,3-triazole motif can not only be used as an anion binding site, but has also been used for the recognition and sensing of cations through binding via the $\mathrm{N}$-lone pair of the triazole. The first example of a redox-active triazole 
dendrimer was reported by Astruc's group who demonstrated $\mathbf{7 4 - 9 , 2 7 , 8 1}$ as voltammetric sensors for $\mathrm{H}_{2} \mathrm{PO}_{4}^{-}$and $\mathrm{ATP}^{2-}$ and also for $\mathrm{Pd}^{2+}, \mathrm{Pt}^{2+}, \mathrm{Cu}^{2+}$ and $\mathrm{Cu}^{+}$(Figure 37). ${ }^{144}$ In DCM all analytes, apart from $\mathrm{Cu}^{+}$, showed a small, but significant negative dendrimeric effect with the response being largest for 74-9 (up to $-200 \mathrm{mV}$ for for $\mathrm{H}_{2} \mathrm{PO}_{4}{ }^{-}$). However in all cases, the response of 74-27 was still significant (e.g. $-160 \mathrm{mV}$ for $\mathrm{H}_{2} \mathrm{PO}_{4}{ }^{-}$). In a later study the

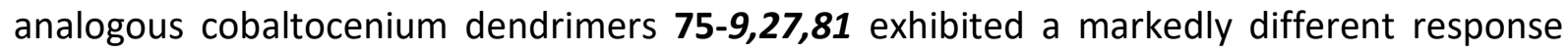
with a positive dendritic effect: only 75-81 responded to $\mathrm{H}_{2} \mathrm{PO}_{4}^{-}(-150 \mathrm{mV}) .^{145}$ However, these latter studies were, for solubility reasons, performed in DMF. In both DMF and ACN these dendrimers showed much poorer reversibility than $\mathbf{7 4}$ with significant adsorption, even for the smaller dendrimers. Fc-dendrimers 76-27,81,243 with a different triazole connectivity also displayed a positive dendritic effect in $\mathrm{DCM}$, however only for $\mathrm{H}_{2} \mathrm{PO}_{4}^{-}(-260$ $\mathrm{mV}$ for 76-243), while ATP ${ }^{2-}$ induced the same response of $-180 \mathrm{mV}$ for all generations. ${ }^{146}$ All receptors showed significant irreversibilities and strong adsorption, with the latter being exploited to form films on Pt. These films showed, in comparison to diffusive sensing conditions, an enhanced response towards $\mathrm{ATP}^{2-}$, with a modest positive dendritic effect (-

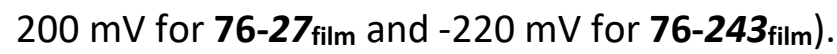

The use of biferrocene as a transducer in the triazole-dendrimers $\mathbf{7 7 - 9 , 2 7 , 8 1 , 2 4 3 , 7 2 9}$ enabled anion as well as cation sensing through different redox couples (Figure 37). ${ }^{147}$ The strong coupling between the Fc groups induced stepwise oxidation, where oxidation of the more electron-rich outer Fc moiety occurs at potentials some $300 \mathrm{mV}$ lower than that of the inner Fc (Figure 38). The addition of ATP2- to 77-81 in DCM caused splitting of the first wave, with appearance of a new wave at lower potentials, indicating electrostatic interactions with the outer Fc (the second wave at higher potentials was highly irreversible). Conversely, upon $\mathrm{Pd}^{2+}$ addition only the inner $\mathrm{Fc}$ was perturbed indicating coordination at the adjacent 
triazole. Such receptors can potentially be exploited for the simultaneous detection of anions and cations if electrochemical reversibility can be retained (see Section 5). $\mathrm{H}_{2} \mathrm{PO}_{4}^{-}$ sensing in DMSO using small biferrocene-amide dendrimers has also been reported by Villena et al. ${ }^{148}$

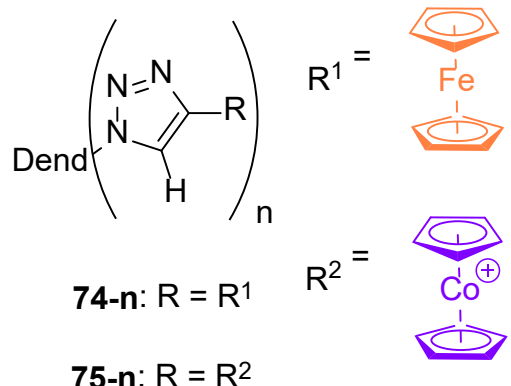

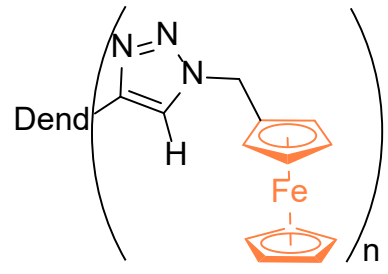

76-n

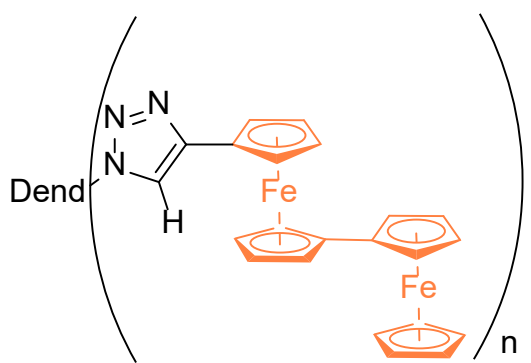

77-n

Figure 37. Metallocene-terminated triazole dendrimers.

a
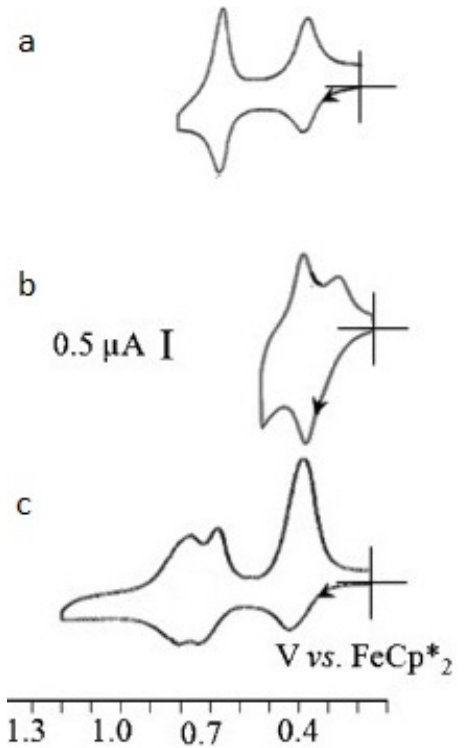

Figure 38. CVs of 77-81 in a) DCM, $100 \mathrm{mM} \mathrm{TBAPF}_{6}$. b) After addition of ATP2- inducing perturbations of the first wave (second wave not shown due to irreversibility). c) After addition of $\mathrm{Pd}^{2+}$ inducing perturbations of the second wave. Reproduced with permission from ref. ${ }^{147}$ Copyright 2010 Wiley-VCH.

In the early 2000s Astruc and coworkers also reported the first redox-receptor modified nanoparticles (NPs) for solution-phase anion sensing. These systems were prepared by 
formation of self-assembled monolayers on gold NPs via thiol-chemistry, akin to the direct electrode modification discussed in detail in Section 2.4. For small NPs these systems are topologically similar to dendrimers and generally display similar behaviour such as enhanced responses over their "Oth" generation monomers/ligands as well as, depending on size and solution phase conditions, often significant adsorption onto the electrode. Advantageously a large number of closely-spaced redox-receptors can easily be introduced into these NPs without additional synthetic steps that are required to form large, higher generation, dendrimers.

In the first report of such a sensor mixed SAMs of dodecanethiol and amidoferrocenylthiols of various length were formed on small Au NPs ( $2 \mathrm{~nm}$ core diameter, Figure 39). ${ }^{149}$ In DCM the reversible Fc couple of $\mathbf{7 8} \mathrm{a}_{\mathrm{AuNP}}$ and $\mathbf{7 8} \mathrm{b}_{\mathrm{AuNP}}$ was cathodically perturbed by $\approx-220 \mathrm{mV}$ in the presence of $\mathrm{H}_{2} \mathrm{PO}_{4}^{-}$. The magnitude of this shift was not only independent of the chain length of the receptor ligands, but, interestingly, also independent on the proportion of this ligand (between 7-38\%) with respect to the diluent $\mathrm{C}_{12}-\mathrm{SH}$ ligand. This is in marked contrast to earlier dendrimeric systems such as $69-3,9,18$ where a significant positive dendrimeric effect was observed (vide supra). This suggests that, even at relatively low receptor loading, cooperative effects can enhance the response of these NP systems and that they resemble large dendritic sensors. In a later study, the influence of the modification of the second Cp ring was studied where it was shown that the response of the permethylated $\mathbf{7 8} \mathrm{c}_{\text {AunP }}$ was significantly smaller $(-130 \mathrm{mV})$, while that of the acetyl-modified $\mathbf{7 8} \mathbf{d}_{\text {AuNP }}$ was larger $(-280$ $\mathrm{mV}$ ), attributed to electronic effects influencing the $\mathrm{H}_{2} \mathrm{PO}_{4}{ }^{-}$anion binding strength. ${ }^{150}$

While $\mathbf{7 8}_{\mathrm{AuNP}}$ also responded to $\mathrm{HSO}_{4}{ }^{-}$, albeit a smaller cathodic perturbation of $\approx-30 \mathrm{mV}$ was observed in comparison to $\mathrm{H}_{2} \mathrm{PO}_{4}^{-}$, the dendrimer functionalised $\mathrm{Au} \mathrm{NP}$ platform 79 $_{\text {AuNP }}$ selectively responded to $\mathrm{H}_{2} \mathrm{PO}_{4}^{-}(-210 \mathrm{mV})$ over $\mathrm{HSO}_{4}^{-}$as well as $\mathrm{Cl}^{-}, \mathrm{Br}^{-}$and $\mathrm{NO}_{3}^{-}$in $\mathrm{DCM}^{151}$ 
An analogous sensor without the amide binding site also displayed a significant response of $110 \mathrm{mV}$ indicating that, akin to many dendrimeric sensors, electrostatic interactions dominate in non-polar solvents. This was then exploited in related non-receptive Fcdendrimer modified Au NPs to sense $\mathrm{H}_{2} \mathrm{PO}_{4}^{-}$and ATP2- ${ }^{2}$. 2 Selectivity of ATP2- over $\mathrm{H}_{2} \mathrm{PO}_{4}{ }^{-}$was later achieved with $\mathrm{Au}$ NPs functionalised with $\left[\mathrm{Fe}_{4}\left(\mu_{3}-\mathrm{CO}\right)_{4}\left(\eta^{5}-\mathrm{C}_{5} \mathrm{H}_{5}\right)_{3}\left(\eta^{5}-\right.\right.$ $\mathrm{C}_{5} \mathrm{H}_{4} \mathrm{CONH}\left(\mathrm{CH}_{2}\right)_{11} \mathrm{SH}$ ] (the same redox-transducer as in 73 ) with a response of $-150 \mathrm{mV}$ and $60 \mathrm{mV}$ in DCM, respectively. ${ }^{153}$

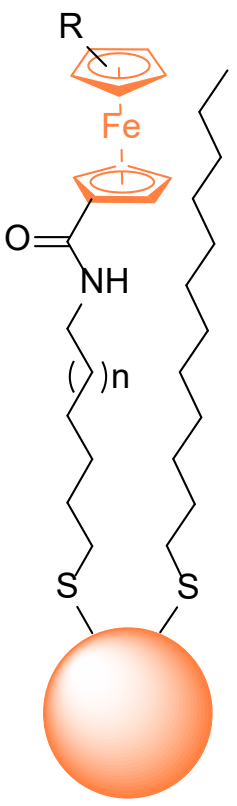

$78 a_{\text {AuNP }}: n=1, R=H$

$78 b_{\text {AuNP }}: n=6, R=H$

$78 \mathrm{c}_{\text {AuNP }}: \mathrm{n}=6, \mathrm{R}=(\mathrm{Me})_{5}$

$78 d_{\text {AuNP }}: n=6, R=(O A c)_{1}$
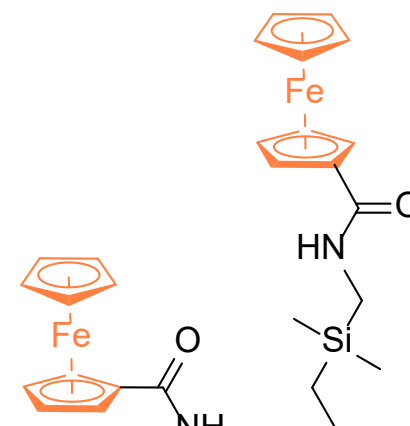

$\mathrm{Si}^{\mathrm{NH}}$<smiles>C[SiH]1CC[SiH]1C</smiles><smiles>CCC[SiH2]C</smiles><smiles>O=[V]</smiles><smiles>C1CCNC1</smiles><smiles>CCCCCCCCCCS</smiles>

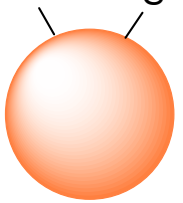

${ }^{79}{ }_{\text {AuNP }}$

Figure 39. Schematic representation of gold nanoparticles modified with mixed SAMs of dodecanethiol and different amidoferrocenyl-containing thiols (for simplicity each ligand is only shown once, the actual ligand ratio is not $1: 1$ ). 


\subsubsection{Redox-active chiral receptors}

Chiral anions, such as $\alpha$-amino carboxylates, play a vital role in a number of physiological processes. Suitably designed comparably simple synthetic receptors and sensors can serve as powerful tools to both detect these species and to elucidate the fundamental processes that govern their chiral influence. ${ }^{154}$ In the early 2000s the groups of Tucker and Moody attempted to prepare a Fc-based chiral anion sensor. ${ }^{155}$ While this system was able to bind and respond to chiral carboxylates, no enantiodiscrimination was observed. The same groups later revisited and improved on their initial receptor design and investigated a range of similar chiral receptors based on Fc-urea derivatives. ${ }^{156}$ Receptor 80 (Figure 40 ) was found to be able to electrochemically differentiate between the enantiomers of N-benzenesulfonyl proline, albeit with very small difference in response in $\mathrm{ACN}$ (cathodic shifts of $-83 \mathrm{mV}$ for the $\mathrm{S}$ enantiomer vs. $-78 \mathrm{mV}$ for $\mathrm{R}$ ). A better voltammetric enantioselective response was achieved more recently utilising the (S)-BINOL-based XB receptor $\mathbf{8 1 .} .^{157}$ This system displayed significantly different cathodic perturbation for the enantiomers of N-Boc-Alanine $(-57 \mathrm{mV}(\mathrm{S}),-63 \mathrm{mV}(\mathrm{R}))$, N-Boc-Leucine (-55 mV (S), -77 mV (R)) and BINOL-phosphate (-55 $m V(S),-38 m V(R))$ in ACN.

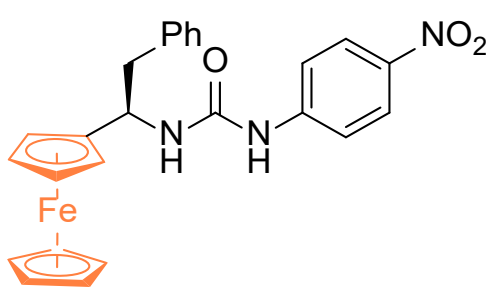

80

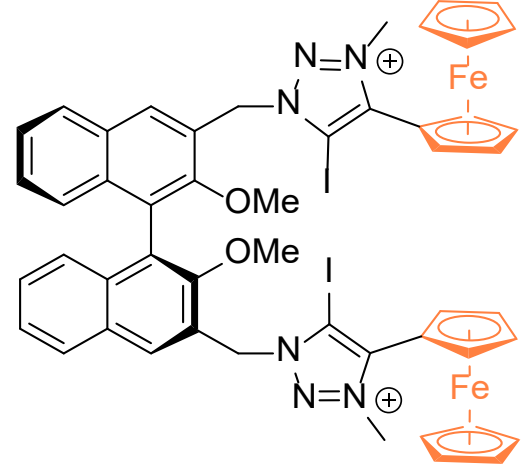

81

Figure 40. Fc-containing receptors for the enantioselective sensing of chiral anions. 


\subsection{Surface-confined voltammetric sensors}

The immobilisation of redox-active (anion) receptors onto conducting (electrode) surfaces is of interest because it facilitates not only continuous anion sensing under flow, but also multiplexed sensing (very difficult to achieve in solution), and the facile integration into various device formats. Anion binding has also been shown to benefit from surface confinement through a combination of receptor preorganisation and cooperative effects. ${ }^{158-}$ ${ }^{159}$ Furthermore, these interfaces can usually be reused after a simple washing step, utilise a much lower receptor-to-target ratio and require a lower quantity of the receptor. Another advantage over solution-phase sensing is that surface-confined receptors do not need to be soluble in the sensing medium. This is particularly relevant when seeking to sense anions in pure water, which, under diffusive conditions, necessitates the introduction of hydrophilic solubilising groups or the use of highly charged receptors, both of which are often synthetically challenging or otherwise undesired, and is reflected in the low number of such sensors that have been prepared that operate in water (see above). However, synthetic efforts have to be invested to facilitate immobilisation of receptors onto electrode surfaces, often by incorporation of suitable anchor groups into the redox-tagged receptors. Additionally, the characterisation of the receptive interface or processes thereat (e.g. binding events) is considerably more difficult than solution-phase studies, where a variety of other techniques (NMR, UV/Vis, fluorescence) are available to obtain supplementary information. Another impediment to voltammetric studies at interfaces is the increased impact of any (redox) instability of immobilised redox groups given the small number of molecules that are being repeatedly probed in any experiment and which cannot be diffusively replenished. In contrast to solution-phase (i.e. diffusive) voltammetry the redox behaviour (and reversibility) cannot be described by the Randles-Sevcik equation, instead 
the peak currents of electroactive films are directly proportional to the scan rate. Furthermore, under ideal conditions, the peak separation $E_{p a}-E_{p c}$ should be 0 (at low scan rates) and the full width at half maximum height (FWHM) is $90 \mathrm{mV}$ (for an exemplary CV of a redox-active films see Figure 43). For further information on electroactive films the interested reader is referred to an excellent review by Meade and coworkers. ${ }^{160}$

Despite some of these complications a variety of redox-active anion receptive films have been successfully utilised as potent voltammetric anion sensors. Most commonly the immobilisation of redox-active receptors is achieved by formation of self-assembled monolayers (SAMs) on gold electrodes through Au-S bonds (from thiols or disulfides), but other approaches have also been employed, as will be discussed in the following sections. As has been the case for solution-phase voltammetric sensors, the most commonly used transducer is Fc.

\subsubsection{SAMs of redox-active anion receptors}

The first example of a SAM-based redox-active anion sensor was reported by Astruc and coworkers in 1999, where a simple amide-containing Fc receptor was self-assembled on gold (82 sam, Figure 41). ${ }^{161}$ This system showed significant cathodic perturbation (-290 $\mathrm{mV}$ ) in the presence of $1 \mathrm{mM} \mathrm{H}_{2} \mathrm{PO}_{4}^{-}$in DCM. However, it was reported that these interfaces were voltammetrically unstable (loss of Fc redox signal after repetitive scanning) and that reversibility was further compromised in the presence of the target anion.

In another early example, sensing of $\mathrm{Cl}^{-}, \mathrm{Br}^{-}$and $\mathrm{H}_{2} \mathrm{PO}_{4}^{-}$was achieved in 2:1 DCM/ACN at 83 sAM containing a FC transducer and amide anion binding sites. ${ }^{162}$ Notably, the presence of 8-9 $\mathrm{mM} \mathrm{H}_{2} \mathrm{PO}_{4}^{-}$induced large cathodic shifts of $-300 \mathrm{mV}$, with smaller, but significant, perturbations being observed for $\mathrm{Cl}^{-}$and $\mathrm{Br}^{-}(-100$ and $-30 \mathrm{mV}$, respectively). Importantly, 
these responses were significantly larger in magnitude than those observed under diffusive conditions (i.e. in solution), which is commonly observed in these interfacial sensors and, in analogy to the previously discussed dendrimeric sensors, can often be attributed to cooperative or topological effects that arise from the high density of adsorbed receptor molecules.

While this and the following examples mainly rely on $\mathrm{N}-\mathrm{H} \mathrm{H}$-bond donors, the voltammetric sensing of $\mathrm{H}_{2} \mathrm{PO}_{4}^{-}$and $\mathrm{ATP}^{2-}$ in $\mathrm{ACN}$ has also been reported at SAMs of simple (FCmethyl)trialkylammonium cations, only relying on electrostatic interactions. ${ }^{163}$

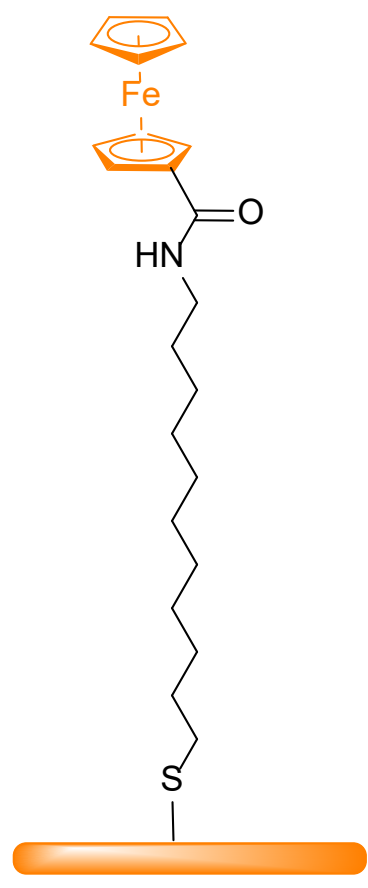

$82_{\text {SAM }}$

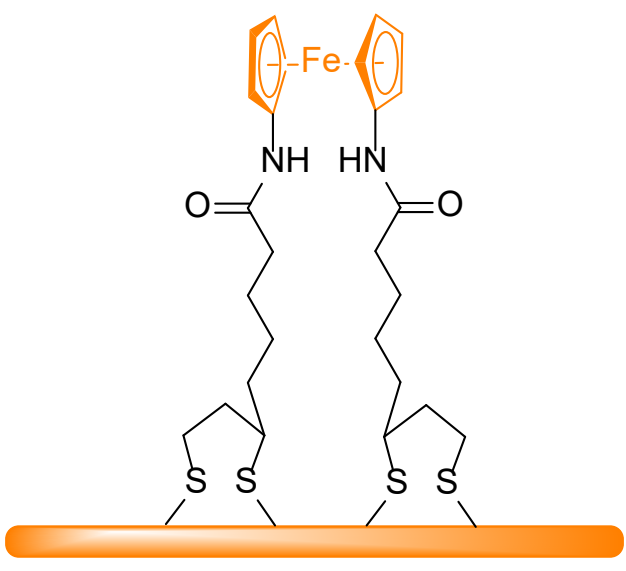

$83_{\text {SAM }}$

Figure 41. Early redox-active anion receptive interfaces.

A more advanced receptor design, 84sAm, based on urea- and amide-modified calix[4]arene was later developed for anion sensing in more competitive solvent systems (Figure 42). ${ }^{164}$ This interface was highly responsive to $\mathrm{H}_{2} \mathrm{PO}_{4}^{-}(-250 \mathrm{mV}), \mathrm{BzO}^{-}(-180 \mathrm{mV})$ and $\mathrm{Cl}^{-}(-120 \mathrm{mV})$ in 
DCM/ACN 1:1 (Figure 43); once again, this response was enhanced in comparison to diffusive sensing under comparable conditions. Interestingly, this interface was also responsive to $5 \mathrm{mM} \mathrm{ReO}_{4}^{-}$in pure water with moderate cathodic perturbations of $-20-30 \mathrm{mV}$ while no such perturbations were observed for other anions. $\mathrm{H}_{2} \mathrm{PO}_{4}^{-}$sensing was also reported at SAMs of a tetraferrocenyl-modified cyclic peptide with a cathodic response ("two-wave" behaviour) of $-200 \mathrm{mV}$ in ACN. ${ }^{165}$

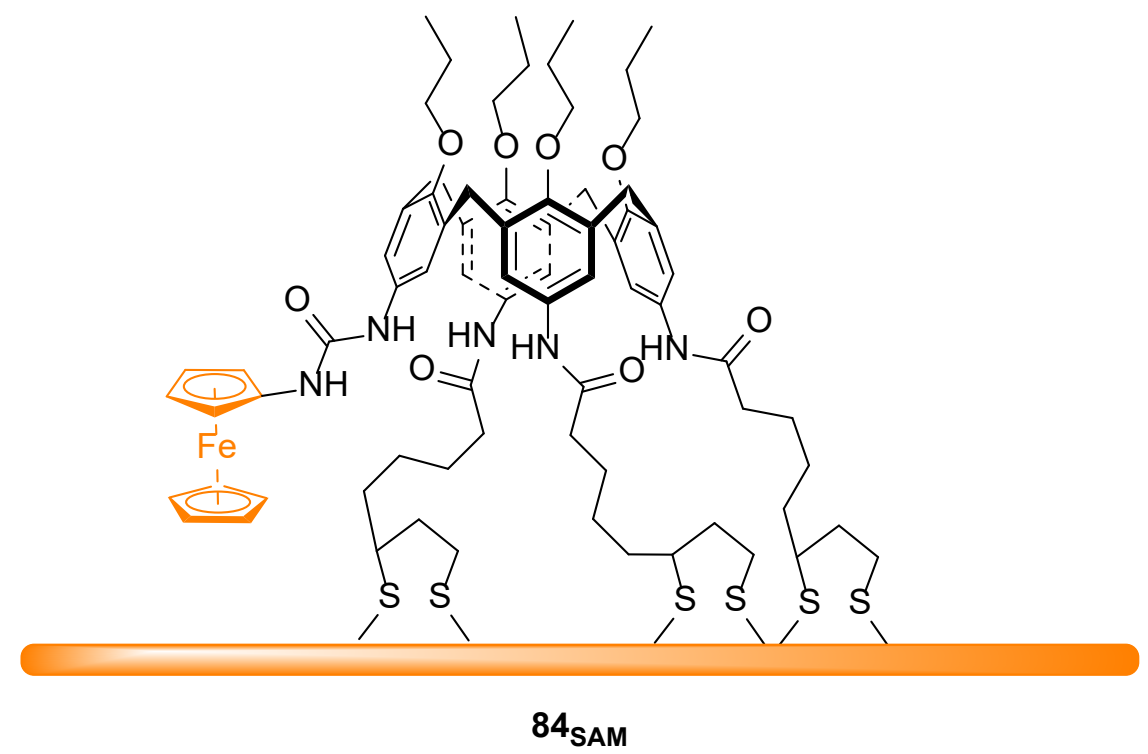

Figure 42. Interfacial calix[4]arene-based voltammetric anion sensor. 


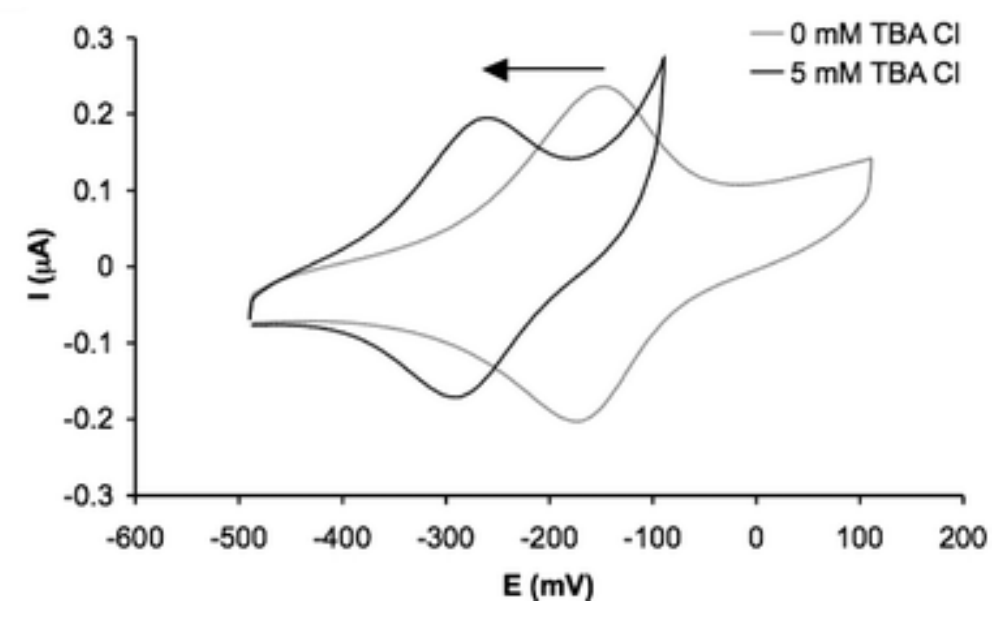

Figure 43. CVs of 84sam on gold electrode in the presence of 0 and $5 \mathrm{mM}$ TBACl. Solvent: 1:1 ACN/DCM containing $100 \mathrm{mM} \mathrm{TBABF}_{4}$. Reproduced with permission from ref. ${ }^{164}$ Copyright 2010 The Royal Society of Chemistry.

Analogous to voltammetric sensors in solution, the use of mechanically interlocked receptors on surfaces has received some attention. The first example, $85_{\text {sAm, }}$ reported in 2007, utilised a surface-confined rotaxane for the selective voltammetric sensing of chloride in ACN (Figure 44). ${ }^{166}$ This structure was assembled via exposure of gold to a redox-active pseudo-rotaxane containing $\mathrm{Fc}$ in both the axle (as a stopper) as well as the macrocycle. Importantly, only minor cathodic perturbations $(<-10 \mathrm{mV})$ were observed for a variety of anions to SAMs of the axle alone or for the axle in solution. Diffusive studies of the macrocycle revealed a response to $\mathrm{H}_{2} \mathrm{PO}_{4}^{-}(\approx-45 \mathrm{mV})$ and $\mathrm{HSO}_{4}^{-}(\approx-15 \mathrm{mV})$ but small perturbations for $\mathrm{OAc}^{-}$and $\mathrm{Cl}^{-}(<-10 \mathrm{mV})$. Only in the surface-confined rotaxane does the macrocycle-Fc show a significant response to $\mathrm{Cl}^{-}(\approx-40 \mathrm{mV}$, with good sensitivity (LOD of 0.2 $\mu \mathrm{M})$ ) while being unresponsive to the other oxoanions, clearly highlighting the important role of the interlocked anion binding cavity for the selective response of chloride over larger anions such as dihydrogenphosphate. 


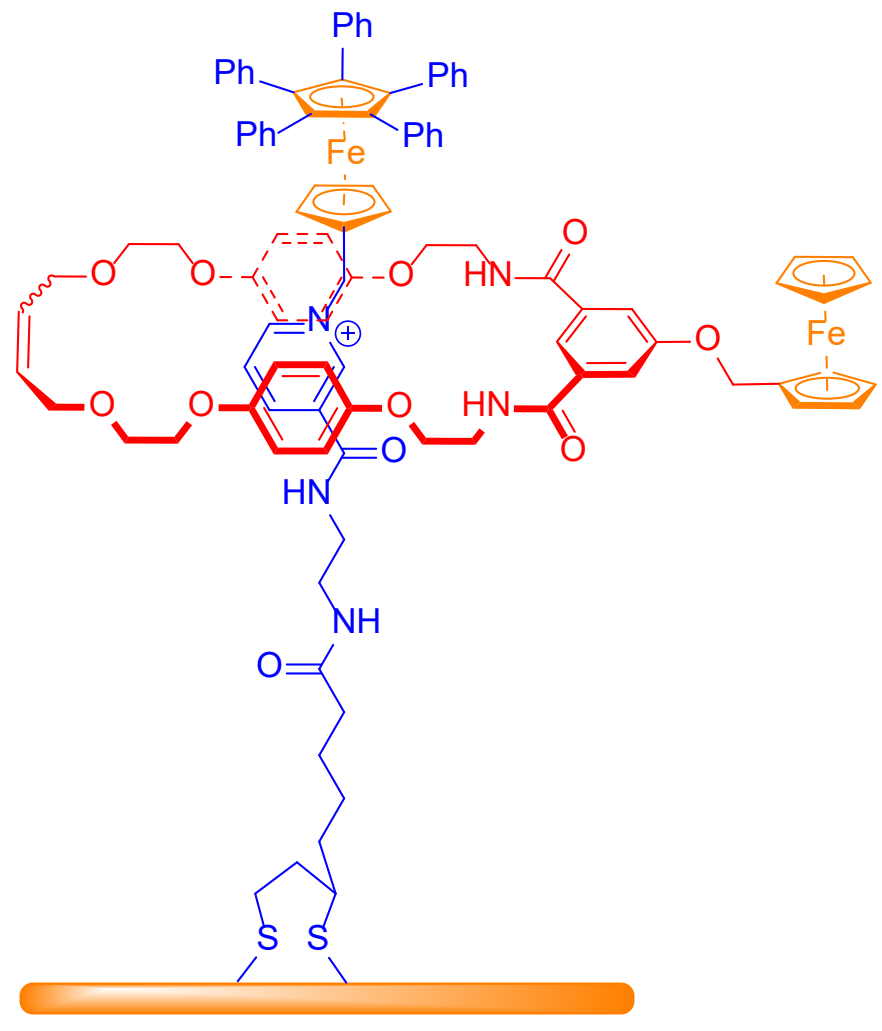

$8_{\text {SAM }}$

Figure 44. Redox-active SAM based on interlocked rotaxane containing two Fc transducers.

A redox-active surface-confined rotaxane sensor based on the $\mathrm{Os}^{2+/ 3+}$ bipyridyl redox couple has also been reported (86 $\mathrm{SAM}$, Figure 45$){ }^{72}$ In contrast to the previous examples, immobilisation of the interlocked receptor was achieved via click reaction of an alkyneterminated SAM with an azide-functionalised pseudo-rotaxane. The osmium-couple was then exploited as a transducer for chloride binding in ACN with modest perturbations (-14 $\mathrm{mV}$ at $50 \mu \mathrm{M} \mathrm{Cl}^{-}$), but good selectivity over $\mathrm{OAc}^{-}$. 


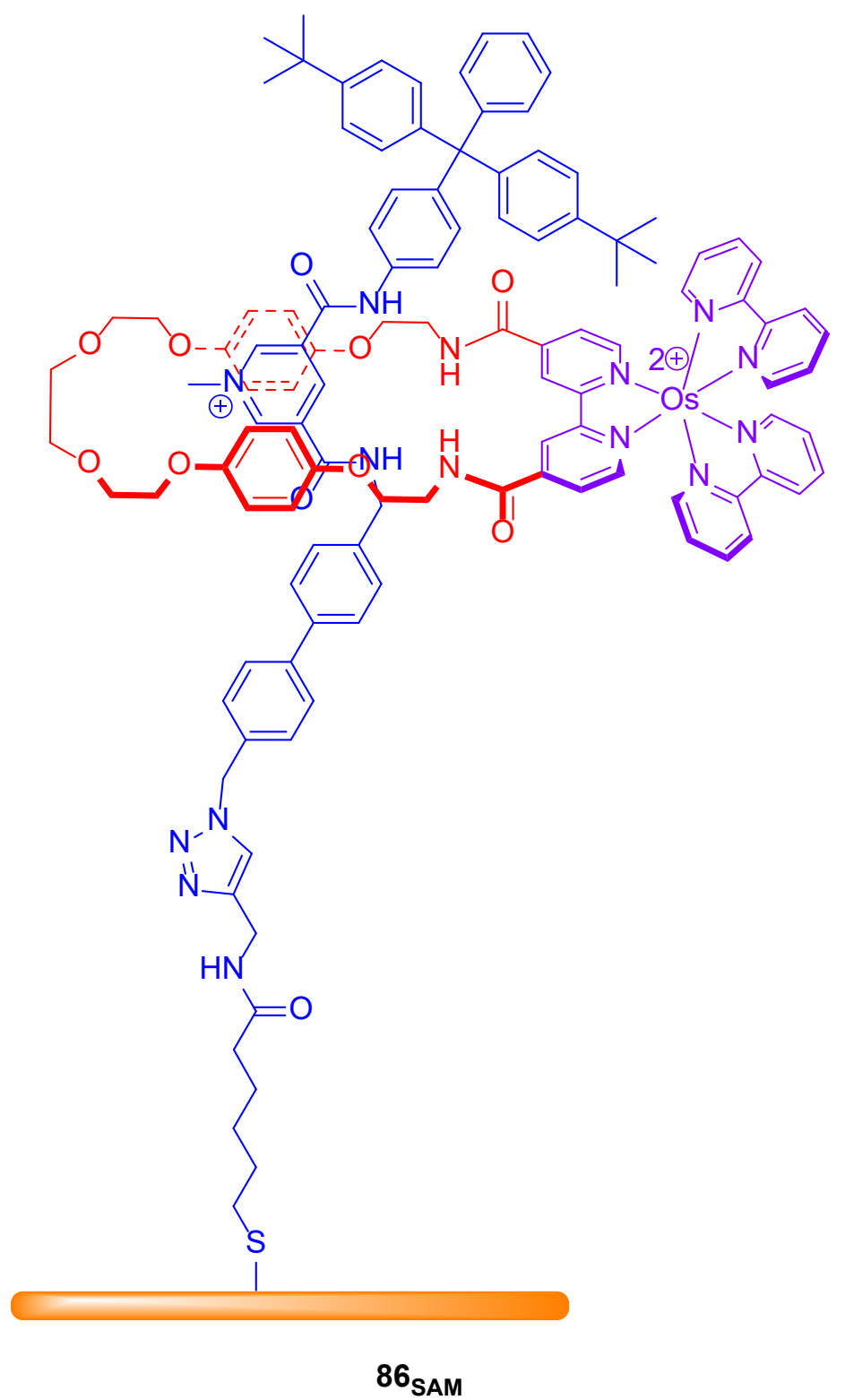

Figure 45. Os(bpy $)_{3}$-based redox-active rotaxane SAM.

Another redox transducer used in surface-confined anion receptors is tetrathiafulvalene (TTF). In an early example, a TTF-modified calix[4]pyrrole SAM 87sAM (Figure 46) was utilised as a chloride sensor. ${ }^{167}$ In contrast to previous examples, the voltammetric response in DCM was reported to be substantially greater under diffusive conditions $(-170 \mathrm{mV})$ than in $87_{\text {SAM }}$ $(\approx-30 \mathrm{mV})$. This was rationalised by reference to potential conformational restrictions in the SAM where the cone-conformation (in which stronger binding/response is observed in 
solution) is disfavoured over the 1,3-alternate conformation. It should however be noted that these TTF systems are often not fully reversible and are particularly prone to rapid voltammetric degradation, in particular in the presence of coordinating anions. This problem was also observed in a recent study in which iodo-TTF derivatives were immobilised on gold to form 88 sAm. ${ }^{168}$ This XB anion receptive interface was capable of sensing $\mathrm{Cl}^{-}$and $\mathrm{Br}^{-}$via perturbations of the first TTF oxidation wave in ACN. Cathodic shifts of around $-150 \mathrm{mV}$ were observed for both anions, where a second redox couple emerged at lower potentials. Importantly, this work is a rare example of an in-depth investigation of anion binding constants at redox-active SAMs. From various electrochemical simulations and data fitting, $K_{\mathrm{Ox}}$ and $\mathrm{K}_{\text {Red }}$ of chloride to $88 \mathrm{SAM}$ were estimated to be around and $570000 \mathrm{M}^{-1}$ and $1000 \mathrm{M}^{-1}$, respectively, much larger than binding constants obtained under similar conditions in solution indicating, as has been the norm, an enhanced interfacial binding. 


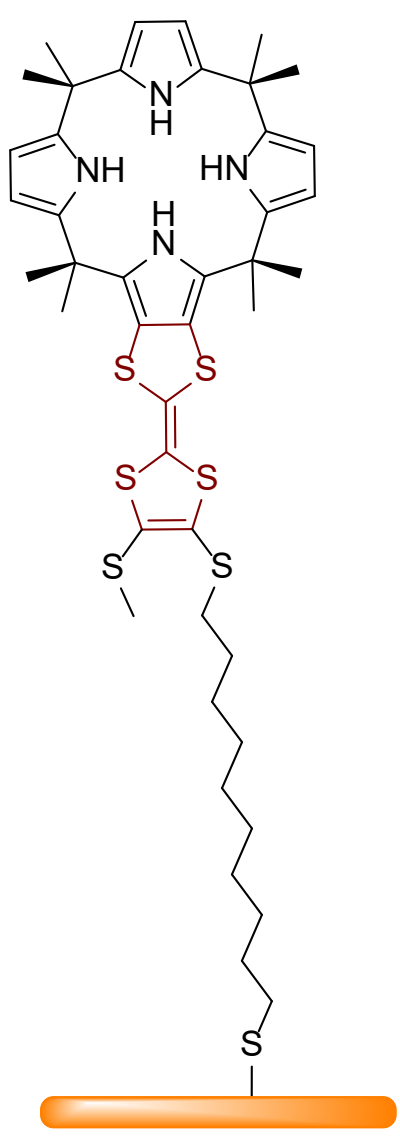

$87_{\text {SAM }}$

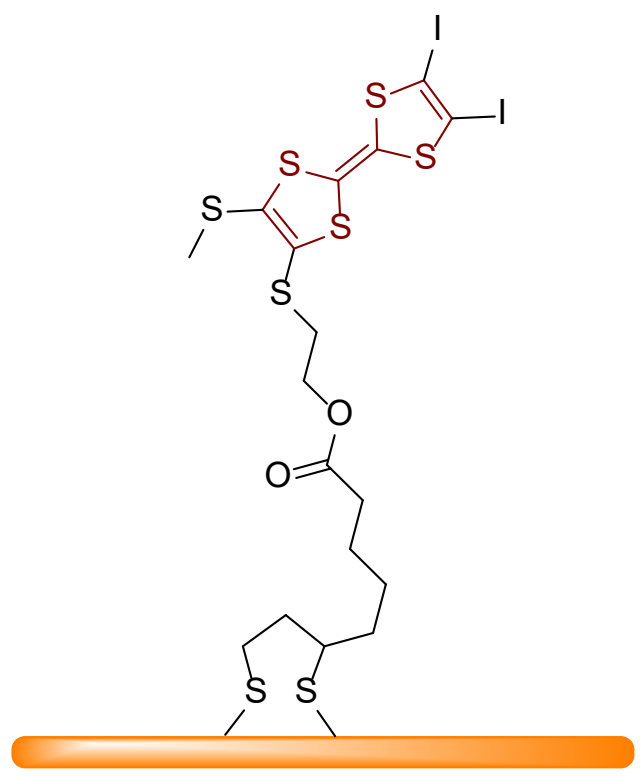

$8_{\text {SAM }}$

Figure 46. Redox-active anion sensory interfaces based on tetrathiafulvalene.

Another recent study reports the use of a TTF-appended foldamer $89_{\text {SAM }}$ for the voltammetric sensing of $\mathrm{Cl}^{-}$and $\mathrm{HSO}_{4}{ }^{-}$in $\mathrm{DCM}$ (Figure 47). ${ }^{169}$ In this solvent system two welldefined TTF redox couples were observed, in good agreement with previous works and supportive of simultaneous, independent oxidation of both TTF-appendages. Addition of 600 $\mu \mathrm{M} \mathrm{Cl}^{-}$or $\mathrm{HSO}_{4}^{-}$led to cathodic shifts of the first couple by $\approx-30 \mathrm{mV}$ and $\approx-90 \mathrm{mV}$, respectively (in the presence of $100 \mathrm{mM} \mathrm{TBAPF}_{6}$ electrolyte). The authors further studied the influence of the electrolyte concentration $(10,100$ and $500 \mathrm{mM})$ on the redox properties of the system showing that the half-wave potential was strongly affected by TBAPF 6 concentration with the lowest $E_{1 / 2}$ observed at $500 \mathrm{mM} \mathrm{TBAPF}_{6}$. It was further shown that 
the magnitude of response to the tested anions was significantly larger at lower concentration of supporting electrolyte. These observations are in good agreement with earlier studies ${ }^{14}$ and the general concepts outlined in Section 2.1. Despite the rather advanced receptor design utilised in this study the authors unfortunately did not comment on the use of this platform in more competitive solvent systems.

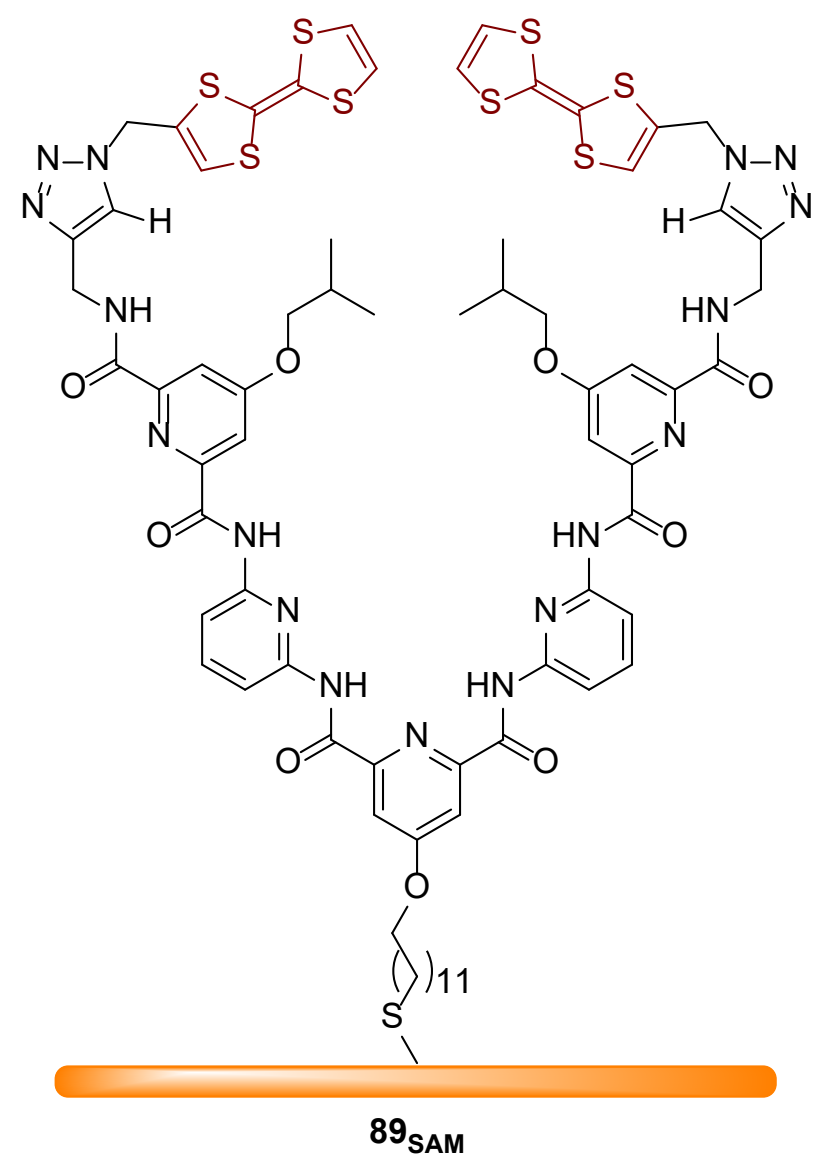

Figure 47. TTF-foldamer SAM on gold.

Based on the promising solution-phase electrochemical properties of a simple nickelazamacrocycle complex ${ }^{170}$ Ohsaka and coworkers developed an analogous interfacial sensor $\left(90_{\text {SAM }}\right.$, Figure 48). ${ }^{171}$ Exploiting the highly charged $\mathrm{Ni}^{2+/ 3+}$ redox couple as a transducer and anion binding (ligation) site this interface was capable of responding to a variety of anions in pure water. Especially the oxoanions $\mathrm{SO}_{4}{ }^{2-}(-110 \mathrm{mV}), \mathrm{H}_{2} \mathrm{PO}_{4}^{-}(-88 \mathrm{mV}), \mathrm{AMP}^{-}(-90 \mathrm{mV}), \mathrm{ADP}^{-}$ 
$(-180 \mathrm{mV})$ and $\operatorname{ATP}^{2-}(-240 \mathrm{mV})$ induced large perturbations at a concentration of $1 \mathrm{mM}$ while chloride induced much smaller cathodic shifts $(-20 \mathrm{mV})$. Further investigations also revealed, as expected, a different binding stoichiometry for sulfate (1:1) and dihydrogenphosphate (2:1). Relying only on electrostatic/dative interactions these simple systems are, similarly to analogous solution-phase sensors (Section 2.3.5), often not very selective. Another metalcontaining interface, incorporating redox active dipyrromethene receptors containing copper(II) or cobalt(II), was recently reported for the voltammetric sensing of $\mathrm{Cl}^{-}, \mathrm{Br}^{-}$and $\mathrm{SO}_{4}{ }^{2-}$ in water. ${ }^{172}$ This interface was assembled in a step-wise fashion, where a mixed SAM of 4-mercaptobutanol and a dipyrromethene-thiol was initially formed on gold. Subsequent metallation with $\mathrm{Co}(\mathrm{II})$ or $\mathrm{Cu}(\mathrm{II})$ was then followed by complexation with an additional receptor-containing dipyrromethene ligand to afford $\mathbf{9 1 .} \mathbf{C u} / \mathrm{Co}_{\text {SAM }}$. The sensor, containing urea, amide and amine groups was demonstrated to respond to the three target anions in pure water at $\mathrm{pH}$ 4.0. Specifically, a clear shift in the oxidation potential of up to $-57 \mathrm{mV},-17$ $\mathrm{mV}$ and $-40 \mathrm{mV}$ as well as $-150 \mathrm{mV},-47 \mathrm{mV}$ and $-61 \mathrm{mV}$ for $\mathrm{Cl}^{-}, \mathrm{Br}^{-}$and $\mathrm{SO}_{4}{ }^{2-}$ at 91. $\mathrm{Cu}_{\text {SAm }}$ and 91. Cosam, respectively, was observed. The enhanced response at 91.Cosam most likely arises from a strong binding switch on $\left(\mathrm{Co}^{2+}\right.$ to $\left.\mathrm{Co}^{3+}\right)$ while binding at $\mathbf{9 1 .} \mathrm{Cu}_{\mathrm{SAM}}$ was observed to be decreased $\left(\mathrm{Cu}^{2+}\right.$ to $\left.\mathrm{Cu}^{+}\right)$. The step-wise assembly of this interface facilitates the use of different dipyrromethene-tagged receptors without the need to isolate the final thiolated receptor, enabling facile construction of different interfaces containing different metals and/or receptors. This has recently been exploited to immobilise a novel dipyrromethenetagged anion-receptive, cyclic peptide for the voltammetric sensing of sulfate in water. ${ }^{173}$ However, it should be noted that the assembly on the surface will often not fully convert all (metallated) ligands to the final receptor complex, resulting in interfaces that are not 
homogeneous and that contain different redox active species which can result in non-ideal voltammetric behavior, as observed in both studies. ${ }^{172-173}$

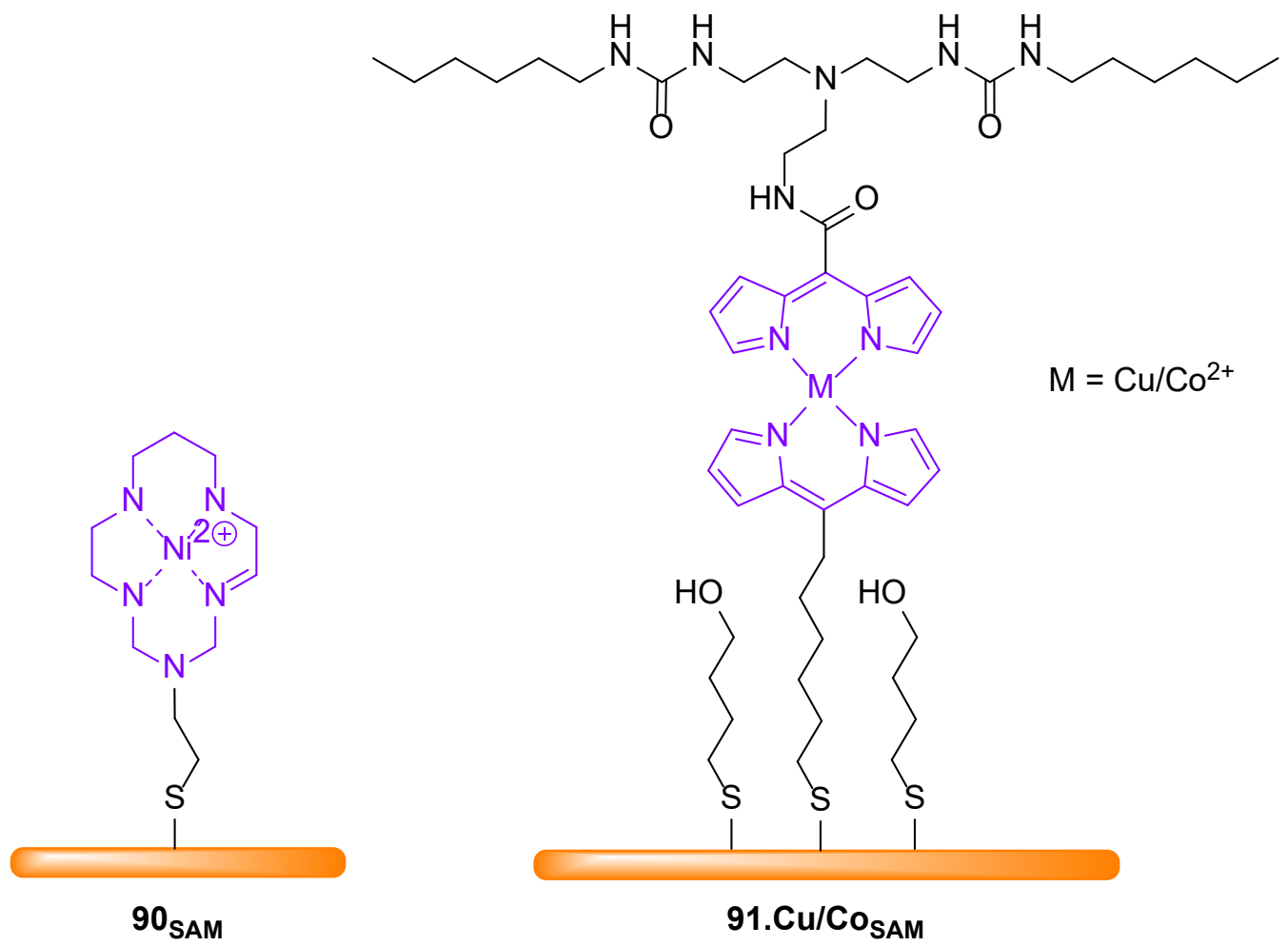

Figure 48. Metal-containing receptors for voltammetric anion sensing in water.

\subsubsection{Polymeric anion receptive interfaces}

Another commonly employed strategy to modify (conducting) interfaces, so as to be specifically responsive, is (electro)polymerization. The incorporation of electropolymerisable groups, such as pyrrole- or thiophene-derivatives allows facile generation of polymeric films on any electrode surface and is thus more versatile than self-assembly on gold. Additionally, film thickness can often be controlled easily by adjusting the polymerisation conditions (e.g. potential window or number of scans). While such films are structurally less well-defined than SAMs, their potentially higher conformational flexibility might be advantageous when 
sensing larger analytes which might be sterically excluded from densely packed SAMs. They also offer the potential for a greater baseline signal.

To the best of our knowledge the first example of such an interface, and the first example of any redox-active anion responsive interface, was reported by Moutet and coworkers in 1996. ${ }^{174}$ They used a redox-active Ru(bpy)3-based receptor containing two different ligands, one with a bis-amide binding site as well as a pyrrole-modified ligand which was utilised to electropolymerize the receptor onto a Pt electrode ( $\mathbf{9} \mathbf{2}_{\text {film }}$, Figure 49$)$. This film displayed a reversible $\mathrm{Ru}^{2+/ 3+}$ redox couple at high potential in $\mathrm{ACN}$ and three reductive couples at lower potential, ascribable to ligand centred reductions. The most positive of these three couples, corresponding to the $\mathbf{9 \mathbf { f i l m }}{ }^{\mathbf{2 + / + \bullet}}$ couple, displayed moderate cathodic perturbations of up to $40 \mathrm{mV}$ in the presence of $\mathrm{Cl}^{-}$, while $\mathrm{Br}^{-}$and $\mathrm{I}^{-}$did not induce any measurable response. The voltammetric behaviour in the presence of $\mathrm{F}^{-}$was more complex with disappearance of this couple, possibly due to receptor deprotonation.

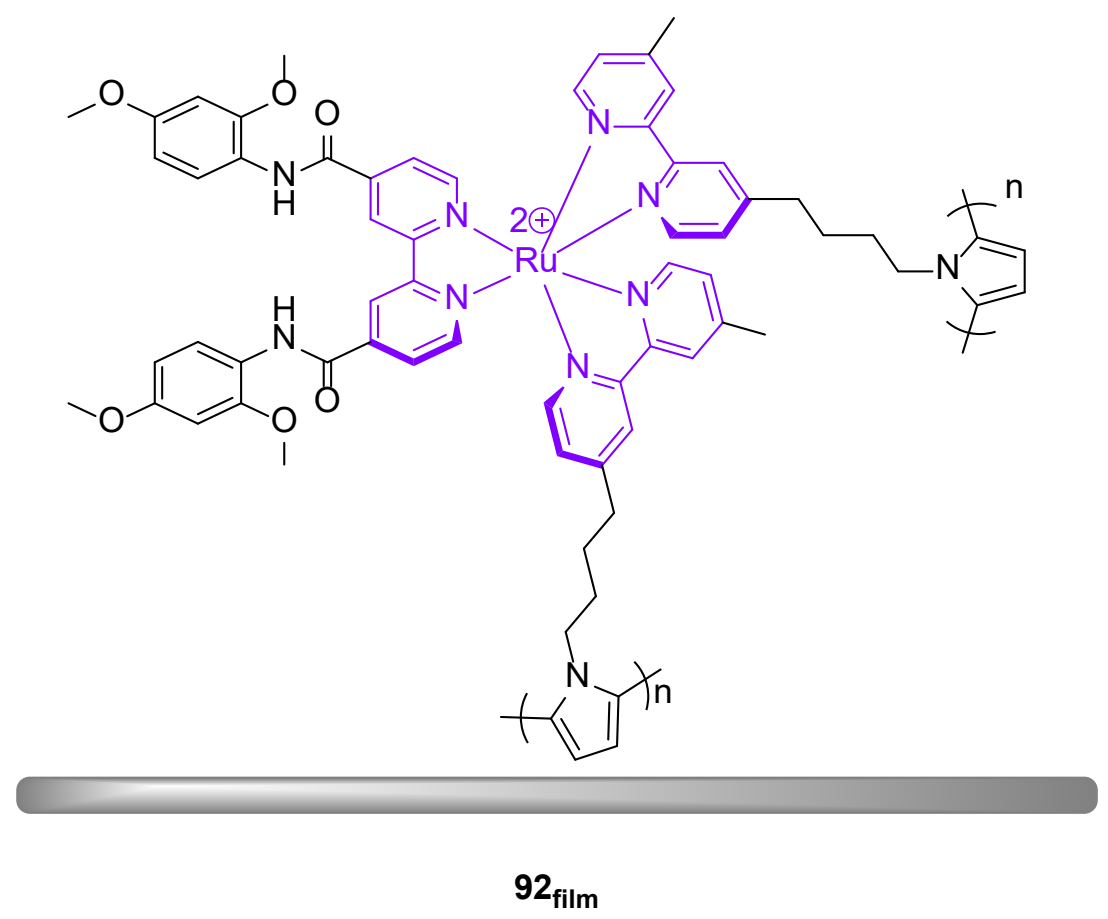

Figure 49. Polymeric anion sensing film on Pt based on Ru(bpy) ${ }_{3}$-pyrrole receptor. 
The same group also formed films of the a much simpler Fc-amide-pyrrole receptor on Pt electrodes (93 $3_{\text {film }}$, Figure 50$) .{ }^{175}$ This interface was responsive to $1 \mathrm{mM}$ of $\mathrm{H}_{2} \mathrm{PO}_{4}{ }^{-}$or ATP2with shifts of $-220 \mathrm{mV}$ and $-180 \mathrm{mV}$ in $\mathrm{ACN}$ and $-260 \mathrm{mV}$ and $-240 \mathrm{mV}$ in DCM, respectively. The response to $\mathrm{HSO}_{4}{ }^{-}$was much smaller $(-30 \mathrm{mV}$ and $-60 \mathrm{mV}$ in $\mathrm{ACN}$ and $\mathrm{DCM})$ while $\mathrm{NO}_{3}{ }^{-}$ failed to induce any response. In alignment with subsequent observations at redox-active SAMs these responses were significantly larger than the shifts observed under diffusive conditions (using the same receptor). At the same time del Peso et al. investigated the sensory properties of the same receptive interface with a cobaltocenium transducer (instead of Fc). ${ }^{176}$ Under similar conditions (in ACN), $\mathbf{9 4}_{\text {film }}$ displayed similar cathodic perturbations as its Fc-analogue: $-210 \mathrm{mV}$ in the presence of $0.1 \mathrm{mM} \mathrm{H}_{2} \mathrm{PO}_{4}^{-}$. Interestingly, and in contrast to 93 film, 94 film did exhibit a large response to $\mathrm{HSO}_{4}{ }^{-}(-250 \mathrm{mV})$, though this was difficult to rationalise chemically. Moutet and coworkers not only studied the sensory behaviour of simple Fc-alkylammonium SAMs ${ }^{163}$, as described in Section 2.4.1, but also of analogous Fcalkylammonium containing pyrrole-based polymeric films, showing good responses to $\mathrm{H}_{2} \mathrm{PO}_{4}^{-}, \mathrm{ATP}^{2-}, \mathrm{HSO}_{4}^{-}$and $\mathrm{F}^{-}$in $\mathrm{ACN}^{177-178}$

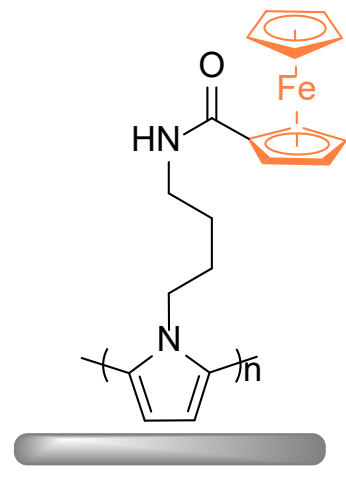

$93_{\text {film }}$

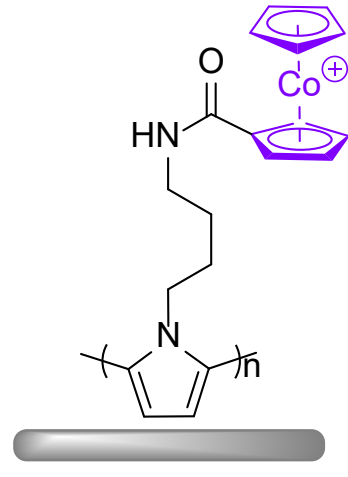

$94_{\text {film }}$

Figure 50. Polymeric anion responsive films on Pt based on metallocene-pyrrole receptors. 
Martínez et al. achieved sensing of $\mathrm{H}_{2} \mathrm{PO}_{4}^{-}$in pure water utilizing a Fc-amide-pyrrole dendrimer interface, 95 $_{\text {film (Figure 51). }}{ }^{179}$ The authors reported that these films were voltammetrically unstable in $\mathrm{ACN}$ (with any electrolyte) and in aqueous $\mathrm{LiClO}_{4}$. Interestingly a stable and reproducible voltammetric behaviour was only observed when using $\operatorname{Li}\left[\mathrm{B}\left(\mathrm{C}_{6} \mathrm{~F}_{5}\right)_{4}\right]$ as electrolyte in pure water. Addition of $\mu \mathrm{M}$ concentrations of $\mathrm{H}_{2} \mathrm{PO}_{4}{ }^{-}$induced significant cathodic perturbations of the $\mathrm{Fc} / \mathrm{Fc}^{+}$couple of up to $-110 \mathrm{mV}$. Unfortunately the authors did not systemically investigate anion selectivity, but did show that the dendrimeric structure of the receptor was integral to the sensing performance of the films in that a similar nondendrimeric Fc-bis(amide-pyrrole) film did not respond to phosphate in the same aqueous medium.
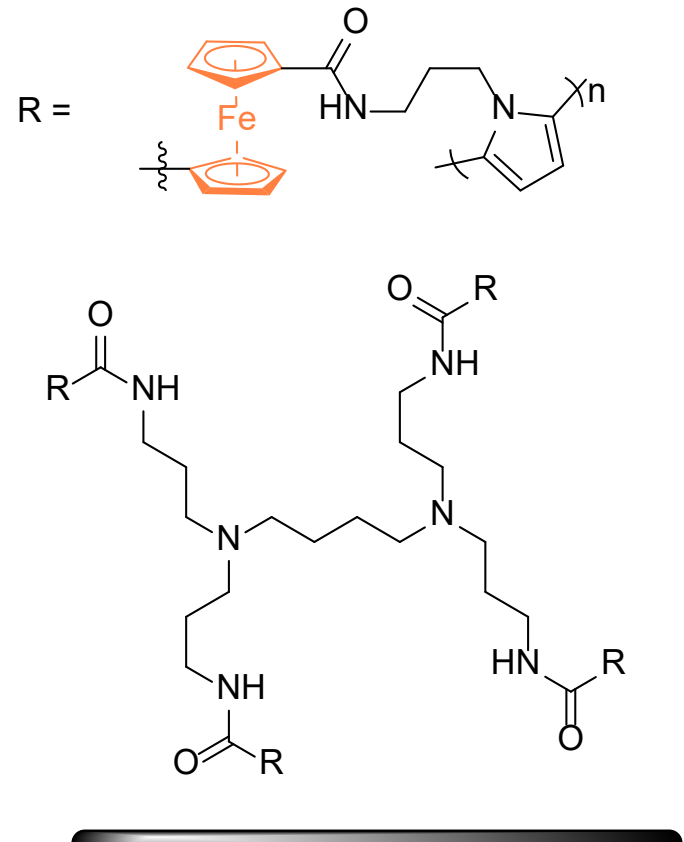

$95_{\text {film }}$

Figure 51. Polymeric anion responsive films on GC based on Fc-pyrrole dendrimer.

An electropolymerizable porphyrin-receptor was reported by Swager and coworkers using a doubly strapped free-base porphyrin film to sense $\mathrm{F}^{-} .{ }^{180}$ Bithiophene groups in the straps 
facilitated electropolymerisation while anion binding was achieved by the porphyrin core and additional amide binding sites. These films displayed two reversible redox couples in DCM, where the more anodic couple was identified as the $\mathrm{P} / \mathrm{P}^{+\bullet}$ couple while the other couple was ascribed to the conjugated polymer back-bone. As expected, addition of $0.3 \mathrm{mM}$ $\mathrm{F}^{-}$induced significant perturbations only for the former, receptive couple with cathodic shifts of $-69 \mathrm{mV}$. More recently Sessler and coworkers reported the sensing properties of calix[4]pyrrole (CP)-based anion receptive films $96_{\text {film }}{ }^{181}$ Conjugation of the receptor to ethylenedioxythiophene (EDOT) enabled the facile electrochemical polymerisation on a wide variety of substrates (Pt or ITO). In order to enhance the conductivity of the polymer film the receptor was copolymerised with (unmodified) EDOT (Figure 52). The resulting copolymer was used for sensitive voltammetric sensing of $\mathrm{F}^{-}$in water; a new redox couple at more negative potential (at $\approx-1 \mathrm{~V}$ ) appeared at the expense of the original wave associated with the CP. Importantly, control experiments with pure pEDOT revealed minimal perturbations in the presence of $\mathrm{F}^{-}$, confirming the role of the $\mathrm{CP}$ as a receptor in this sensitive sensor (LOD of $11 \mu \mathrm{M})$. 


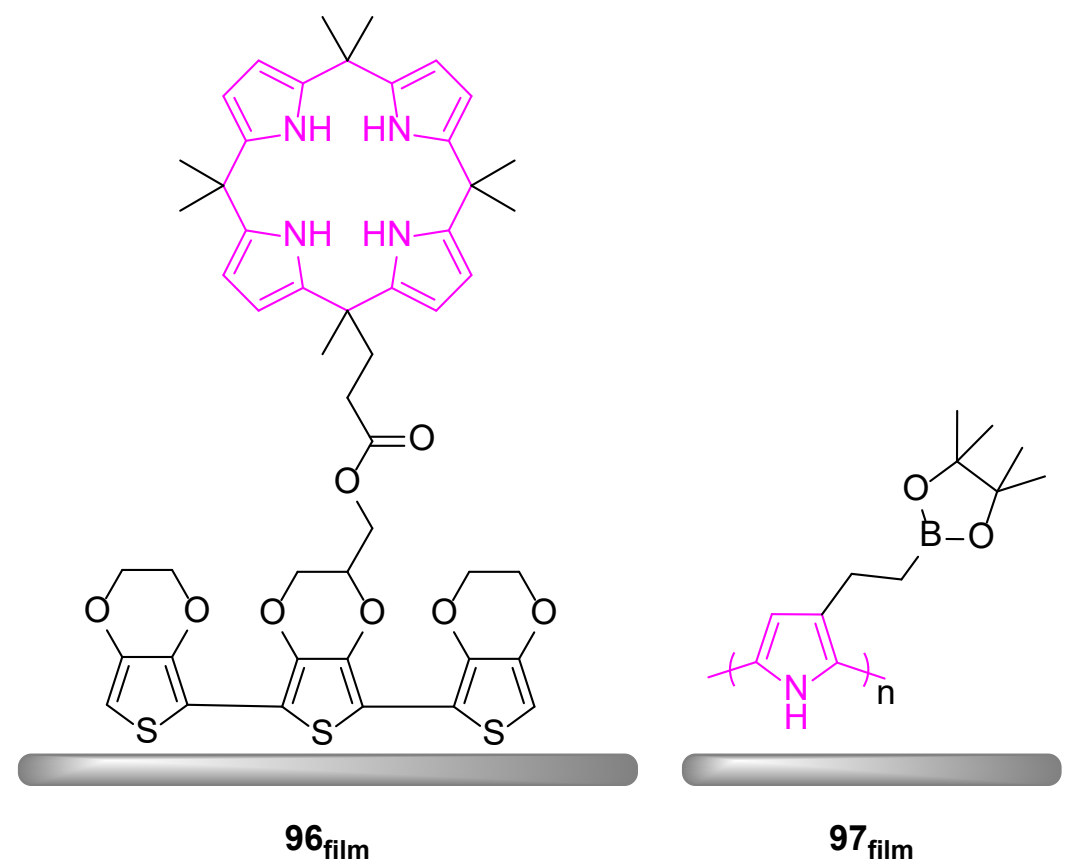

Figure 52. Anion receptive polymer film generated by electropolymerisation of a 1:1 mixture of EDOT and EDOT-Calix[4]pyrrole on ITO and polypyrrole-boronic acid based sensor.

In analogy to solution-phase studies, boronic acid motifs have been incorporated into polymeric architectures. An early example included the anodic polymerisation of a vinylderivative of the triphenylamine-boronic acid receptor $\mathbf{5 3}$ (Section 2.3.4) which reportedly responded to $\mathrm{F}^{-}$by a gradual loss in redox activity. ${ }^{114} \mathrm{~A}$ more reversible sensor was developed based on a pyrrole-boronic acid conjugate which was polymerised onto Pt to produce $97_{\text {film }}{ }^{182}$ In contrast to previous examples this study exploited the inherent redoxactivity of the polypyrrole film as the transducer, omitting the need for an additional redox group. Addition of $2 \mathrm{mM} \mathrm{F}^{-}$to $97_{\text {film }}$ in $1: 1 \mathrm{ACN} / \mathrm{H}_{2} \mathrm{O}$ induced a selective cathodic perturbation of $-260 \mathrm{mV}$ (over $\mathrm{Cl}^{-}$and $\mathrm{Br}$ ).

In a more recent study a completely different methodology was utilised to sense $\mathrm{F}^{-}$at polymeric films. To this end 3-aminophenylboronic acid was oxidatively polymerised onto the electrode. ${ }^{183}$ While polyanilines are inherently redox active, $\mathrm{F}^{-}$sensing was carried out in 
pure water $\left(\mathrm{pH}^{3.0}\right)$ in the presence of $\left[\mathrm{Fe}(\mathrm{CN})_{6}\right]^{3-}$ as a solution-phase redox probe. Upon $\mathrm{F}^{-}$ binding to the interface, electrostatic repulsion between the generated boronate and the negatively charged transducer led to reduced Faradaic currents of the latter, as measured by SWV. A current suppression of up to $35 \%$ in the presence of $1 \mathrm{mM} \mathrm{F}^{-}$was observed at this interface which responded to $\mathrm{F}^{-}$over a wide linear concentration range and a very low LOD of $90 \mathrm{pM}$. As expected, a large variety of other anions did not significantly interfere with this detection. An analogous voltammetric sensor based on SAMs of 4-mercaptophenylboronic acid has also been reported ${ }^{184}$ while phosphate ${ }^{185-186}$ and sulfate ${ }^{187}$ sensing based on this principle has also been reported.

\subsubsection{Physisorbed and drop-casted anion receptive interfaces}

As highlighted in Section 2.3.7 redox-active dendrimers (and also nanoparticles) have an observed tendency to physisorb onto electrodes, in particular the larger, higher generation, dendrimers. This can be exploited to conveniently form redox-active responsive films. Most commonly the dendrimers are immobilised onto glassy carbon (GC) or Pt electrodes by either simple exposure of the electrode to the dendrimer solution or by additional application of a potential (either cycling or controlled potential electrolysis) where, depending on the solvent, the charged receptor often physisorbs more strongly (usually reflected in asymmetric diffusive CVs resulting in the cathodic backward scan resembling a stripping peak; see Section 2.3.7). ${ }^{188}$

In pioneering work Casado et al. electrodeposited a dendrimer onto GC electrodes to form 98 film (Figure 53). ${ }^{189}$ This sensor was subsequently used for sensing of $\mathrm{H}_{2} \mathrm{PO}_{4}{ }^{-}$in $\mathrm{DCM}$, with a response of up to $-170 \mathrm{mV}$ (at $0.5 \mathrm{mM}$ ). This cathodic shift magnitude is, unlike many of the previously described SAM-based sensors, somewhat smaller than that observed under 
diffusive conditions, indicating that the "enhanced response" of SAM based sensors largely arises from cooperative and topological effects, which in the case of the dendrimers, are (at least in part) already present under diffusive conditions. 98 film was also, more weakly, responsive to $\mathrm{HSO}_{4}^{-}(-85 \mathrm{mV}), \mathrm{Cl}^{-}(-30 \mathrm{mV})$ and $\mathrm{Br}^{-}(-10 \mathrm{mV}$; all at $500 \mu \mathrm{M})$. As highlighted previously, the tendency of dendrimers to adsorb onto the electrode is usually dependent on their size, with larger dendrimers interacting more strongly. To this end, Astruc and coworkers investigated the electrode modification by giant alkylferrocenyl dendrimers. ${ }^{190-191}$ Even without any specific anion binding site the large sixth and seventh generation dendrimers with 6561 and 19683 Fc-termini respectively, displayed a significant cathodic response to both $\mathrm{H}_{2} \mathrm{PO}_{4}{ }^{-}$and $A T P^{2-}$ in $\mathrm{DCM}$, again highlighting the importance of electrostatic interactions and the care that must be taken in assuming anion interactions are confined to integrated receptive sites. ${ }^{191}$

Alonso, Casado, Losada and coworkers reported interfacial sensors based on smaller amidoferrocenyl dendrimers $99-4,8,16,32$ film. ${ }^{188}$ The authors not only reported a positive dendrimeric effect but also noted that the peak currents were significantly supressed upon anion binding, indicating electrochemical irreversibility and/or strong ion-pairing (ultimately this signal suppression was used as the reporting function). More importantly however, it was shown that $99-4_{\text {film }}$ can be employed to sense low $\mathrm{mM} \mathrm{H}_{2} \mathrm{PO}_{4}^{-}$and $\mathrm{ATP}^{2-}$ in pure water, highlighting the benefit of using dendrimer films as sensors, circumventing solubility issues which have arguably been the major drawback of these systems in solution. 
<smiles>[R][C]([R])CCC[Si](C)(C)N</smiles>

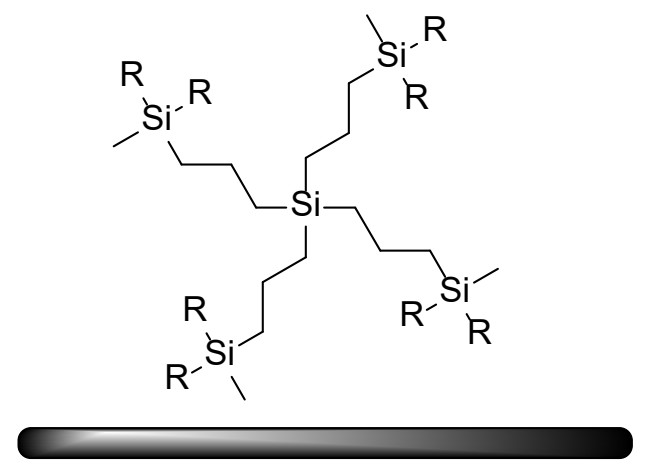

$98_{\text {film }}$

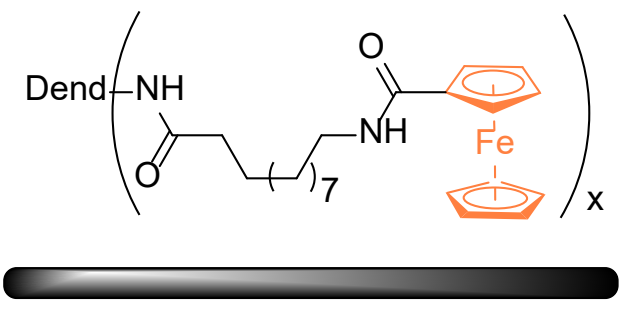

$99_{\text {film }}$

Figure 53. Schematic representation of dendrimer films on GC.

An alternative approach to immobilize dendrimers was achieved in a step-wise manner by first immobilising an azide-terminated dendrimer onto an alkyne-modified GC electrode via click chemistry (Figure 54). ${ }^{192}$ Due to the dendrimer topology, and the large number of azide termini, further modifcation with ethynylferrocene resulted in a covalently immobilised, redox-active dendrimer. Scanning electrochemical microscopy, in which a current at a probing tip is measured as a function of distance to the substrate, was then used to show that $\mathrm{H}_{2} \mathrm{PO}_{4}{ }^{-}$binds to this interface in DMF in a manner that facilitated Fc oxidation and thus electron transfer across the interface. 

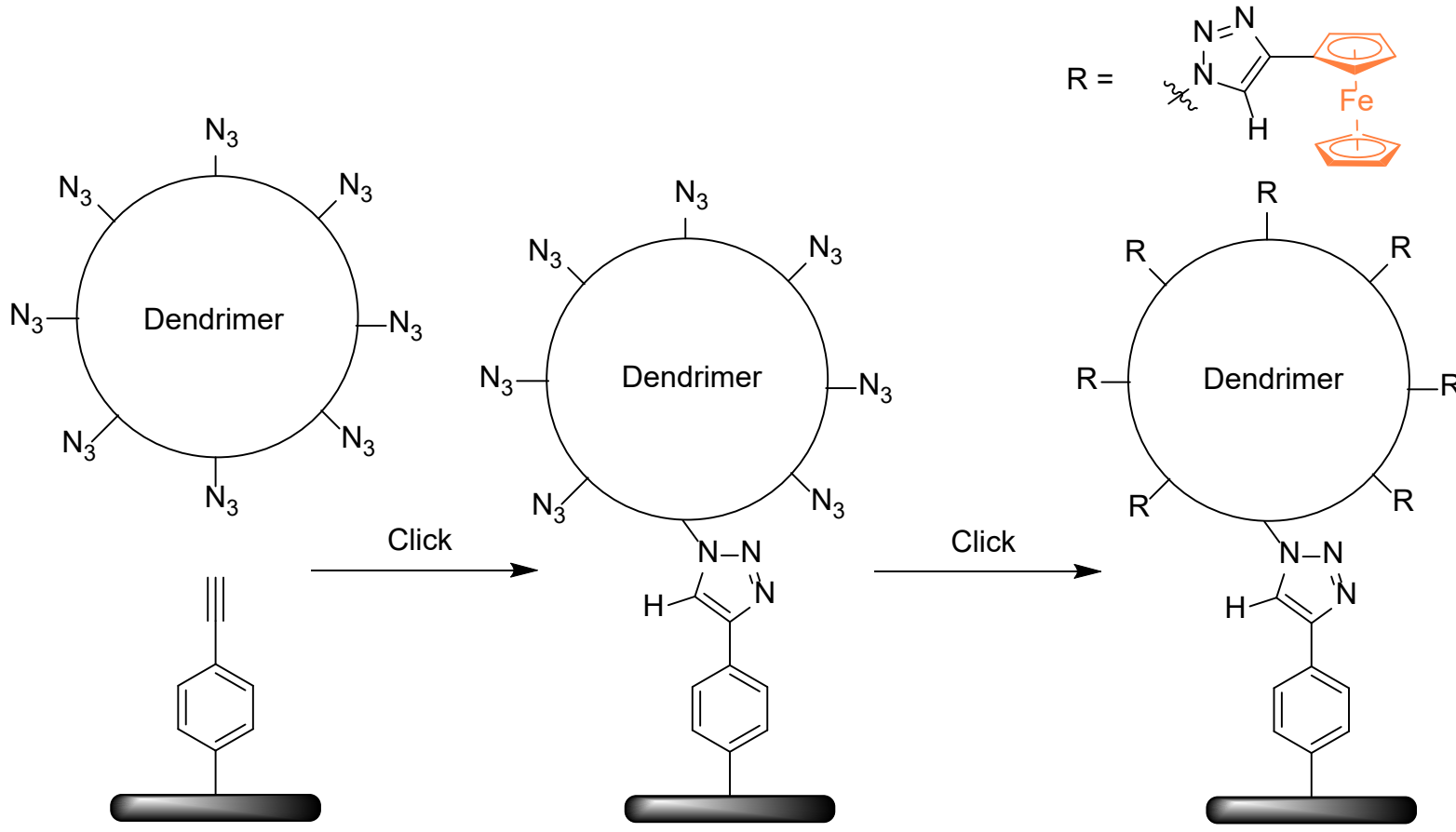

Figure 54. Schematic representation of step-wise modification of a GC electrode with Fc-triazole terminated dendrimer by multiple click reactions.

\section{Impedimetric and Capacitive Anion Sensing in Molecular Films}

\subsection{Faradaic Impedimetric Anion Sensing}

Of all electroanalytical techniques electrochemical impedance spectroscopy (EIS) stands out as one which is particularly sensitive to interfacial events. The application of a small amplitude AC perturbation at a fixed bias potential allows facile extraction of a range of interfacial parameters (e.g. resistance and capacitance) with minimal perturbations of the interface. EIS is commonly exploited for sensing of large biomolecules whereby the charge transfer resistance $\left(R_{c t}\right)$ of a receptor (e.g. antibody) modified electrode in the presence of a redox probe (most commonly $\mathrm{Fe}(\mathrm{CN})_{6}^{3-/ 4-}$ ) is utilised as transducer for analyte binding. ${ }^{193}$ This concept has been expanded to the sensing of small molecules and ions also. In particular 
impedimetric cation sensing at crown ether modified electrodes has received some attention $^{194-197}$, though impedimetric anion sensing remains rare. In this section we highlight advances in impedimetric anion sensing in the presence of a redox probe and discuss benefits and limitations. All of the following examples were conducted in pure aqueous media.

Early work in this field was conducted by Echegoyen et al. who exploited SAMs of cyclotriveratrylene (CTV) $)^{198}$ and calixarene-based ${ }^{199}$ anion receptors on gold electrodes (98 SAM and 99 SAM, Figure 55). Sensing of various anions such as phosphate, acetate, fluoride and others was achieved in the presence of either $\mathrm{Ru}\left(\mathrm{NH}_{3}\right)_{6}{ }^{2+/ 3+}$ or $\mathrm{Fe}(\mathrm{CN})_{6}^{3-/ 4-}$; a decrease or increase in $R_{c t}$, respectively, was observed upon anion binding (Figure 56). These altered charge-transfer characteristics can be attributed to electrostatic interactions between the surface-captured anion of interest and the solution-phase redox probe, whereby electrostatic attraction facilitates electron transfer, i.e. leads to a lower $R_{c t}$, and, conversely, repulsion results in an increased $R_{c t}$. 

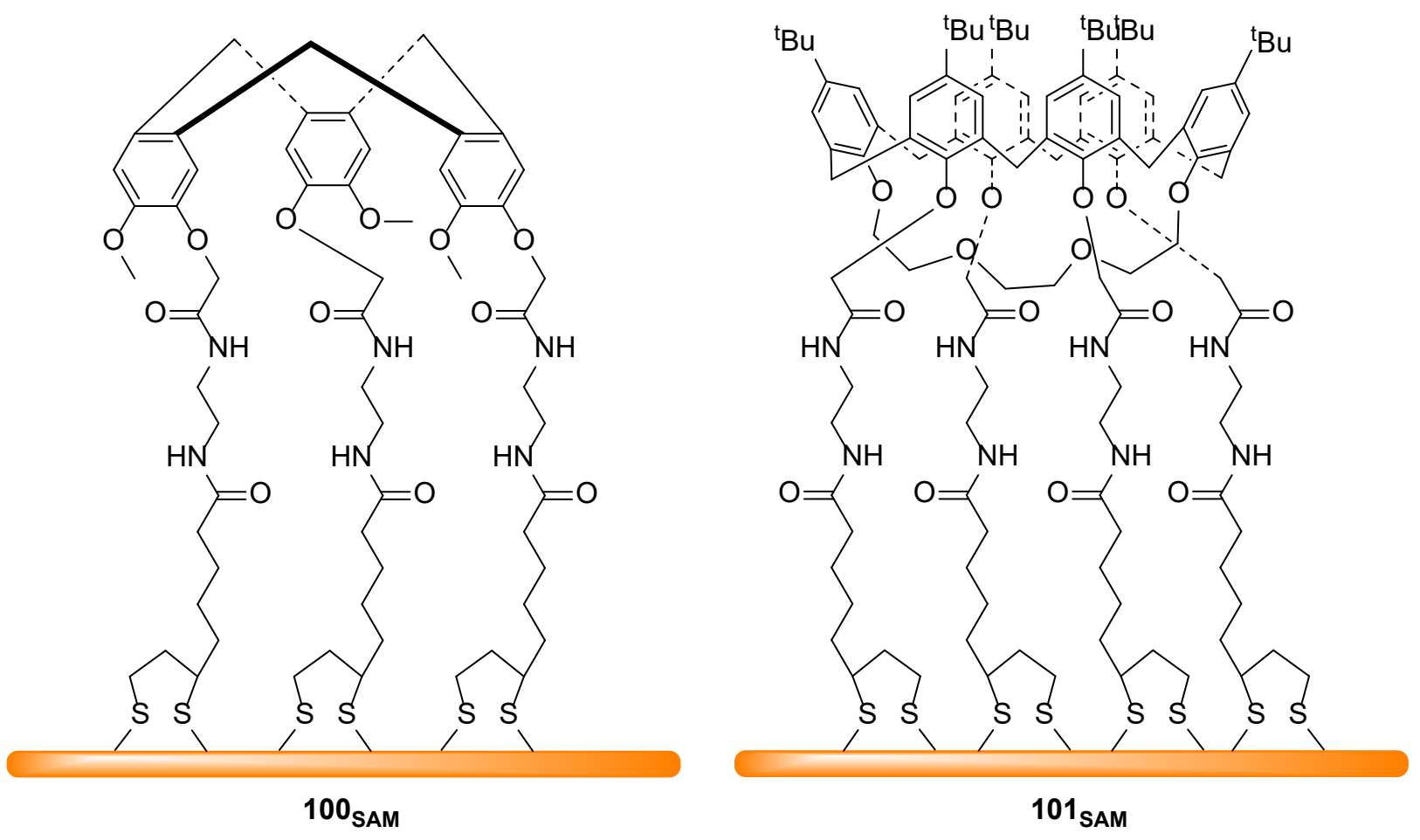

Figure 55. SAMs of CTV and Calix[6]arene-based anion receptors on gold for impedimetric anion sensing.
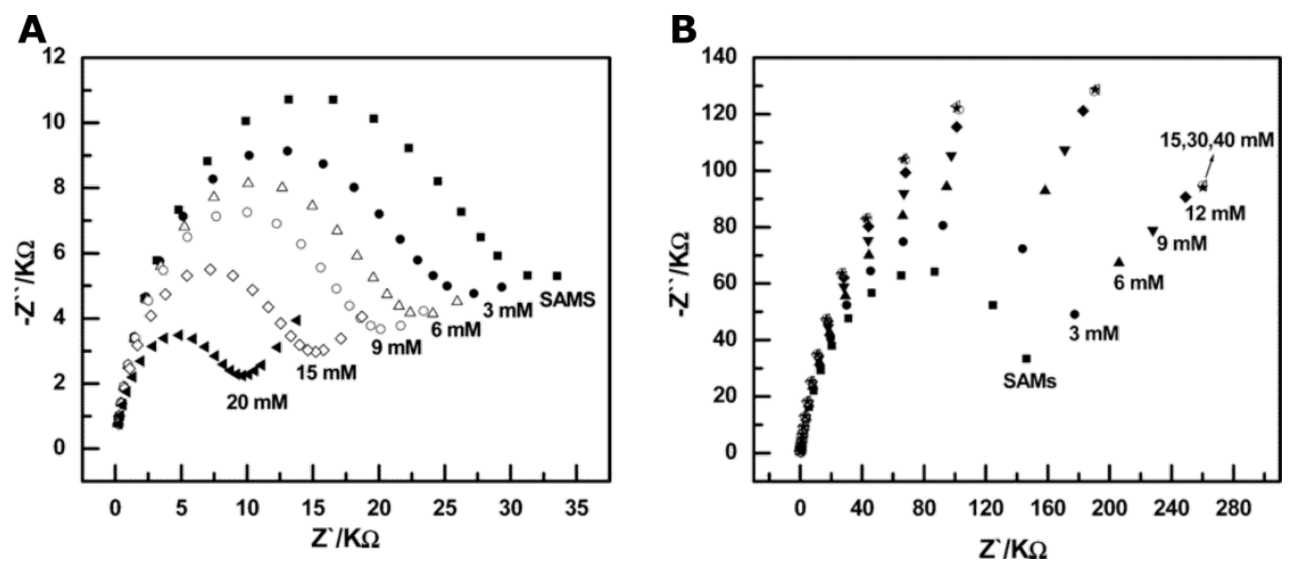

Figure 56. Impedimetric Nyquist plots of 100 sAm in the presence of increasing [OAc'] utilising $\mathrm{Ru}\left(\mathrm{NH}_{3}\right)_{6}{ }^{2+/ 3+}(\mathbf{A})$ or $\mathrm{Fe}(\mathrm{CN})_{6}^{3-/ 4-}$ (B) as redox probes. In both plots the change of the impedance (charge-transfer resistance) can be seen, which arises from electrostatic attraction and repulsion between the bound anion and the redox-probe, respectively. Reprinted with permission from ref. ${ }^{198}$ Copyright 2005 American Chemical Society. 
The impedimetric sensing of $\mathrm{H}_{2} \mathrm{PO}_{4}^{-}$was also achieved at SAMs of free-base porphyrin

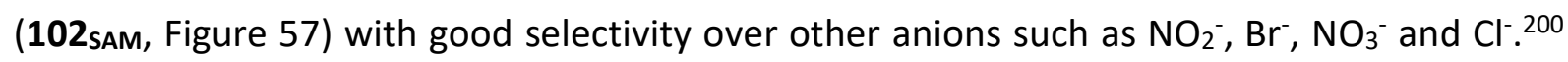
Interestingly, the $\mathrm{R}_{\mathrm{ct}}$ of this interface decreased upon addition of $\mathrm{H}_{2} \mathrm{PO}_{4}^{-}$(in the presence of $\left.\mathrm{Fe}(\mathrm{CN})_{6}^{3-/ 4-}\right)$. This was rationalised by double-protonation of the porphyrin-core in the presence of the anion, resulting in an overall positively charged SAM with an enhanced electron transfer by virtue of the electrostatic attraction of the solution redox probe. Similarly, the highly toxic $\mathrm{HCrO}_{4}^{-}$was detected at azacrown ether modified interfaces $103_{\text {SAM }}$ where the chromate is supposedly sandwiched between azacrown ethers complexed with $\mathrm{K}^{+} / \mathrm{H}^{+} .201$ Sensing of the analyte in the presence of $\mathrm{Fe}(\mathrm{CN})_{6}{ }^{3-/ 4-}$ at $\mathrm{pH} 5.0$ in aqueous $\mathrm{KCl}$ was achieved with an exceptionally low limit of detection (LOD) of 78 pM. 


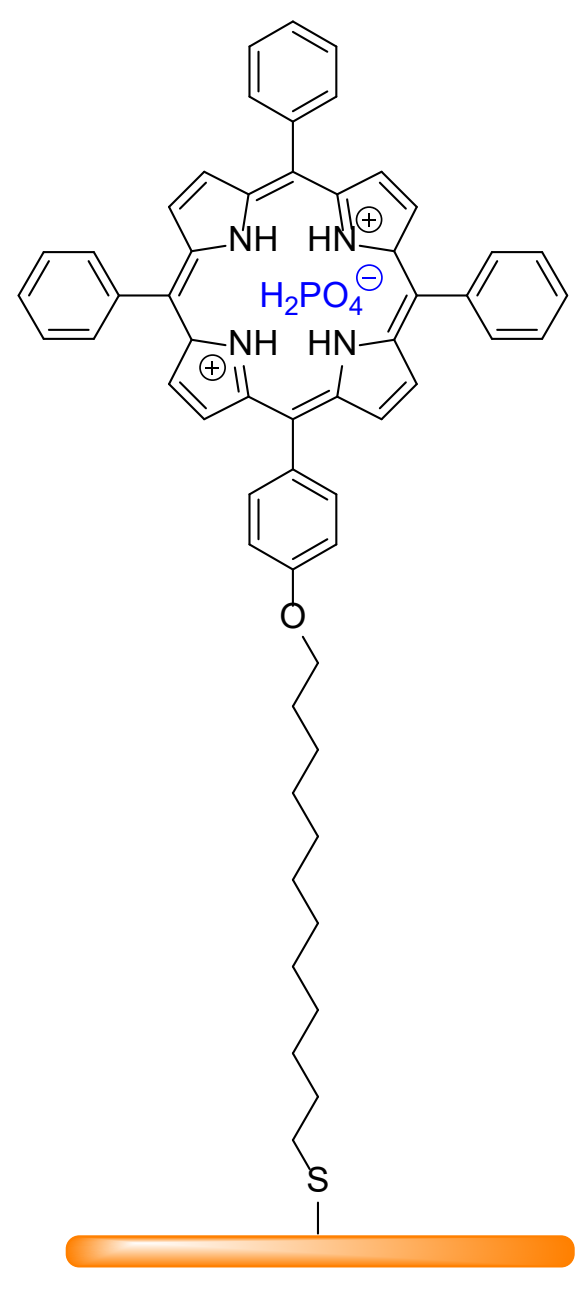

102 SAM

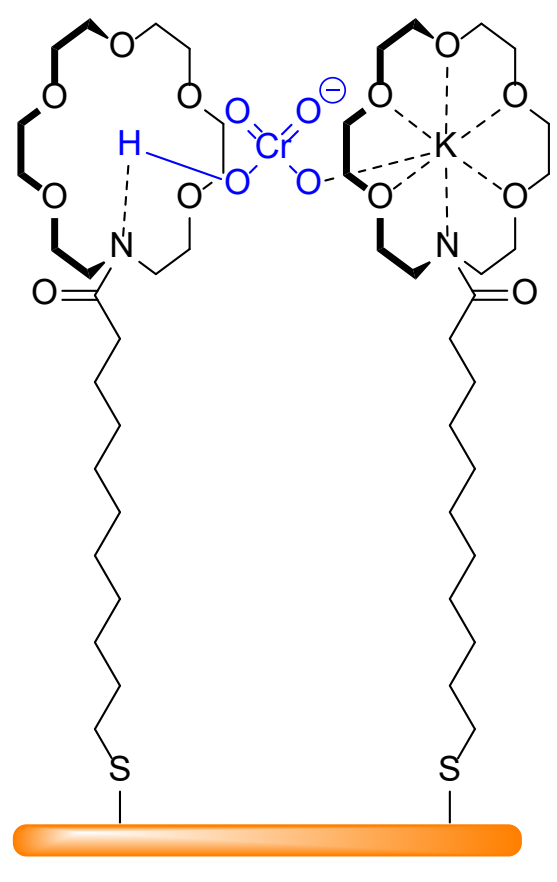

$103_{\text {SAM }}$

Figure 57. Schematic representation SAMs of phorphyrin and azacrown ether-based anion receptors on gold for impedimetric sensing of phosphate and chromate including proposed binding modes.

While these examples, and a majority of electrochemical sensors in general, are prepared by self-assembly on gold electrodes, impedimetric anion sensing has also been carried out at other interfaces. In a recent report two polyaza-acridine receptors were immobilized on screen printed carbon electrodes by voltammetric deposition (potential cycling) enabling impedimetric sensing of $\mathrm{SeO}_{3}{ }^{2-}$ in the presence of $\mathrm{Fe}(\mathrm{CN})_{6}{ }^{3-/ 4-} \cdot 202$

A few reports exist of impedimetric anion sensing that do not rely on specific, supramolecular anion-receptor interactions. For example, a cyanide selective impedimetric 
sensor was constructed based on a SAM of a copper-tris(pyridyl)amine complex (Figure 58). ${ }^{203}$ In the presence of $\mathrm{CN}^{-}$the chelated copper cation was abstracted from 104 SAM as a $\mathrm{Cu}(\mathrm{CN})_{\mathrm{x}}{ }^{(\mathrm{n}-1)-}$ complex leaving behind the free ligand-modified interface which, due to the lack of the positive charge, possesses a higher $\mathrm{R}_{\mathrm{ct}}$ to ferricyanide (reduced electrostatic attraction of the redox probe). Due to this selective, strong abstraction of the metal, a low LOD of $1 \mathrm{nM}$ for $\mathrm{CN}^{-}$was attainable with excellent selectivity over $\mathrm{OAc}^{-}, \mathrm{H}_{2} \mathrm{PO}_{4}^{-}, \mathrm{F}^{-}$and $\mathrm{NO}_{3}{ }^{-}$. Another metal-based sensor was developed for the impedimetric detection of phosphate at $\mathrm{Zr}^{4+}$ terminated SAMs. ${ }^{204}$ To this end a carboxy-terminated SAM of mercaptopropionic acid was first assembled on gold onto which $\mathrm{Zr}^{4+}$ was adsorbed. This interface was then shown to sensitively respond to sub-micromolar levels of phosphate at pH 3.0. Good selectivity then allowed phosphate detection in pre-purified serum samples.

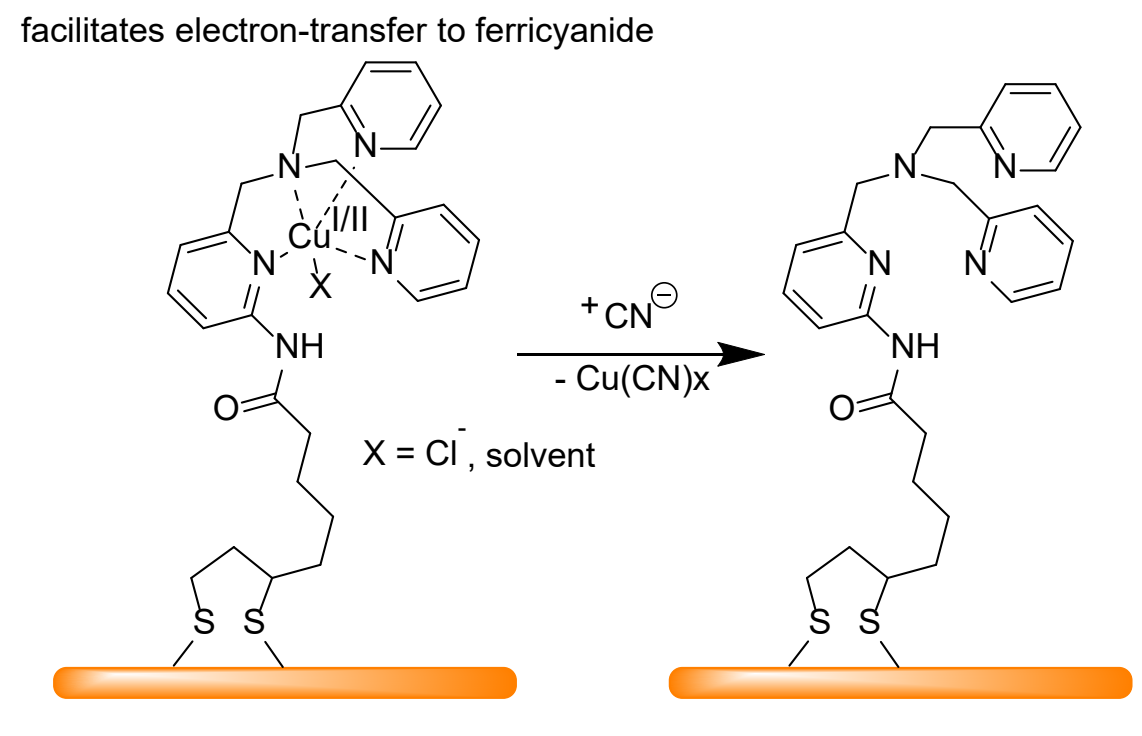

$104_{\text {SAM }}$

Figure 58. Schematic representation of Cu-tris(pyridyl)amine-based SAM for impedimetric detection of $\mathrm{CN}^{-}$by abstraction of $\mathrm{Cu}$. 
An interesting indirect approach for the impedimetric sensing of ascorbate has been developed based on the copper(I) catalysed azide-alkyne cycloaddition (CuAAC; Figure 59). ${ }^{205}$ An azide-terminated SAM was exposed to a Fc-containing alkyne in the presence of $\mathrm{Cu}(\mathrm{II})$. In the presence of ascorbate the $\mathrm{Cu}(\mathrm{II})$ was reduced to the catalytically active $\mathrm{Cu}(\mathrm{I})$ species thus inducing the interfacial "click" reaction. The enhanced steric bulk on the modified interface was then utilised as an efficient, indirect, impedimetric transducer for the presence of ascorbate with a LOD of $2.6 \mathrm{pM}$. The use of a redox-tagged alkyne also provided an additional voltammetric means to monitor the reaction progress, however, it should be noted that this approach is somewhat limited by the difficulty of regenerating the original sensory interface.

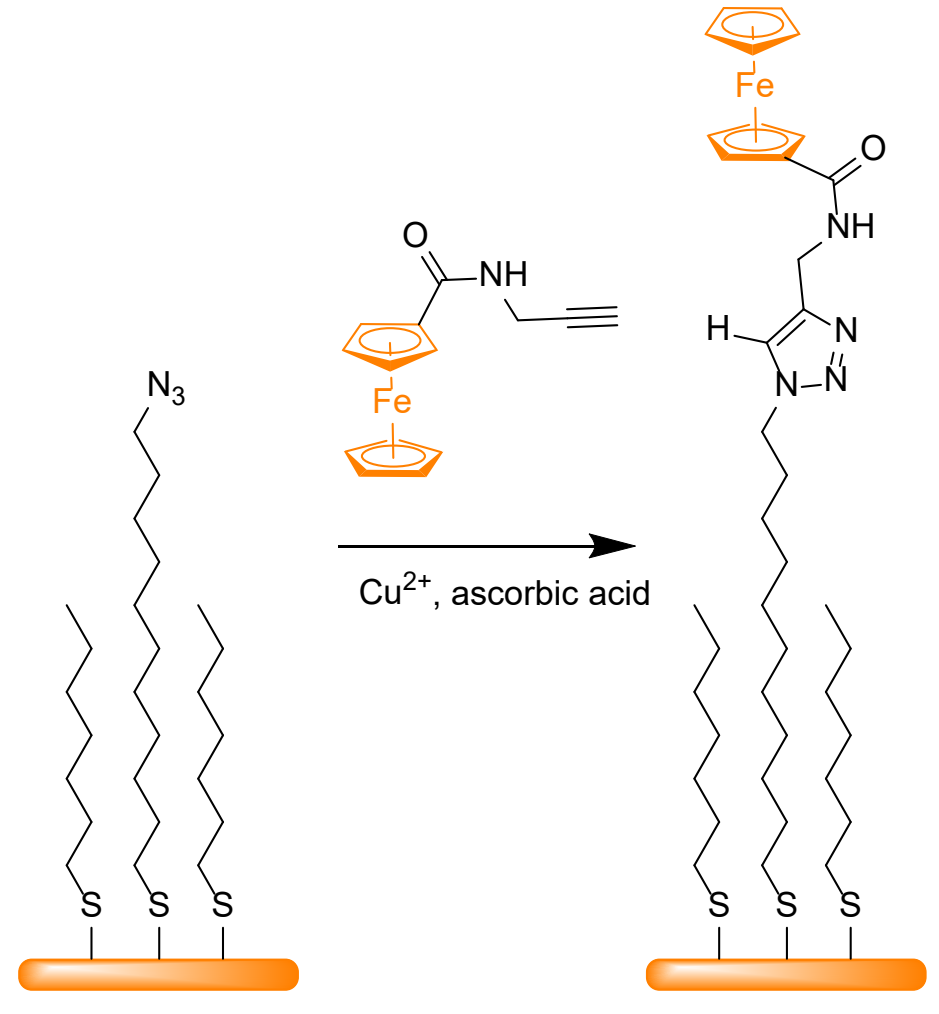

Figure 59. Initial azide-terminated SAM and the SAM after CUAAC click reaction via in situ generated Cu(I) from $\mathrm{Cu}(\mathrm{II})$ and ascorbate. Ascorbate can thus be indirectly sensed at the latter, more sterically blocking, interface by EIS. 
Although impedimetric sensing of cations using bioreceptors (e.g. aptamers) has received considerable attention ${ }^{206-208}$, anion sensing based on this strategy is rare. One recent example is of an aptamer-based sensor for $\mathrm{As}(\mathrm{III})$ (sensed as meta-arsenite, $\mathrm{AsO}_{2}{ }^{-}$) at gold electrodes. ${ }^{209}$ Upon binding of $\mathrm{AsO}_{2}{ }^{-}$the conformation of this aptamer changed to a folded state in which electron-transfer to the electrode was facilitated leading to a significant decrease in $R_{c t}$.

While these works demonstrate the large potential of EIS as a sensitive tool for the detection of a variety of anions, progress in this area since its emergence more than a decade ago has been slow. We attribute this mainly to the need for a redox probe which imposes multiple restrictions on sensor design and performance: 1) Faradaic EIS is almost exclusively performed in pure aqueous media due to lack of suitable (charged) redox probes compatible with organic solvents (solubility/unfavourable charge-transfer characteristics). This requires the synthesis of anion-receptors that not only contain anchor groups for surfaceimmobilisation but that are also capable of anion recognition in pure water. 2) The DC bias potential during the measurement is fixed to the half-wave potential of the redox-probe prohibiting detection of anions that are electroactive close to these potentials. 3) Interactions of the redox-probe with the interface that might lead to baseline instabilities or compete with binding.

The omission of a redox probe thus offers many advantages and has been preliminarily investigated for cation sensing. ${ }^{196-197}$ Anion sensing using non-Faradaic approaches to EIS has remained elusive until very recently and will be discussed in the following section. 


\subsection{Capacitive anion sensing}

We have recently reported an anion receptive SAM based on halogen- and hydrogenbonding foldamers capable of selective anion sensing using impedance-derived capacitance spectroscopy (105 SAM, Figure 60). ${ }^{210}$ In the absence of a redox probe in the aqueous phase, anion sensing was achieved utilising the film capacitance as a sensitive transducer for binding. This capacitance can be easily obtained from the capacitive Nyquist plot (Figure 61) by simple graphical analysis or from data fitting to a suitable equivalent circuit. We not only demonstrated sensitive sensing of the environmentally and biologically relevant chargediffuse anions $\mathrm{ReO}_{4}^{-}, \mathrm{I}^{-}$and $\mathrm{SCN}^{-}$utilising this new methodology, but also reported on the first examples of a XB-receptive interface showing improved performance over the analogous HB film.

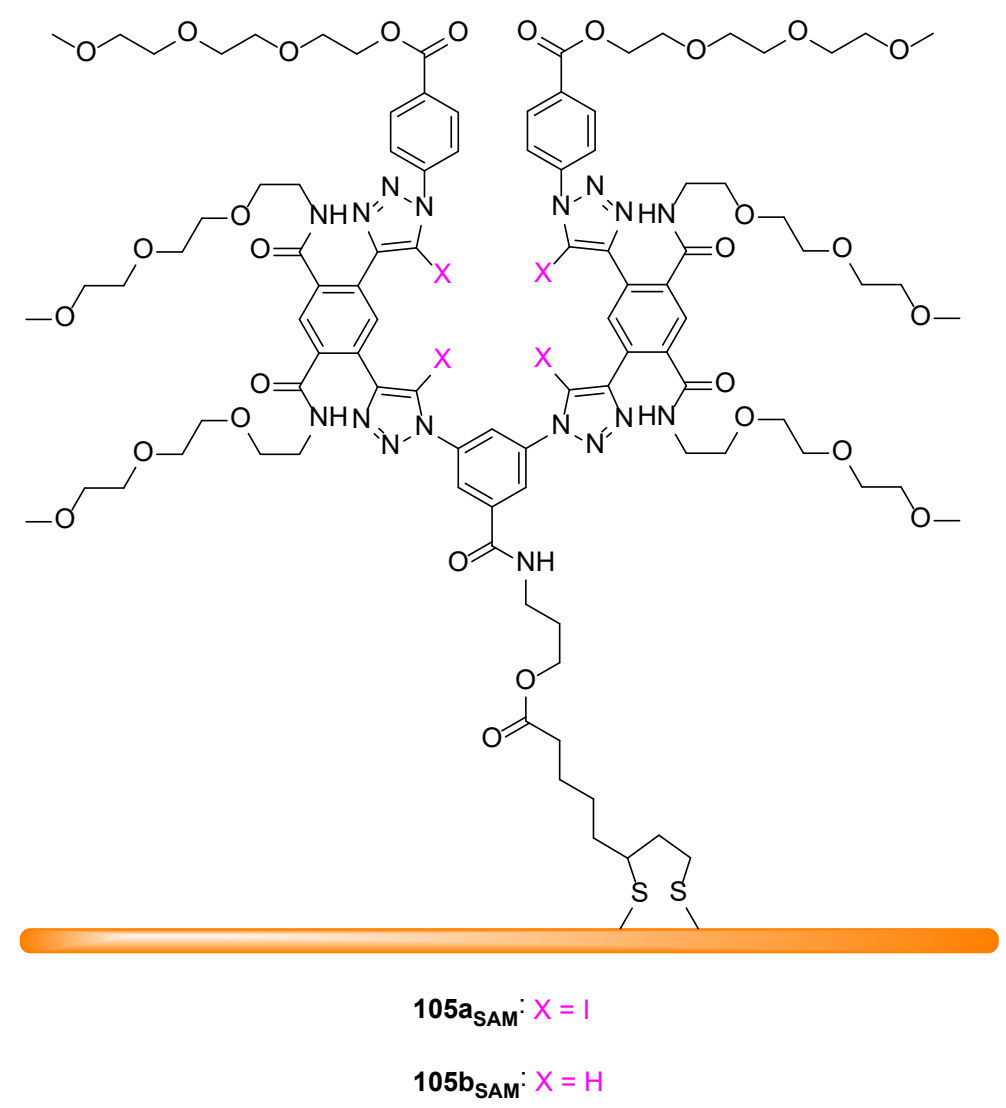

Figure 60. Halogen- and hydrogen-bonding foldamer SAMs for anion sensing in pure water via non-Faradaic capacitance spectroscopy. 


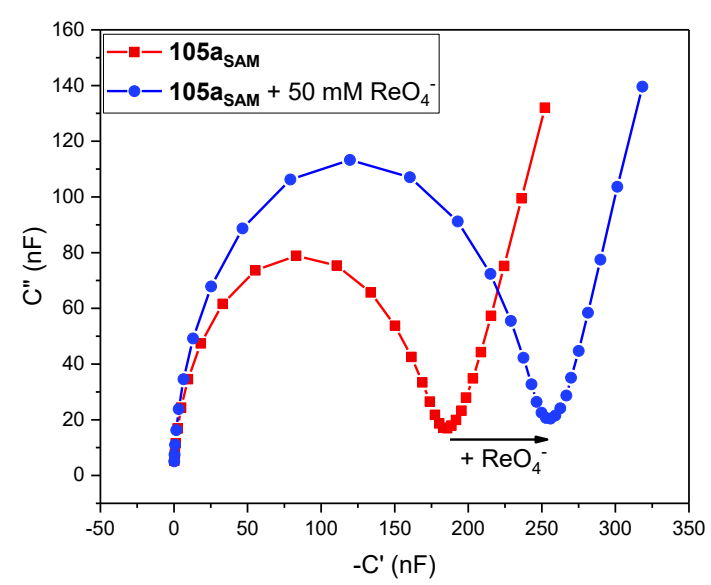

Figure 61. Capacitive Nyquist plots of 105asam in the absence and presence of $50 \mathrm{mM} \mathrm{ReO}_{4}^{-}$showing an increased capacitance in the presence of bound anion. Measurements were performed at open-circuit potential $(\approx 0 \mathrm{~V})$ in the presence of $100 \mathrm{mM}$ electrolyte $(x \mathrm{NaCl}+\mathrm{y} \mathrm{NaReO}, x+y=100 \mathrm{mM})$. Chem. Commun., 2019,55, 4849-4852. Reproduced by permission of The Royal Society of Chemistry.

Anion binding to the receptive interface was macroscopically described by a simple Langmuir adsorption model with low limits of detections (as low as $14 \mu \mathrm{M}$ for $\mathrm{I}^{-}$at 105asam). Importantly, an increase in capacitance upon anion binding can be directly attributed to an increased film dielectric constant due to introduction of a charged species and a concomitant increased film hydration. In contrast to standard Faradaic EIS, where ion binding is transduced due to electrostatic interactions between the surface-confined ion and the charged redox-probe (see Section 3.1), this approach may also facilitate capacitive ionpair sensing and is entirely "reagentless" in completely omitting diffusive or surface-bound electroactive transducers. 


\section{Potentiometric Anion Sensing}

\subsection{General Experimental and Theoretical Considerations}

Potentiometry is an electroanalytical technique in which the electromotive force (emf; a potential) is measured between two electrodes immersed in the analyte solution. The potential is measured between an indicator electrode and a reference electrode, ideally quite unresponsive. Potentiometry is the simplest electroanalytical technique and has been studied in some detail for over a century. By far the most common application of this technique is in ion-selective electrodes (ISEs), whereby, through chemical means, the indicator electrode selectively responds to the concentration (or more accurately the activity) of the target analyte. This is achieved through the selectivity of a membrane that separates the inner filling solution of the indicator electrode and the analyte solution (Figure 62). The response of the system is only dependent on the membrane potential of the indicator electrode; all other potentials (e.g. of the reference electrode) are constant or can be corrected for (e.g. junction potentials, see below). A membrane potential arises when a specific ion selectively partitions into the membrane inducing a charge separation at the membrane boundary and therefore a measurable emf. Of paramount importance to the successful application of such systems is, then, that only one specific ion can partition into the membrane. A variety of different membranes have been used for this purpose such as glass membranes in the ubiquitously used $\mathrm{pH}$-probes, crystalline membranes such as $\mathrm{LaF}_{3}$ (for $\mathrm{F}^{-}$-ISEs) as well as liquid and polymeric membranes. The two latter types rely on the incorporation of ion-exchangers and/or ionophores (ion carriers) to impart selectivity for the desired ion. In this review we will only discuss such systems in which anion selectivity is imparted through the integration of synthetic supramolecular $\mathrm{H}$-bonding hosts. 


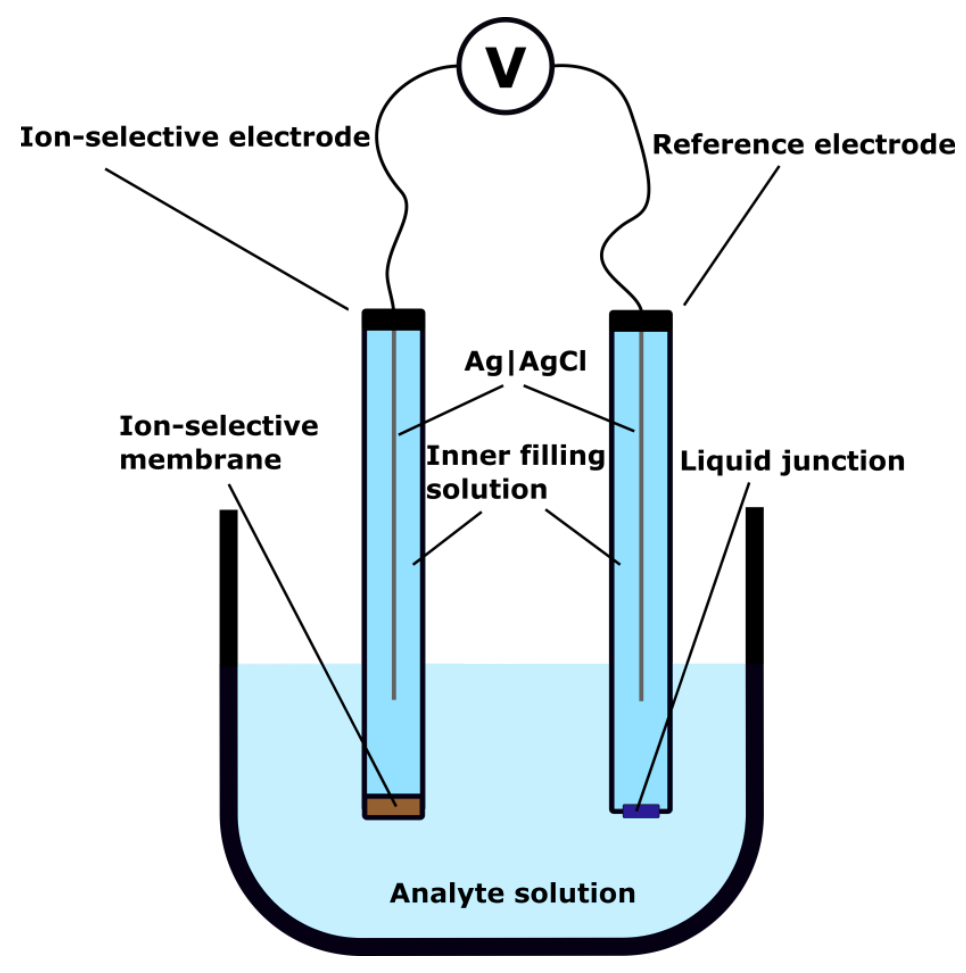

Figure 62. Schematic depiction of a membrane-based ion-selective electrode.

The following discussion briefly describes how the measured potential is related to the concentration of the target analyte. As previously mentioned, the partitioning of the analyte ions into the membrane results in a phase boundary potential whose magnitude can be described accurately by eqn. 3 where $E^{0}$ is a constant and $a_{I}$ and $z_{I}$ the activity and charge of the ion, respectively.

$$
E=E^{0}+\frac{R T}{z_{I} F} \ln a_{I}
$$

It should be noted that two of such phase boundary potentials develop across the membrane; at both the inner and the outer side such that the overall potential across the whole membrane is $E_{M e m b}=E_{\text {Outer }}-E_{\text {Inner }}$. The inner side of the membrane is in contact with the inner filling solution of the electrode which contains a known, constant amount of 
the target analyte. The term $E_{\text {Inner }}$ is thus a constant and like $E^{0}$ does not contribute towards the change in emf that is measured as a function of analyte activity. From this follows that a change in the membrane potential, and also the potential of the whole system (with all junction potentials being constant), is only dependent on $a_{I}$ at the outer membrane, i.e. $a_{I}$ in the analyte solution. The overall emf as a function of $a_{I}$ is hence still described by eqn. 3 whereby the constant $E^{0}$ contains all phase-boundary/junction potentials apart from that at the outer membrane interface. From this equation it can be seen that, at room-temperature, a ten-fold change in the ion activity in the sample induces a measurable potential change of $59.2 \mathrm{mV} / \mathrm{z}_{I}$. This so called "Nernstian response" is however not always observed in reality, whereby, depending on many factors, small deviations from the ideal behaviour can be observed. In this case the response can be described more generally by eqn. 4 , where if $S=59.2 \frac{\mathrm{mV}}{z_{I}}$, ideal Nernstian behaviour according to eqn. 3 is obtained again.

$$
E=E^{0}+S \log a_{I}
$$

While an ideal Nernstian response is desirable, arguably more important is the selectivity for the target analyte. The response of an ISE in the presence of an interfering ion " $\mathrm{J}$ " can be described by the Nicolskii-Eisenman equation (eqn. 5):

$$
E=E^{0}+\frac{R T}{z_{I} F} \log \left(a_{I}+K_{I J}^{p o t} a_{J}^{z_{I} / z_{J}}\right)
$$

where $K_{I J}^{p o t}$ is the selectivity coefficient between the target and interfering ion. A smaller $K_{I J}^{\text {pot }}$ indicates a smaller interference and is ultimately one of the most important parameters that needs to be assessed and tuned. Importantly, depending on the desired application, the ISE does not have to be selective over all potentially interfering anions (i.e. $K_{I J}^{\text {pot }}$ can be $>1$ ) 
as long as the activity of the interfering ion is small enough (i.e. as long as the $K_{I J}^{p o t} a_{J}^{z_{I} / z_{J}}$ term in eqn. 5 is significantly smaller than $a_{I}$ ). The selectivity coefficients of ionophores over various interfering anions are often represented graphically and logarithmically, as depicted in Figure 66 or Figure 72. A negative $\log K_{I J}^{\text {pot }}$ indicates that the ion of interest "I" induces a larger response in comparison to the interfering ion "J". For example, a $\log K_{I J}^{p o t}$ of -1 represents a response that is $10 \mathrm{x}$ smaller for "J" than "I" i.e. $5.7 \mathrm{mV} /$ decade vs. 57 $\mathrm{mV} /$ decade, in an ideal case.

In these systems the response selectivity is primarily determined by the ionophore, but not exclusively (the membrane matrix itself can play a role even if it is chosen to be electrostatically neutral, such as polyvinyl chloride (PVC) or fluorinated polymers). One challenge is that associated with the detection of hydrophilic, strongly solvated anions, such as sulfates or phosphates, where the enthalpic penalty associated with their entering the membrane is pronounced. The presence of lipophilic interfering anions such as thiocyanate or salicylate, which can thus more easily partition into the membrane, can also be problematic. Despite some of these shortcomings ISEs are by far the most common and useful electroanalytical devices for ion sensing applications and are generally cheap and easy to produce and operate. A large variety of ISEs for different ions, in particular for cations, are commercially available and widely used, for example in clinical applications. In comparison to other analytical techniques, their somewhat lower precision is offset by a large detection range and fast response time (usually a few tens of seconds). For more details on the concepts discussed above the interested reader is referred to seminal works by Bakker, Bühlmann, Pretsch and others. ${ }^{211-218}$ 
On a final note, potentiometric techniques can also be applied in other formats, namely that presented by field-effect transistors (FETs). ${ }^{219-221}$ For example, recently, an organic FET (OFET) based on a SAM of a phenylboronic acid derivative for sensing of $\mathrm{F}^{-}$in water has been developed. ${ }^{222}$ Although the transduction mechanisms of these FET sensors differs from that of ISEs, ultimately the selectivity arises from the same ionophore design principles. In the following section we discuss the development of ionophores and ISEs for anions. As for the impedimetric sensors discussed in Section 3, these systems all operate in aqueous media.

\section{2 lonophores for anion-selective electrodes}

As discussed above, the selectivity of ISEs is largely imparted by synthetic ionophores, which are almost always non-covalently incorporated into the membrane matrix by simple mixing, but can be covalently attached to polymeric backbones. The design of anion receptor ionophores for ISEs largely follows principles that are established for solution-phase anion receptors. For example, size complementarity between the target analyte and the ionophore is of considerable importance. Different ionophore topologies have thus been investigated whereby most commonly multiple reversible covalent, dative or non-covalent interactions are exploited to enable strong and selective binding. While strong binding is not per se important for the successful application of a receptor in an ISE, it is beneficial if selective binding of the more hydrated anions is sought (to compensate for the energetic penalty associated with anion-dehydration). This can, for example, be achieved by exploitation of electrostatic interactions, as long as the introduction of charged, or otherwise polar groups, does not render the ionophore too hydrophilic (thus potentially leaching out of the membrane). One complication in design is the difficulty of translating solution-phase binding data (i.e. binding constants/selectivities) to the performance of the receptors as ionophores 
in ISEs, namely because the membrane environment significantly differs from that of a simple solvent. Furthermore, the difficulty of assessing binding stochiometries and conformations as well as possible interactions with the membrane itself additionally hampers the understanding of processes that govern ionophore performance. While the simple signal output (i.e. the "direct" conversion of ion activity to an emf) is attractive for sensing applications it does not - in contrast to voltammetric or impedimetric techniquesallow extraction of further information on binding processes in the system and is thus of low relevance for fundamental studies. Despite these impediments a variety of anion-selective electrodes based on reversible, non-covalent host-guest systems have been developed and examples of anion-ionophores 106-111, developed in the 90s, are given in Figure $63 .{ }^{223-228}$ As can be seen, many of these host-guest based ionophores rely on hydrogen-bond donors such as thioureas and guanidiniums or metal complexes such as corrin (108) or porphyrins (not shown). While, from a supramolecular chemist's point of view, some of these receptors are structurally rather simple they can display remarkable selectivities and the depicted ionophores for chloride $(\mathbf{1 0 6})^{228}$, sulfate $(\mathbf{1 0 7})^{227}$ and sulfite $(\mathbf{1 0 8})^{223}$ are commercially available. For a more comprehensive overview of earlier examples and further details please see reviews by Reinhoudt ${ }^{229}$ and Pretsch. ${ }^{230}$ 


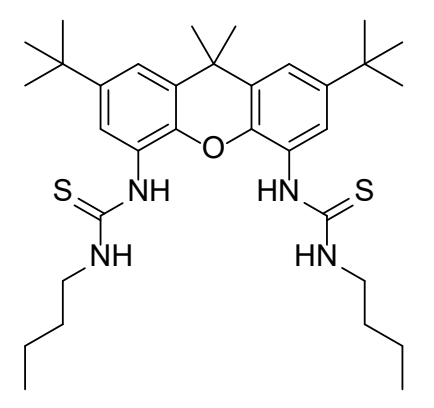

106, for chloride

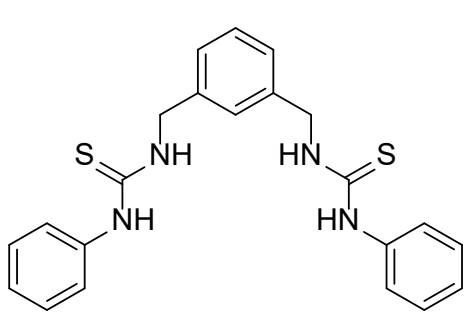

107, for sulfate

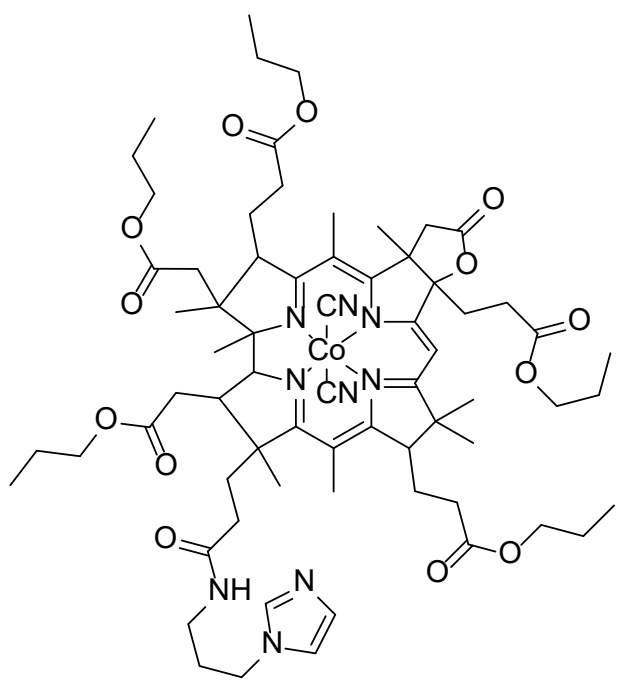

108, for iodide

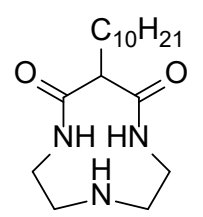

111, for phosphate

109, for sulfite

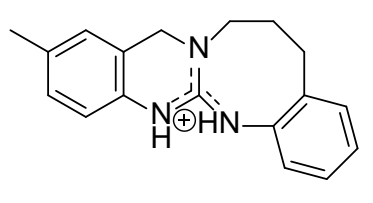

110 , for salicylate

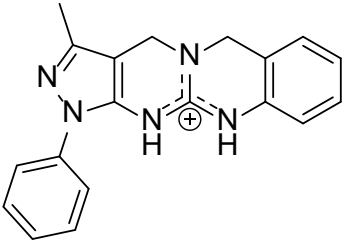

Figure 63. Representative examples of early anion-ionophores for potentiometric sensing of the highlighted anions.

A large number of these (early) anionophores are based on coordinative interactions with metal complexes or reversible covalent bond formation. While ubiquitous, it should be noted that there is some concern regarding the potential toxicity of metal-based ionophores. In the following paragraphs we will not discuss these examples, but will introduce a few more recent examples of anionophores based on other non-covalent interactions, specifically hydrogen-bonding.

Based on the design principles developed towards the end of the last century, anionophores studied in the last two decades have continued to exploit acyclic and cyclic receptors based on established $\mathrm{H}$-bond donors such as amides, ${ }^{231}$ (thio)ureas ${ }^{232-233}$ and guanidiniums. ${ }^{234}$ In 
parallel a variety of other receptive moieties and receptor topologies have been established which are highlighted in more detail below.

While metalloporphyrins have long been established as potent ionophores, their free base analogues have been studied as well. ${ }^{235-237}$ For example, an ISE based on 112 (Figure 64) was shown to exhibit excellent nitrate selectivity over all tested anions in the following order: $\mathrm{NO}_{3}^{-}>\mathrm{SCN}^{-}>\mathrm{OAC}^{-}>\mathrm{NO}_{2}^{-}>\mathrm{ClO}_{4}^{-}>\mathrm{I}^{-}>\mathrm{Br}^{-}>\mathrm{HSO}_{3}^{-}>\mathrm{HCO}_{3}^{-} \cdot .^{237}$ Additionally a Nernstian response $(-57.4 \mathrm{mV} /$ decade) over a wide concentration range $(10 \mu \mathrm{M}-0.1 \mathrm{M})$ with a low LOD $(1.9 \mu \mathrm{M})$ was achieved.

In expanding the toolbox of receptor designs a range of other $\mathrm{H}$-bond donors have been applied in ionophores. The 2,4-dinitrophenylhydrazine motif was investigated in an ionophore for $\mathrm{OAc}^{-238}$ While only possessing moderate selectivity, the sensor was successfully applied to quantify $\mathrm{OAc}^{-}$in vinegar. A very similar ionophore $\mathbf{1 1 3}$ was applied in a $\mathrm{CO}_{3}{ }^{2-}$ sensor. ${ }^{239}$ In this study a new conditioning protocol significantly extended the linear range (6 orders of magnitude) and LOD (down to $80 \mathrm{pM}$ ) of the ISE and was successfully applied in artificial sea water with near-Nernstian response $(26.9 \mathrm{mV})$ towards the divalent anion. Another less common $\mathrm{H}$-bond donor motif, the dithioxamide, was utilised in a $\mathrm{HPO}_{4}{ }^{2-}$ selective electrode based on the cyclic ionophore $114 .{ }^{240}$ This ISE not only possessed a Nernstian response (here $29.6 \mathrm{mV} /$ decade), but also showed excellent selectivity ( $\log K_{\mathrm{HPO}_{4}{ }^{2-}, A^{-}}^{\mathrm{pot}}<-1.55$ in all cases) over all tested anions with a clear anti-Hofmeister bias, i.e. a preference for the more strongly hydrated anions: $\mathrm{HPO}_{4}{ }^{2-}>\mathrm{OAC}^{-}>\mathrm{SO}_{4}{ }^{2-}>\mathrm{HSO}_{4}{ }^{-}>$ $\mathrm{HCO}_{3}{ }^{-}>\mathrm{NO}_{3}{ }^{-}>\mathrm{ClO}_{4}^{-}>\mathrm{I}^{-}>\mathrm{SCN}^{-}>\mathrm{Cl}^{-}>\mathrm{Br}^{-}>\mathrm{F}^{-}>\mathrm{CrO}_{4}{ }^{2-}>\mathrm{MnO}_{4}^{-}>\mathrm{BrO}_{3}^{-}$. 


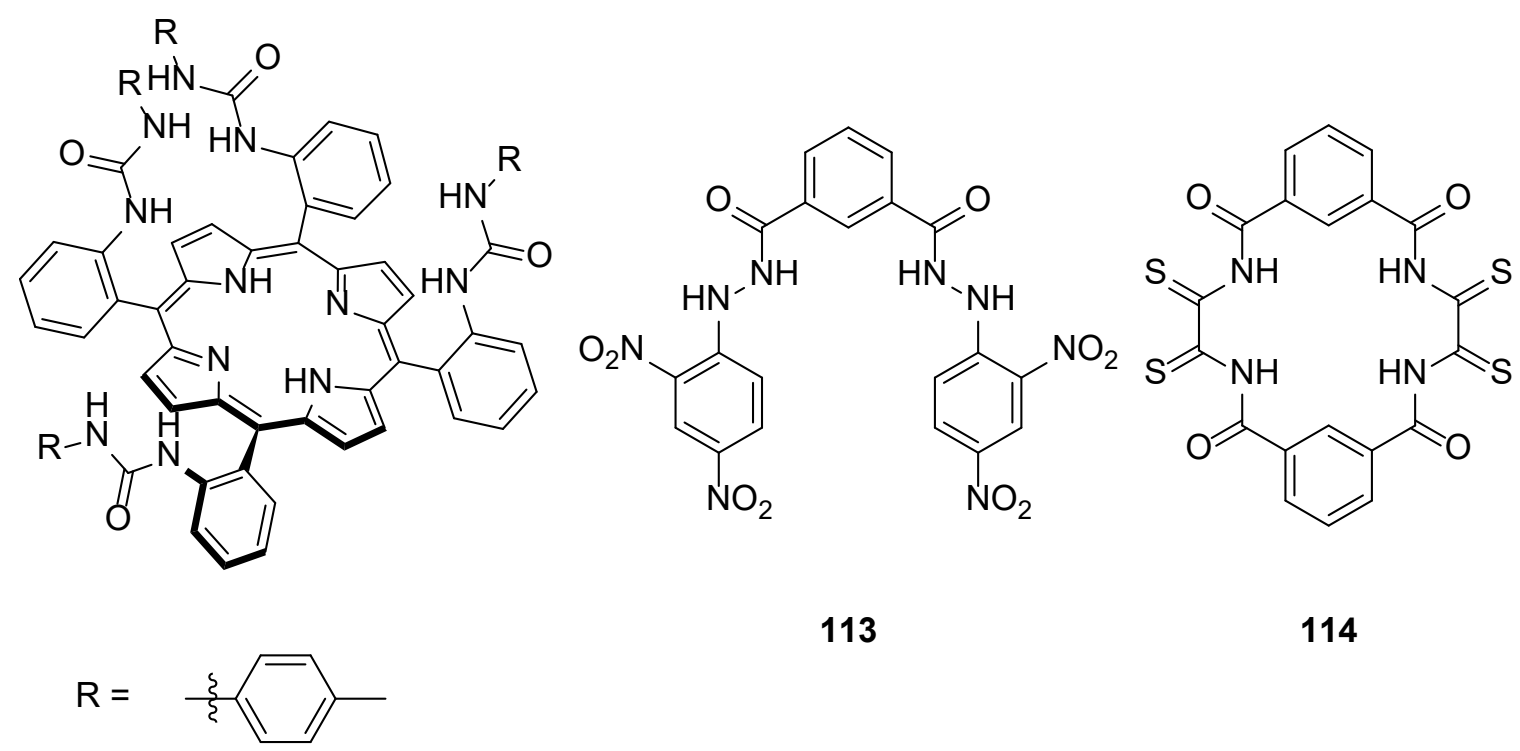

112

Figure 64. Examples of different ionophores based on different topologies and H-bond donors including ureas, hydrazides and dithioxamides.

Urea ionophores with a tripodal topology were first investigated by Bachas and coworkers in 2000 for the sensing of sulfate. ${ }^{241}$ A related amide analogue based on the tris(2aminoethylamine) scaffold was later investigated as a nitrate ionophore, ${ }^{242}$ enabling a nearNernstian response $\left(-54.7 \mathrm{mV} /\right.$ decade) towards nitrate with good selectivities over $\mathrm{Br}^{-}, \mathrm{Cl}^{-}$ and $\mathrm{HPO}_{4}{ }^{2-}$

In a more recent study Liu et al. have investigated three tris(squaramide) ionophores 115a-c based on the same scaffold (Figure 65 ). ${ }^{243}$ While a near-Nernstian response for sulfate was achieved with all ionophores only the ISE based on $115 \mathrm{c}$ showed selectivity over $\mathrm{H}_{2} \mathrm{PO}_{4}{ }^{2-}, \mathrm{Cl}^{-}$, $\mathrm{Br}^{-}$and $\mathrm{NO}_{3}{ }^{-}$, though with no selectivity over $\mathrm{ClO}_{4}{ }^{-}, \mathrm{SCN}^{-}$and $\mathrm{I}^{-}$. The performance of the two other ionophores was significantly worse, in particular for 115a. Importantly, in comparison to Bachas' original tris(urea) ionophore the sulfate selectivity of $\mathbf{1 1 5 c}$ is significantly improved over all tested anions demonstrating the potential of the squaramide motif as a 
potent motif for the recognition of hydrophilic oxoanions. Similarly, four fluorinated tris((thio)ureas 116a-d were recently studied as ionophores for $\mathrm{Cl}^{-} \cdot{ }^{244}$ As can be seen in Figure 66, in particular 116a imparted good chloride selectivity, while the thiourea analogues 116c-d performed worse, with poor selectivity over salicylate. Sufficient selectivities of 116a over salicylate and bicarbonate enabled $\mathrm{Cl}^{-}$assaying in undiluted human serum with a response of $49.8 \mathrm{mV} /$ decade and good recoveries (ratio of measured vs. actual concentration).<smiles></smiles>

115a: $R=H$

115b: $\mathrm{R}=\mathrm{CF}_{3}$

115c: $\mathrm{R}=\mathrm{NO}_{2}$<smiles>[R]NC([X])NCCN(CCNC([X])N[R])CCNC([X])N[R]</smiles>

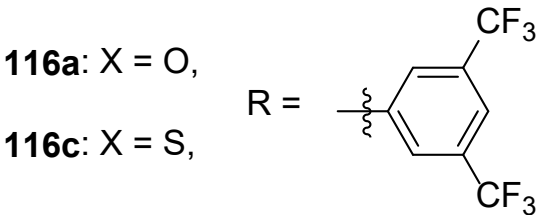

116b: $X=0$,

116d: $X=S$

Figure 65. Tripodal ionophores based on squaramide-containing or fluorinated receptors. 


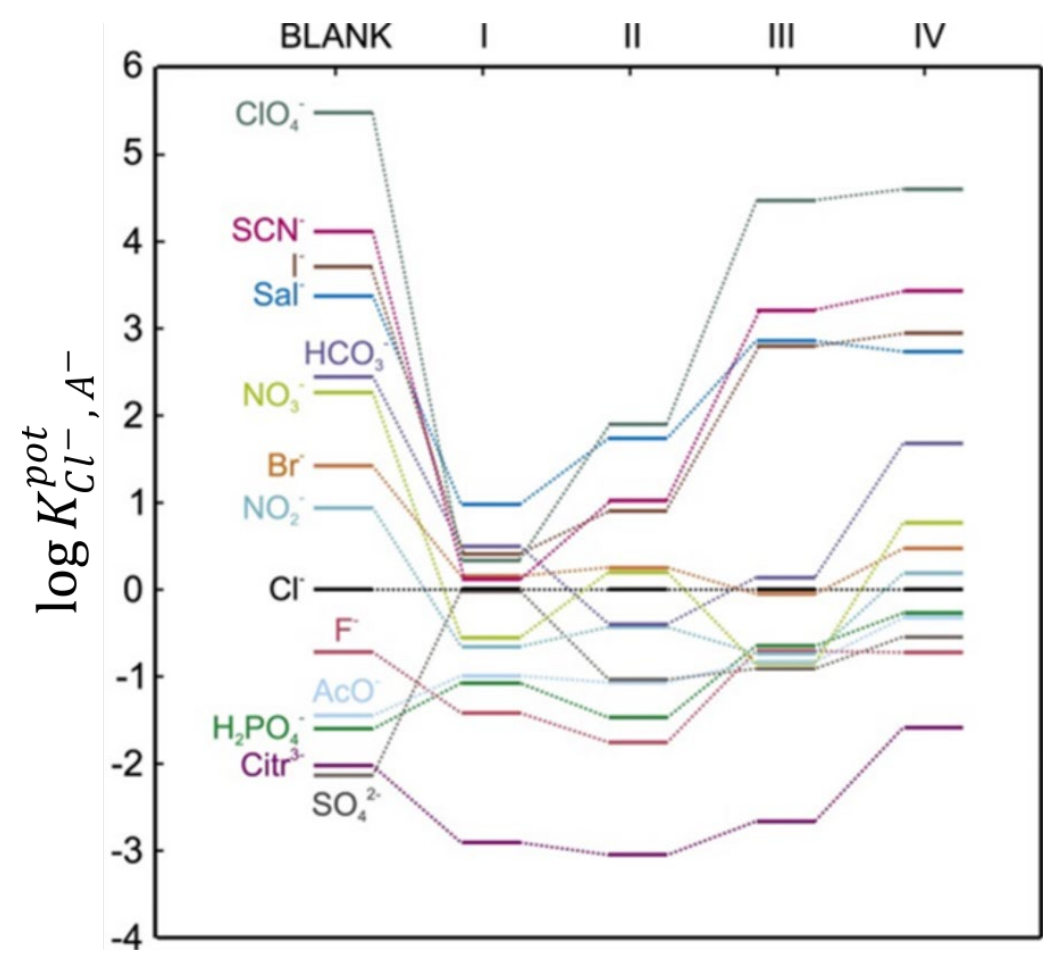

Figure 66. Selectivities of chloride over other anions of ISEs based on fluorinated tripodal receptors 116a-d (IIV). Reprinted with permission from ref. ${ }^{244}$ Copyright 2018 Elsevier.

Ortuño's group have developed a series of benzopyrrole and carbazole-based ionophores for the detection of divalent anions in ISEs. In their first study they investigated the amide- and pyrrole appended benzodipyrroles 117 and 118 (Figure 67). ${ }^{245}$ While ISEs based on these ionophores still showed a bias towards lipophilic monovalent anions (though greatly reduced) their selectivity towards the divalent anions $\mathrm{SO}_{3}{ }^{2-}, \mathrm{SO}_{4}{ }^{2-}, \mathrm{S}_{2} \mathrm{O}_{3}{ }^{2-}$ and $\mathrm{C}_{2} \mathrm{O}_{4}{ }^{2-}$ was significantly enhanced in comparison to a blank membrane. The pyrrole appended ionophore 117 showed particular improvement of oxalate, sulfate and thiosulfate selectivity while the simpler $\mathbf{1 1 8}$ more significantly improved the selectivity towards sulfite. The larger carbazolocarbazole $\mathbf{1 1 9}$ was later shown to significantly enhance the selectivities towards 
the dicarboxylates oxalate, adipate, malonate, succinate and glutarate. ${ }^{246}$ While this ISE displayed good Nernstian response to all these analytes with low LODs of $\leq 3.3 \mu \mathrm{M}$ it should be noted that in contrast to the previous examples this system does not (in comparison to the blank membrane) lower the interference from many of the tested monovalent anions, for example the selectivity towards $\mathrm{ClO}_{4}{ }^{-}$over $\mathrm{Cl}^{-}$actually increases (albeit not as much as for the dicarboxylates). Very recently the urea-carbazole $\mathbf{1 2 0}$ has been utilised as an ISE ionophore for acetate, with reduced interference from $\mathrm{SCN}^{-}, \mathrm{I}^{-}, \mathrm{Br}^{-}$and $\mathrm{NO}_{3}^{-}$, although an interference from ibuprofen, naproxen and benzoate was reported. ${ }^{247}$<smiles>COc1c(OC)c2cc(C(=O)NCc3ccc[nH]3)[nH]c2c2[nH]c(C(=O)NCc3ccc[nH]3)cc12</smiles>

117<smiles>CCCCNC(=O)C1=Cc2cc(C(=O)NCCCC)[nH]c2-c2[nH]c1cc2OC</smiles>

118

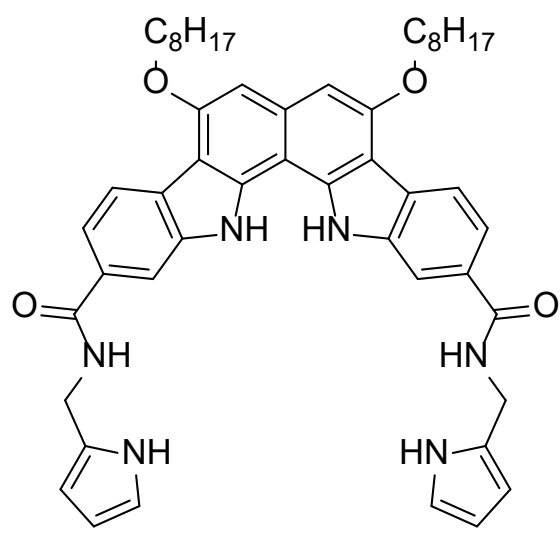

119

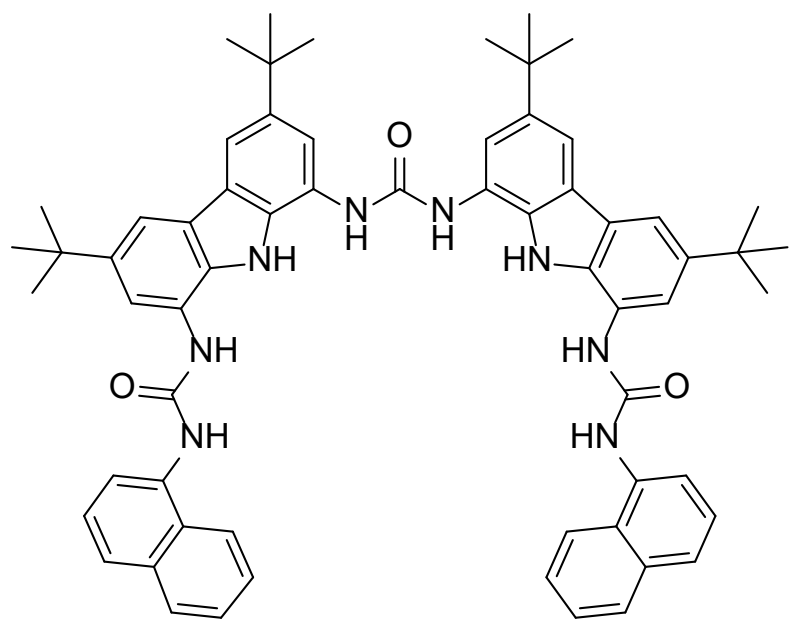

120

Figure 67. Carbazole-based receptors as ionophores for sensing of divalent anions. 
Another class of anionophores that have received considerable attention are those based on calixarenes and calixpyrroles. An early example includes the use of a hexaamide modified calix[6]arene as an ionophore for $\mathrm{HPO}_{4}{ }^{2-}$ with moderate selectivities over other anions. ${ }^{248}$ More in depth studies have been conducted on a variety of urea- and thiourea-containing calix[4]arenes 121a-e (Figure 68). The simple bis-urea ionophore 121a was utilised in a very potent carbonate selective electrode. ${ }^{249}$ The system showed a response of $-29.2 \mathrm{mV}$, as expected for a divalent anion, with excellent selectivities over all tested anions, even $\mathrm{ClO}_{4}{ }^{-}$ $\left(\log \mathrm{K}_{\mathrm{CO}_{3}{ }^{2-}}^{\mathrm{pot}}, \mathrm{ClO}_{4}{ }^{-}=-1.85\right)$, salicylate $\left(\log \mathrm{K}_{\mathrm{CO}_{3}{ }^{2-}}^{\mathrm{pot}}, \mathrm{Sal}^{-}=-1.72\right)$ and $\mathrm{I}^{-}\left(\log \mathrm{K}_{\mathrm{CO}_{3}{ }^{2-}, \mathrm{I}^{-}}^{\mathrm{pot}}=\right.$ -1.68). The very similar $\mathbf{1 2 1 b}$ has later been explored as an ionophore for $\mathrm{NO}_{3}{ }^{-250}$ While not as selective against the less hydrophilic anions $\mathrm{I}^{-}$and $\mathrm{SCN}^{-}$as the aforementioned ISE this system still displayed good selectivity over $\mathrm{Cl}^{-}\left(\log \mathrm{KOO}_{3}{ }^{-}, \mathrm{Cl}^{-}=-3.41\right)$ and a "superNernstian" response of $-72.8 \mathrm{mV} /$ decade. Another slightly adapted receptor $121 \mathrm{c}$-alt based on a 1,3-alternating calix[4]arene and a nitrophenyl-urea receptor displays a significantly different selectivity. ${ }^{251}$ An ISE based on this system has been observed to display a nearNernstian response (-55.7 mV/decade) towards $\mathrm{Cl}^{-}$with good selectivities over a large variety of anions including $\mathrm{NO}_{3}{ }^{-}\left(\log K_{\mathrm{Cl}^{-}}^{\mathrm{pot}}, \mathrm{NO}_{3}{ }^{-}=-2.60\right)$ and $\mathrm{CO}_{3}{ }^{2-}\left(\log K_{\mathrm{Cl}^{-}, \mathrm{CO}_{3}{ }^{2-}}{ }^{\mathrm{ot}}=-3.65\right)$. While the cone conformer 121c-cone displays almost identical selectivities, ${ }^{252}$ the thiourea analogues $121 \mathrm{~d}$-alt/cone and 121e-alt/cone differ somewhat with the 121e-alt being more selective for chloride over almost all tested anions. ${ }^{252}$ 


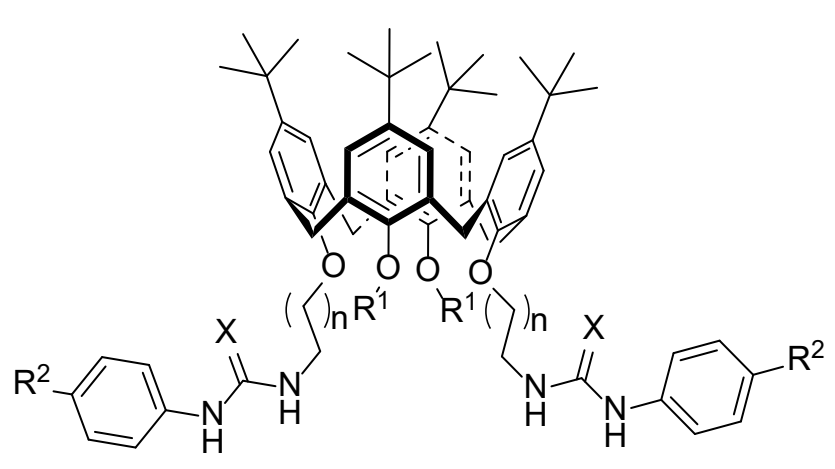

$$
\begin{aligned}
& \text { 121a: } X=O, R^{1}=n, R_{2}=H, n=1 \\
& \text { 121b: } X=O, R^{1}=\operatorname{Pr}, R_{2}=H, n=3 \\
& \text { 121c-alt: } X=O, R^{1}=\operatorname{Pr}, R_{2}=N_{2}, n=1 \\
& \text { 121d-alt/cone: } X=S, R^{1}=\operatorname{Pr}, R_{2}=H, n=1 \\
& \text { 121e-alt/cone: } X=S, R^{1}=\operatorname{Pr}, R_{2}=N_{2}, n=1
\end{aligned}
$$

Figure 68. Calix[4]arene-based ionophores, shown is only the cone conformation.

Like calixarenes, calixpyrroles have been investigated as ionophores in ISEs. While an early study of a [2]pyridine[2]pyrrole has been investigated for a salicylate selective electrode ${ }^{253}$ a more in depth study of various calix[4]pyrroles has been carried out more recently. ${ }^{254}$ To this end Sabek et al. prepared a range of aryl-appended calix[4]pyrroles 122a-g where, in addition to hydrogen-bonds, anion- $\pi$ interactions can drive recognition (Figure 69 and Figure 70). All ISEs based on these ionophores responded to $\mathrm{Cl}^{-}$with near-Nernstian response and a LOD of $\leq 10 \mu \mathrm{M}$. While ionophores $122 \mathrm{a}-\mathrm{c}$ induced sufficient chloride selectivity over $\mathrm{SCN}^{-}$, $\mathrm{NO}_{3}{ }^{-}, \mathrm{HCO}_{3}{ }^{-}$and lactate to enable $\mathrm{Cl}^{-}$sensing in biological fluids, the salicylate selectivity is not sufficient. Only the nitrophenyl-containing ionophore $\mathbf{1 2 2 d}$ shows sufficient selectivity over all anions. These results indicate that anion- $\pi$ interactions can play a significant role in governing the selectivities. Interestingly, receptors $122 \mathrm{e}$ as well as receptors $122 \mathrm{f}-\mathrm{g}$ did not enable $\mathrm{Cl}^{-}$sensing in biological samples due to lowered selectivities over salicylate or $\mathrm{SCN}^{-}$, respectively, in spite of enhanced anion- $\pi$ interactions. The authors further investigated the predictive power of solution phase selectivities of $\mathrm{Cl}^{-}$over $\mathrm{NO}_{3}^{-}$(in $\mathrm{ACN}$ ) showing that they are not correlated to the performance of the ionophore in the ISE format. ${ }^{254}$ A similar behaviour was also reported by Xiao et al. who demonstrated that the use of ionophore 106 in a different sensor format displays altered selectivities. ${ }^{185}$ Specifically, a monolayer of 106 
was formed by physisorption on highly oriented pyrolytic graphite (HOPG) electrodes whereby anion binding to this film was transduced by a modulation of the redox properties of the solution-phase $\left[\mathrm{Fe}(\mathrm{CN})_{6}\right]^{4-}$ probe (decreased peak currents and potential shifts; for further examples of such voltammetric sensors see Section 2.4.2). This interface was most responsive to $\mathrm{H}_{2} \mathrm{PO}_{4}^{-}$while the analogous ISE was selective for $\mathrm{Cl}^{-}$as discussed above.

These observations again demonstrate the difficulty of rationally designing ionophores for specific analytes, as also demonstrated by the wide variation of selectivities of the aforementioned calixarene ionophores. It has to be reiterated that key analytical parameters, including selectivites, can depend strongly on the membrane/interface composition and not only the ionophore itself.<smiles>[R]C(C)c1ccc([C@H]([R])c2ccc([C@H](C)c3ccc([C@H]([R])C)[nH]3)[nH]2)[nH]1</smiles>

$\mathrm{R}^{1}=\mathrm{Me}$

$122 a$<smiles>CC(C)(C)c1ccccc1</smiles>

122b<smiles>CC(C)(C)c1ccc(N)cc1</smiles>

122c<smiles>CC(C)(C)c1ccc([N+](=O)[O-])cc1</smiles>

122d<smiles>O=[N+]([O-])c1cc([N+](=O)[O-])cc([N+](=O)[O-])c1</smiles>

$122 e$
$\mathrm{R}=\mathrm{R}^{1}=$<smiles>CC(C)(C)c1ccc([N+](=O)[O-])cc1</smiles>

$122 f$

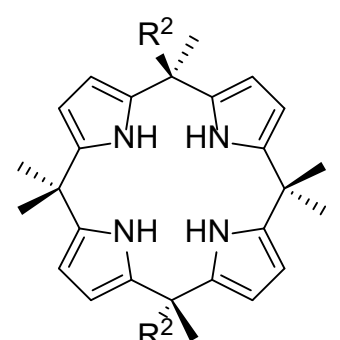

$\mathrm{R}^{2}=$<smiles>CC(C)(C)c1ccc([N+](=O)[O-])cc1</smiles>

$122 \mathrm{~g}$

Figure 69. Calix[4]pyrrole-based ionophores for the investigation of anion- $\pi$ interactions as driving force for anion binding and selectivity. 


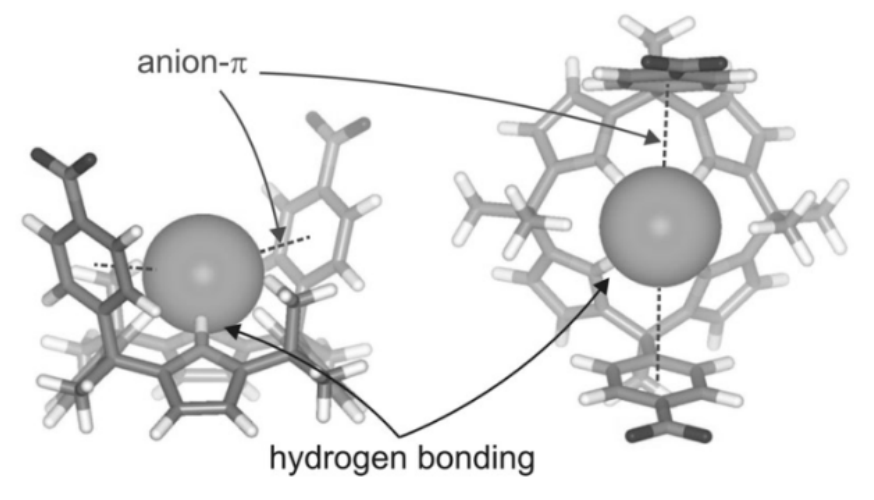

Figure 70. X-ray crystal structure of the $\mathbf{1 2 2} \mathrm{d}_{-\mathrm{Cl}^{-}}$host-guest complex in side and top view highlighting $\mathrm{HB}$ and anion- $\pi$ interactions. Reproduced with permission from Ref. ${ }^{254}$ Copyright 2015 Wiley-VCH.

More recently the groups of Bachas and Flood investigated the performance of macrocyclic C-H bond donors as anionophores. ${ }^{255-257}$ In their first study they investigated the triazolophane 123 (Figure 71) as a potent halide selective ionophore forming 1:1 host-guest complexes as schematically shown in Figure $72 a .^{255}$ In good agreement with previous solution-phase studies an ISE based on this receptor displayed a near-Nernstian response for $\mathrm{Cl}^{-}\left(-54.6 \mathrm{mV} /\right.$ decade) and a Nernstian response for $\mathrm{Br}^{-}(-60.2 \mathrm{mV} /$ decade). The electrode displayed anti-Hofmeister selectivity towards bromide with good selectivity over salicylate $\left(\log K_{B r^{-}}^{p o t}\right.$, sal $\left.^{-}=-1.54\right)$. Furthermore the selectivity over all other interfering ions was large enough to facilitate bromide quantification in spiked horse serum with good recoveries. Using a slightly different membrane composition the ISE could, in the absence of $\mathrm{Br}^{-}$and salicylate, also be used for $\mathrm{Cl}^{-}$determination in serum.

A high iodide selectivity was later achieved with a very similar pyridyl-triazolophane $\mathbf{1 2 4 . 2 5 7}$ The lone pairs of the two central pyridine units disfavour the formation of a $1: 1$ complex with halides in favor of a 2:1 host-guest complex. This renders ISE based on this ionophore particularly iodide selective with good selectivities over all tested anions (Figure 73). This 
iodide sensor showed a near-Nernstian response of $(-62.0 \mathrm{mV} /$ decade) with a LOD of 0.25 $\mu \mathrm{M}$ and a large linear range of $0.8 \mu \mathrm{M}$ to $0.1 \mathrm{M}$.

Similarly, based on the 2:1 host-guest formation of cyanostar 125 (Figure 72b) the same groups also recently reported a $\mathrm{ClO}_{4}^{-}$selective electrode. ${ }^{256}$ While most ISE-membranes without an ionophore would inherently show selectivity towards $\mathrm{ClO}_{4}^{-}$(Hofmeister bias) this ISE is more selective by at least two orders of magnitude over other anions. For example a very large selectivity over salicylate of $\log \mathrm{K}_{\mathrm{ClO}_{4}{ }^{-}}^{\mathrm{pot}} \mathrm{Sal}^{-}=-6.50$ was achieved with nearNernstian response $(-56.7 \mathrm{mV} /$ decade), submicromolar LOD and a wide linear range. It was further shown that this ISE could be used to determine $\mathrm{ClO}_{4}^{-}$in lake water, tap water and horse serum.

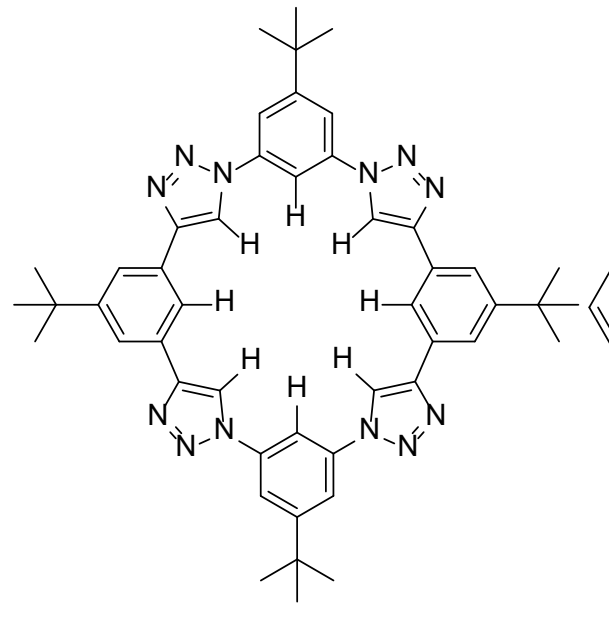

123

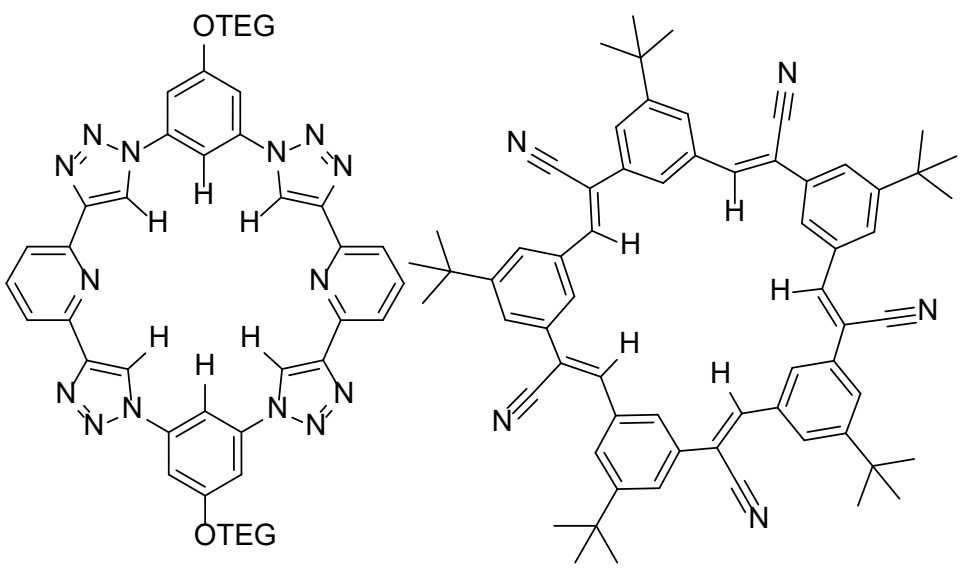

124

125

Figure 71. $\mathrm{C}-\mathrm{H} \mathrm{H}$-bond based anion ionophores. TEG = triethylene glycol. 


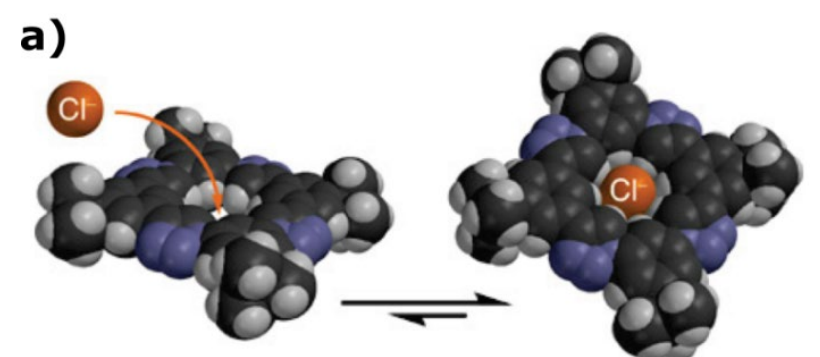

\section{b)}

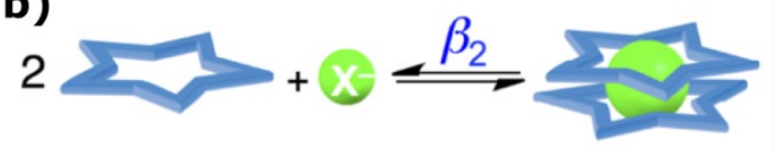

Figure 72. Schematic representation of a) 1:1 chloride binding to triazolophane 123. Reproduced with permission from Ref. ${ }^{255}$ Copyright 2010 American Chemical Society. b) anion binding to cyanostar 125 under formation of a 2:1 host-guest complex. Reproduced with permission from Ref. ${ }^{256}$ Copyright 2018 American Chemical Society

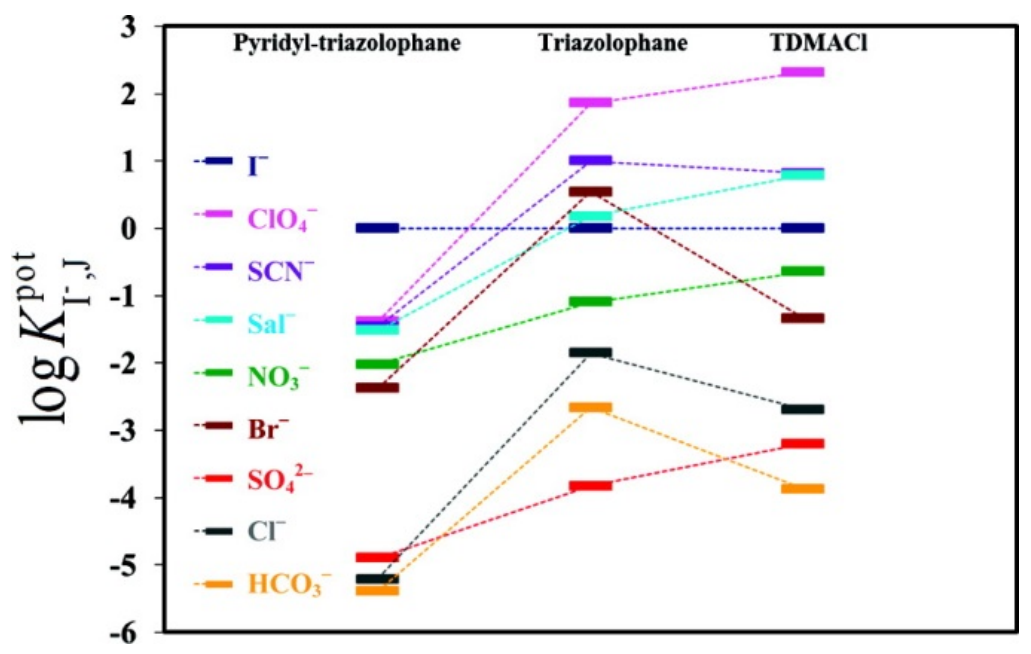

Figure 73. Selectivities of iodide over other anions of ISEs based on pyridyl-triazolophane 124 and triazolophane 123 as well as a control membrane without ionophore (labelled TDMACl). Reprinted with permission from ref. ${ }^{257}$ Copyright 2011 American Chemical Society.

Although boron and boronic acid motifs have gained considerable attention in various (electrochemical) sensors as discussed in Section 2, their use in ISEs has been surprisingly limited. While an early report ${ }^{258}$ indicated that the simple napthylboronic acid can be utilised as an ionophore for $\mathrm{F}^{-}$, few follow-up studies have been conducted. A study by Jańczyk et al. 
showed that different boronic acid derivatives can be utilised to impart good selectivity over the other halides as well as sulfate. ${ }^{259}$ The authors further investigated the performance of the ISE at different $\mathrm{pH}$ values and showed that significant deviations from Nernstian behaviour arise from the complex binding equilibria in this system. Interestingly, a very different selectivity was observed at a poly(3-aminophenylboronic acid) film that was electrochemically synthesized on a Pt electrode. ${ }^{260}$

As can be seen from works highlighted in this section, more selective anionophores are being continually developed to further improve the performance of ISEs. Despite the century long development of ISEs as potent analytical devices many fundamental studies are still being carried out with substantial challenges remaining in terms of chemically engineering high levels of selectivity. ${ }^{217}$ These efforts are focused on various aspects including the development of more real-life relevant, sensitive and compact devices, ${ }^{214}$ as well as exploiting new sensor and transduction formats, ${ }^{261-262}$ including wearable sensors, ${ }^{263}$ paperbased sensors ${ }^{264-265}$ as well as other smart devices. ${ }^{266}$

\section{Summary and Outlook}

As highlighted herein, significant advances have been made in the development of a myriad of electrochemical anion sensors capable of the selective sensing of anions. Importantly, these studies can significantly improve our understanding of (electrochemically mediated) supramolecular host-guest interactions in solution and at interfaces and thus serve as an important tool to investigate such interactions. Voltammetric techniques will undoubtedly remain primary for such fundamental studies offering a high information density while being experimentally accessible. It is likely that ISEs and other potentiometric devices will, due to 
their low cost as well as ease of use and fabrication, continue to be the most widely applied electrochemical anion sensors for real sample analysis for some time to come. While impedimetric approaches are relatively underdeveloped for ion sensing applications they may be able to combine the advantages of both voltammetric and impedimetric techniques in offering not only a high information density, but saliently a high real-life potential (Table 2).

Despite promising developments there remains much untapped capability in bringing electrochemical anion sensors to academic and industrial applications. We believe that future efforts in the field will focus on the following general points:

Exploitation of other supramolecular interactions: Regardless of the transduction mechanism, almost all electrochemical anion sensors employ receptors based on "traditional" supramolecular interactions such as hydrogen-bonding and electrostatic interactions. The use of other "novel" interactions, such as halogen-, chalcogen- or pnictogen bonding, ${ }^{267}$ anion-pi interactions and others promises to be a powerful approach to achieve improved performance.

Multiplexed anion sensing and development of advanced devices: Imperative for the successful application of sensors in various real-life settings is that they are applied in useful formats. Continuing attention will be given to fabricate (shelf-)stable, small and simple devices exploiting microfabrication and microfluidic integration. The simultaneous, multiplexed sensing of different ionic species is highly desirable for many applications (clinical, environmental and industrial e.g. food/beverage testing) and can, for example, be achieved with sensing arrays. In a recent proof-of-concept Swager and coworkers developed 
a novel chemiresistor platform enabling real-time and wireless detection of multiple anions, albeit only in organic solvents. ${ }^{268}$

Fundamental studies on transduction mechanisms and the influence of electrolytes (relevant for voltammetric and impedimetric sensors): The development of a better understanding of the fundamental processes that govern anion binding and the transduction thereof would greatly advance the field and enable a more rational approach to designing advanced sensors capable of detecting specific anionic targets. In particular the influence of the electrolyte and local hydration on signal transduction and anion binding is of crucial importance when application in real-life samples, where different salt concentrations are encountered, is being sought.

Ion-pair recognition (relevant for voltammetric and impedimetric sensors): The (simultaneous) detection of different ionic species or zwitterions is highly desirable in a variety of applications. In combining both anion and cation recognition sites, cooperative effects can lead to significantly enhanced binding as well as other interesting properties. ${ }^{269} \mathrm{~A}$ variety of such ditopic redox active receptors have been investigated for the (simultaneous) voltammetric sensing of anions and cations. ${ }^{40,270-276}$ While fundamentally interesting these sensors are not particularly useful; the oppositely charged ions induce opposing voltammetric shifts that largely cancel each other. While ion-pair sensing has not been investigated via Faradaic EIS the same effect is expected. The reliance on electrostatic interactions as a signal transducer precludes efficient sensing of oppositely charged species. This can most likely be circumvented by use of non-Faradaic techniques such as 
electrochemical capacitance spectroscopy whereby both anions and cations have been separately shown to induce the same response (i.e. increase in capacitance, see Section 3.2).

In the following we also want to highlight future developments that are specifically relevant to each of the discussed electrochemical sensing techniques:

\section{Voltammetric Sensors}

Utilisation of novel redox transducers: While voltammetric anion sensors have incorporated a myriad of redox transducers, the utilisation of other transducers could significantly expand the toolbox when designing systems with specific properties. As discussed above, depending on the target anion, a transducer with an appropriate half-wave potential needs to be employed; many transducers, like Fc, TTF or porphyrin, are incompatible with anions possessing a low oxidation potential, such as iodide or bromide. The incorporation of multiple transducers may also present an opportunity to develop novel systems with enhanced control over binding processes.

Voltammetric anion sensing in competitive (aqueous) media: While a few examples of voltammetric anion sensors have been shown to operate in pure water the vast majority remain restricted to non-polar organic solvents. This illustrates the vast potential that lies in exploring sophisticated molecular architectures that enable anion recognition and electrochemical sensing in pure water.

\section{Impedimetric Sensors}


Impedimetric/capacitive anion sensing in organic media: In contrast to voltammetric sensors which are largely studied in less polar solvent media, impedimetric techniques are currently restricted to (pure) aqueous media. In Faradaic EIS this restriction arises from the redoxprobe itself which needs to possess favourable charge-transfer characteristics (e.g. it needs to be surface sensitive). So far only $\mathrm{Ru}\left(\mathrm{NH}_{3}\right)_{6}{ }^{2+/ 3+}$ or $\mathrm{Fe}(\mathrm{CN})_{6}^{3-/ 4-}$ have been thoroughly investigated for this purpose and only possess appropriate charge-transfer and solubility properties in water. The exploration of other redox-probes could potentially circumvent this, but in completely omitting the transducer capacitive techniques appear even more promising.

Exploration of novel techniques and methodologies: Having received much attention for biosensing, EIS and derived techniques have not been routinely employed for (an)ion sensing. In particular, capacitive approaches are promising as a simple, sensitive means to transduce (anion) binding events. While redox capacitive sensing of large molecules has been successfully employed in recent years ${ }^{277-278}$, redox capacitive (an)ion sensing remains open to exploration.

\section{Potentiometric Sensors}

Development of novel ionophores: The selective sensing of many anions, in particular strongly hydrated anions such as sulfate and phosphate, still present a formidable challenge, in particular when the concentration of interfering, hydrophobic anions is large. As highlighted in the previous section the exploitation of ionophores of different topologies has significantly expanded the pool of useful ionophores. A particularly promising ionophore 
topology which should impart interesting selectivities, but has to the best of our knowledge, not been applied in ISEs, is that presented by mechanically interlocked structures.

Miniaturization and other sensory formats: While many ISEs are routinely employed in in vitro diagnostics their in vivo application remains limited. This mainly arises from difficulties to miniaturize these systems, a problem that has received considerable attention recently, resulting in, for example, development of solid-contact ISEs in which the internal filling solution is eliminated resulting in more durable and minituarisable ISEs. ${ }^{217-218}$ Going forward, it is likely that suitably selective and robust electrochemical anion sensors will play a valuable role in accessible "point of care" diagnostics.

Table 2. Comparison of different electroanalytical techniques in the context of anion sensing and the fundamental study of host-guest interactions.

\begin{tabular}{|c|c|c|c|}
\hline & Voltammetry & Impedance/Capacitance & Potentiometry \\
\hline Advantages & $\begin{array}{l}\text {-High information density } \\
\text {-Experimentally simple }\end{array}$ & $\begin{array}{l}\text {-High information density } \\
\text {-System at equilibrium } \\
\text {-Potentially high real-life } \\
\text { potential }\end{array}$ & $\begin{array}{l}\text {-High real-life potential } \\
\text {-Applicable to any } \\
\text { ionophore } \\
\text {-Well understood }\end{array}$ \\
\hline Disadvantages & $\begin{array}{l}\text {-Low real-life potential } \\
\text {-Requires receptor and } \\
\text { transducer } \\
\text {-Highly dependent on } \\
\text { solvent/electrolyte conditions }\end{array}$ & $\begin{array}{l}\text {-Experimentally difficult } \\
\text {-Often requires receptor } \\
\text { and transducer/anchor } \\
\text { groups } \\
\text {-Transduction mechanisms } \\
\text { poorly understood }\end{array}$ & $\begin{array}{l}\text {-Low information density } \\
\text {-Molecularly ill-defined } \\
\text { systems }\end{array}$ \\
\hline Future efforts & $\begin{array}{l}\text {-Investigation of electrolyte } \\
\text { effects } \\
\text {-More routine application in } \\
\text { water } \\
\text {-Exploitation in switches and } \\
\text { other advanced systems }\end{array}$ & $\begin{array}{l}\text {-Implementation in real-life } \\
\text { sensors } \\
\text {-Study of transduction } \\
\text { mechanisms } \\
\text {-Development of capacitive } \\
\text { approaches }\end{array}$ & $\begin{array}{l}\text {-Development of (more) } \\
\text { selective ionophores } \\
\text {-Miniaturization and } \\
\text { application in vivo }\end{array}$ \\
\hline
\end{tabular}

\section{Author Information}

\section{Corresponding Author}


*E-mail: jason.davis@chem.ox.ac.uk

*E-mail: paul.beer@chem.ox.ac.uk

\section{Notes}

The authors declare no competing financial interest.

\section{Acknowledgements}

We gratefully acknowledge Andrew Docker, Dr. Xiaoxiong Li for helpful comments. We furthermore thank Ausra Baradoke for providing the raw data that was utilized to generate schematic, simulated CVs.

\section{References}

(1) Beer, P. D.; Gale, P. A.; Chen, G. Z. Mechanisms of Electrochemical Recognition of Cations, Anions and Neutral Guest Species by Redox-Active Receptor Molecules. Coord. Chem. Rev. 1999, 185, 3-36.

(2) Valeur, B.; Leray, I. Design Principles of Fluorescent Molecular Sensors for Cation Recognition. Coord. Chem. Rev. 2000, 205, 3-40.

(3) Beer, P. D.; Gale, P. A. Anion Recognition and Sensing: The State of the Art and Future Perspectives. Angew. Chem. Int. Ed. 2001, 40, 486-516.

(4) Kubik, S. Anion Recognition in Water. Chem. Soc. Rev. 2010, 39, 3648-3663.

(5) Langton, M. J.; Serpell, C. J.; Beer, P. D. Anion Recognition in Water: Recent Advances from a Supramolecular and Macromolecular Perspective. Angew. Chem. Int. Ed. 2016, 55, 19741987.

(6) Gilday, L. C.; Robinson, S. W.; Barendt, T. A.; Langton, M. J.; Mullaney, B. R.; Beer, P. D. Halogen Bonding in Supramolecular Chemistry. Chem. Rev. 2015, 115, 7118-7195.

(7) Molina, P.; Zapata, F.; Caballero, A. Anion Recognition Strategies Based on Combined Noncovalent Interactions. Chem. Rev. 2017, 117, 9907-9972.

(8) Caballero, A.; Zapata, F.; Beer, P. D. Interlocked Host Molecules for Anion Recognition and Sensing. Coord. Chem. Rev. 2013, 257, 2434-2455.

(9) Bakker, E.; Telting-Diaz, M. Electrochemical Sensors. Anal. Chem. 2002, 74, 2781-2800.

(10) Beer, P. D.; Gale, P. A.; Chen, G. Z. Electrochemical Molecular Recognition: Pathways between Complexation and Signalling. J. Chem. Soc., Dalton Trans. 1999, 1897-1910.

(11) Miller, S. R.; Gustowski, D. A.; Chen, Z. H.; Gokel, G. W.; Echegoyen, L.; Kaifer, A. E. Rationalization of the Unusual Electrochemical Behavior Observed in Lariat Ethers and Other Reducible Macrocyclic Systems. Anal. Chem. 1988, 60, 2021-2024.

(12) Oliveira, R.; Groni, S.; Fave, C.; Branca, M.; Mavre, F.; Lorcy, D.; Fourmigue, M.; Schollhorn, B. Electrochemical Activation of a Tetrathiafulvalene Halogen Bond Donor in Solution. Phys. Chem. Chem. Phys. 2016, 18, 15867-15873.

(13) Jin, S.; Wang, D.; Jin, X.; Chen, G. Z. Intramolecular Electrostatics: Coulomb's Law at SubNanometers. ChemPhysChem 2004, 5, 1623-1629. 
(14) Bao, D.; Millare, B.; Xia, W.; Steyer, B. G.; Gerasimenko, A. A.; Ferreira, A.; Contreras, A.; Vullev, V. I. Electrochemical Oxidation of Ferrocene: A Strong Dependence on the Concentration of the Supporting Electrolyte for Nonpolar Solvents. J. Phys. Chem. A 2009, 113, 1259-1267.

(15) Bao, D.; Ramu, S.; Contreras, A.; Upadhyayula, S.; Vasquez, J. M.; Beran, G.; Vullev, V. I. Electrochemical Reduction of Quinones: Interfacing Experiment and Theory for Defining Effective Radii of Redox Moieties. J. Phys. Chem. B 2010, 114, 14467-14479.

(16) Sun, R.; Wang, L.; Yu, H.; Abdin, Z.-U.-.; Chen, Y.; Huang, J.; Tong, R. Molecular Recognition and Sensing Based on Ferrocene Derivatives and Ferrocene-Based Polymers. Organometallics 2014, 33, 4560-4573.

(17) Astruc, D. Why Is Ferrocene So Exceptional? Eur. J. Inorg. Chem. 2017, 2017, 6-29.

(18) Beer, P. D.; Chen, Z.; Goulden, A. J.; Graydon, A.; Stokes, S. E.; Wear, T. Selective Electrochemical Recognition of the Dihydrogen Phosphate Anion in the Presence of Hydrogen Sulfate and Chloride lons by New Neutral Ferrocene Anion Receptors. J. Chem. Soc., Chem. Commun. 1993, 1834-1836.

(19) Beer, P. D.; Keefe, A. D. A New Approach to the Coordination of Anions, Novel Polycobalticinium Macrocyclic Receptor Molecules. J. Organomet. Chem. 1989, 375, C40-C42.

(20) Canevet, D.; Sallé, M.; Zhang, G.; Zhang, D.; Zhu, D. Tetrathiafulvalene (TTF) Derivatives: Key Building-Blocks for Switchable Processes. Chem. Commun. 2009, 2245-2269.

(21) Schröder, H. V.; Schalley, C. A. Tetrathiafulvalene - a Redox-Switchable Building Block to Control Motion in Mechanically Interlocked Molecules. Beilstein J. Org. Chem. 2018, 14, 2163-2185.

(22) Biesaga, M.; Pyrzyńska, K.; Trojanowicz, M. Porphyrins in Analytical Chemistry. A Review. Talanta 2000, 51, 209-224.

(23) Ghosh, T.; Maiya, B. G.; Wong, M. W. Fluoride lon Receptors Based on Dipyrrolyl Derivatives Bearing Electron-Withdrawing Groups: Synthesis, Optical and Electrochemical Sensing, and Computational Studies. J. Phys. Chem. A 2004, 108, 11249-11259.

(24) Anzenbacher, P.; Palacios, M. A.; Jursíková, K.; Marquez, M. Simple Electrooptical Sensors for Inorganic Anions. Org. Lett. 2005, 7, 5027-5030.

(25) Satheshkumar, A.; Manivannan, R.; Elango, K. P. Spectroscopic, Electrochemical and Theoretical Studies on Anion Recognition by Receptors with Redox Active Ferrocene and Quinone Centers Bridged by Imidazole. J. Organomet. Chem. 2014, 750, 98-106.

(26) Fahrenbach, A. C.; Warren, S. C.; Incorvati, J. T.; Avestro, A.-J.; Barnes, J. C.; Stoddart, J. F.; Grzybowski, B. A. Organic Switches for Surfaces and Devices. Adv. Mater. 2013, 25, 331-348.

(27) Beer, P. D.; Cadman, J. Electrochemical and Optical Sensing of Anions by Transition Metal Based Receptors. Coord. Chem. Rev. 2000, 205, 131-155.

(28) Beer, P. D.; Gale, P. A.; Chen, Z. In Adv. Phys. Org. Chem.; Elsevier, 1999; Vol. 31.

(29) Beer, P. D.; Cadman, J.; Lloris, J. M.; Martínez-Máñez, R.; Soto, J.; Pardo, T.; Marcos, M. D. Anion Interaction with Ferrocene-Functionalised Cyclic and Open-Chain Polyaza and Aza-Oxa Cycloalkanes. J. Chem. Soc., Dalton Trans. 2000, 1805-1812.

(30) Beer, P. D.; Bernhardt, P. V. A Ferrocene Functionalised Macrocyclic Receptor for Cations and Anions. J. Chem. Soc., Dalton Trans. 2001, 1428-1431.

(31) Bernhardt, P. V.; Creevey, N. L. Electrochemical Anion Recognition with Ferrocene Functionalised Macrocycles. Dalton Trans. 2004, 914-920.

(32) Reynes, O.; Bucher, C.; Moutet, J.-C.; Royal, G.; Saint-Aman, E.; Ungureanu, E.-M. Electrochemical Sensing of Anions by Redox-Active Receptors Built on the Ferrocenyl Cyclam Framework. J. Electroanal. Chem. 2005, 580, 291-299.

(33) Kuo, L.-J.; Liao, J.-H.; Chen, C.-T.; Huang, C.-H.; Chen, C.-S.; Fang, J.-M. Two-Arm Ferrocene Amide Compounds: Synclinal Conformations for Selective Sensing of Dihydrogen Phosphate Ion. Org. Lett. 2003, 5, 1821-1824. 
(34) Huang, X.; Wu, B.; Jia, C.; Hay, B. P.; Li, M.; Yang, X. J. Stepwise Encapsulation of Sulfate lons by Ferrocenyl-Functionalized Tripodal Hexaurea Receptors. Chem. Eur. J. 2013, 19, 90349041.

(35) Abouderbala, L. O.; Belcher, W. J.; Boutelle, M. G.; Cragg, P. J.; Steed, J. W.; Turner, D. R.; Wallace, K. J. Cooperative Anion Binding and Electrochemical Sensing by Modular Podands. Proc. Natl. Acad. Sci. U. S. A. 2002, 99, 5001.

(36) Reynes, O.; Maillard, F.; Moutet, J.-C.; Royal, G.; Saint-Aman, E.; Stanciu, G.; Dutasta, J.-P.; Gosse, I.; Mulatier, J.-C. Complexation and Electrochemical Sensing of Anions by AmideSubstituted Ferrocenyl Ligands. J. Organomet. Chem. 2001, 637, 356-363.

(37) Li, C.; Wang, L.; Deng, L.; Yu, H.; Huo, J.; Ma, L.; Wang, J. Electrochemical Assessment of the Interaction of Dihydrogen Phosphate with a Novel Ferrocenyl Receptor. J. Phys. Chem. B 2009, 113, 15141-15144.

(38) Zapata, F.; Caballero, A.; Espinosa, A.; Tárraga, A.; Molina, P. Cation Coordination Induced Modulation of the Anion Sensing Properties of a Ferrocene-Imidazophenanthroline Dyad: Multichannel Recognition from Phosphate-Related to Chloride Anions. J. Org. Chem. 2008, 73, 4034-4044.

(39) Alfonso, M.; Espinosa Ferao, A.; Tárraga, A.; Molina, P. Electrochemical and Fluorescent Ferrocene-Imidazole-Based Dyads as lon-Pair Receptors for Divalent Metal Cations and Oxoanions. Inorg. Chem. 2015, 54, 7461-7473.

(40) Alfonso, M.; Tárraga, A.; Molina, P. Ferrocenylbenzobisimidazoles for Recognition of Anions and Cations. Inorg. Chem. 2013, 52, 7487-7496.

(41) Zapata, F.; Caballero, A.; Tárraga, A.; Molina, P. Ferrocene-Substituted Nitrogen-Rich Ring Systems as Multichannel Molecular Chemosensors for Anions in Aqueous Environment. J. Org. Chem. 2010, 75, 162-169.

(42) Alfonso, M.; Tárraga, A.; Molina, P. Preparation and Sensing Properties of a Nitrogen-Rich Ferrocene-Imidazole-Quinoxaline Triad Decorated with Pyrrole Rings. Dalton Trans. 2016, 45, 19269-19276.

(43) Evans, N. H.; Serpell, C. J.; Christensen, K. E.; Beer, P. D. Amide and Urea FerroceneContaining Macrocycles Capable of the Electrochemical Sensing of Anions. Eur. J. Inorg. Chem. 2012, 2012, 939-944.

(44) Deng, L.; Wang, L.; Huo, J.; Tan, Q.; Yang, Q.; Yu, H.; Gao, H.; Wang, J. Preparation of N, N 'Bisethoxyethane [12] Amideferrocenophane and Its Application in Anion Recognition. J. Phys. Chem. B 2008, 112, 5333-5337.

(45) Otón, F.; Espinosa, A.; Tárraga, A.; Ratera, I.; Wurst, K.; Veciana, J.; Molina, P. Mononuclear Ferrocenophane Structural Motifs with Two Thiourea Arms Acting as a Dual Binding Site for Anions and Cations. Inorg. Chem. 2009, 48, 1566-1576.

(46) Nieto, D.; González-Vadillo, A. M.; Bruña, S.; Pastor, C. J.; Kaifer, A. E.; Cuadrado, I. Pt (II)Activated Coupling of Aminoethylferrocene with Benzonitrile. A Facile Access Route to a New Redox-Active Bis (Ferrocenyl-Amidine) Anion Sensor. Chem. Commun. 2011, 47, 1039810400.

(47) Otón, F.; Espinosa, A.; Tárraga, A.; de Arellano, C. R.; Molina, P. [3.3] Ferrocenophanes with Guanidine Bridging Units as Multisignalling Receptor Molecules for Selective Recognition of Anions, Cations, and Amino Acids. Chem. Eur. J. 2007, 13, 5742-5752.

(48) Sola, A.; Orenes, R. A.; García, M. Á.; Claramunt, R. M.; Alkorta, I.; Elguero, J.; Tárraga, A.; Molina, P. Unprecedented 1, 3-Diaza [3] Ferrocenophane Scaffold as Molecular Probe for Anions. Inorg. Chem. 2011, 50, 4212-4220.

(49) Gale, P. A.; Hursthouse, M. B.; Light, M. E.; Sessler, J. L.; Warriner, C. N.; Zimmerman, R. S. Ferrocene-Substituted Calix[4]Pyrrole: A New Electrochemical Sensor for Anions Involving $\mathrm{CH}$-..Anion Hydrogen Bonds. Tetrahedron Lett. 2001, 42, 6759-6762.

(50) Guo, D.-S.; Liu, Z.-P.; Ma, J.-P.; Huang, R.-Q. A Novel Ferrocene-Based Thiacalix [4] Arene Ditopic Receptor for Electrochemical Sensing of Europium (III) and Dihydrogen Phosphate lons. Tetrahedron Lett. 2007, 48, 1221-1224. 
(51) Tomapatanaget, B.; Tuntulani, T.; Chailapakul, O. Calix [4] Arenes Containing Ferrocene Amide as Carboxylate Anion Receptors and Sensors. Org. Lett. 2003, 5, 1539-1542.

(52) Evans, A. J.; Matthews, S. E.; Cowley, A. R.; Beer, P. D. Anion Binding by Calix [4] Arene Ferrocene Ureas. Dalton Trans. 2003, 4644-4650.

(53) Métay, E.; Duclos, M. C.; Pellet-Rostaing, S.; Lemaire, M.; Schulz, J.; Kannappan, R.; Bucher, C.; Saint-Aman, E.; Chaix, C. Synthesis and Anion-Binding Properties of Novel Redox-Active Calixarene Receptors. Eur. J. Org. Chem. 2008, 2008, 4304-4312.

(54) Shaabani, B.; Shaghaghi, Z. Anion-Binding Properties of Two Calix [4] Arene Derivatives Containing Two Ferrocene Imine or Ferrocene Amine Units at the Upper Rim. Appl. Organomet. Chem. 2011, 25, 317-322.

(55) Heuzé, K.; Mézière, C.; Fourmigué, M.; Batail, P.; Coulon, C.; Canadell, E.; Auban-Senzier, P.; Jérome, D. An Efficient, Redox-Enhanced Pair of Hydrogen-Bond Tweezers for Chloride Anion Recognition, a Key Synthon in the Construction of a Novel Type of Organic Metal Based on the Secondary Amide-Functionalized Ethylenedithiotetrathiafulvalene, $\beta$ ".-(EDT-TTFCONHMe)2[Cl.H2O]. Chem. Mater. 2000, 12, 1898-1904.

(56) Nielsen, K. A.; Jeppesen, J. O.; Levillain, E.; Becher, J. Mono-Tetrathiafulvalene Calix [4] Pyrrole in the Electrochemical Sensing of Anions. Angew. Chem. Int. Ed. 2003, 42, 187-191.

(57) Lu, H.; Xu, W.; Zhang, D.; Zhu, D. Highly Effective Phosphate Electrochemical Sensor Based on Tetrathiafulvalene. Chem. Commun. 2005, 4777-4779.

(58) Lu, H.; Xu, W.; Zhang, D.; Chen, C.; Zhu, D. A Novel Multisignaling Optical-Electrochemical Chemosensor for Anions Based on Tetrathiafulvalene. Org. Lett. 2005, 7, 4629-4632.

(59) Xiong, J.; Sun, L.; Liao, Y.; Li, G.-N.; Zuo, J.-L.; You, X.-Z. A New Optical and Electrochemical Sensor for Fluoride Ion Based on the Functionalized Boron-Dipyrromethene Dye with Tetrathiafulvalene Moiety. Tetrahedron Lett. 2011, 52, 6157-6161.

(60) Bejger, C.; Park, J. S.; Silver, E. S.; Sessler, J. L. Tetrathiafulvalene Diindolylquinoxaline: A Dual Signaling Anion Receptor with Phosphate Selectivity. Chem. Commun. 2010, 46, 7745-7747.

(61) Lee, M. H.; Cao, Q.-Y.; Kim, S. K.; Sessler, J. L.; Kim, J. S. Anion Responsive TTF-Appended Calix[4]Arenes. Synthesis and Study of Two Different Conformers. J. Org. Chem. 2011, 76, 870-874.

(62) Shi, Z.; Han, Q.-H.; Li, X.-Y.; Shao, M.-Y.; Zhu, Q.-Y.; Dai, J. Bis(Diamino-Diamido)Tetrathiafulvalene, a Redox Active Sensor for Proton, Anions, and Cations. Dalton Trans. 2011, 40, 7340-7347.

(63) Shi, Z.; Lu, Z.-J.; Zhu, Q.-Y.; Huo, L.-B.; Han, Q.-H.; Bian, G.-Q.; Dai, J. Diamino-Diamido Tetrathiafulvalene for the Sensing of Anions and Cations: A View in Electrochemistry and Structure. J. Phys. Chem. B 2011, 115, 3020-3026.

(64) D. Beer, P.; G. B. Drew, M.; Jagessar, R. Selective Anion Recognition by Novel 5,10,15,20Tetrakis(o-Ferrocenylcarbonylaminophenyl-Substituted) Zinc Metalloporphyrin Receptors. J. Chem. Soc., Dalton Trans. 1997, 881-886.

(65) Cormode, D. P.; Murray, S. S.; Cowley, A. R.; Beer, P. D. Sulfate Selective Anion Recognition by a Novel Tetra-Imidazolium Zinc Metalloporphyrin Receptor. Dalton Trans. 2006, 51355140 .

(66) Cormode, D. P.; Drew, M. G. B.; Jagessar, R.; Beer, P. D. Metalloporphyrin Anion Sensors: The Effect of the Metal Centre on the Anion Binding Properties of Amide-Functionalised and Tetraphenyl Metalloporphyrins. Dalton Trans. 2008, 6732-6741.

(67) Schumacher, A. L.; Hill, J. P.; Ariga, K.; D’Souza, F. Highly Effective Electrochemical Anion Sensing Based on Oxoporphyrinogen. Electrochem. Commun. 2007, 9, 2751-2754.

(68) Bhaumik, C.; Saha, D.; Das, S.; Baitalik, S. Synthesis, Structural Characterization, Photophysical, Electrochemical, and Anion-Sensing Studies of Luminescent Homo- and Heteroleptic Ruthenium(II) and Osmium(II) Complexes Based on Terpyridyl-Imidazole Ligand. Inorg. Chem. 2011, 50, 12586-12600. 
(69) Bhaumik, C.; Maity, D.; Das, S.; Baitalik, S. Anion Sensing Studies of Luminescent BisTridentate Ruthenium(II) and Osmium(II) Complexes Based on Terpyridyl-Imidazole Ligand through Different Channels. Polyhedron 2013, 52, 890-899.

(70) Maity, D.; Bhaumik, C.; Mondal, D.; Baitalik, S. Ru(II) and Os(II) Complexes Based on Terpyridyl-Imidazole Ligand Rigidly Linked to Pyrene: Synthesis, Structure, Photophysics, Electrochemistry, and Anion-Sensing Studies. Inorg. Chem. 2013, 52, 13941-13955.

(71) Das, A.; Mondal, P.; Dasgupta, M.; Kishore, N.; Lahiri, G. K. Substituent Directed Selectivity in Anion Recognition by a New Class of Simple Osmium-Pyrazole Derived Receptors. Dalton Trans. 2016, 45, 2605-2617.

(72) Lehr, J.; Lang, T.; Blackburn, O. A.; Barendt, T. A.; Faulkner, S.; Davis, J. J.; Beer, P. D. Anion Sensing by Solution-and Surface-Assembled Osmium (II) Bipyridyl Rotaxanes. Chem. Eur. J. 2013, 19, 15898-15906.

(73) Beer, P. D.; Szemes, F.; Balzani, V.; Salà, C. M.; Drew, M. G. B.; Dent, S. W.; Maestri, M. Anion Selective Recognition and Sensing by Novel Macrocyclic Transition Metal Receptor Systems. 1H NMR, Electrochemical, and Photophysical Investigations. J. Am. Chem. Soc. 1997, 119, 11864-11875.

(74) Beer, P. D.; Berry, N. G.; Cowley, A. R.; Hayes, E. J.; Oates, E. C.; Wong, W. W. Metal-Directed Self-Assembly of Bimetallic Dithiocarbamate Transition Metal Cryptands and Their Binding Capabilities. Chem. Commun. 2003, 2408-2409.

(75) Berry, N. G.; Pratt, M. D.; Fox, O. D.; Beer, P. D. Transition Metal Self-Assembly of Dithiocarbamate Based Anion Receptors. Supramol. Chem. 2001, 13, 677-682.

(76) Beer, P. D.; Berry, N.; Drew, M. G.; Fox, O. D.; Padilla-Tosta, M. E.; Patell, S. Self-Assembled Dithiocarbamate-Copper (ii) Macrocycles for Electrochemical Anion Recognition. Chem. Commun. 2001, 199-200.

(77) Clare, J. P.; Statnikov, A.; Lynch, V.; Sargent, A. L.; Sibert, J. W. "Wurster-Type" Ureas as Redox-Active Receptors for Anions. J. Org. Chem. 2009, 74, 6637-6646.

(78) Eytel, L. M.; Fargher, H. A.; Haley, M. M.; Johnson, D. W. The Road to Aryl CH ‥Anion Binding Was Paved with Good Intentions: Fundamental Studies, Host Design, and Historical Perspectives in CH Hydrogen Bonding. Chem. Commun. 2019, 55, 5195-5206.

(79) Thomas, J.-L.; Howarth, J.; Hanlon, K.; McGuirk, D. Ferrocenyl Imidazolium Salts as a New Class of Anion Receptors with C-H $\cdots$ X- Hydrogen Bonding. Tetrahedron Lett. 2000, 41, 413416.

(80) Weng, T.-Q.; Huang, Y.-F.; Xue, L.-S.; Cheng, J.; Jin, S.; Liu, S.-H.; Wu, D.-Y.; Chen, G. Z. AnionBinding-Induced Electrochemical Signal Transduction in Ferrocenylimidazolium: Combined Electrochemical Experimental and Theoretical Investigation. Molecules 2019, $24,238$.

(81) Zhuo, J.-B.; Lin, C.-X.; Wan, Q.; Xie, L.-L.; Yuan, Y.-F. Anion Receptors of NFerrocenylmethylene-Substituted Bis-Imidazolium Salts Linked by Xylene Spacers. J. Organomet. Chem. 2015, 791, 289-297.

(82) Zhuo, J.-B.; Zhu, X.-X.; Lin, C.-X.; Bai, S.; Xie, L.-L.; Yuan, Y.-F. Design, Synthesis and Anion Recognition of Ferrocene-Based Benzimidazolium Receptors. J. Organomet. Chem. 2014, 770, 85-93.

(83) Zhuo, J.-B.; Zhang, C.-Y.; Lin, C.-X.; Bai, S.; Xie, L.-L.; Yuan, Y.-F. Acyclic Ferrocene-Based Imidazolium Salts as Multi-Site Anion Receptors. J. Organomet. Chem. 2014, 763, 34-43.

(84) Kong, D.; Weng, T.; He, W.; Liu, B.; Jin, S.; Hao, X.; Liu, S. Synthesis, Characterization, and Electrochemical Properties of Ferrocenylimidazolium. J. Organomet. Chem. 2013, 727, 19-27.

(85) Caballero, A.; White, N. G.; Beer, P. D. A Ferrocene Imidazolium-Based Macrocycle as an Electrochemical Chemosensor for Halide Anions. CrystEngComm 2014, 16, 3694-3698.

(86) Amendola, V.; Boiocchi, M.; Colasson, B.; Fabbrizzi, L.; Monzani, E.; Douton-Rodriguez, M. J.; Spadini, C. Redox Active Cage for the Electrochemical Sensing of Anions. Inorg. Chem. 2008, 47, 4808-4816. 
(87) Hua, Y.; Flood, A. H. Click Chemistry Generates Privileged CH Hydrogen-Bonding Triazoles: The Latest Addition to Anion Supramolecular Chemistry. Chem. Soc. Rev. 2010, 39, 12621271.

(88) Romero, T.; Caballero, A.; Tárraga, A.; Molina, P. A Click-Generated Triazole Tethered Ferrocene-Pyrene Dyad for Dual-Mode Recognition of the Pyrophosphate Anion. Org. Lett. 2009, 11, 3466-3469.

(89) Cao, Q.-Y.; Pradhan, T.; Kim, S.; Kim, J. S. Ferrocene-Appended Aryl Triazole for Electrochemical Recognition of Phosphate lons. Org. Lett. 2011, 13, 4386-4389.

(90) Cao, Q.-Y.; Pradhan, T.; Lee, M. H.; Choi, D. H.; Kim, J. S. 'Cleft-Form' Electrochemical Anion Chemosensor with Amide and Triazole Donor Groups. Tetrahedron Lett. 2012, 53, 4917-4920.

(91) Romero, T.; Orenes, R. A.; Tarraga, A.; Molina, P. Preparation, Structural Characterization, Electrochemistry, and Sensing Properties toward Anions and Cations of Ferrocene-Triazole Derivatives. Organometallics 2013, 32, 5740-5753.

(92) White, N. G.; Beer, P. D. A Ferrocene Redox-Active Triazolium Macrocycle That Binds and Senses Chloride. Beilstein J. Org. Chem. 2012, 8, 246.

(93) Li, C.-T.; Cao, Q.-Y.; Li, J.-J.; Wang, Z.-W.; Dai, B.-N. Ferrocene-Containing Macrocyclic Triazoles for the Electrochemical Sensing of Dihydrogen Phosphate Anion. Inorg. Chim. Acta 2016, 449, 31-37.

(94) Karagollu, O.; Gorur, M.; Gode, F.; Sennik, B.; Yilmaz, F. Phosphate lon Sensors Based on Triazole Connected Ferrocene Moieties. Sens. Actuators, B 2014, 193, 788-798.

(95) Hosseinzadeh, R.; Maliji, F.; Golchoubian, H.; Bekhradnia, A. A Novel Ferrocene-Based Calix [4] Arene as an Efficient Optical and Electrochemical Sensor for Highly Selective Fluoride Recognition. ChemistrySelect 2019, 4, 3914-3920.

(96) Brown, A.; Beer, P. D. Halogen Bonding Anion Recognition. Chem. Commun. 2016, 52, 86458658.

(97) Lim, J. Y. C.; Cunningham, M. J.; Davis, J. J.; Beer, P. D. Halogen Bonding-Enhanced Electrochemical Halide Anion Sensing by Redox-Active Ferrocene Receptors. Chem. Commun. 2015, 51, 14640-14643.

(98) Lim, J. Y. C.; Beer, P. D. A Halogen Bonding 1,3-Disubstituted Ferrocene Receptor for Recognition and Redox Sensing of Azide. Eur. J. Inorg. Chem. 2017, 2017, 220-224.

(99) Zapata, F.; Caballero, A.; Molina, P. Ferrocene-Triazole Combination as a Benchmark for the Electrochemical Detection of Noncovalent Halogen-Bonding Interactions. Eur. J. Inorg. Chem. 2017, 2017, 237-241.

(100) Oliveira, R.; Groni, S.; Vacher, A.; Barrière, F.; Lorcy, D.; Fourmigué, M.; Maisonhaute, E.; Schöllhorn, B.; Fave, C. Electrochemical Activation of TTF-Based Halogen Bond Donors: A Powerful, Selective and Sensitive Analytical Tool for Probing a Weak Interaction in Complex Media. ChemistrySelect 2018, 3, 8874-8880.

(101) Mullaney, B. R.; Cunningham, M. J.; Davis, J. J.; Beer, P. D. Acyclic Halogen and Hydrogen Bonding Diquat-Containing Receptors for the Electrochemical Sensing of Anions. Polyhedron 2016, 116, 20-25.

(102) Wade, C. R.; Broomsgrove, A. E. J.; Aldridge, S.; Gabbaï, F. P. Fluoride Ion Complexation and Sensing Using Organoboron Compounds. Chem. Rev. 2010, 110, 3958-3984.

(103) Dusemund, C.; Sandanayake, K. S.; Shinkai, S. Selective Fluoride Recognition with Ferroceneboronic Acid. J. Chem. Soc., Chem. Commun. 1995, 333-334.

(104) Bresner, C.; Day, J. K.; Coombs, N. D.; Fallis, I. A.; Aldridge, S.; Coles, S. J.; Hursthouse, M. B. Fluoride Anion Binding by Cyclic Boronic Esters: Influence of Backbone Chelate on Receptor Integrity. Dalton Trans. 2006, 3660-3667.

(105) Broomsgrove, A. E.; Addy, D. A.; Bresner, C.; Fallis, I. A.; Thompson, A. L.; Aldridge, S. AND/NOT Sensing of Fluoride and Cyanide lons by Ferrocene-Derivatised Lewis Acids. Chem. Eur. J. 2008, 14, 7525-7529. 
(106) Thakur, A.; Mandal, D.; Sao, S.; Ghosh, S. Catecholboryl-Functionalized Ferrocene Based Lewis Acid System: A Selective Probe for Fluoride Ion through Multiple Channels. J. Organomet. Chem. 2012, 715, 129-135.

(107) Su, Z.-M.; Lin, C.-X.; Zhou, Y.-T.; Xie, L.-L.; Yuan, Y.-F. Selective Anion Receptor for Fluoride Detection Using Ferrocenyl-Boronate Derivative. J. Organomet. Chem. 2015, 788, 17-26.

(108) Li, J.; Zhang, G.; Zhang, D.; Zheng, R.; Shi, Q.; Zhu, D. Boron-Containing MonopyrroloAnnelated Tetra Thiafulvalene Compounds: Synthesis and Absorption Spectral/Electrochemical Responsiveness toward Fluoride Ion. J. Org. Chem. 2010, 75, 53305333.

(109) Mulla, K.; Zhao, Y. Ttfv Molecular Tweezers with Phenylboronic Acid and Phenylboronate Endgroups: Modular Synthesis and Electrochemical Responses to Saccharides and Fluoride Ion. Tetrahedron Lett. 2014, 55, 382-386.

(110) Fabre, B.; Lehmann, U.; Schlüter, A. Boronic Ester-Substituted Terpyridine Metal Complex as a Novel Fluoride-Sensitive Redox Receptor. Electrochim. Acta 2001, 46, 2855-2861.

(111) Nicolas, M.; Fabre, B.; Simonet, J. Electrochemical Sensing of Fluoride and Sugars with a Boronic Acid-Substituted Bipyridine Fe (II) Complex in Solution and Attached onto an Electrode Surface. Electrochim. Acta 2001, 46, 1179-1190.

(112) Wade, C. R.; Gabbaï, F. o. P. Cyanide Anion Binding by a Triarylborane at the Outer Rim of a Cyclometalated Ruthenium (II) Cationic Complex. Inorg. Chem. 2010, 49, 714-720.

(113) Nicolas, M.; Fabre, B.; Chapuzet, J.; Lessard, J.; Simonet, J. Boronic Ester-Substituted Triphenylamines as New Lewis Base-Sensitive Redox Receptors. J. Electroanal. Chem. 2000, 482, 211-216.

(114) Nicolas, M.; Fabre, B.; Simonet, J. Voltammetric Investigation of New Boronic EsterSubstituted Triphenylamines-Based Redox Receptors in Solution and Attached to an Electrode Surface. Effects of F- as an Anionic Guest. Electrochim. Acta 2001, 46, 3421-3429.

(115) Melaïmi, M.; Solé, S.; Chiu, C.-W.; Wang, H.; Gabbaï, F. P. Structural and Electrochemical Investigations of the High Fluoride Affinity of Sterically Hindered 1, 8-Bis (Boryl) Naphthalenes. Inorg. Chem. 2006, 45, 8136-8143.

(116) Dorsey, C. L.; Jewula, P.; Hudnall, T. W.; Hoefelmeyer, J. D.; Taylor, T. J.; Honesty, N. R.; Chiu, C.-W.; Schulte, M.; Gabbaï, F. P. Fluoride Ion Complexation by a B 2/Hg Heteronuclear Tridentate Lewis Acid. Dalton Trans. 2008, 4442-4450.

(117) Reynes, O.; Bucher, C.; Moutet, J.-C.; Royal, G.; Saint-Aman, E. Redox Sensing of Anions in Pure Aqueous Environment by Ferrocene-Containing 4, 4'-Bipyridinium-Based Receptors and Polymer Films. Chem. Commun. 2004, 428-429.

(118) Reynes, O.; Moutet, J.-C.; Pecaut, J.; Royal, G.; Saint-Aman, E. (Ferrocenylmethyl) Trimethylammonium Cation: A Very Simple Probe for the Electro-Chemical Sensing of Dihydrogen Phosphate and ATP Anions. New J. Chem. 2002, 26, 9-12.

(119) Bucher, C.; Devillers, C. H.; Moutet, J.-C.; Royal, G.; Saint-Aman, E. Anion Recognition and Redox Sensing by a Metalloporphyrin-Ferrocene-Alkylammonium Conjugate. New J. Chem. 2004, 28, 1584-1589.

(120) Bruña, S.; Garrido-Castro, A. F.; Perles, J.; Montero-Campillo, M. M.; Mó, O.; Kaifer, A. E.; Cuadrado, I. Multi-Ferrocene-Containing Silanols as Redox-Active Anion Receptors. Organometallics 2016, 35, 3507-3519.

(121) Chmielewski, M. J.; Davis, J. J.; Beer, P. D. Interlocked Host Rotaxane and Catenane Structures for Sensing Charged Guest Species Via Optical and Electrochemical Methodologies. Org. Biomol. Chem, 2009, 7, 415-424.

(122) Langton, M. J.; Beer, P. D. Rotaxane and Catenane Host Structures for Sensing Charged Guest Species. Acc. Chem. Res. 2014, 47, 1935-1949.

(123) Evans, N. H.; Beer, P. D. A Ferrocene Functionalized Rotaxane Host System Capable of the Electrochemical Recognition of Chloride. Org. Biomol. Chem, 2011, 9, 92-100. 
(124) Evans, N. H.; Serpell, C. J.; White, N. G.; Beer, P. D. A 1, 2, 3, 4, 5-PentaphenylferroceneStoppered Rotaxane Capable of Electrochemical Anion Recognition. Chem. Eur. J. 2011, 17, 12347-12354.

(125) Evans, N. H.; Serpell, C. J.; Beer, P. D. A Redox-Active [3] Rotaxane Capable of Binding and Electrochemically Sensing Chloride and Sulfate Anions. Chem. Commun. 2011, 47, 8775-8777.

(126) Evans, N. H.; Rahman, H.; Leontiev, A. V.; Greenham, N. D.; Orlowski, G. A.; Zeng, Q.; Jacobs, R. M. J.; Serpell, C. J.; Kilah, N. L.; Davis, J. J.; Beer, P. D. Solution and Surface-Confined Chloride Anion Templated Redox-Active Ferrocene Catenanes. Chem. Sci. 2012, 3, 10801089.

(127) Lim, J. Y. C.; Cunningham, M. J.; Davis, J. J.; Beer, P. D. Neutral Redox-Active Hydrogen- and Halogen-Bonding [2]Rotaxanes for the Electrochemical Sensing of Chloride. Dalton Trans. 2014, 43, 17274-17282.

(128) Lim, J. Y.; Beer, P. D. Electrochemical Bromide Sensing with a Halogen Bonding [2] Rotaxane. Eur. J. Org. Chem. 2018.

(129) Brown, A.; Beer, P. D. Porphyrin-Functionalised Rotaxanes for Anion Recognition. Dalton Trans. 2012, 41, 118-129.

(130) Astruc, D.; Boisselier, E.; Ornelas, C. Dendrimers Designed for Functions: From Physical, Photophysical, and Supramolecular Properties to Applications in Sensing, Catalysis, Molecular Electronics, Photonics, and Nanomedicine. Chem. Rev. 2010, 110, 1857-1959.

(131) Astruc, D.; Ruiz, J. The Redox Functions of Metallodendrimers. J. Inorg. Organomet. Polym. Mater. 2015, 25, 2-11.

(132) Astruc, D.; Deraedt, C.; Djeda, R.; Ornelas, C.; Liu, X.; Rapakousiou, A.; Ruiz, J.; Wang, Y.; Wang, $Q$. Dentromers, a Family of Super Dendrimers with Specific Properties and Applications. Molecules 2018, 23, 966.

(133) Valério, C.; Fillaut, J.-L.; Ruiz, J.; Guittard, J.; Blais, J.-C.; Astruc, D. The Dendritic Effect in Molecular Recognition: Ferrocene Dendrimers and Their Use as Supramolecular Redox Sensors for the Recognition of Small Inorganic Anions. J. Am. Chem. Soc. 1997, 119, 25882589.

(134) Astruc, D. Electron-Transfer Processes in Dendrimers and Their Implication in Biology, Catalysis, Sensing and Nanotechnology. Nat. Chem. 2012, 4, 255.

(135) Kaifer, A. E. Electron Transfer and Molecular Recognition in Metallocene-Containing Dendrimers. Eur. J. Inorg. Chem. 2007, 2007, 5015-5027.

(136) Valério, C.; Ruiz, J.; Filiaux, J.-L.; Astruc, D. Dendritic Effect in the Recognition of Small Inorganic Anions Using a Polycationic Nona-Cobalticinium Dendrimer. C. R. Acad. Sci., Ser. Ilc: Chim. 1999, 2, 79-83.

(137) Daniel, M. C.; Ruiz, J.; Blais, J. C.; Daro, N.; Astruc, D. Synthesis of Five Generations of RedoxStable Pentamethylamidoferrocenyl Dendrimers and Comparison of Amidoferrocenyl-and Pentamethylamidoferrocenyl Dendrimers as Electrochemical Exoreceptors for the Selective Recognition of H2PO4-, HSO4-, and Adenosine 5'-Triphosphate (ATP) Anions: Stereoelectronic and Hydrophobic Roles of Cyclopentadienyl Permethylation. Chem. Eur. J. 2003, 9, 4371-4379.

(138) Alonso, B.; Casado, C. M.; Cuadrado, I.; Morán, M.; Kaifer, A. E. Effective Recognition of H 2 PO 4- by a New Series of Dendrimers Functionalized with Ferrocenyl-Urea Termini. Chem. Commun. 2002, 1778-1779.

(139) Daniel, M.-C.; Ruiz, J.; Astruc, D. Supramolecular H-Bonded Assemblies of Redox-Active Metallodendrimers and Positive and Unusual Dendritic Effects on the Recognition of H2PO4. J. Am. Chem. Soc. 2003, 125, 1150-1151.

(140) Daniel, M.-C.; Ba, F.; Aranzaes, J. R.; Astruc, D. Assemblies of Redox-Active Metallodendrimers Using Hydrogen Bonding for the Electrochemical Recognition of the H2PO4-and Adenosine-Triphosphate (ATP2-) Anions. Inorg. Chem. 2004, 43, 8649-8657. 
(141) Callegari, A.; Marcaccio, M.; Paolucci, D.; Paolucci, F.; Tagmatarchis, N.; Tasis, D.; Vázquez, E.; Prato, M. Anion Recognition by Functionalized Single Wall Carbon Nanotubes. Chem.

Commun. 2003, 2576-2577.

(142) Aranzaes, J. R.; Belin, C.; Astruc, D. Assembly of Dendrimers with Redox-Active [\{CpFe ( $\mu 3-$ CO) 4 4] Clusters at the Periphery and Their Application to Oxo-Anion and Adenosine-5'Triphosphate Sensing. Angew. Chem. Int. Ed. 2006, 45, 132-136.

(143) Astruc, D.; Liang, L.; Rapakousiou, A.; Ruiz, J. Click Dendrimers and Triazole-Related Aspects: Catalysts, Mechanism, Synthesis, and Functions. A Bridge between Dendritic Architectures and Nanomaterials. Acc. Chem. Res. 2012, 45, 630-640.

(144) Ornelas, C.; Ruiz Aranzaes, J.; Cloutet, E.; Alves, S.; Astruc, D. Click Assembly of 1,2,3-TriazoleLinked Dendrimers, Including Ferrocenyl Dendrimers, Which Sense Both Oxo Anions and Metal Cations. Angew. Chem. Int. Ed. 2007, 46, 872-877.

(145) Rapakousiou, A.; Wang, Y.; Belin, C.; Pinaud, N. I.; Ruiz, J.; Astruc, D. 'Click'synthesis and Redox Properties of Triazolyl Cobalticinium Dendrimers. Inorg. Chem. 2013, 52, 6685-6693.

(146) Camponovo, J.; Ruiz, J.; Cloutet, E.; Astruc, D. New Polyalkynyl Dendrons and Dendrimers: "Click" Chemistry with Azidomethylferrocene and Specific Anion and Cation Electrochemical Sensing Properties of the 1, 2, 3-Triazole-Containing Dendrimers. Chem. Eur. J. 2009, 15, 2990-3002.

(147) Djeda, R.; Rapakousiou, A.; Liang, L.; Guidolin, N.; Ruiz, J.; Astruc, D. Click Syntheses of 1, 2, 3Triazolylbiferrocenyl Dendrimers and the Selective Roles of the Inner and Outer Ferrocenyl Groups in the Redox Recognition of ATP2- and Pd2+. Angew. Chem. Int. Ed. 2010, 49, 81528156.

(148) Villena, C.; Losada, J.; García-Armada, P.; Casado, C. M.; Alonso, B. Synthesis and Electrochemical Anion-Sensing Properties of a Biferrocenyl-Functionalized Dendrimer. Organometallics 2012, 31, 3284-3291.

(149) Labande, A.; Astruc, D. Colloids as Redox Sensors: Recognition of H2PO4- and HSO4- by Amidoferrocenylalkylthiol-Gold Nanoparticles. Chem. Commun. 2000, 1007-1008.

(150) Labande, A.; Ruiz, J.; Astruc, D. Supramolecular Gold Nanoparticles for the Redox Recognition of Oxoanions: Syntheses, Titrations, Stereoelectronic Effects, and Selectivity. J. Am. Chem. Soc. 2002, 124, 1782-1789.

(151) Daniel, M.-C.; Ruiz, J.; Nlate, S.; Palumbo, J.; Blais, J.-C.; Astruc, D. Gold Nanoparticles Containing Redox-Active Supramolecular Dendrons That Recognize H2PO4-. Chem. Commun. 2001, 2000-2001.

(152) Daniel, M.-C.; Ruiz, J.; Nlate, S.; Blais, J.-C.; Astruc, D. Nanoscopic Assemblies between Supramolecular Redox Active Metallodendrons and Gold Nanoparticles: Synthesis, Characterization, and Selective Recognition of H2PO4-, HSO4-, and Adenosine-5 'Triphosphate (ATP2-) Anions. J. Am. Chem. Soc. 2003, 125, 2617-2628.

(153) Ruiz Aranzaes, J.; Belin, C.; Astruc, D. Assembly between Gold-Thiolate Nanoparticles and the Organometallic Cluster [Fe(n5-C5H5)( $\mu 3-\mathrm{CO})] 4$ toward Redox Sensing of Oxo-Anions. Chem. Commun. 2007, 3456-3458.

(154) Hembury, G. A.; Borovkov, V. V.; Inoue, Y. Chirality-Sensing Supramolecular Systems. Chem. Rev. 2008, 108, 1-73.

(155) Laurent, P.; Miyaji, H.; Collinson, S. R.; Prokeš, I.; Moody, C. J.; Tucker, J. H.; Slawin, A. M. Asymmetric Synthesis of Chiral $\alpha$-Ferrocenylalkylamines and Their Use in the Preparation of Chiral Redox-Active Receptors. Org. Lett. 2002, 4, 4037-4040.

(156) Willener, Y.; Joly, K. M.; Moody, C. J.; Tucker, J. H. R. An Exploration of Ferrocenyl Ureas as Enantioselective Electrochemical Sensors for Chiral Carboxylate Anions. J. Org. Chem. 2008, 73, 1225-1233.

(157) Lim, J. Y. C.; Marques, I.; Ferreira, L.; Félix, V.; Beer, P. D. Enhancing the Enantioselective Recognition and Sensing of Chiral Anions by Halogen Bonding. Chem. Commun. 2016, 52, 5527-5530.

(158) Major, R. C.; Zhu, X. Y. The Surface Chelate Effect. J. Am. Chem. Soc. 2003, 125, 8454-8455. 
(159) Zhang, S.; Cardona, C. M.; Echegoyen, L. Ion Recognition Properties of Self-Assembled Monolayers (SAMs). Chem. Commun. 2006, 4461-4473.

(160) Eckermann, A. L.; Feld, D. J.; Shaw, J. A.; Meade, T. J. Electrochemistry of Redox-Active SelfAssembled Monolayers. Coord. Chem. Rev. 2010, 254, 1769-1802.

(161) Alonso, E.; Labande, A.; Raehm, L.; Kern, J.-M.; Astruc, D. Recognition of the Dihydrogenophosphate Anion on a Gold Electrode Derivatized with an Amidoferrocenylalkylthiolate Ligand. C. R. Acad. Sci., Ser. Ilc: Chim. 1999, 2, 209-213.

(162) Beer, P. D.; Davis, J. J.; Drillsma-Milgrom, D. A.; Szemes, F. Anion Recognition and Redox Sensing Amplification by Self-Assembled Monolayers of 1, 1'-Bis (Alkyl-N-Amido) Ferrocene. Chem. Commun. 2002, 1716-1717.

(163) Reynes, O.; Bucher, C.; Moutet, J.-C.; Royal, G.; Saint-Aman, E. Electrochemical Sensing of Dihydrogen Phosphate and Adenosine- $5^{\prime}$-Triphosphate Anions by Self-Assembled Monolayers of (Ferrocenylmethyl) Trialkylammonium Cations on Gold Electrodes. Inorg. Chim. Acta 2008, 361, 1784-1788.

(164) Cormode, D. P.; Evans, A. J.; Davis, J. J.; Beer, P. D. Amplification of Anion Sensing by Disulfide Functionalized Ferrocene and Ferrocene-Calixarene Receptors Adsorbed onto Gold Surfaces. Dalton Trans. 2010, 39, 6532-6541.

(165) Devillers, C. H.; Boturyn, D.; Bucher, C.; Dumy, P.; Labbé, P.; Moutet, J.-C.; Royal, G.; SaintAman, E. Redox-Active Biomolecular Architectures and Self-Assembled Monolayers Based on a Cyclodecapeptide Regioselectively Addressable Functional Template. Langmuir 2006, 22, 8134-8143.

(166) Bayly, S. R.; Gray, T. M.; Chmielewski, M. J.; Davis, J. J.; Beer, P. D. Anion Templated Surface Assembly of a Redox-Active Sensory Rotaxane. Chem. Commun. 2007, 2234-2236.

(167) Jensen, L. G.; Nielsen, K. A.; Breton, T.; Sessler, J. L.; Jeppesen, J. O.; Levillain, E.; Sanguinet, L. Self-Assembled Monolayers of Mono-Tetrathiafulvalene Calix [4] Pyrroles and Their Electrochemical Sensing of Chloride. Chem. Eur. J. 2009, 15, 8128-8133.

(168) Hijazi, H.; Vacher, A.; Groni, S.; Lorcy, D.; Levillain, E.; Fave, C.; Schöllhorn, B. Electrochemically Driven Interfacial Halogen Bonding on Self-Assembled Monolayers for Anion Detection. Chem. Commun. 2019, 55, 1983-1986.

(169) Faour, L.; Adam, C.; Gautier, C.; Goeb, S.; Allain, M.; Levillain, E.; Canevet, D.; Sallé, M. RedoxControlled Hybridization of Helical Foldamers. Chem. Commun. 2019, 55, 5743-5746.

(170) Vengatajalabathy Gobi, K.; Ohsaka, T. Electrochemical and Spectral Properties of Novel Dinickel(II) and Dicopper(II) Complexes with N,N-Linked Bis(Pentaazacyclotetradecane). Electrochim. Acta 1998, 44, 269-278.

(171) Gobi, K. V.; Ohsaka, T. Anion Recognition and Electrochemical Characteristics of the SelfAssembled Monolayer of Nickel(II) Azamacrocyclic Complex. J. Electroanal. Chem. 2000, 485, 61-70.

(172) Kaur, B.; Erdmann, C. A.; Daniëls, M.; Dehaen, W.; Rafiński, Z.; Radecka, H.; Radecki, J. Highly Sensitive Electrochemical Sensor for the Detection of Anions in Water Based on a RedoxActive Monolayer Incorporating an Anion Receptor. Anal. Chem. 2017, 89, 12756-12763.

(173) Gołębiewski, P.; Puciłowski, B.; Sommer, F.; Kubik, S.; Daniels, M.; Dehaen, W.; Sivasankaran, U.; Kumar, K. G.; Radecka, H.; Radecki, J. Electrochemical Sensing of Sulfate in Aqueous Solution with a Cyclopeptide-Dipyrromethene-Cu(II) or Co(II) Complex Attached to a Gold Electrode. Sens. Actuators, B 2019, 285, 536-545.

(174) Lopez, C.; Moutet, J.-C.; Saint-Aman, E. Electrochemical Recognition of Chloride lons by a Poly [Tris-(2, 2'-Bipyridine) Ruthenium (II)] Modified Electrode. J. Chem. Soc., Faraday Trans. 1996, 92, 1527-1532.

(175) Reynes, O.; Gulon, T.; Moutet, J.-C.; Royal, G.; Saint-Aman, E. Amplification Upon Polymerization of the Electrochemical Anion Sensing Properties of an Amidoferrocene Monoreceptor Molecule. J. Organomet. Chem. 2002, 656, 116-119.

(176) del Peso, I.; Alonso, B.; Lobete, F.; Casado, C. M.; Cuadrado, I.; del Barrio, J. L. A Polymerizable Pyrrole-Cobaltocenium Receptor for the Electrochemical Recognition of 
Anions in Solution and Immobilised onto Electrode Surfaces. Inorg. Chem. Commun. 2002, 5, 288-291.

(177) Reynes, O.; Royal, G.; Chaînet, E.; Moutet, J. C.; Saint-Aman, E. Poly (Ferrocenylalkylammonium): A Molecular Electrode Material for Dihydrogenphosphate Sensing. Electroanalysis 2003, 15, 65-69.

(178) Reynes, O.; Moutet, J.-C.; Royal, G.; Saint-Aman, E. Electrochemical Sensing of Anions by (Ferrocenylmethyl) Trialkylammonium Cations in Homogeneous Solution and in Polymer Films. Electrochim. Acta 2004, 49, 3727-3735.

(179) Martínez, F. J.; González, B.; Alonso, B.; Losada, J.; García-Armada, M. P.; Casado, C. M. Synthesis and Redox Properties of an Electropolymerizable Amido Ferrocenyl PyrroleFunctionalized Dendrimer. J. Inorg. Organomet. Polym. Mater. 2008, 18, 51-58.

(180) Takeuchi, M.; Shioya, T.; Swager, T. M. Allosteric Fluoride Anion Recognition by a Doubly Strapped Porphyrin. Angew. Chem. Int. Ed. 2001, 40, 3372-3376.

(181) Aydogan, A.; Koca, A.; Şener, M. K.; Sessler, J. L. Edot-Functionalized Calix [4] Pyrrole for the Electrochemical Sensing of Fluoride in Water. Org. Lett. 2014, 16, 3764-3767.

(182) Nicolas, M.; Fabre, B.; Marchand, G.; Simonet, J. New Boronic-Acid- and BoronateSubstituted Aromatic Compounds as Precursors of Fluoride-Responsive Conjugated Polymer Films. Eur. J. Org. Chem. 2000, 2000, 1703-1710.

(183) Wu, S.; Han, T.; Guo, J.; Cheng, Y. Poly(3-Aminophenylboronic Acid)-Reduced Graphene Oxide Nanocomposite Modified Electrode for Ultrasensitive Electrochemical Detection of Fluoride with a Wide Response Range. Sens. Actuators, B 2015, 220, 1305-1310.

(184) Ćwik, P.; Wawrzyniak, U. E.; Jańczyk, M.; Wróblewski, W. Electrochemical Studies of SelfAssembled Monolayers Composed of Various Phenylboronic Acid Derivatives. Talanta 2014, 119, 5-10.

(185) Xiao, K. P.; Bühlmann, P.; Umezawa, Y. lon-Channel-Mimetic Sensing of Hydrophilic Anions Based on Monolayers of a Hydrogen Bond-Forming Receptor. Anal. Chem. 1999, 71, 11831187.

(186) Aoki, H.; Hasegawa, K.; Tohda, K.; Umezawa, Y. Voltammetric Detection of Inorganic Phosphate Using lon-Channel Sensing with Self-Assembled Monolayers of a Hydrogen BondForming Receptor. Biosens. Bioelectron. 2003, 18, 261-267.

(187) Gołębiewski, P.; Sommer, F.; Kubik, S.; Radecka, H.; Radecki, J. Ion-Channel Mimetic Sensor Incorporating an Anion-Binding Cyclopeptide Designed for Sulfate Determination in Dilute Aqueous Solutions. J. Electroanal. Chem. 2018, 812, 249-257.

(188) Villoslada, R.; Alonso, B.; Casado, C. M.; García-Armada, P.; Losada, J. Anion Receptor Electrochemical Sensing Properties of Poly (Propyleneimine) Dendrimers with Ferrocenylamidoalkyl Terminal Groups. Organometallics 2009, 28, 727-733.

(189) Casado, C. M.; Cuadrado, I.; Alonso, B.; Morán, M.; Losada, J. Silicon-Based Ferrocenyl Dendrimers as Anion Receptors in Solution and Immobilized onto Electrode Surfaces. J. Electroanal. Chem. 1999, 463, 87-92.

(190) Ornelas, C.; Ruiz, J.; Belin, C.; Astruc, D. Giant Dendritic Molecular Electrochrome Batteries with Ferrocenyl and Pentamethylferrocenyl Termini. J. Am. Chem. Soc. 2008, 131, 590-601.

(191) Ornelas, C.; Ruiz, J.; Astruc, D. Dendritic and lon-Pairing Effects in Oxo-Anion Recognition by Giant Alkylferrocenyl Dendrimers. Organometallics 2009, 28, 4431-4437.

(192) Leroux, Y. R.; Hui, F.; Ruiz, J.; Astruc, D.; Hapiot, P. Robust Assembly of Dendrimers as an Active Redox-Sensing Monolayer: An Example of Oxo-Anion Sensing. Chem. Eur. J. 2012, 18, 7041-7044.

(193) Xu, Q.; Davis, J. J. The Diagnostic Utility of Electrochemical Impedance. Electroanalysis 2014, $26,1249-1258$.

(194) Ebdelli, R.; Rouis, A.; Mlika, R.; Bonnamour, I.; Jaffrezic-Renault, N.; Ouada, H. B.; Davenas, J. Electrochemical Impedance Detection of $\mathrm{Hg} 2+, \mathrm{Ni2}+$ and Eu3+ lons by a New Azo-Calix [4] Arene Membrane. J. Electroanal. Chem. 2011, 661, 31-38. 
(195) Flink, S.; Boukamp, B. A.; Van Den Berg, A.; Van Veggel, F. C.; Reinhoudt, D. N. Electrochemical Detection of Electrochemically Inactive Cations by Self-Assembled Monolayers of Crown Ethers. J. Am. Chem. Soc. 1998, 120, 4652-4657.

(196) Flink, S.; Van Veggel, F. C.; Reinhoudt, D. N. Recognition of Cations by Self-Assembled Monolayers of Crown Ethers. J. Phys. Chem. B 1999, 103, 6515-6520.

(197) Wanichacheva, N.; Soto, E. R.; Lambert, C. R.; McGimpsey, W. G. Surface-Based Lithium lon Sensor: An Electrode Derivatized with a Self-Assembled Monolayer. Anal. Chem. 2006, 78, 7132-7137.

(198) Zhang, S.; Echegoyen, L. Selective Anion Sensing by a Tris-Amide CTV Derivative: 1H NMR Titration, Self-Assembled Monolayers, and Impedance Spectroscopy. J. Am. Chem. Soc. 2005, 127, 2006-2011.

(199) Zhang, S.; Palkar, A.; Echegoyen, L. Selective Anion Sensing Based on Tetra-Amide Calix [6] Arene Derivatives in Solution and Immobilized on Gold Surfaces Via Self-Assembled Monolayers. Langmuir 2006, 22, 10732-10738.

(200) Zhi, F.; Lu, X.; Yang, J.; Wang, X.; Shang, H.; Zhang, S.; Xue, Z. Selective Anion Sensing through a Self-Assembled Monolayer of Thiol-End-Functionalized Porphyrin. J. Phys. Chem. C 2009, 113, 13166-13172.

(201) Wei, J.; Guo, Z.; Chen, X.; Han, D.-D.; Wang, X.-K.; Huang, X.-J. Ultrasensitive and Ultraselective Impedimetric Detection of $\mathrm{Cr}(\mathrm{VI})$ Using Crown Ethers as High-Affinity Targeting Receptors. Anal. Chem. 2015, 87, 1991-1998.

(202) Bettazzi, F.; Voccia, D.; Bencini, A.; Giorgi, C.; Palchetti, I.; Valtancoli, B.; Conti, L. Optical and Electrochemical Study of Acridine-Based Polyaza Ligands for Anion Sensing. Eur. J. Inorg. Chem. 2018, 2018, 2675-2679.

(203) Sanz, M. P. Effective Anion Sensing Based on the Ability of Copper to Affect Electron Transport across Self-Assembled Monolayers. Chem. Commun. 2007, 5010-5012.

(204) Shervedani, R. K.; Pourbeyram, S. Zirconium Immobilized on Gold-Mercaptopropionic Acid Self-Assembled Monolayer for Trace Determination of Phosphate in Blood Serum by Using CV, EIS, and OSWV. Biosens. Bioelectron. 2009, 24, 2199-2204.

(205) Qiu, S.; Gao, S.; Liu, Q.; Lin, Z.; Qiu, B.; Chen, G. Electrochemical Impedance Spectroscopy Sensor for Ascorbic Acid Based on Copper (I) Catalyzed Click Chemistry. Biosens. Bioelectron. 2011, 26, 4326-4330.

(206) Lin, Z.; Li, X.; Kraatz, H.-B. Impedimetric Immobilized DNA-Based Sensor for Simultaneous Detection of $\mathrm{Pb} 2+, \mathrm{Ag}+$, and Hg2+. Anal. Chem. 2011, 83, 6896-6901.

(207) Zhou, Y.; Tang, L.; Xie, X.; Zeng, G.; Wang, J.; Deng, Y.; Yang, G.; Zhang, C.; Zhang, Y.; Chen, J. Sensitive Impedimetric Biosensor Based on Duplex-Like DNA Scaffolds and Ordered Mesoporous Carbon Nitride for Silver (I) Ion Detection. Analyst 2014, 139, 6529-6535.

(208) Qiu, Z.; Tang, D.; Shu, J.; Chen, G.; Tang, D. Enzyme-Triggered Formation of Enzyme-Tyramine Concatamers on Nanogold-Functionalized Dendrimer for Impedimetric Detection of $\mathrm{Hg}$ (II) with Sensitivity Enhancement. Biosens. Bioelectron. 2016, 75, 108-115.

(209) Vega-Figueroa, K.; Santillán, J.; Ortiz-Gómez, V.; Ortiz-Quiles, E. O.; Quiñones-Colón, B. A.; Castilla-Casadiego, D. A.; Almodóvar, J.; Bayro, M. J.; Rodríguez-Martínez, J. A.; Nicolau, E. Aptamer-Based Impedimetric Assay of Arsenite in Water: Interfacial Properties and Performance. ACS Omega 2018, 3, 1437-1444.

(210) Hein, R.; Borissov, A.; Smith, M. D.; Beer, P. D.; Davis, J. J. A Halogen-Bonding Foldamer Molecular Film for Selective Reagentless Anion Sensing in Water. Chem. Commun. 2019, 55, 4849-4852.

(211) Bakker, E.; Bühlmann, P.; Pretsch, E. Carrier-Based Ion-Selective Electrodes and Bulk Optodes. 1. General Characteristics. Chem. Rev. 1997, 97, 3083-3132.

(212) Bakker, E.; Bühlmann, P.; Pretsch, E. Polymer Membrane Ion-Selective Electrodes-What Are the Limits? Electroanalysis 1999, 11, 915-933.

(213) Bühlmann, P.; Chen, L. D. Ion-Selective Electrodes with lonophore-Doped Sensing Membranes. Supramolecular Chemistry: From Molecules to Nanomaterials 2012. 
(214) Crespo, G. A. Recent Advances in lon-Selective Membrane Electrodes for in Situ

Environmental Water Analysis. Electrochim. Acta 2017, 245, 1023-1034.

(215) Mikhelson, K. N. Ion-Selective Electrodes; Springer, 2013.

(216) Pretsch, E. The New Wave of Ion-Selective Electrodes. TrAC, Trends Anal. Chem. 2007, 26, 4651.

(217) Zdrachek, E.; Bakker, E. Potentiometric Sensing. Anal. Chem. 2019, 91, 2-26.

(218) Bobacka, J.; Ivaska, A.; Lewenstam, A. Potentiometric lon Sensors. Chem. Rev. 2008, 108, 329-351.

(219) Torsi, L.; Magliulo, M.; Manoli, K.; Palazzo, G. Organic Field-Effect Transistor Sensors: A Tutorial Review. Chem. Soc. Rev. 2013, 42, 8612-8628.

(220) Bergveld, P. Thirty Years of ISFETOLOGY: What Happened in the Past 30 Years and What May Happen in the Next 30 Years. Sens. Actuators, B 2003, 88, 1-20.

(221) Jimenez-Jorquera, C.; Orozco, J.; Baldi, A. ISFET Based Microsensors for Environmental Monitoring. Sensors 2010, 10, 61-83.

(222) Minami, T.; Minamiki, T.; Tokito, S. An Anion Sensor Based on an Organic Field Effect Transistor. Chem. Commun. 2015, 51, 9491-9494.

(223) Hutchins, R. S.; Molina, P.; Alajarin, M.; Vidal, A.; Bachas, L. G. Use of a Guanidinium lonophore in a Hydrogen Sulfite-Selective Electrode. Anal. Chem. 1994, 66, 3188-3192.

(224) Hutchins, R. S.; Bansal, P.; Molina, P.; Alajarín, M.; Vidal, A.; Bachas, L. G. Salicylate-Selective Electrode Based on a Biomimetic Guanidinium lonophore. Anal. Chem. 1997, 69, 1273-1278.

(225) Carey, C. M.; Riggan, W. B. Cyclic Polyamine lonophore for Use in a Dibasic PhosphateSelective Electrode. Anal. Chem. 1994, 66, 3587-3591.

(226) Daunert, S.; Bachas, L. G. Anion-Selective Electrodes Based on a Hydrophobic Vitamin B12 Derivative. Anal. Chem. 1989, 61, 499-503.

(227) Nishizawa, S.; Bühlmann, P.; Xiao, K. P.; Umezawa, Y. Application of a Bis-Thiourea lonophore for an Anion Selective Electrode with a Remarkable Sulfate Selectivity. Anal. Chim. Acta 1998, 358, 35-44.

(228) Xiao, K. P.; Bühlmann, P.; Nishizawa, S.; Amemiya, S.; Umezawa, Y. A Chloride lon-Selective Solvent Polymeric Membrane Electrode Based on a Hydrogen Bond Forming lonophore. Anal. Chem. 1997, 69, 1038-1044.

(229) Antonisse, M. M. G.; Reinhoudt, D. N. Potentiometric Anion Selective Sensors. Electroanalysis 1999, 11, 1035-1048.

(230) BühImann, P.; Pretsch, E.; Bakker, E. Carrier-Based Ion-Selective Electrodes and Bulk Optodes. 2. Ionophores for Potentiometric and Optical Sensors. Chem. Rev. 1998, 98, 15931688.

(231) Gupta, V. K.; Singh, L. P.; Chandra, S.; Kumar, S.; Singh, R.; Sethi, B. Anion Recognition through Amide-Based Dendritic Molecule: A Poly(Vinyl Chloride) Based Sensor for Nitrate Ion. Talanta 2011, 85, 970-974.

(232) Jeong, D.-C.; Lee, H.-K.; Jeon, S.-W. Polymeric lodide-Ion Selective Electrodes Based on Urea Derivative as an lonophore. Bull. Korean Chem. Soc. 2006, 27, 1985-1988.

(233) Watts, A. S.; Gavalas, V. G.; Cammers, A.; Andrada, P. S.; Alajarín, M.; Bachas, L. G. NitrateSelective Electrode Based on a Cyclic Bis-Thiourea lonophore. Sens. Actuators, B 2007, 121, 200-207.

(234) Fibbioli, M.; Berger, M.; Schmidtchen, F. P.; Pretsch, E. Polymeric Membrane Electrodes for Monohydrogen Phosphate and Sulfate. Anal. Chem. 2000, 72, 156-160.

(235) Amemiya, S.; Bühlmann, P.; Umezawa, Y.; Jagessar, R. C.; Burns, D. H. An lon-Selective Electrode for Acetate Based on a Urea-Functionalized Porphyrin as a Hydrogen-Bonding lonophore. Anal. Chem. 1999, 71, 1049-1054.

(236) Lee, H.-K.; Song, K.-j.; Seo, H.-R.; Jeon, S.-w. Polymeric Acetate-Selective Electrodes Based on Meso-( $\alpha, \alpha, \alpha, \alpha)$-Tetrakis-[(2-Arylphenylurea) Phenyl] Porphyrins: Electormic and pH Effects. Bull. Korean Chem. Soc. 2002, 23, 1409-1412. 
(237) Lee, H. K.; Song, K.; Seo, H. R.; Jeon, S. Nitrate-Selective Electrodes Based on Meso-Tetrakis [(2-Arylphenylurea)-Phenyl] Porphyrins as Neutral Lipophilic lonophores. Talanta 2004, 62, 293-297.

(238) Gupta, V. K.; Goyal, R. N.; Sharma, R. A. Anion Recognition Using Newly Synthesized Hydrogen Bonding Disubstituted Phenylhydrazone-Based Receptors: Poly (Vinyl Chloride)Based Sensor for Acetate. Talanta 2008, 76, 859-864.

(239) Mendecki, L.; Fayose, T.; Stockmal, K. A.; Wei, J.; Granados-Focil, S.; McGraw, C. M.; Radu, A. Robust and Ultrasensitive Polymer Membrane-Based Carbonate-Selective Electrodes. Anal. Chem. 2015, 87, 7515-7518.

(240) Jain, A. K.; Gupta, V. K.; Raisoni, J. R. A Newly Synthesized Macrocyclic Dithioxamide Receptor for Phosphate Sensing. Talanta 2006, 69, 1007-1012.

(241) Berrocal, M. J.; Cruz, A.; Badr, I. H.; Bachas, L. G. Tripodal Ionophore with Sulfate Recognition Properties for Anion-Selective Electrodes. Anal. Chem. 2000, 72, 5295-5299.

(242) Ortuño, J. A.; Expósito, R.; Sánchez-Pedreño, C.; Albero, M. I.; Espinosa, A. A Nitrate-Selective Electrode Based on a Tris (2-Aminoethyl) Amine Triamide Derivative Receptor. Anal. Chim. Acta 2004, 525, 231-237.

(243) Liu, Y.; Qin, Y.; Jiang, D. Squaramide-Based Tripodal lonophores for Potentiometric SulfateSelective Sensors with High Selectivity. Analyst 2015, 140, 5317-5323.

(244) Pankratova, N.; Cuartero, M.; Jowett, L. A.; Howe, E. N. W.; Gale, P. A.; Bakker, E.; Crespo, G. A. Fluorinated Tripodal Receptors for Potentiometric Chloride Detection in Biological Fluids. Biosens. Bioelectron. 2018, 99, 70-76.

(245) Cuartero, M.; Ortuño, J. A.; García, M. S.; Sánchez, G.; Más-Montoya, M.; Curiel, D. Benzodipyrrole Derivates as New lonophores for Anion-Selective Electrodes: Improving Potentiometric Selectivity Towards Divalent Anions. Talanta 2011, 85, 1876-1881.

(246) Cuartero, M.; Más-Montoya, M.; García, M. S.; Curiel, D.; Ortuño, J. A. New Carbazolo [1, 2-a] Carbazole Derivative as Ionophore for Anion-Selective Electrodes: Remarkable Recognition Towards Dicarboxylate Anions. Talanta 2014, 123, 200-206.

(247) Martin, K.; Kadam, S. A.; Mattinen, U.; Bobacka, J.; Leito, I. Solid-Contact Acetate-Selective Electrode Based on a 1,3-Bis(Carbazolyl)Urea-lonophore. Electroanalysis 2019.

(248) Gupta, V. K.; Ludwig, R.; Agarwal, S. Anion Recognition through Modified Calixarenes: A Highly Selective Sensor for Monohydrogen Phosphate. Anal. Chim. Acta 2005, 538, 213-218.

(249) Lee, H. K.; Oh, H.; Nam, K. C.; Jeon, S. Urea-Functionalized Calix[4]Arenes as Carriers for Carbonate-Selective Electrodes. Sens. Actuators, B 2005, 106, 207-211.

(250) Schazmann, B.; Diamond, D. Improved Nitrate Sensing Using lon Selective Electrodes Based on Urea-Calixarene lonophores. New J. Chem. 2007, 31, 587-592.

(251) Babu, J. N.; Bhalla, V.; Kumar, M.; Mahajan, R.; Puri, R. K. A Chloride Selective Sensor Based on a Calix [4] Arene Possessing a Urea Moiety. Tetrahedron Lett. 2008, 49, 2772-2775.

(252) Babu, J. N.; Bhalla, V.; Kumar, M.; Puri, R. K.; Mahajan, R. K. Chloride Ion Recognition Using Thiourea/Urea Based Receptors Incorporated into 1, 3-Disubstituted Calix [4] Arenes. New J. Chem. 2009, 33, 675-681.

(253) Shishkanova, T. V.; Sýkora, D.; Sessler, J. L.; Král, V. Potentiometric Response and Mechanism of Anionic Recognition of Heterocalixarene-Based Ion Selective Electrodes. Anal. Chim. Acta 2007, 587, 247-253.

(254) Sabek, J.; Adriaenssens, L.; Guinovart, T.; Parra, E. J.; Rius, F. X.; Ballester, P.; Blondeau, P. Chloride-Selective Electrodes Based on "Two-Wall" Aryl-Extended Calix[4]Pyrroles: Combining Hydrogen Bonds and Anion $-\pi$ Interactions to Achieve Optimum Performance. Chem. Eur. J. 2015, 21, 448-454.

(255) Zahran, E. M.; Hua, Y.; Li, Y.; Flood, A. H.; Bachas, L. G. Triazolophanes: A New Class of HalideSelective lonophores for Potentiometric Sensors. Anal. Chem. 2010, 82, 368-375.

(256) Zahran, E. M.; Fatila, E. M.; Chen, C.-H.; Flood, A. H.; Bachas, L. G. Cyanostar: C-H Hydrogen Bonding Neutral Carrier Scaffold for Anion-Selective Sensors. Anal. Chem. 2018, 90, 19251933. 
(257) Zahran, E. M.; Hua, Y.; Lee, S.; Flood, A. H.; Bachas, L. G. Ion-Selective Electrodes Based on a Pyridyl-Containing Triazolophane: Altering Halide Selectivity by Combining Dipole-Promoted Cooperativity with Hydrogen Bonding. Anal. Chem. 2011, 83, 3455-3461.

(258) Yuchi, A.; Sakurai, J. k.; Tatebe, A.; Hattori, H.; Wada, H. Performance of Arylboronic Acids as lonophore for Inorganic Anions Studied by Fluorometry and Potentiometry. Anal. Chim. Acta 1999, 387, 189-195.

(259) Jańczyk, M.; Adamczyk-Woźniak, A.; Sporzyński, A.; Wróblewski, W. Organoboron Compounds as Lewis Acid Receptors of Fluoride lons in Polymeric Membranes. Anal. Chim. Acta 2012, 733, 71-77.

(260) Çiftçi, H.; Tamer, U. Electrochemical Determination of lodide by Poly(3-Aminophenylboronic Acid) Film Electrode at Moderately Low pH Ranges. Anal. Chim. Acta 2011, 687, 137-140.

(261) Jarolímová, Z.; Bosson, J.; Labrador, G. M.; Lacour, J.; Bakker, E. Ion Transfer Voltammetry in Polyurethane Thin Films Based on Functionalised Cationic [6]Helicenes for Carbonate Detection. Electroanalysis 2018, 30, 1378-1385.

(262) Xie, X.; Zhai, J.; Bakker, E. Potentiometric Response from lon-Selective Nanospheres with Voltage-Sensitive Dyes. J. Am. Chem. Soc. 2014, 136, 16465-16468.

(263) Parrilla, M.; Cuartero, M.; Crespo, G. A. Wearable Potentiometric lon Sensors. TrAC, Trends Anal. Chem. 2019, 110, 303-320.

(264) Hu, J.; Stein, A.; Bühlmann, P. A Disposable Planar Paper-Based Potentiometric lon-Sensing Platform. Angew. Chem. Int. Ed. 2016, 55, 7544-7547.

(265) Lou, B.; Chen, C.; Zhou, Z.; Zhang, L.; Wang, E.; Dong, S. A Novel Electrochemical Sensing Platform for Anions Based on Conducting Polymer Film Modified Electrodes Integrated on Paper-Based Chips. Talanta 2013, 105, 40-45.

(266) Zdrachek, E.; Bakker, E. Electrochemically Switchable Polymeric Membrane Ion-Selective Electrodes. Anal. Chem. 2018, 90, 7591-7599.

(267) Lim, J. Y. C.; Beer, P. D. Sigma-Hole Interactions in Anion Recognition. Chem 2018, 4, 731-783.

(268) Choi, S. J.; Yoon, B.; Ray, J. D.; Netchaev, A.; Moores, L. C.; Swager, T. M. Chemiresistors for the Real-Time Wireless Detection of Anions. Adv. Funct. Mater. 2019, doi.org/10.1002/adfm.201907087.

(269) McConnell, A. J.; Beer, P. D. Heteroditopic Receptors for lon-Pair Recognition. Angew. Chem. Int. Ed. 2012, 51, 5052-5061.

(270) Beer, P. D.; Chen, Z.; Ogden, M. I. Voltammetric and NMR Studies of a Bis (Ferrocenecarboxamide)-Substituted Diaza 18-Crown-6 Receptor That Simultaneously Complexes and Electrochemically Recognises Both Cations and Anions. J. Chem. Soc., Faraday Trans. 1995, 91, 295-302.

(271) Miyaji, H.; Gasser, G.; Green, S. J.; Molard, Y.; Strawbridge, S. M.; Tucker, J. H. Selective Electrochemical Sensing of Acidic Organic Molecules Via a Novel Guest-to-Host Proton Transfer Reaction. Chem. Commun. 2005, 5355-5357.

(272) Murashima, T.; Tsukiyama, S.; Fujii, S.; Hayata, K.; Sakai, H.; Miyazawa, T.; Yamada, T. Amino Acid Ester Salt Recognition by Ferrocene-Based Ditopic Receptor Bearing Oligoethylene Glycol with Pendant Bipy Subunits: CV, UV-vis and ESR Studies. Org. Biomol. Chem, 2005, 3, 4060-4064.

(273) Alfonso, M.; Sola, A.; Caballero, A.; Tárraga, A.; Molina, P. Heteroditopic Ligands Based on Ferrocenyl Benzimidazoles Fused to an Additional Diaza Heterocyclic Ring System. Dalton Trans. 2009, 9653-9658.

(274) Alfonso, M.; Tárraga, A.; Molina, P. A Bisferrocene-Benzobisimidazole Triad as a Multichannel Ditopic Receptor for Selective Sensing of Hydrogen Sulfate and Mercury lons. Org. Lett. 2011, 13, 6432-6435.

(275) Alfonso, M.; Espinosa, A.; Tárraga, A.; Molina, P. A Simple but Effective Dual Redox and Fluorescent Ion Pair Receptor Based on a Ferrocene- Imidazopyrene Dyad. Org. Lett. 2011, 13, 2078-2081. 
(276) Alfonso, M.; Tárraga, A.; Molina, P. Ferrocene-Based Heteroditopic Receptors Displaying High Selectivity toward Lead and Mercury Metal Cations through Different Channels. J. Org. Chem. 2011, 76, 939-947.

(277) Bedatty Fernandes, F. C.; Patil, A. V.; Bueno, P. R.; Davis, J. J. Optimized Diagnostic Assays Based on Redox Tagged Bioreceptive Interfaces. Anal. Chem. 2015, 87, 12137-12144.

(278) Piccoli, J.; Hein, R.; El-Sagheer, A. H.; Brown, T.; Cilli, E. M.; Bueno, P. R.; Davis, J. J. Redox Capacitive Assaying of C-Reactive Protein at a Peptide Supported Aptamer Interface. Anal. Chem. 2018, 90, 3005-3008. 


\section{Biographies}

Robert Hein obtained his B.Sc. from Jacobs University Bremen, Germany in 2016, where he worked in the field of supramolecular chemistry under the supervision of Prof. Werner M. Nau. During his studies he spent a semester abroad at Cornell University (with Prof. Geoffrey W. Coates) and furthermore completed a summer project in the group of Prof. Oren A. Scherman at the University of Cambridge. He is currently pursuing a Ph.D. at the University of Oxford under the guidance of Prof. Paul D. Beer and Prof. Jason J. Davis working on electrochemical, supramolecular anion sensors. Other research interests include the development of novel antifouling interfaces for electrochemical (bio)sensors, surface functionalization via diazonium chemistry as well as host-guest chemistry.

Prof. Jason Davis is a Professor of Chemistry and a Tutorial Fellow and Dr Lee's Reader in Chemistry at Christ Church, Oxford. He studied Chemistry at Kings College London, where he was awarded The Victor Gold, Ivor John and Robert Wakeford Memorial Prizes in Chemistry and a First Class honours degree in 1993. He then undertook a DPhil in Chemistry at Oxford (1994-1998) he was elected to an Extraordinary Junior Research Fellowship at The Queens College in 1998 and a Royal Society University Research Fellowship in 1999. He was appointed to a University Lectureship in 2003 and made a full professor in 2014. His research interests are broad and primarily focussed on the design and utilisation of advanced functional interfaces, particularly those associated with diagnostics, sensing, molecular switches and imaging. His group have published more than 160 primary peer reviewed publications, including 3 book chapters, one edited volume and numerous invited reviews spanning molecular imaging, nanotechnology, nanoparticle based molecular imaging, 
molecular electronics, supramolecular chemistry, molecular machines and fundamental electrochemistry.

Prof. Paul Beer obtained a PhD from King's College London in 1982 with Dr. C. Dennis Hall. After a Royal Society European Post-doctoral Fellowship with Professor J.-M. Lehn and a Demonstratorship at the University of Exeter, he was awarded a Lectureship at the University of Birmingham in 1984. In 1990, he moved to the University of Oxford, where he was made a University Lecturer and Tutorial Fellow at Wadham College, and became a Professor of Chemistry in 1998. His research interests include coordination and supramolecular chemistry.

\section{For Table of Contents Only}

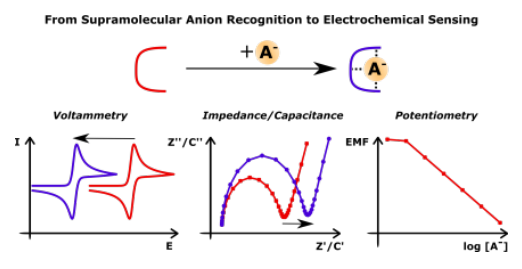

